\title{
Comparison of Cask and Drywell Storage Concepts for a Monitored Retrievable Storage/ Interim Storage System
}

\author{
D. E. Rasmussen
}

Program Manager

December 1982

Prepared for the U.S. Department of Energy under Contract DE-AC06-76RLO 1830

Pacific Northwest Laboratory Operated for the U.S. Department of Energy by Battelle Memorial Institute 


\title{
DISCLAIMER
}

This report was prepared as an account of work sponsored by an agency of the United States Government. Neither the United States Government nor any agency thereof, nor any of their employees, makes any warranty, express or implied, or assumes any legal liability or responsibility for the accuracy, completeness, or usefulness of any information, apparatus, product, or process disclosed, or represents that its use would not infringe privately owned rights. Reference herein to any specific commercial product, process, or service by trade name, trademark, manufacturer, or otherwise, does not necessarily constitute or imply its endorsement, recommendation, or favoring by the United States Government or any agency thereof. The views and opinions of authors expressed herein do not necessarily state or reflect those of the United States Government or any agency thereof.

\author{
PACIFIC NORTHWEST L.ABORATORY \\ operated by \\ BATTELLE \\ for the \\ UNITED STATES DEPARTMENT OF ENERGY \\ under Contract DE-AC06-76RLO 1830
}

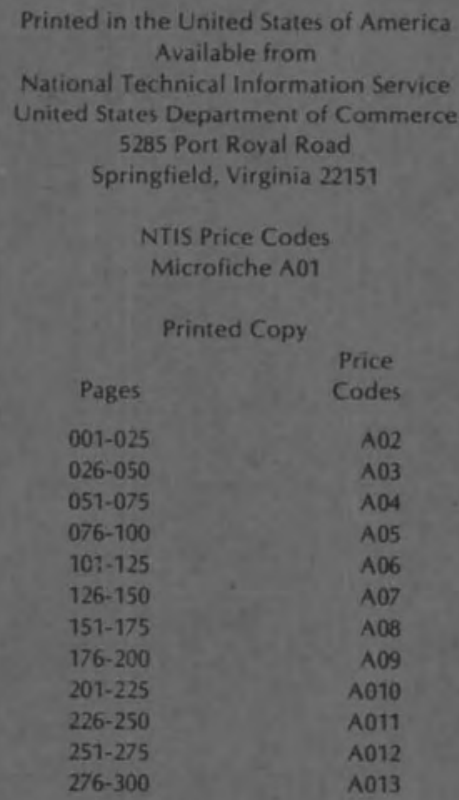


COMPARISON OF CASK AND DRYWELL STORAGE CONCEPTS FOR A MONITORED RETRIEVABLE STORAGE/ INTERIM STORAGE SYSTEM

D. E. Rasmussen

Program Manager

December 1982

Prepared for

the U.S. Department of Energy

under Contract DE-AC06-76RLO 1830

Pacific Northwest Laboratory Richland, Washington 99352 


\section{ACKNOWLEDGMENTS}

This report represents the combined efforts of a large group of contributors. Without detracting from those efforts, the specific support of the team members that assembled, edited, and processed this report are specifically acknowledged. The team members were:

Technical Contributors/Editors

T. A. Evans - AGNS*

J. F. Fletcher

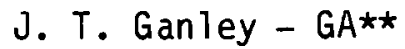

W. L. Godfrey - AGNS

G. M. Holter

K. D. Hayden - WHC***
W. S. Kelly

W. Knox - AGNS

R. P. Morissette - GA

J. F. Nesbitt

K. J. Schneider

R. I. Smith

Formal Editing

J. A. Powell

R. I. Smith

Word Processing

S. C. Cozad

H. K. Mills

J. A. Smith

Duplicating

E. Anderson, et al.

Coordination and Secretarial

P. N. McDuffie

C. A. Jones

* Allied-General Nuclear Services, Barnwell, South Carolina

** General Atomic Company, San Diego, Cal ifornia

$\star \star \star$ Westinghouse Hanford Company, Richland, Washington 
CONTENTS

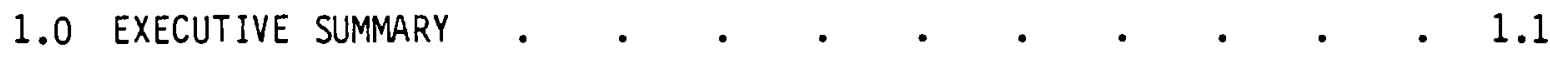

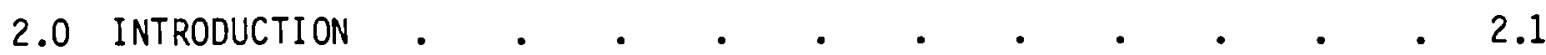

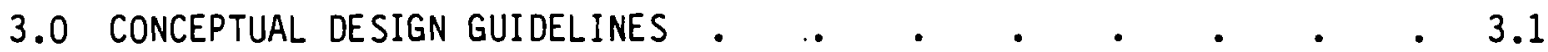

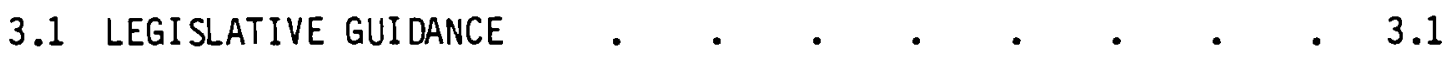

3.1.1 Emergency Storage of Spent Fuel . . . . . 3.1

3.1.2 Monitored Retrievable Storage . . . . . 3.2

3.1.3 Storage of Transuranic Wastes . . . . . 3.3

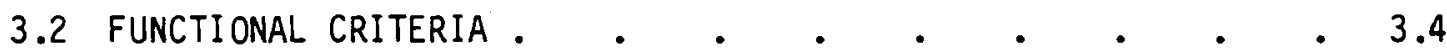

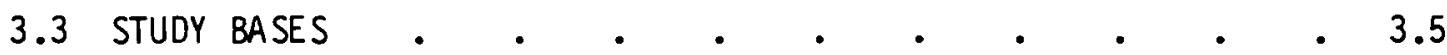

3.3.1 MRS/IS Facility and Operating Cost Bases . . . 3.5

3.3.2 MRS/IS Transportation Guidelines . • . . . 3.6

3.3.3 Fuel Cycle and Waste Scenarios . . . . . $\quad$. 3.7

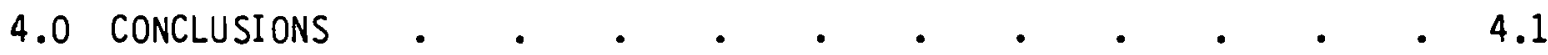

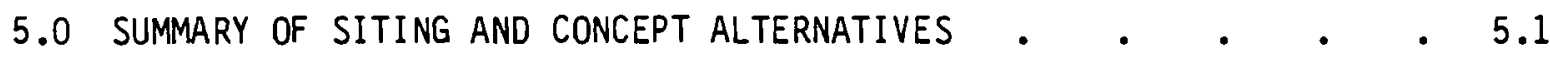

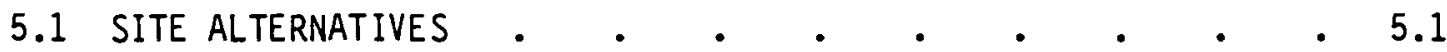

5.1.1 Site Location and Description for a Facility
Co-located with Reprocessing Plant . . . . $\quad$. 5.1

5.1.2 Siting of Stand-Alone MRS/IS Facility . . . $\quad . \quad 5.5$

5.1.3 Site Location and Description for a Facility
Co-located with Repository $. \quad . \quad . \quad . \quad 5.9$

5.2 GENERIC STORAGE CASK AND DRYWELL DESIGNS $\quad . \quad \ldots \quad . \quad$ • 5.13

5.2.1 Reference Metal Cask . . . . . . . . 5.13

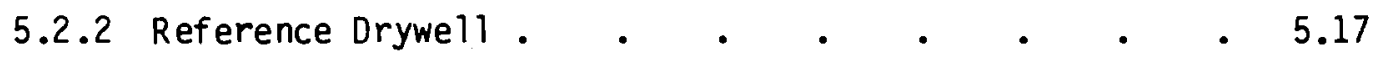

5.3 MRS/IS COLLOCATED WITH A REPROCESSING PLANT • . $\quad$ • $\quad 5.20$

5.3.1 Receiving and Handling Facility . . . . . 5.20 
5.3.2 Contact-Handled TRU Storage . . . . . 5.20

5.3.3 Remote-Handled Waste Storage . . . . . 5.23

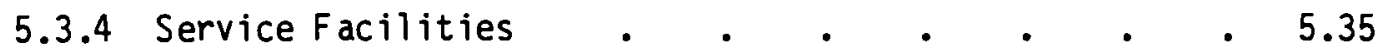

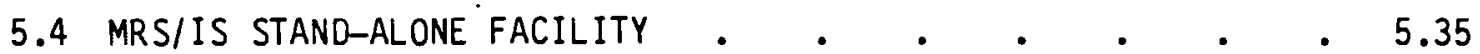

5.4.1 Receiving and Handling Facility . . . . . 5.39

5.4.2 Contact-Handled Waste Storage . . . . . 5.50

5.4.3 Remote-Handled Waste Storage . . . . 5.50

5.4 .4 Service Facilities $\quad$. $\quad$. $\quad$. $\quad$ • $\quad$. 5.60

5.5 MRS/IS COLLOCATED WITH A REPOSITORY $\quad$ • $\quad$ • $\quad$ • $\quad$ • $\quad 5.63$

5.5.1 Receiving and Handling Facility . . . . 5.63

5.5.2 Transfer and Storage of Contact-Handled Waste -

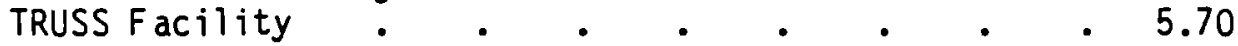

5.5.3 Transfer and Storage of Remote-Handled Wastes Casks . . . . . . . . . 5.72

5.5.4 Transfer and Storage of Remote-Handled Wastes Drywells

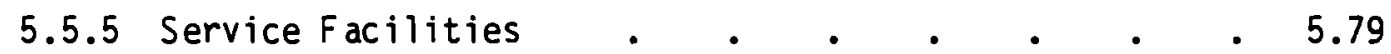

5.5.6 Service Utilities and Systems . . . . . $\quad$. 5.81

6.0 STUDY RESULTS

6.1 COMPARISON OF THE THREE MRS/IS FACILITY CONCEPTS • • • $\quad$ • 6.1

6.1.1 Construction and Operating Schedules . . . 6.1

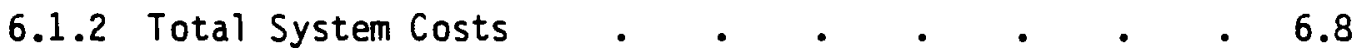

6.1.3 Technical Merits of Casks Versus Drywells . . $\quad 6.11$

6.1.4 Possibilities for Life-Cycle Cost Reductions . $\quad 6.12$

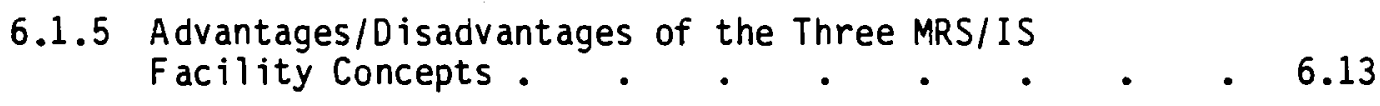




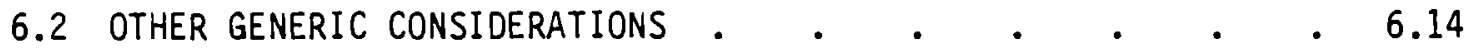

6.2.1 Licensing and Safety Considerations . • . $\quad$ • 6.15

6.2.2 Environmental Considerations . . . . . 6.19

6.2.3 Transportation Considerations . $\quad$ • . . . $\quad$ - 6.24

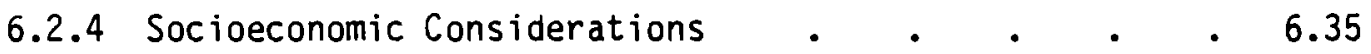

6.2.5 Relation to Other Facilities . . . . . $\quad$. 6.36

6.2.6 Advantages/Disadvantages of Utilizing
an Existing Federal Site . . . . . . . 6.37

6.2.7 Technical Status of System Components . . . $\quad$. 6.41

6.2.8 Research and Development Requirements . . . . 6.45

APPENDIX A - DETAILS OF ECONOMIC COMPARISONS

A.1 MRS/IS FACILITY CO-LOCATED WITH A

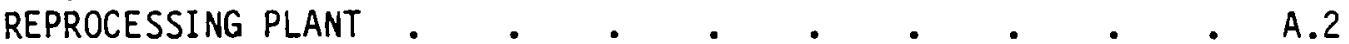

A.2 MRS/IS STAND-ALONE FACILITY • • • . • • . A.20

A.3 MRS/IS FACILITY CO-LOCATED WITH A REPOSITORY . . . . A.38 APPENDIX B - STUDY DATA BASE AND EVALUATION GUIDELINES

B.1 MRS/IS FUEL CYCLE AND WASTE SCENARIOS.$\quad \cdot \quad \cdot \quad \cdot \quad \cdot$ B.1

B.2 CONSIDERATIONS FOR MRS/IS COST EVALUATION $\quad$ • $\quad$ • $\quad$ • $\quad$ B.25

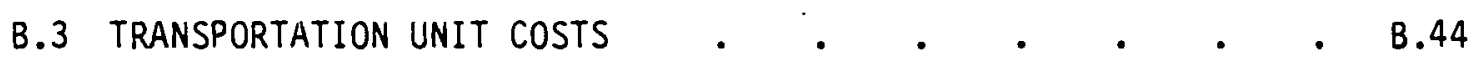


FIGURES

1.1 Inventories of Spent Fuel and HLW Requiring Storage . . $\quad 1.3$

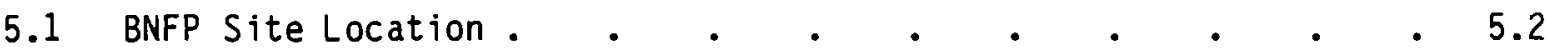

5.2 National Screening Results for a Stand-Alone MRS/IS

Facility in the Eastern U.S. . . . . . . . . . . 5.6

5.3 National Screening Results for a Stand-Alone MRS/IS

Facility in the Western U.S. . . . . . . . 5.7

5.4 Location Map - Hanford Site . . . . . . . . . 5.10

5.5 REA 2023 Storage Cask . . . . . . . . . . . . . . 5.14

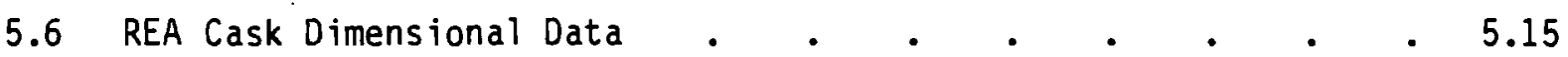

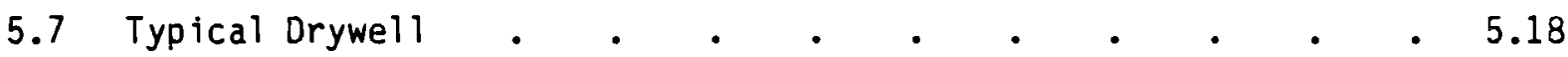

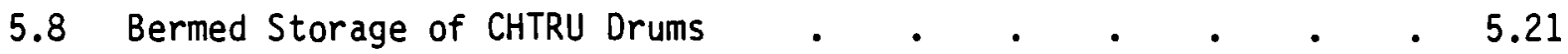

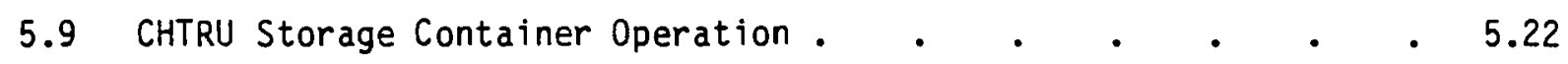

5.10 GNS $1 C$ Storage/Shipping Cask . . . . . . . . . 5.24

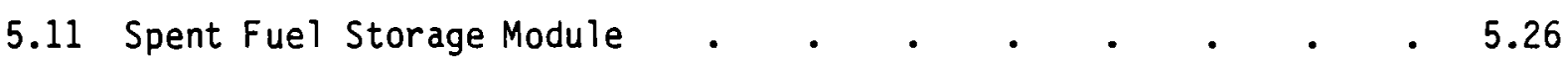

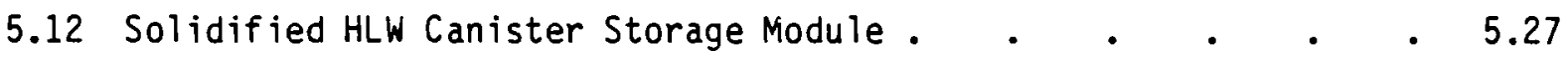

\begin{tabular}{l}
5.13 MRS/IS Facility Co-located with a Reprocessing Plant, \\
Reference Scenario. \\
\hline
\end{tabular}

5.14 MRS/IS Facility Co-located with a Reprocessing Plant,
Delayed Reprocessing Scenario $. \quad . \quad . \quad . \quad . \quad . \quad 5.29$

5.15 MRS/IS Facility Co-located with a Reprocessing Plant,

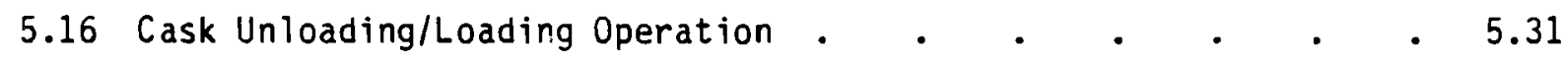

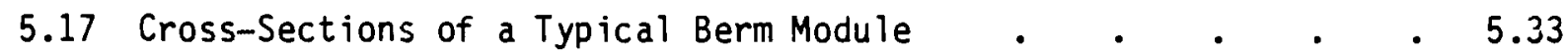

5.18 Typical Berm Module for Drywell Storage of Spent Fuel . • 5.36

5.19 Typical Berm Module for Drywell Storage of HLW $\quad$ • $\quad$ • 5.37

5.20 Typical Berm Module for Drywell Storage
of RHTRU Wastes . $\quad . \quad . \quad . \quad . \quad . \quad . \quad . \quad . \quad 5.38$ 
5.21 Spent Fuel/HLW Receiving and Storage Flow Diagram $\quad$ • $\quad$ • 5.41

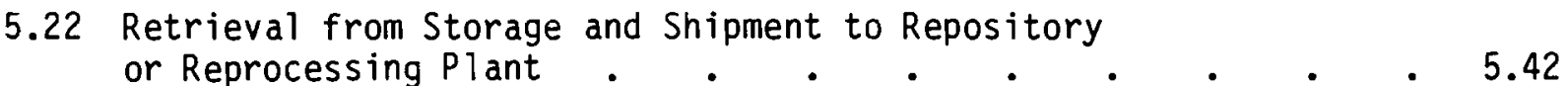

5.23 MRS/IS Facility Spent Fuel and High-Level Waste Handling Building Plan . . . . . . . . . 5.44

5.24 TRU Waste Receiving and Transfer Facility . $\quad$. $\quad$. $\quad$. 5.49

5.25 Indoor Storage Facility for CHTRU Waste $\quad . \quad+\quad . \quad$. $\quad . \quad 5.51$

5.26 MRS/IS Stand-Alone Facility Cask Storage Site Plan • • 5.53

5.27 Spent Fuel Canister for Open-Field Dry Well Storage 5.55

5.28 MRS/IS Stand-Alone Facility Drywell Storage Site Plan . 5.56

5.29 Indoor Storage Facility for RHTRU Waste $\quad$ • $\quad$ • $\quad$ • $\quad$ • 5.59

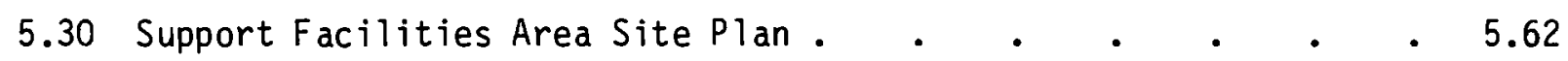

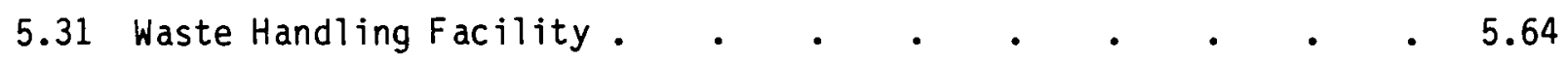

5.32 Waste Handling Facility - Ground Floor Plan . . . . . 5.66

5.33 Waste Handling Facility - Upper Levels . . . . . . 5.67

5.34 Waste Handling Facility - Sections and Elevations . • • 5.68

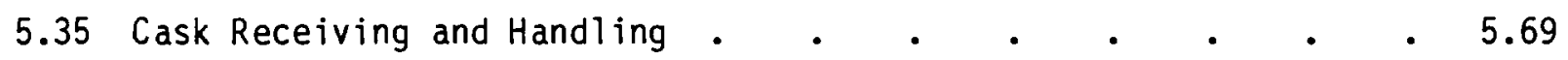

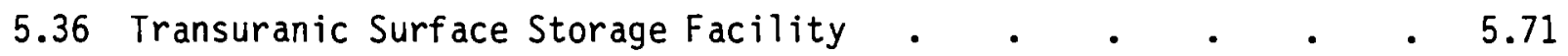

5.37 Concrete Cask for RHTRU Waste Storage . . . . . 5.73

5.38 Yard Gantry Crane . . . . . . . . . . . . 5.75

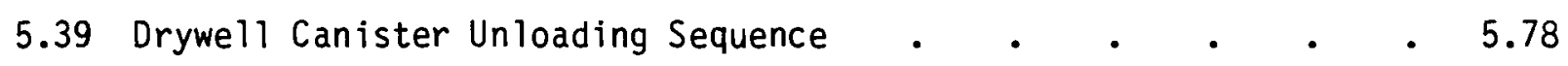

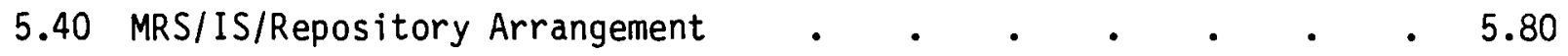

6.1 MRS/IS Facilities Construction Schedule Comparisons • $\quad$ • $\quad$ • 6.2

6.2 MRS/IS Life Cycles for Reference Scenario . . . . . . $\quad 6.3$

6.3 MRS/IS Life Cycles for Delayed Reprocessing Scenario • $\quad$ • $\quad$ • $\quad 6.4$

6.4 MRS/IS Life Cycles for Delayed Disposal Scenario . . . . $\quad$ • 6.5 
6.5 Inventories of Spent Fuel and HLW Requiring Storage . . . 6.6

6.6 Spent Fuel and Waste Flow Routes for an

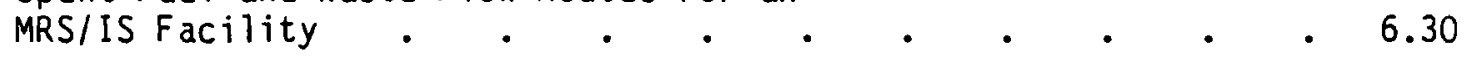


TABLES

1.1 Estimated. Life-Cycle Costs for Conceptual

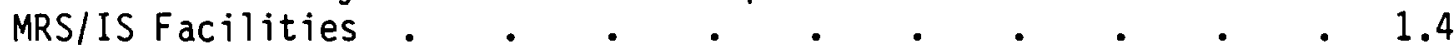

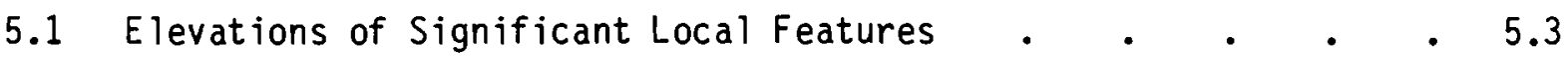

5.2 REA 2023 Storage Capacity . . . . . . . . 5.16

5.3 Nominal Nuclear and Thermal Characteristics of Spent

5.4 Receiving and Handling Facility Handling Rates
for Spent Fuel . . . . 5.47

5.6 Number of Casks and Pads Required for Study Scenarios . . $\quad 5.54$

5.7 MRS/IS Reference Scenario Storage Requirements • • 5.72

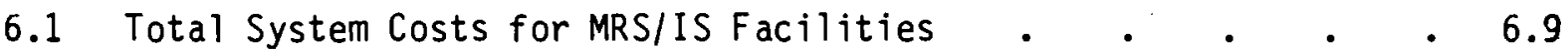

6.2 Reference Shipping Systems Selected for This Study . $\quad$ • 6.28

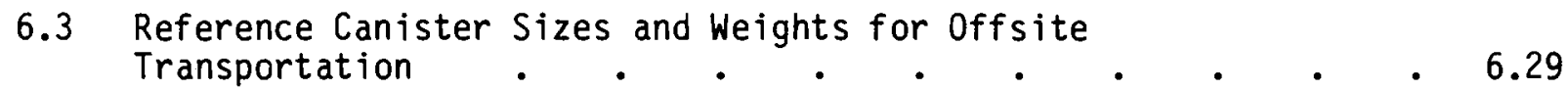

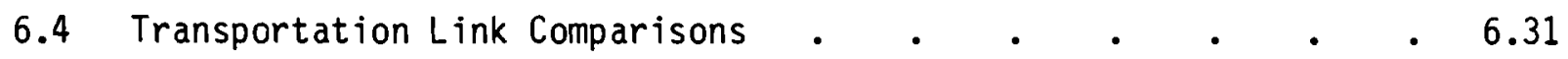

6.5 Life-Cycle Offsite Transportation Costs for Waste
Management System

6.6 Sensitivity of Transportation Costs to
Rail/Truck Split . . . . . . . . . . . . . . 6.33

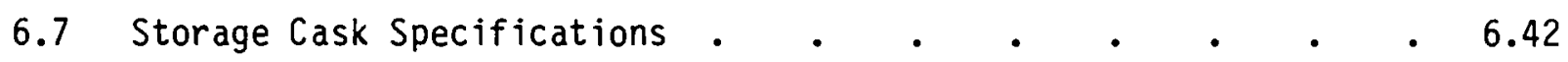




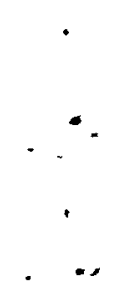

.

. 


\subsection{EXECUTIVE SUMMARY}

Changes in recent years in federal policies regarding spent nuclear reactor fuel reprocessing and/or disposal have produced delays in completing the construction and startup of commercial fuel reprocessing plants, and in the development and deployment of waste disposal facilities. As a result, some nuclear power plants are running out of spent fuel storage capacity. Start of reprocessing would improve spent fuel storage capacity. However, the sizeable quantities of waste produced in reprocessing would need to be stored until a repository is available. Legislative initiatives are under way in Congress to provide storage and disposal capabilities responsive to this situation.

The Department of Energy (DOE), through its Richland Operations Office is evaluating the feasibility, timing, and cost of providing a federal capability for storing the spent fuel, high-level wastes (HLW), and transuranic (TRU) wastes that DOE may be obligated by law to manage until permanent waste disposal facilities are available. Three concepts utilizing a monitored retrievable storage/interim storage (MRS/IS) facility have been developed and analyzed. The first concept, co-location with a reprocessing plant, has been developed by staff of Allied General Nuclear Services. The second concept, a stand-alone facility, has been developed by staff of the General Atomic Company. The third concept, co-location with a deep geologic repository, has been developed by the Pacific Northwest Laboratory with the assistance of the Westinghouse Hanford Company and Kaiser Engineers. This report summarizes the results of those studies.

The MRS/IS facility co-located with a fuel reprocessing plant utilizes the water pool receiving, inspection, and handling facilities and other support facilities already present on the site as part of the reprocessing plant. Spent fuel and solidified HLW are stored either in large metal dry storage casks or in subsurface drywells in built-up berms. Remote-handled TRU (RHTRU) wastes are stored in metal drywells in built-up berms. Contacthandled TRU (CHTRU) wastes are stored in cargo containers that are covered by a berm to protect against tornado damage. 
The MRS/IS stand-alone facility, located separately from other nuclear fuel cycle facilities, utilizes a water pool receiving station and dry, shielded cells for inspection, handling, and packaging as needed. Spent fuel and solidified HLW are stored either in large metal dry storage casks or in subsurface drywells. RHTRU wastes are stored either in a shielded storage building or in subsurface drywells in a built-up berm, depending on the surface radiation dose rates of the containers. CHTRU wastes are stored in a conventional surface warehouse structure.

The MRS/IS facility co-located with a repository utilizes a dry receiving station for inspection, handling, and packaging as needed. Spent fuel and HLW are stored either in large metal dry storage casks or in subsurface drywells. RHTRU wastes are stored in concrete storage casks. CHTRU wastes are stored in a conventional surface warehouse structure.

The objectives of this study are: 1) to develop preconceptual designs for MRS/IS facilities, 2) to examine various issues such as transportation of wastes, licensing of the facilities, and environmental concerns associated with operation of such facilities, and 3 ) to estimate the life-cycle costs of the facilities when operated in response to a set of scenarios that define the quantities and types of waste requiring storage in specific time periods, generally spanning the years 1989 to 2037.

Three scenarios are examined to develop estimates of life-cycle costs for the MRS/IS facilities. In the first scenario, the reprocessing plant is placed in service in 1989 and HLW canisters are stored until a repository is opened in the year 1998. Additional reprocessing plants and repositories are placed in service at intervals as needed to meet the demand. In the second scenario, the reprocessing plants are delayed in starting operations by 10 years, but the repositories open on schedule. In the third scenario, the repositories are delayed 10 years, but the reprocessing plants open on schedule.

The inventories of spent fuel and HLW requiring storage in an MRS/IS facility are shown in Figure 1.1 as a function of time for each of the three scenarios. The life-cycle costs estimated in this study include: the capital 


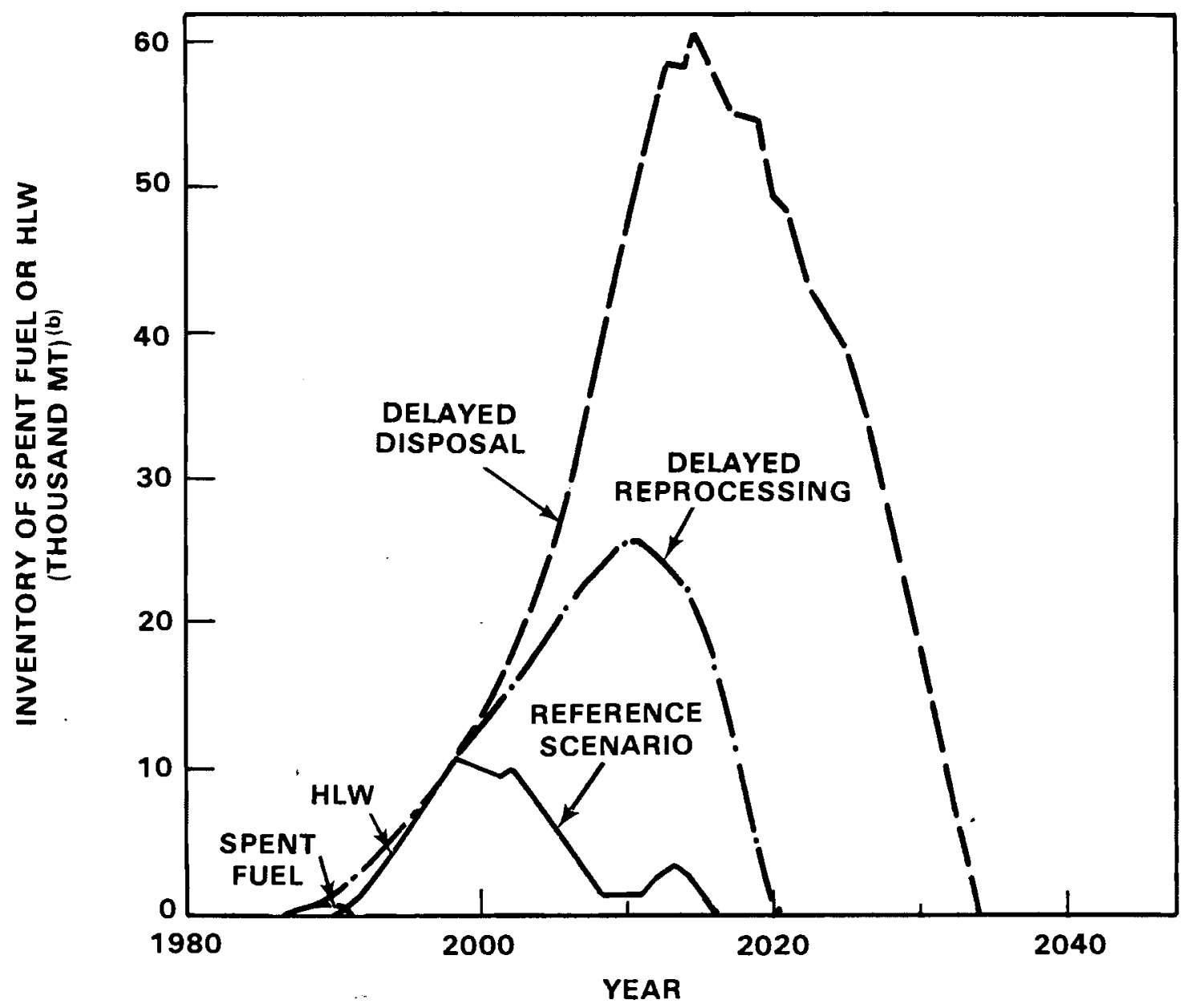

FIGURE 1.1. Inventories of Spent Fuel and HLW Requiring Storage (a)

(a) These scenarios represent maximum capacities and do not include any moderating effects of extended burnup operation, rod consolidation, or private AFRs.

(b) To convert from MTHM to fuel assemblies or HLW canisters, divide the MTHM values by 0.18 MTHM/BWR, 0.42 MTHM/PWR, 2.143 MTHM/canister.

expenditures for structures, casks and/or drywells, storage areas and pads, and transfer equipment; the cost of staff labor, supplies, and services; and the incremental cost of transporting the waste materials from the site of origin to the MRS/IS facility (costs in excess of the normal reactor-toreprocessing plant-to-repository transport costs). 
The estimated life-cycle costs (undiscounted) for each of the conceptual facilities, in each of the three fuel cycle scenarios, utilizing metal casks or drywells for storage of spent fuel and HLW, are summarized in Table 1.1 .

TABLE 1.1. Estimated Life-Cycle Costs for Conceptual MRS/IS Facilities (millions of mid-1982 dollars, undiscounted)

\begin{tabular}{|c|c|c|c|c|c|c|}
\hline \multirow[b]{3}{*}{ Scenario } & \multicolumn{6}{|c|}{ Location of the Storage Facility } \\
\hline & \multicolumn{2}{|c|}{ Reprocessing Plant } & \multicolumn{2}{|c|}{ Stand-Alone } & \multicolumn{2}{|c|}{ Repository } \\
\hline & Cask & Drywe Tा & Cask & Drywe Tा & $\overline{C a s k}$ & Drywe Tा \\
\hline Reference & 379 & 277 & 1340 & 1124 & 731 & 518 \\
\hline $\begin{array}{l}\text { Delayed } \\
\text { Reprocessing }\end{array}$ & 839 & 340 & 1722 & 1513 & 2257 & 1973 \\
\hline $\begin{array}{l}\text { Delayed } \\
\text { Disposal }\end{array}$ & 2224 & 1713 & 4376 & 2989 & 2487 & 1235 \\
\hline
\end{tabular}

From the results of this study it is concluded that:

- The use of a modular dry storage system utilizing large metal casks and/or drywells is feasible. Such a system could be developed and deployed to meet the projected storage needs.

- Storage in drywells is less expensive than storage in large metal casks.

- Co-location with a reprocessing plant is somewhat less expensive than the other alternatives, due principally to the use of available handling facilities at the reprocessing plant.

- Consolidation of spent fuel assemblies at the reactor sites and shipment in transportable large metal storage casks would significantly reduce overall waste management system costs.

- Storage in large metal casks would be more cost-effective if the stored materials could be also shipped to the storage site in sealed storage casks, thus eliminating the need for a transfer facility. 
The principal advantages/disadvantages of each MRS/IS concept evaluated in this report are described below:

MRS/IS/Reprocessing Plant. Co-location with a reprocessing plant reduces the capital cost of the MRS/IS facility since the receiving and handling station and other supporting facilities at the reprocessing plant can also serve the storage facility.

Since the site is already approved for nuclear applications, the time required to obtain the necessary permits and licenses should be reduced, as compared with a new site. Thus, authorization, construction and utilization of the storage facility could be accomplished at an earlier date.

The incremental transportation links for this concept (transport in addition to the normal reactor-to-reprocessor-to-repository links) are zero. Thus waste management transportation costs are minimized.

Storage at the reprocessing plant may be publicly perceived as likely to become permanent disposal, a perception that might lead to public opposition to siting of the storage facility.

MRS/IS/Stand-Alone. The stand-alone facility can be sited in many places, since the location does not have to be suitable for either a reprocessing plant or a geologic repository. Thus, selection of a site and the obtaining of necessary permits and licenses might be accomplished more quickly, compared with a repository-based site.

The incremental transportation links for this concept are longer than for the repository concept except with the delayed reprocessing scenario.

Storage at the stand-alone facility may be publicly perceived as likely to become permanent disposal, a perception that might lead to public opposition to siting of the storage facility.

MRS/IS/Repository. Co-location with a geologic repository reduces the overall capital investment in the waste management system since the waste handling facility and its supporting facilities become the surface installations for the repository. Using these facilities over the life span of the 
repository approximately doubles the useful life of the structures and permits amortization of the capital costs over a longer time period.

Except for the delayed reprocessing scenario, the incremental transportation links are zero, thus minimizing waste management transportation costs.

The stored materials are transferred directly from storage to the repository without leaving the site, thereby minimizing the potential for transportation accidents and the possible exposure of the public that could otherwise result from such accidents. 


\subsection{INTRODUCTION}

Until 1975, commercial nuclear power generating plant owners had planned to store spent fuel at the reactor for only a short period prior to shipment to a reprocessing plant. Reactors built in that era initially had storage space for only one or two batch discharges of spent fuel in addition to a full core discharge capability. While installation of larger capacity storage racks has alleviated the situation temporarily, changes in federal policies in the late seventies have delayed completion and startup of commercial fuel reprocessing plants, and some nuclear power generating plants are faced with the possibility of shutdown due to lack of spent fuel storage capacity.

Similarly, delay in selecting waste disposal methods and sites has delayed the projected completion date of waste repositories. This delay has raised the question of where will spent fuel not suited to reprocessing and wastes from a reprocessing $\mathrm{plant}$ be stored and/or disposed of.

In recognition of this situation, legislative initiatives are under way in Congress to provide appropriate storage and disposal facilities. In response to these legislative initiatives, the Department of Energy (DOE), through its Richland Operations Office, is evaluating the feasibility and cost of storing spent nuclear fuel, solidified high-level wastes (HLW), and transuranic (TRU) wastes in government facilities until a reprocessing plant and/or appropriate waste disposal facilities are available. Three conceptual government-owned monitored retrievable storage/interim storage (MRS/IS) facilities for wastes that the government may become obligated to manage are the subject of this report.

Three MRS/IS siting alternatives were studied. Two storage methods for spent fuel and high-level waste were evaluated for each site. Systems for handling both remote-handled and contact-handled transuranic waste were also evaluated for each site. The use of dry passive storage was assumed in these studies. The three siting alternatives studied were:

- located on a reprocessing site

- strategically located stand-alone site

- located at a future geologic repository site. 
The storage methods evaluated for spent fuel and HLW were:

- large metal casks

- drywells.

Study of each alternative site was assigned to a study team. Each team independently developed the storage concept most appropriate to the specific site and responsive to previously established common criteria, guidelines, and storage methods. The study team assignments were:

- co-located with a reprocessing plant site - Allied-General Nuclear Services

- stand-alone site - General Atomic

- co-located with a repository site - Pacific Northwest Laboratory, with assistance from Westinghouse Hanford Company and Kaiser

Engineers.

Each study team completed its study assignment and prepared a final (drait) report. This report is a summary of the information, results, and conclusions presented in those reports. Each study team participated in preparation of this summary report.

This report has six sections and appendices. Section 1 contains the executive summary, and Section 2 contains the introduction. Conceptual design guidelines, including legislative guidance, functional criteria for the MRS/IS facility, and planning assumptions are presented in Section 3, and conclusions and recommendations are presented in Section 4. The siting alternatives and facility concepts are summarized in Section 5. Concept evaluations are compared in Section 6, including the technical and economic merits and the specific attributes of each concept. Detailed information on economic comparisons is provided in Appendix A. The data bases and evaluation guidelines are given in Appendix $B$. 


\subsection{CONCEPTUAL DESIGN GUIDELINES}

To ensure valid and equitable comparisons of the various conceptual designs for monitored retrievable storage/interim storage (MRS/IS) facilities, PNL provided specific guidelines for the preparation of critical sections of the studies. The legislative guidance that provides the bases for the MRS/IS concept is discussed in Section 3.1. The functional criteria for an MRS/IS facility, used to develop the conceptual designs, are presented in Section 3.2. The study bases used in evaluating the conceptual designs are described in Section 3.3. Additional details are presented in Appendix B.

\subsection{LEGISLATIVE GUIDANCE}

Several bills presently under consideration by Congress deal with interim storage of commercial spent nuclear fuel; monitored retrievable storage of spent fuel, solidified high-level wastes, and transuranic wastes; and permanent disposal of these nuclear wastes in deep geologic repositories. Each bill under consideration provides for establishment of repositories, mechanisms to ensure full recovery of the costs of storage and disposal operations from the waste generators, and procedures to ensure that interested states and Indian tribes can be involved in the siting process. Several of the proposed bills differ regarding who has title to the radioactive material while in storage prior to final disposal in a repository.

Specific provisions of the pending legislation that are unique to interim storage, monitored retrievable storage, and transuranic waste storage are discussed in the following subsections. It should be noted that many of the subjects addressed in pending legislation are still being debated, including monitored retrievable storage. At the time of this writing, the final form of the legislation is not known.

\subsubsection{Emergency Storage of Spent Fuel}

The bills contain language that would make licensing of additional spent fuel storage capacity at existing reactor sites easier by eliminating some of the issues that would otherwise have to be considered (availability or 
desirability of alternatives, the need for power from the reactor, any issues relating to reactor operation, etc.).

In addition, use of federally-owned away-from-reactor facilities for emergency storage is proposed. The facilities would be limited in capacity [1700 (H.R.3809) or 2800 (S.1662) metric tons], would be exempt from licensing if located at an existing federal site (H.R.3809), and woula not be a major federal action as defined in the National Environmental Policy Act (NEPA) (H.R.3809). The operation of an emergency storage facility is limited to 5 to 7 years (President Reagan's letter to T. P. O'Neill dated April 28, 1982), or 8 to 12 years $(S .1662$ ).

The emergency storage provisions are intended to provide a way to avoid shutdown of operating power reactors if full core discharge capability is lost as the quantities of stored fuel approach the pool's capacity. This type of storage is intended as a very limited effort, of relatively short duration. Longer-term storage of radioactive materials such as spent fuel, solidified high-level waste, and transuranic waste would be provided for by monitored retrievable storage facilities, which are discussed in the next subsection.

\subsubsection{Monitored Retrievable Storage}

In pending legislation, the DOE is directed to submit to Congress within 1 year of passage of the enabling legislation a proposal to develop one or more MRS facilities. This proposal is to include: 1) the federal program for developing, siting, building, and operating licensed storage facilities for spent fuel and HLW; 2) site-specific designs, specifications, and cost estimates suitable for construction authorization; and 3) a plan for integration of the MRS facility into the federal nuclear waste management program, especially in terms of away-from-reactor storage and of the deep geologic disposal repositories also mandated by the legislation.

In all cases, an environmental assessment (EA) is required at the time the proposal is submitted, with an environmental impact statement (EIS) to be issued before construction is initiated. The MRS facility must be licensed by the NRC. During the NEPA and licensing processes, some issues normally 
considered, such as the need for the facility, alternative sites, and alternative designs, need not be considered.

Both S.1662 and H.R.3809 treat the MRS facility as a complement to a repository program. Both the MRS facility and the repositories are to be paid for by a nuclear waste management fund financed by a $1-m i 11 / k$ Wh fee paid by users of electricity from nuclear power generating plants.

No specific instructions are given in the various House bills regarding the capacity of an MRS facility. However, in the Senate bill (S.1662), until a second repository is in operation, a limit of 70,000 metric tons of spent fuel is placed on the combined capacity of an MRS facility and the first repository when located within 50 miles of each other.

Similarly, no clearly defined limit is proposed for the duration of MRS operations, when the MRS facility is to be built or when MRS waste must be transferred to a repository. Instead, the MRS facilities are simply to remain in service until geologic repositories are available.

The House bills exclude military waste from licensed nuclear waste management facilities; S. 1662 requires military waste to be included in such facilities.

\subsubsection{Storage of Transuranic Wastes}

The bill also defines high-level radioactive waste, in part, as any solid material derived from liquid waste produced directly in reprocessing, that contains fission products and transuranic waste in sufficient concentrations. Those TRU wastes which result from reprocessing are considered in this study.

In addressing storage and disposal of transuranic (TRU) wastes, House bill 7187 specifically states that TRU wastes, regardless of concentration, from decommissioning and decontamination of civilian nuclear facilities (except utilization facilities) and from civilian fuel R\&D program can be stored in facilities owned by the government at the time the act is enacted. TRU waste from those sources are not considered in this study. 


\subsection{FUNCTIONAL CRITERIA}

The following functional criteria were used as the basis for development of the three conceptual studies.

- The MRS/IS system shall have the capability to receive, inspect, repackage where necessary, and store and retrieve for subsequent shipment spent fuel, solidified HLW and TRU waste.

- The MRS/IS system shall be capable of containing radioactive material within the storage package during the entire storage period.

- The MRS/IS system shall have a monitoring system capable of detecting any releases of radioactive material.

- The MRS/IS system shall be capable of protecting the stored material against any likely natural or man-created events, excluding acts of war.

- The MRS/IS system shall be capable of passively removing the heat generated from decay of radioactive materials that have been aischarged from a reactor at least 10 years.

- The MRS/IS system shall be capable of adequately protecting operating personnel and the public from the radiation emitted from stored materials.

- The MRS/IS system shall be capable of interfacing with all systems within the total waste management system, including the reprocessing and disposal systems.

- The MRS/IS system shall be capable of accounting for the quantity, type, and history of the material stored in the facility.

- Security, surveillance, and physical protection shall be provided for the facility, with additional safeguards provided to vital areas, in accordance with federal regulations.

- The MRS/IS facility shall be designed to preclude any criticality events. 
- The MRS/IS facility shall be of modular design and capable of incrementally increasing or decreasing its processing rate and storage capacity to accommodate different circumstances.

- The MRS/IS facility shall be capable of handling existing rail and truck shipping casks.

\subsection{STUDY BASES}

The study bases serve as guidelines in the evaluation of the conceptual designs for an MRS/IS facility. The facility and operating cost bases, presented in Section 3.3.1, ensure that all costs are calculated in equivalent dollars and that present worth values are calculated using the same discount factors, so that the relative costs of the various concepts are directly comparable. Guidelines provided for transportation unit costs, reference shipping distances, and transport modes are discussed in Section 3.3.2. The reference and alternative fuel cycle waste scenarios, briefly described in Section 3.3.3, ensure that the analyses are all based on the same quantities and mixes of wastes to be handled.

\subsubsection{MRS/IS Facility and Operating Cost Bases}

It is assumed that an MRS/IS facility will be government-owned and financed. To establish a common cost basis and thus facilitate evaluation of the relative costs of each concept, all costs are based on mid-1982 dollars. It is assumed that the government's cost of money is 2 percent over inflation. Thus all costs are estimated without inflation or escalation beyond mid-1982, and a discount rate of 2 percent is used to obtain the present worth of future year expenditures.

All costs from the present through the final year of decommissioning are entered into a calendarized (yearly) cash flow table in mid-1982 dollars. The present worth of expenditures in each year is calculated using the discount factors provided. The annual costs are summed for all years to provide undiscounted program costs and the present worth costs at a 2 percent discount. The present worth costs (discounted) are used for comparing the options. 
To ensure equitable and valid cost comparisons of the three concepts, the details of component costs, background, and cost bases are presented in support of the costs given in the cash flow table.

\subsubsection{MRS/IS Transportation Guidelines}

Truck and rail transportation systems are specified for spent fuel, solidified HLW, canistered RHTRU wastes, RHTRU wastes $<5 \mathrm{R} / \mathrm{hr}$, RHTRU wastes $>5 \mathrm{R} / \mathrm{hr}$ and CHTRU wastes. All truck shipping systems are legal weight systems, i.e., 80,000 pounds maximum gross vehicle weight. There is no intent to endorse or reject any particular shipping system. Where possible, the systems selected are existing and licensed. Where no such system exists, those postulated for use are well along in the design stage and are expected to eventually meet the packaging regulations in 00 CFR 70 . Reference canister sizes, compatible with the reference shipping casks, are specified for shipping HLW and TRU wastes.

Reference one-way shipping distances selected are 500 miles and 2500 miles. The 500-mile distance approximates a typical distance between eastern power reactors and the Barnwell Nuclear Fuel Plant (BNFP), a reprocessing plant. The 2500-mile distance approximates a typical distance between either an eastern power reactor or the BNFP and a repository located in the western United States. The stand-alone facility is assumed to be located 500 miles from reactors and the BNFP, and $2500 \mathrm{miles}$ from the repository. Only the incremental shipping distances, beyond those that would be encountered without introduction of an MRS/IS facility, are used in calculating the transportation costs in this study.

It is assumed that 50 percent by volume of the spent fuel and of each of the waste types transported to and from the MRS/IS facility is shipped by truck and 50 percent by rail. Each transport mode has its own advantages and disadvantages, and the reference split reflects no bias toward either mode.

To establish a basis for cost comparisons among the various MRS/IS concepts, a common set of unit transportation costs is used. Mid-year 0982 dollars are used for calculating transportation unit costs. Transport costs are calculated based on the use of private industry carriers and shipping 
containers. Total transportation costs include round-trip shipping charges, special equipment/security costs, shipping container leasing fees and demurrage fees. Transportation unit costs for both truck and rail modes are calculated in dollars per shipment for each type of waste and its reference shipping system.

\subsubsection{Fuel Cycle and Waste Scenarios}

Three spent fuel and waste handling scenarios are developed as baselines for evaluation of the three MRS/IS facility concepts. Each of these, the reference scenario, the delayed reprocessing scenario, and the delayed disposal scenario are addressed in each evaluation.

The reference scenario defines the number of metric tons of spent fuel or metric tons equivalent of HLW (the quantity of HLW resulting from reprocessing a metric ton of spent fuel) to be considered in facility designs. To convert from MTHM to fuel assemblies or HLW canisters, divide the MTHM values by 0.18 MTHM/BWR, 0.42 MTHM/PWR, 2.143 MTHM/canister. Annual quantities are projected for up to 50 years covering:

- spent fuel discharged per year

- spent fuel storage inventories at-reactor, at MRS/IS facilities, shipped to disposal, and in inventory in repositories

- reprocessing rate

- HLW inventories at reprocessing plant(s), stored at MRS/IS facilities, shipped to disposal, and in inventory in repositories

- TRU waste generated by the reprocessing and fuel fabrication plant (s).

The other scenarios project the annual quantities expected if reprocessing is delayed or repository start-up is delayed. In the reference scenario, HLW canisters are stored until the repository is assumed to be opened in the year 1998. Additional reprocessing plants and repositories are placed in service at intervals as needed to meet the demand. In the delayed reprocessing scenario, the reprocessing plants are delayed in starting operations by 10 
years, but the repositories open on schedule. In the delayed disposal scenario, the repositories are delayed 10 years, but the reprocessing plants open on schedule. Since the storage facilities are postulated to begin operation in 1990, all spent fuel in excess of existing storage capacity through 1990 is assumed to be stored either in metal casks at reactor sites or in government-owned emergency storage. Detailed discussions of these scenarios are given in Appendix B. 


\subsection{CONCLUSIONS}

The studies on which this report is based were performed under a well-defined set of criteria and for sites characterized in relation to other facilities associated with the nuclear fuel cycle. Within those limits and based on the specific drywell and metal storage cask concepts used in the studies, the study team made the following conclusions:

- The use of drywells of the type studied herein for monitored retrievable storage of either high-level waste or spent fuel is less costly than the use of large metal storage casks of the type studied herein.

- Large metal storage casks would be more cost-competitive if they were licensed for shipping. The savings involve reduced capital and operating cost for receiving and transfer facilities. Licensing would also reduce the cost of transport in the overall fuel cycle. See next item.

- Transport of spent fuel and nuclear wastes represents a major cost in the fuel cycle. Most of the transport is required with or without an MRS/IS facility, and only the transportation cost increases (or increment) due to use of a storage facility are included in this report. For the reference scenario, neither the facility co-located with a repository nor the facility co-located with a reprocessing plant incurs any incremental transportation costs. The stand-alone MRS/IS facility has incremental transportation costs in all scenarios.

- Based on the concepts studied herein, no large differences in total cost exist between the facility co-located with a repository and the facility co-located with a reprocessing plant because each shares facilities and infra-structure with the co-located facility. The stand-alone facility is more expensive since it must provide its own support facilities with no opportunity for cost sharing.

- There are no technological breakthroughs needed to successfully deploy an MRS/IS system using either cask or drywell storage. 
Technology development is needed to firmly establish design criteria and to provide information for license applications.

- The MRS/IS concepts, in the reference and delayed disposal scenarios, are principally waste (high-level and transuranic) storage facilities. Only in the delayed reprocessing scenario is the capability to store large quantities of spent fuel required.

- In the delayed reprocessing scenario, the facility co-located with a reprocessing plant is apparently the least costly. This occurs because one round trip between the storage facility and the reprocessing plant is required for any other location. Note: If the reprocessing plant were late, much of the spent fuel sent to the MRS/IS facility might go directly to disposal when the repository opened. The reprocessing plant could be supplied with all the spent fuel needed for full-time operation directly from reactor storage without drawing any from the MRS/IS facility.

- The handling and storage of TRU waste is a very significant part of the overall facility requirements. The volume of material is large, exceeding the volume of solidified high-level waste resulting from the same fuel.

- Development of the technology needed to support licensing (e.g., experiments and analysis of solidified HLW canisters stored in drywells) should proceed.

- Development of standardized waste packages and transportation containers should be undertaken. This includes solidified HLW canisters, TRU waste containers, and transportation containers for both.

- A more thorough understanding of the interfaces between an MRS/IS facility and the other waste management system components should be developed, including:

1. common use of facilities

2. usefulness of lag storage to reprocessing and/or repository

3. canisters and container configurations. 


\subsection{SUMMARY OF SITE AND CONCEPT ALTERNATIVES}

This report covers MRS/IS facilities that would be co-located with specific plants that provide another part of fuel cycle processing as well as one that would be a stand-alone or generic site. These sites are identified in Section 5.1. Generic aspects of the storage concepts that may be applicable to any one or all of the sites are noted in Section 5.2. The processing and storage concepts considered are identified and described in Sections 5.3, 5.4, and 5.5.

\subsection{SITE ALTERNATIVES}

The MRS/IS facility sites examined in this study are: 1) a facility co-located with a reprocessing plant, 2) a facility located separate from any other fuel cycle facility, and 3) a facility co-located with a geologic repository. These sites are identified and discussed in this section.

\subsubsection{Site Location and Description for a Facility Co-located with Reprocessing P1ant}

The assumed location for the MRS/IS facility co-located with a reprocessing plant is at the Barnwell Nuclear Fuel Processing (BNFP) plant. The BNFP is located about 7 miles west of the City of Barnwell on a site of over 1700 acres of 1and, in a predominantly rural area in Barnwell County, South Carolina. The location of the BNFP Site is shown in Figure 5.1.

\subsubsection{Site Description and Arrangement}

The BNFP is located on the eastern edge of the Aiken Plateau portion of the Atlantic Coastal Plain physiographic province. The landform of the area is a gently sloping, gently rolling smooth plain.

The BNFP Site is largely forest land, with a small number of abandoned farm fields undergoing secondary succession, and several Carolina Bays. There are no natural streams on the BNFP Site. 


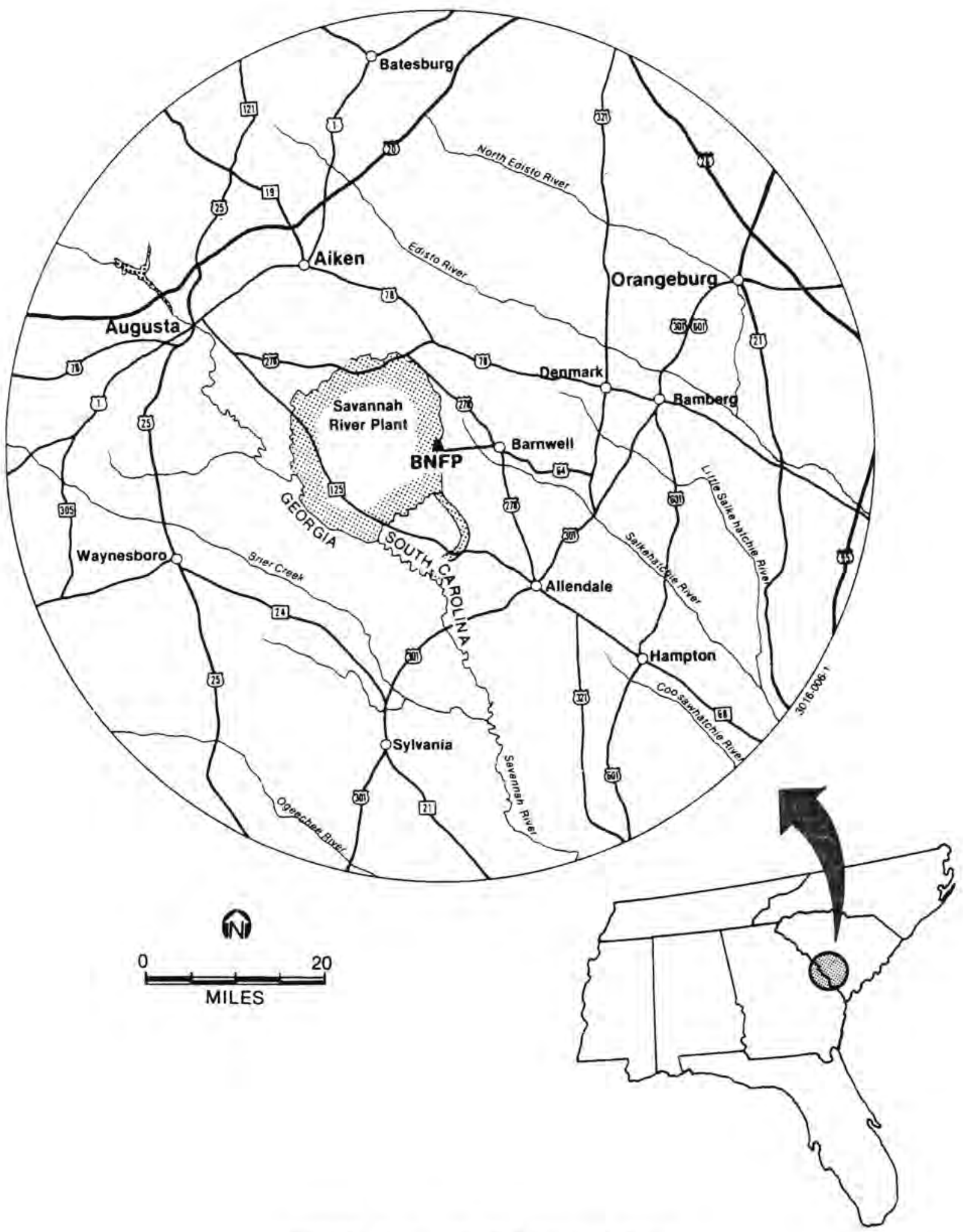

FIGURE 5.1. BNFP Site Location 
The plant site is wholly-owned private property. A right-of-way for the principal access road to the site has been granted to the State of South Carolina. An easement for the power transmission lines that supply the BNFP has been granted to South Carolina Electric and Gas Company. The railroad spur serving the BNFP is a wholly-owned plant property within the site boundary.

\subsubsection{Site Parameters}

The conditions at the BNFP Site, including meteorology, hydrology, geology, and seismic information, are discussed in the following paragraphs. There are no hills or valleys in the vicinity of the BNFP Site that tend to channel airflow or create mechanical air turbulence. There are no bodies of water in the area large enough to create atmospheric diffusion problems associated with a water/1and transition zone.

The BNFP Site is in the northeasterly portion of the watershed of Lower Three Runs Creek (LTRC), a tributary of the Savannah River. The site is in the interfluvial area between LTRC and the Salkehatchie River and lies completely within the LTRC drainage area. There are no surface streams on the site and, for a11 practical purposes, there are no surface runoff features. Except for unusually heavy precipitation, rainfall is held in local surface depressions, and is dissipated by evaporation, by transpiration and, in part, by infiltration into the groundwater table. In general, the BNFP Site is considerably higher than any reasonably expected flood stage of LTRC. The outfall structure through which Beacon Pond discharges into LTRC appears to be the only component of the plant area that may be subject to flooding. The ground-surface elevations of area features important to the BNFP are listed in Table 5.1.

TABLE 5.1. Elevations of Significant Local Features (feet, MSL)

$\begin{array}{ll}\text { Par Pond water surface } & 200 \\ \text { LTRC bed (just below Par Pond Dam) } & 140 \\ \text { Beacon Pond water surface } & 241 \\ \text { BNFP Facilities area ground surface } & 250\end{array}$


The surface runoff from the site is not materially affected by the BNFP facility or operations therein.

The BNFP Site is underlain by about $1000 \mathrm{ft}$ of unconsolidated and occasionally cemented sediments of Quaternary, Tertiary, and Cretaceous ages. The base rock is mostly Triassic basalt and Precambrian schist.

The surface soils are generally dry and firm. These soils consist of 1oose-to-medium-density fine Quaternary sands extending from 2 to $7 \mathrm{ft}$ below the ground surface. The average thickness is about $4 \mathrm{ft}$.

A seismic reflection survey was conducted at the site in 1968 to provide subsurface data that would complement information obtained during drilling and sampling operations for foundation investigations and for hydrologic programs. The seismic work consisted of seismic refraction surveys and seismic cross-hole surveys to determine compressional (P) and shear (S) wave velocities in the subsurface geologic strata for assessing elastic properties of subsurface soils, which bear on the evaluation of dynamic response characteristics of foundations and structures during seismic excitations.

There are historic records for more than 400 earthquakes with epicenters at Summerville (near Charleston), which was the epicenter of the Charleston earthquake of 1886. This earthquake and its aftershocks have dominated the seismic record of the southeast. The Charleston area is located about 80 miles east of the BNFP Site and has been described as having the highest concentration of epicenters and as having experienced the largest single earthquake in the southeastern United States.

There are no known capable faults within a $100-$ mile radius of the BNFP. In the Valley and Ridge and in the Blue Ridge-Piedmont provinces, there is no known correlation between earthquakes and tectonic structures. Earthquakes in the Charleston seismic zone are considered to be associated with a tectonic structure buried under more than $3000 \mathrm{ft}$ of sediments of the Coastal Plain physiographic province.

In summary, extensive field investigations, laboratory tests, and engineering analyses have shown conclusively that the seismic design criteria used for BNFP facilities accord with a11 accepted safety standards. 


\subsubsection{Siting of Stand-ATone MRS/IS Facility}

This section describes the natural features desired for an MRS/IS site and delineates locations having these features.

The stand-alone MRS/IS facility could be located in most states of the U.S. because it does not use the geologic features of the site as one of the radionuclide containment boundaries. In reality, however, the characteristics of a particular site will have an impact on the design of the MRS/IS facility. In addition, the licensing of a particular site for storage of radioactive material may be more or less difficult, depending upon the seismic or meteorological conditions of the site.

\subsubsection{Site Location and Arrangement}

A study to identify suitable locations for MRS/IS facilities was conducted by Woodward and Clyde (1981). A set of judgment standards and screening specifications was applied to data on the 48 contiguous states. The screening process was divided into two phases, national and regional. The first phase applied specifications that were uniform for the entire U.S., and the second phase applied specifications on a regional or state-by-state basis. The screening process, which was intended to be conservative and to focus attention on areas containing many suitable sites, did not consider engineering measures that would alleviate minor problems nor take into account additional information that would indicate a site's suitability for a surface MRS/IS facility.

The national screening for surface drywell facilities identified large potential areas in 40 states; the regional screening reduced this to 36 . The results of the national screening, shown in Figures 5.2 and 5.3, indicate that there are many potential sites for a surface MRS/IS facility in both the eastern and western U.S. Although Figure 5.3 does not include the Hanford Site or the Nevada Test Site, these areas are also considered suitable sites. They are excluded from the study described because they were already considered suitable and are discussed under separate reports. Also not included on Figure 5.2 is the BNFP Site, excluded by Woodward and Clyde because of water table limitations. However, drywell designs for the BNFP Site are of the berm type, which makes that site suitable. 


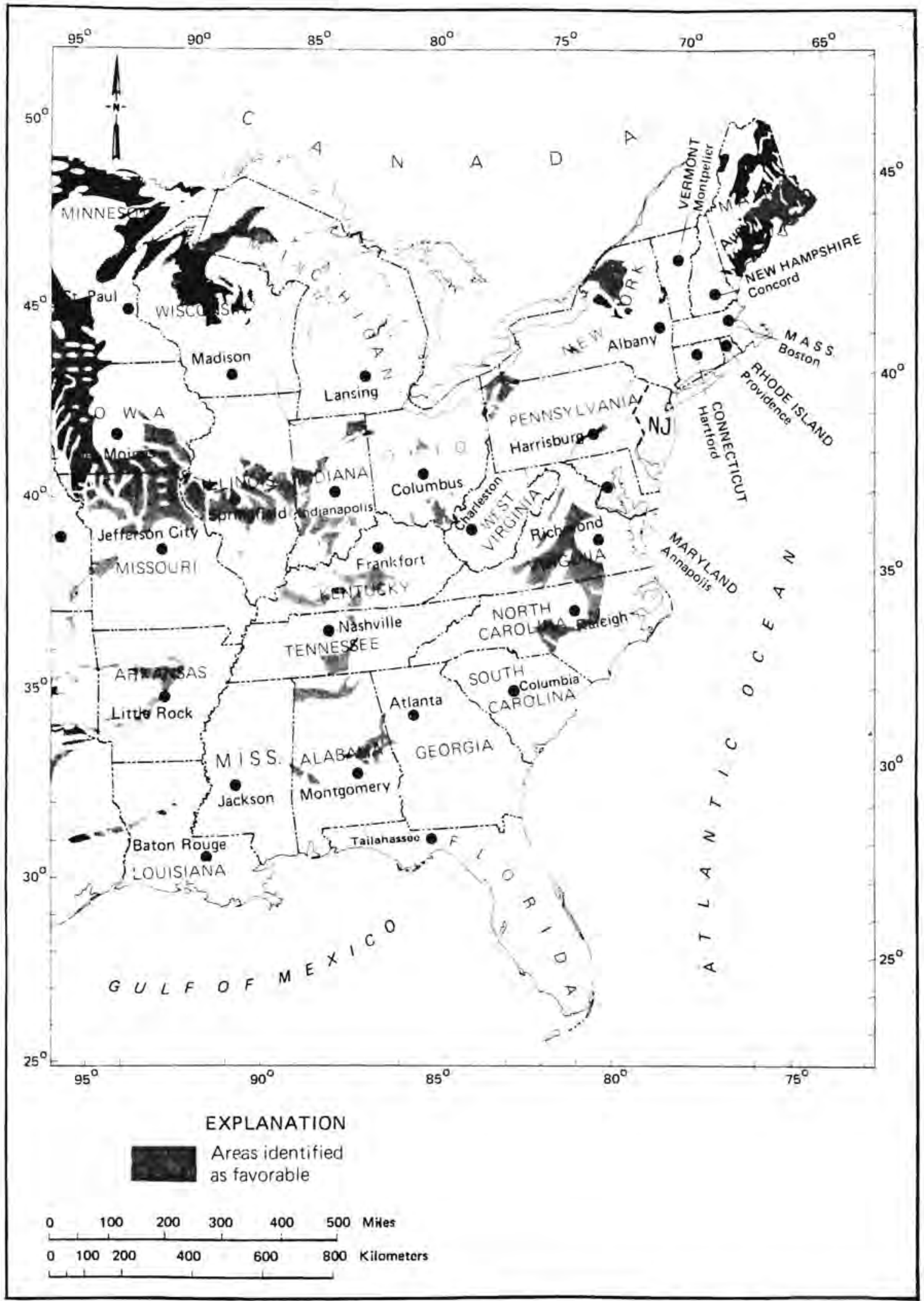

FIGURE 5.2. National Screening Resuits for a Stand-Alone MRS/IS Facility in the Eastern U.S. 


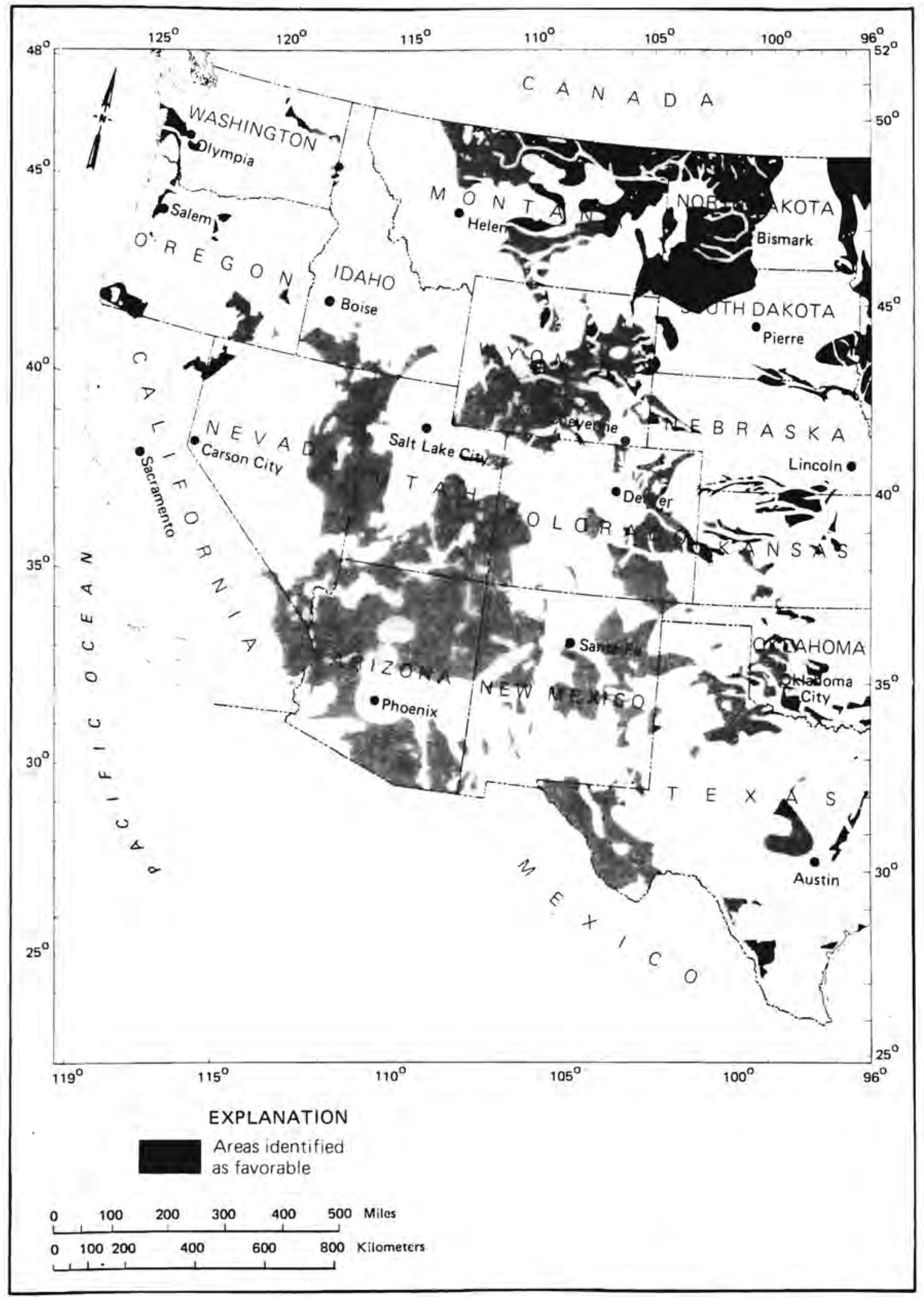

FIGURE 5.3. National Screening Results for a Stand-Alone MRS/IS Facility in the Western U.S. 
Thus, as indicated in Figures 5.2 and 5.3, there are numerous locations in the continental U.S. that would be adequate for the site of an MRS/IS facility from the aspect of natural features. No specific area is assumed as the hypothetical site for the stand-alone MRS/IS facility in this study. However, the receiving, handling, storage, and service facilities as identified or described in Sections 5.3, 5.4, and 5.5 are generic in nature and compatible with any site that may be selected within the continental U.S.

\subsubsection{Site Parameters}

The desirable natural features of a surface MRS/IS facility are given below. Although some of the MRS/IS concepts examined in this study use drywells or other below-grade storage, the depths are no greater than $14 \mathrm{ft}$. Therefore, consideration of a surface facility is appropriate.

The major considerations affecting the construction and operation of a surface MRS/IS facility, as well as the containment and retrieval of the spent fuel or waste, are: 1) surface and groundwater system characteristics;

2) karst topography; 3) tectonics; 4) meteorology; 5) the possibility of human intrusion; and 6) the impact of handling and storage operations on population centers and the environment.

The natural features for the site are as follows:

1. Good drainage and a low water table. The site should be away from rivers, lakes, playas, or floodplains. Excessive moisture could accelerate degradation of the container and provide a pathway for release if the containment failed. The groundwater level should be below the base of the drywells to provide a buffer zone.

2. Satisfactory karst conditions such that no ground or rock dissolves or subsides. This will prevent ground collapse, which could open paths for groundwater flow.

3. Good thermal conductivity of the rock or soil. This is important for drywe11 design.

4. Adequate surface area. To minimize grading and excavation costs during construction, the site should be relatively flat or gently sloping. 
5. Suitable tectonics. The site should not be located where there is any significant probability of fault rupture, ground motion, or volcanic activity that could degrade the performance of the system below acceptable levels.

6. Low probability of inadvertent human intrusion. The site should be located away from exploitable natural resources (e.g., oil, gas, coal, geothermal resources, mineral deposits) or any natural attractions.

7. Avoidance of existing hazardous operations. The site should be located away from major industrial and transportation installations.

8. Low density of nearby population centers. The facility should be located to minimize potential risk to and conflict with nearby population centers.

9. Adequate environmental protection. Numerous federal and state laws require that site location not adversely affect the environment. The site should be outside national parks, wildlife refuges, and wilderness preserves.

10. Satisfactory meteorological conditions. Areas of high tornado or windstorm activity, for example, should be avoided.

11. Easy access to rail lines and interstate highways. This will reduce the additional costs of constructing extensive rail lines or highways.

\subsubsection{Site Location and Description for a Facility Co-Located with Repository}

Likely locations for an MRS/IS facility co-located with a repository in the western U.S. all have rather similar characteristics. For purposes of this analysis, a location within the boundaries of the Hanford Site in the semi-arid southeastern portion of Washington State is assumed. The general geographic location of the site is illustrated in Figure 5.4.

\subsubsection{Site Location and Arrangement}

A hypothetical site for the MRS/IS facility is postulated to be located west of the 200 West Area within the Hanford Site above the Cold Creek Syncline. The facility site arrangement is compatible with the constraints of the hypothetical site and should also satisfy the requirement of the follow-on 


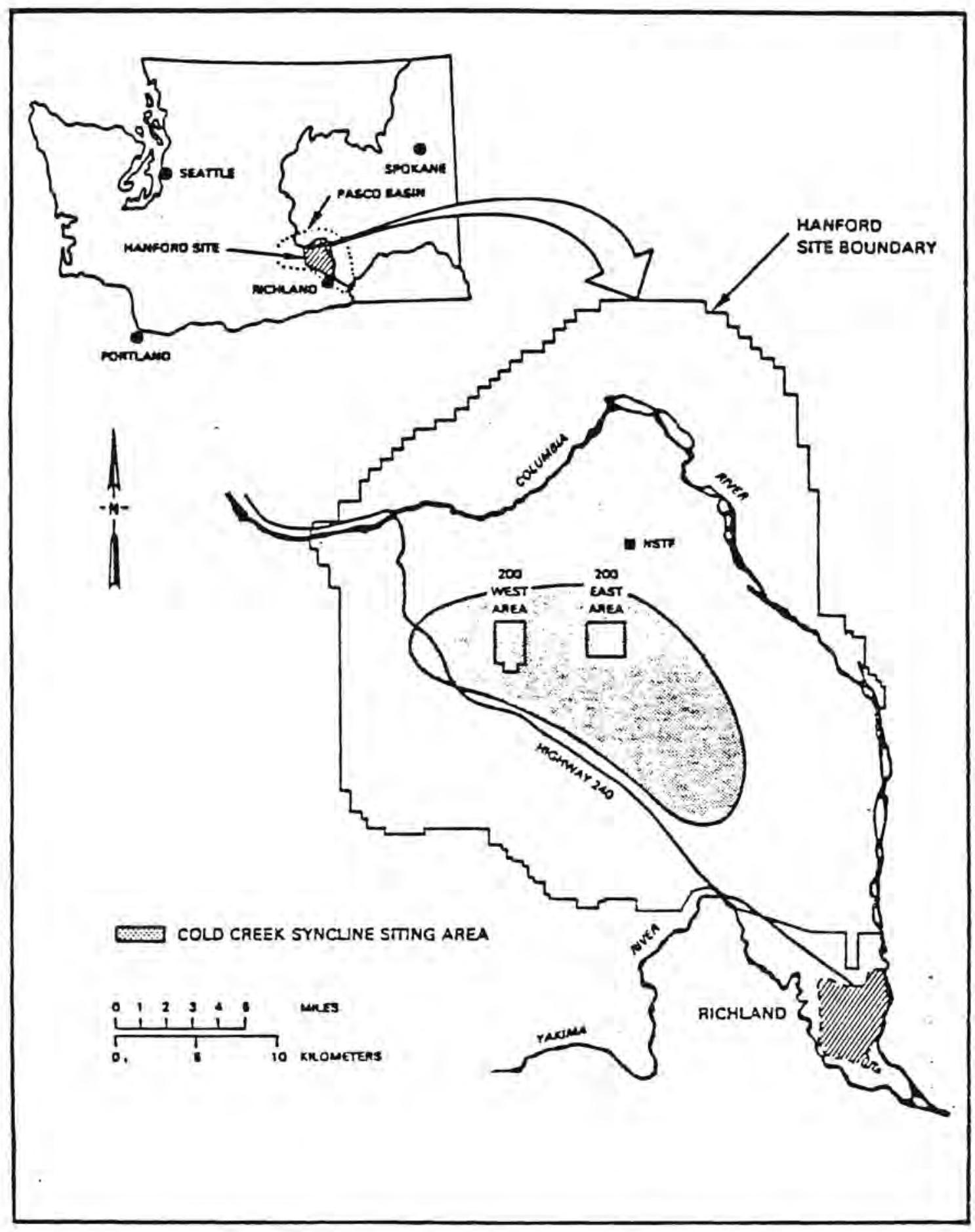

FIGURE 5.4. Location Map - Hanford Site 
repository and its operation. Approximately 250 acres wi11 be required for the initial facility. To cover the interim storage requirements for the various scenarios, up to 400 acres may be required. The 400 acres are part of the total approximately 550 acres projected to be required at the surface to supply and support an underground respository of up to 2000 acres.

The initial area will be developed by the required site preparation, roads, fences, walkways, and rail systems with due consideration and provisions for the additional areas and facilities that may be required later.

\subsubsection{Site Parameters}

Conditions of this hypothetical site are assumed to be similar to typical conditions found at Hanford. These assumed conditions are discussed in this subsection.

The Hanford climate is generally mild and dry, with occasional periods of high winds and with hot summers and mi1d winters. Average annual precipitation is 6.25 inches $(15.9 \mathrm{~cm})$. Average monthly wind speeds range from $5 \mathrm{mph}(2.3 \mathrm{~m} / \mathrm{s})$ to $9 \mathrm{mph}(4.1 \mathrm{~m} / \mathrm{s})$ with the prevailing wind direction from the northwest, although the strongest winds are from the southwest.

The number of thunderstorm days at Hanford gives an estimated annual lightning-strike frequency of 0.022 for a building 30 feet $(9 \mathrm{~m})$ high. This frequency corresponds to about one strike per 45 years.

Tornadoes are infrequent in the region; they tend to be small and cause little damage when they do occur. Data have been analyzed to determine the probability of a tornado hitting a particular Hanford facility. During any year, it is estimated that the probability is six chances in a million or less than once in 100,000 years.

The Hanford Site lies on the low-lying, partly dissected and modified alluvial plain of the Columbia River within the central part of the Pasco Basin. The MRS/IS facility site is underlain by 1000 feet $(300 \mathrm{~m})$ of sands, silts, and clays laying on a basalt lava accumulation estimated to be 10,000 feet $(3000 \mathrm{~m})$ thick. The soil type which makes up the site consists of Rupert Sand, which is mostly composed of granitic, quartzitic, and basaltic sand. 
The Hanford Site is described as a "shrub-steppe" zone characterized by low precipitation and wide daily and annual temperature ranges. The vegetation consists primarily of eight major kinds of shrub-steppe communities.

The MRS/IS facility site is to be incorporated into an environment already slightly altered from its original state due to 1) livestock grazing and 2) the activities associated with Hanford projects since the early $1940 \mathrm{~s}$. Land within a $50-$ mile $(80 \mathrm{~km})$ radius is used primarily for grazing, growing wheat, and irrigated farm crops. The nearest military facility is the U.S. Army Yakima Firing Range located $\sim 30$ miles $(48 \mathrm{~km}$ ) to the northwest. There are no recreational facilities within a 5 -mile radius of the proposed site. The closest public highways are State Highways 12, 240 and 24.

The Hanford Site lies in a region characterized by few earthquakes of damaging intensity, with no clear-cut relationships of epicenters to specific surface faulting or specific geologic structures. To date, no intensities greater than four on the Modified Mercalli Scale (MM-IV) with a gravitational ground acceleration of $0.01 \mathrm{~g}$ have occurred in the immediate Hanford Site area, although intensities as high as MM-V or MM-VI have been observed in surrounding areas.

The hydrology of the Hanford Site consists of both surface and subsurface flow systems. The Columbia and Yakima Rivers form the principal surface water drainage of the area. The groundwater flow systems consist of unconfined and numerous confined aquifers. Hydrologic knowledge of aquifer properties is quite extensive for the unconfined system. An extensive field testing program is under way to acquire a solid understanding of all confined aquifers that may be important in designing and siting an underground repository.

The proposed facility site is not located in a floodplain as defined by 10 CFR 122. The estimated 100-year maximum Columbia River flood of 444,000 cfs would result in a river elevation of $356 \pm 2$ feet mean sea leve 1 (MSL), based on U.S. Corps of Engineers projections. The probable maximum flood (PMF) would result in a Columbia River elevation of $382 \pm 4$ feet with an occurrence rate of once every several thousand years. The hypothetical site 
for the MRS/IS facility is at an elevation of $\sim 600$ feet MSL; therefore, it is concluded that the site would not be subject to inundation by any flood having a volume equal to or less than the PMF.

\subsection{GENERIC STORAGE CASK AND DRYWELL DESIGNS}

A11 siting concepts utilize the same large metal dry storage cask design, and two of the three siting concepts utilize the same drywell design. These generic designs are described in this section.

\subsubsection{Reference Metal Cask}

A11 MRS/IS concepts in this study utilize the same metal cask design, the REA 2023 cask, being designed by Ridihalgh-Eggers Associates (REA) of Columbus, Ohio, and fabricated by Brooks and Perkins (Livonia, Michigan) for the DOE. The PWR fuel version has a cavity $66 \mathrm{in.}$ in diameter by $167 \mathrm{in}$. in length and would be suitable for consolidated fuel, or with a special basket, for solidified HLW storage. The design of the cask body closely follows the proven construction concepts of the NL $10 / 24$ cask, which was domestically licensed in 1976 for shipment of spent fuel. The construction is a stainless steel composite with a poured lead gamma shield and a water jacket (for neutron shielding). The primary containment meets the requirements of the ASME Boiler and Pressure Code. The shield wall thickness and thermal capability are based on fuel aged at least $5^{+}$years. The neutron poison in the basket is Boral (a borated aluminum composite), which has been used extensively for high-density spent fuel racks. Boral (a Brooks and Perkins product) has been extensively evaluated for corrosion, irradiation stability, heat transfer, and nuclear criticality prevention over a 20-year period and has been approved by the NRC for a number of applications.

The cask design is illustrated in Figures 5.5 and 5.6. The cask capacity for spent fuel storage is listed in Table 5.2. As noted previously, the cask has a smooth-walled stainless steel exterior and is passively cooled. The design is based on nominal nuclear and thermal characteristics given in Table 5.3. Aging fuel beyond 5 years (particularly for high-burnup fuel) could be required to reduce the decay heat output and to lower the neutron and gamma source strength. 


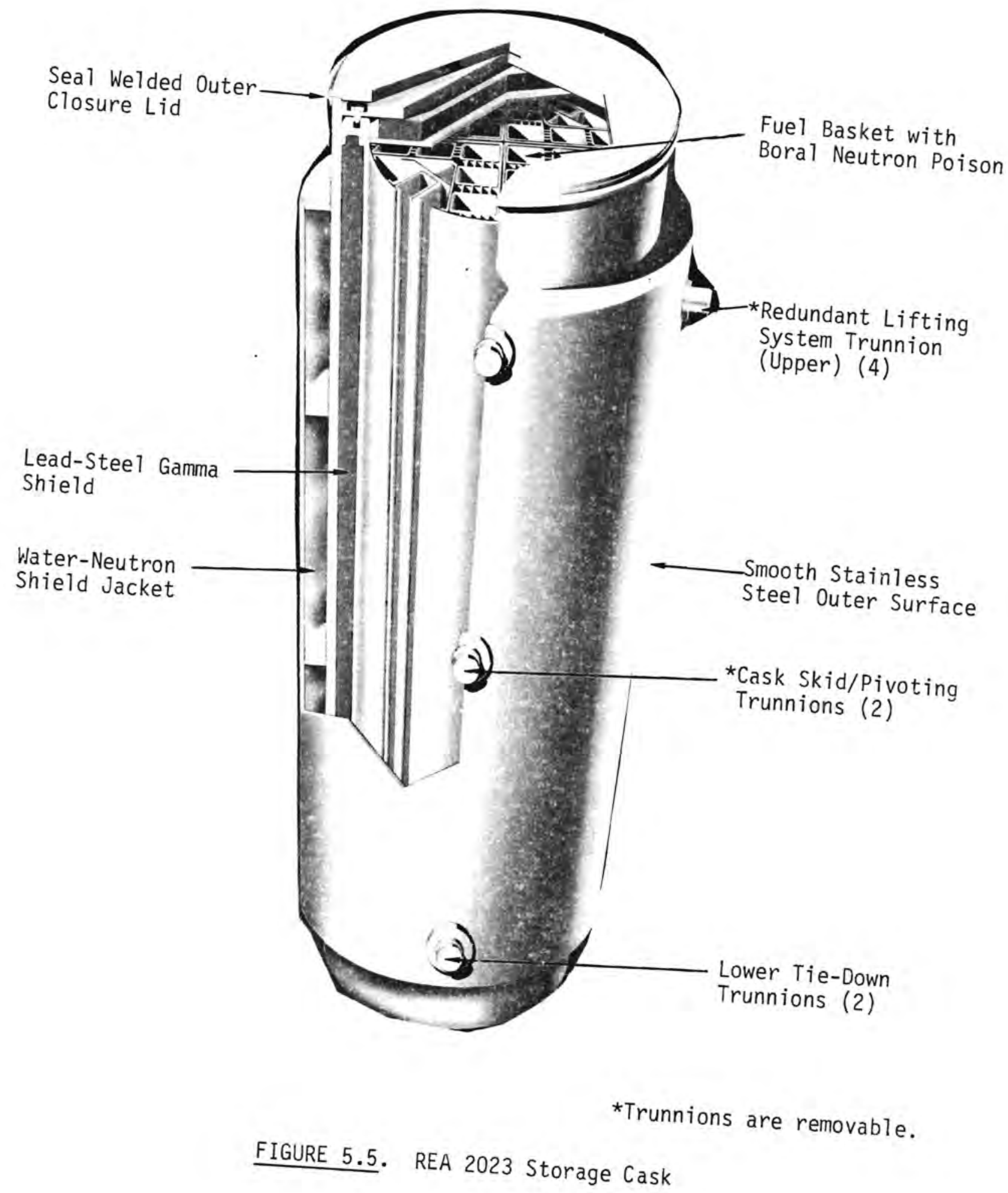



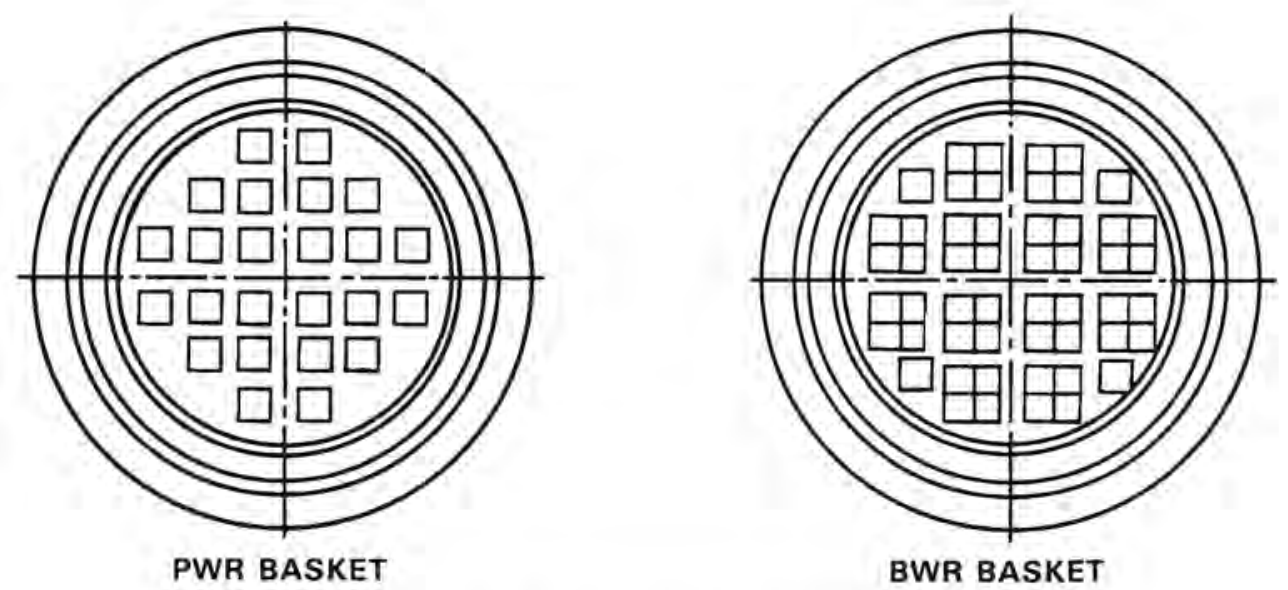

\begin{tabular}{|l|c|c|l|c|}
\hline \multicolumn{5}{|c|}{ STORAGE QUANTITY } \\
\hline FUEL TYPE & \multicolumn{2}{|c|}{ INTACT } & \multicolumn{2}{c|}{ CONSOLIDATED } \\
\hline & OTY. & MTU's & QTY. & MTU's \\
$\begin{array}{l}\text { BWR } \\
\text { ELEMENTS }\end{array}$ & 52 & 10 & 104 & 20 \\
\hline $\begin{array}{l}\text { PWR } \\
\text { ELEMENTS }\end{array}$ & 24 & 11.5 & 48 & 23 \\
\hline
\end{tabular}

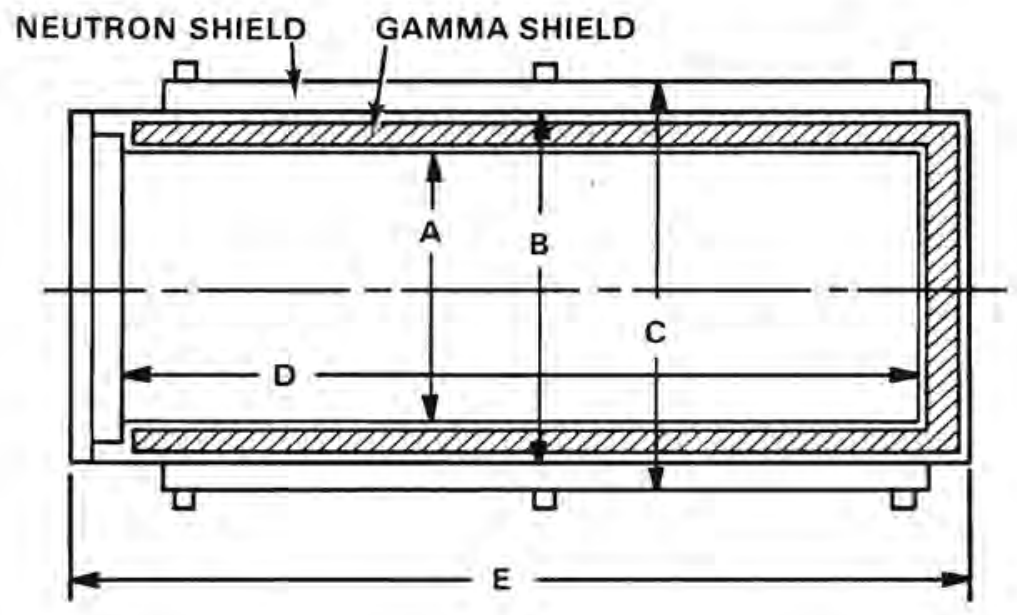

\begin{tabular}{|l|c|c|c|c|c|c|c|c|}
\hline FUEL TYPE & $\begin{array}{c}\text { A } \\
\text { IN }\end{array}$ & $\begin{array}{c}\text { B } \\
\text { IN }\end{array}$ & $\begin{array}{c}\text { C } \\
\text { IN }\end{array}$ & $\begin{array}{c}\text { D } \\
\text { IN }\end{array}$ & $\begin{array}{c}\text { E } \\
\text { IN }\end{array}$ & $\begin{array}{c}\text { WT } \\
\text { T }\end{array}$ & $\begin{array}{c}\text { NEUTRON } \\
\text { SHIELD }\end{array}$ & $\begin{array}{c}\text { GAMMA* } \\
\text { SHIELD }\end{array}$ \\
\hline PWR & 66 & 80.5 & 93 & 166.7 & 182 & 97 & $6 \mathrm{in}$. & $4.5 \mathrm{in}$. \\
\hline BWR & 61 & 75 & 87.5 & 177.3 & 192.6 & 95 & $6 \mathrm{in}$. & $4.3 \mathrm{in}$. \\
\hline
\end{tabular}

* LEAD ONLY

FIGURE 5.6. REA Cask Dimensional Data 
TABLE 5.2. REA 2023 Storage Capacity

BWR Fuel
(a) Intact - uncanned
52
9.4
$21(5 \mathrm{yr})$
32,500
(b) Intact - canned
52
9.4
21 (5 yr)
44,200
(c) Consolidated
104
18.8
$21(8.5 \mathrm{yr})$
81,000
PWR Fuel

$\begin{array}{lllll}\text { (a) Intact - uncanned } & 24 & 10.1 & 24(5 \mathrm{yr}) & 34,800 \\ \text { (b) Intact - canned } & 24 & 10.1 & 24(5 \mathrm{yr}) & 48,000 \\ \text { (c) Consolidated } & 48 & 20.2 & 24(10.5 \mathrm{yr}) & 84,000 \\ \text { HLW canister } & 14 & 30.0 & 33(10.5 \mathrm{yr}) & 32,400\end{array}$

TABLE 5.3. Nominal Nuclear and Thermal Characteristics of Spent Fuel Storage in the Reference Metal Cask

\begin{tabular}{|c|c|c|}
\hline & BWR & PWR \\
\hline \multicolumn{3}{|l|}{ Fuel Data } \\
\hline Enrichment & $3.5 \%{ }^{235} \mathrm{U}$ & $3.5 \%{ }^{235} U$ \\
\hline Age-out-of-reactor & $5 \mathrm{yr}$ & $5 \mathrm{yr}$ \\
\hline Maximum width, intact-in. & 5.75 & 8.75 \\
\hline Maximum length, intact-in. & 176 & 165.5 \\
\hline \multicolumn{3}{|l|}{ Shielding Data } \\
\hline Gamma source, photons/sec-cask & $9.0 \times 10^{16}$ & $9.5 \times 10^{16}$ \\
\hline Neutron source, neutrons/sec-cask & $3.9 \times 10^{9}$ & $3.3 \times 10^{9}$ \\
\hline Surface dose rate, $\mathrm{mrem} / \mathrm{hr}$ & 20 & 20 \\
\hline \multicolumn{3}{|l|}{ Thermal Data } \\
\hline Decay heat, kW/assy & 0.4 & 1.0 \\
\hline Maximum fue $1 \mathrm{clad}$ temperature & $250^{\circ} \mathrm{C}$ & $250^{\circ} \mathrm{C}$ \\
\hline
\end{tabular}


Separate designs for PWR and BWR fuel are offered primarily to accommodate the additional length of BWR fuel assemblies. The inner cavity coolant is air, initially at ambient temperature and pressure. Two bolted closure heads are employed. The outer closure provides for seal-welding the flange before storage, thus ensuring a leak-tight container. Literature on the REA cask indicates that continuous monitoring of the primary containment (inner cavity) and secondary containment (space between the closure heads) is possible.

The cask body is designed to accommodate a variety of handling alternatives. It has a total of eight trunnions--all removable-with the following functions:

- Upper (1ifting) trunnions (4) - To accommodate redundant lifting system and mate with tiedown system.

- Mid-body (pivoting) trunnions (2) - Pivoting operation minimizes required handling space and permits horizontal lift of cask skid.

- Lower (tiedown) trunnions (2) - Mates with rear tiedown on the skid.

A key design feature is the incorporation of the handling/storage skid with the tiedowns. This permits a direct movement between a storage pad and a rail car. The only additional equipment required for shipping is the upper and lower impact limiters and the rail car.

\subsubsection{Reference Drywell}

The same drywell reference design is used in the stand-alone MRS/IS facility and in the facility co-located with the repository. This design is described herein. The drywell used in the facility co-located with a reprocessing plant, is of a different design and is described in Section 5.3.3.2.

A typical drywe11 Toaded with a spent fuel assembly or HLW canister is shown in Figure 5.7.

Each drywel1 consists of a cylindrical carbon steel encasement vessel buried vertically in the ground. The encasement may be surrounded by concrete 


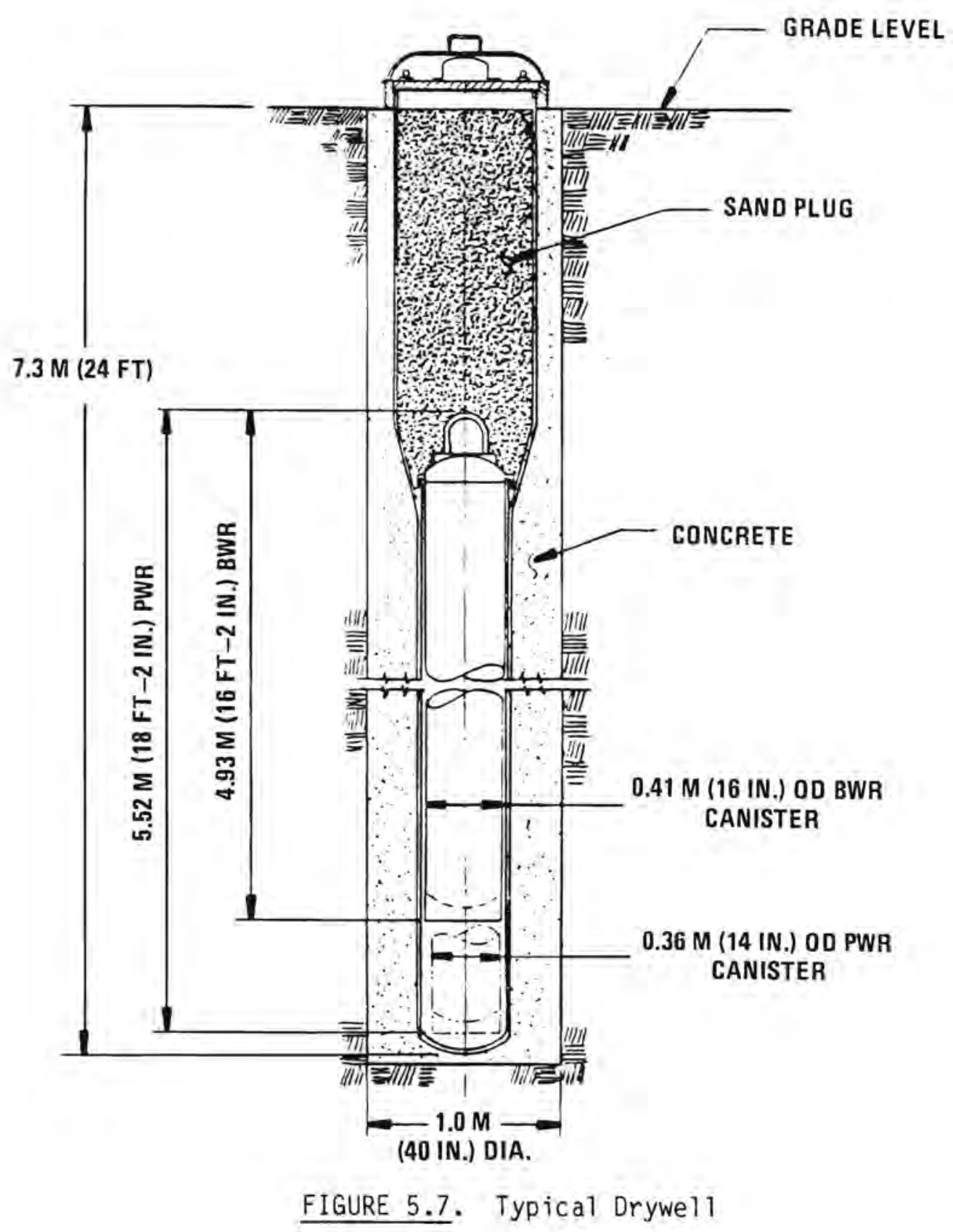


or sand, depending on the thermal criteria to be established on heat output and temperature limits. The encasement vessel is designed, fabricated, and tested in accordance with the current ASME Boiler and Pressure Vessel Code, Section VIII, Division 2. The encasement vessels are shop-fabricated of standard pipe sections. The closure plate on top of the encasement vessel is field-welded to the encasement to complete the containment after a waste package canister and radiation shield plug are placed.

The canister is suspended in the drywell by a dish-shaped steel support ring welded to the pipe reducer section of the encasement. A similar dish-shaped ring is welded to the upper portion of the package canister during fabrication of the canister. As received HLW canisters do not include this ring; therefore, the ring is welded on the canister while in the receiving and packaging facility. In addition to supporting the package, the dish-shaped rings seal the sand shield plug in the upper compartment of the encasement vessel. The ring configuration a1so centers the package in the drywell during placement.

A loose sand fill placed in the compartment space above the canister in each drywell encasement creates a radiation shield plug. A stainless steel tube through the sand shield plug permits the drywell interior to be sampled for airborne activity.

Each drywell encasement vessel has a steel cover plate that is field-welded to the top of the drywell after a canister and the shield sand are placed. The closure plate has lifting lugs and a sample valve assembly. The sample valve is protected by a detachable weather cover. A nameplate atop the closure plate identifies the steel canister. A reusable metal cover protects empty drywells from the weather prior to canister placement.

A stainless steel thermowe11 attached to the exterior of the drywe11 encasement protects a thermocouple used to periodically measure the exterior surface temperature of the drywe11 encasement, to detect any abnormal thermal conditions. 


\subsection{MRS/IS FACILITY CO-LOCATED WITH A REPROCESSING PLANT}

One option being studied is to construct the MRS facility adjacent to a reprocessing plant. This approach differs from other options in that the delayed repository case results in multiple MRSs-one at each reprocessing plant. The system described relies on the existing capabilities of the associated reprocessing plant(s) for shipping and receiving waste or spent fuel. A modular approach to constructing the storage areas allows the facilities to be built in annual increments. Contact-handled TRU (CHTRU) is stored in standard cargo containers, while remote-handled TRU (RHTRU) is stored in drywells constructed in engineered berms. Spent fuel or solidified high-level waste (HLW) is stored either in the same type drywell or in metal storage casks arranged in a parking-lot configuration. (a) These storage concepts are discussed in the following sections.

\subsubsection{Receiving and Handling Facility}

For the reference and delayed disposal scenarios where the wastes from reprocessing are stored in the MRS/IS facility, shipment comprises an onsite waste transfer. For the delayed reprocessing scenario where spent fuel is stored in the MRS/IS facility, the reprocessing plant's existing cask handiing facilities are utilized to receive fuel for transfer to either storage casks or drywells. Thus, in either case no special receiving or handling facility is required.

\subsubsection{Contact-Handled TRU Storage}

The criteria for selecting a storage system for contact-handled transuranic wastes (CHTRU) include modular construction, protection from design-basis natural disasters, maintenance of double confinement for plutonium-bearing materials, low cost, and ease of decommissioning.

The concept used in this analysis is illustrated in Figures 5.8 and 5.9 .

(a) The drywe11 and cargo container concepts presented are identical, except for dimensions, to detailed designs (Title II) which exist for the BNFP solid waste storage area (SWA). The SWA has already been the subject of NRC licensing action, and additional design details are available. 


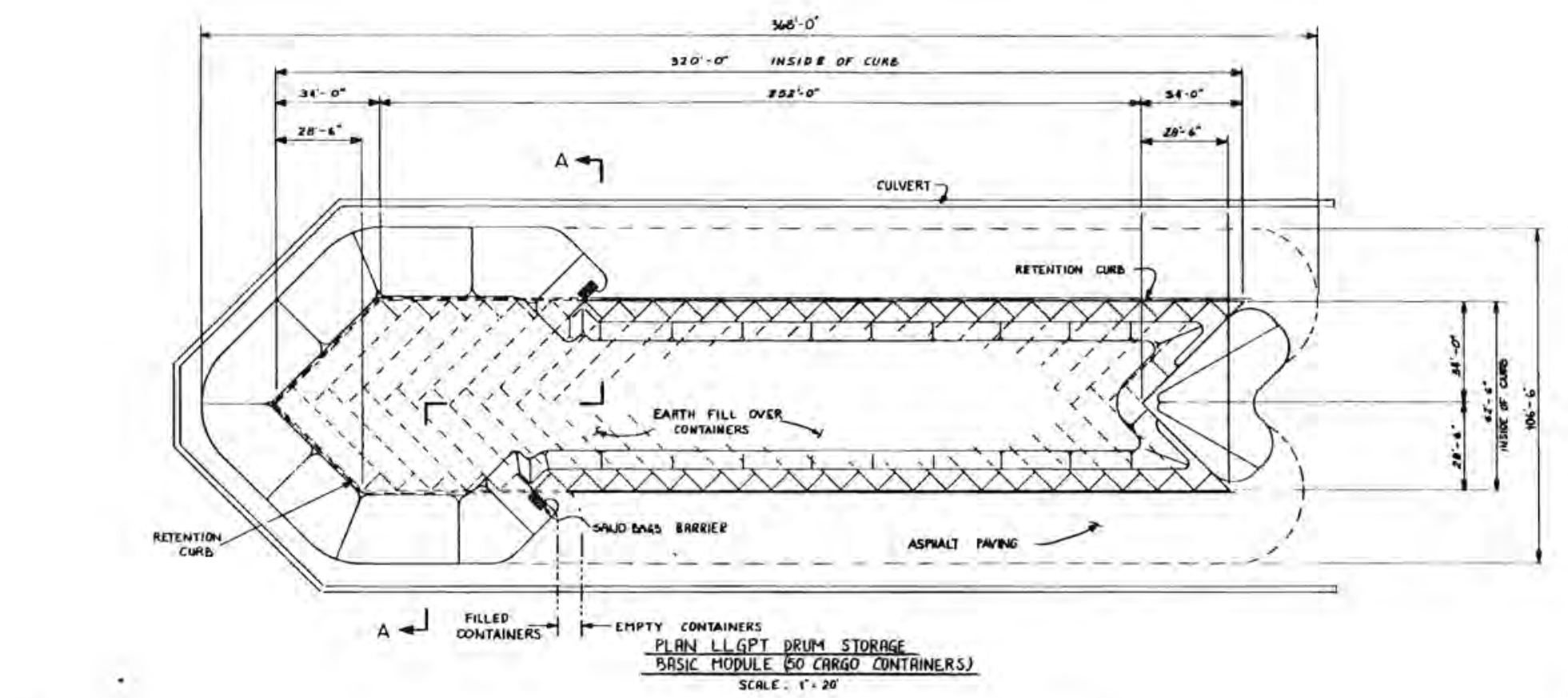

$\stackrel{\sim}{\sim}$
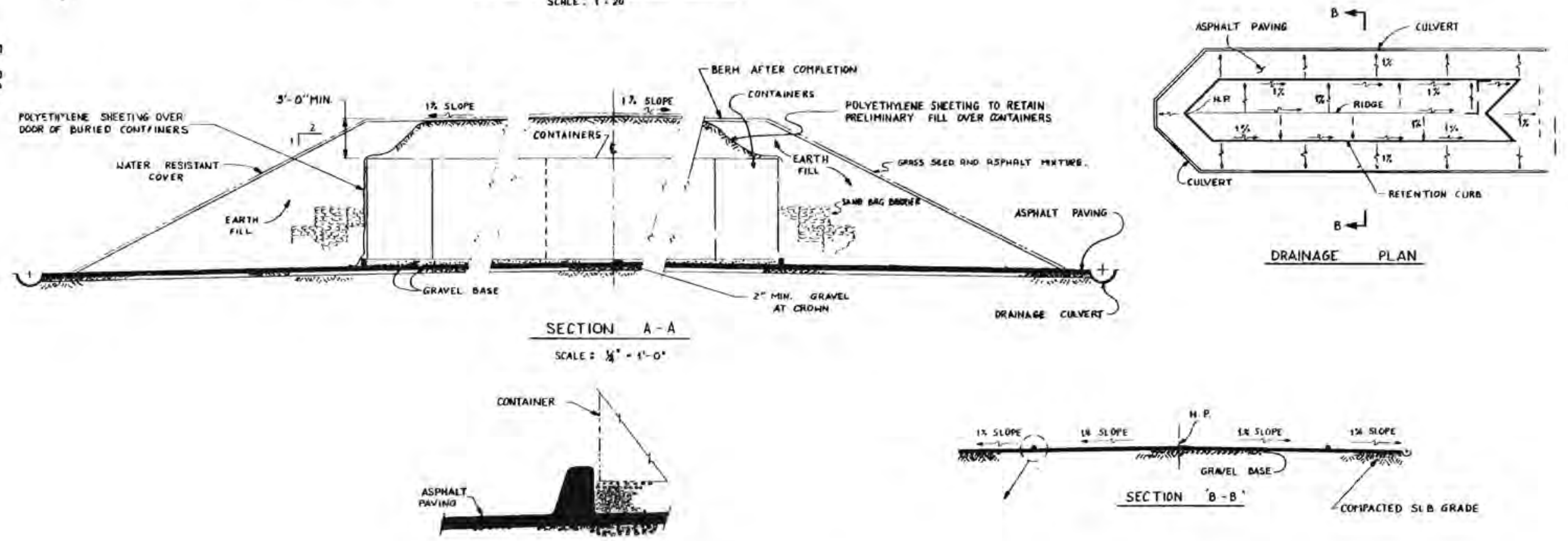

RETENTION CURB DETALL

SCALE $11^{\prime} \cdot 1^{\prime}-0^{\circ}$

FIGURE 5.8. Bermed Storage of CHTRU Drums 


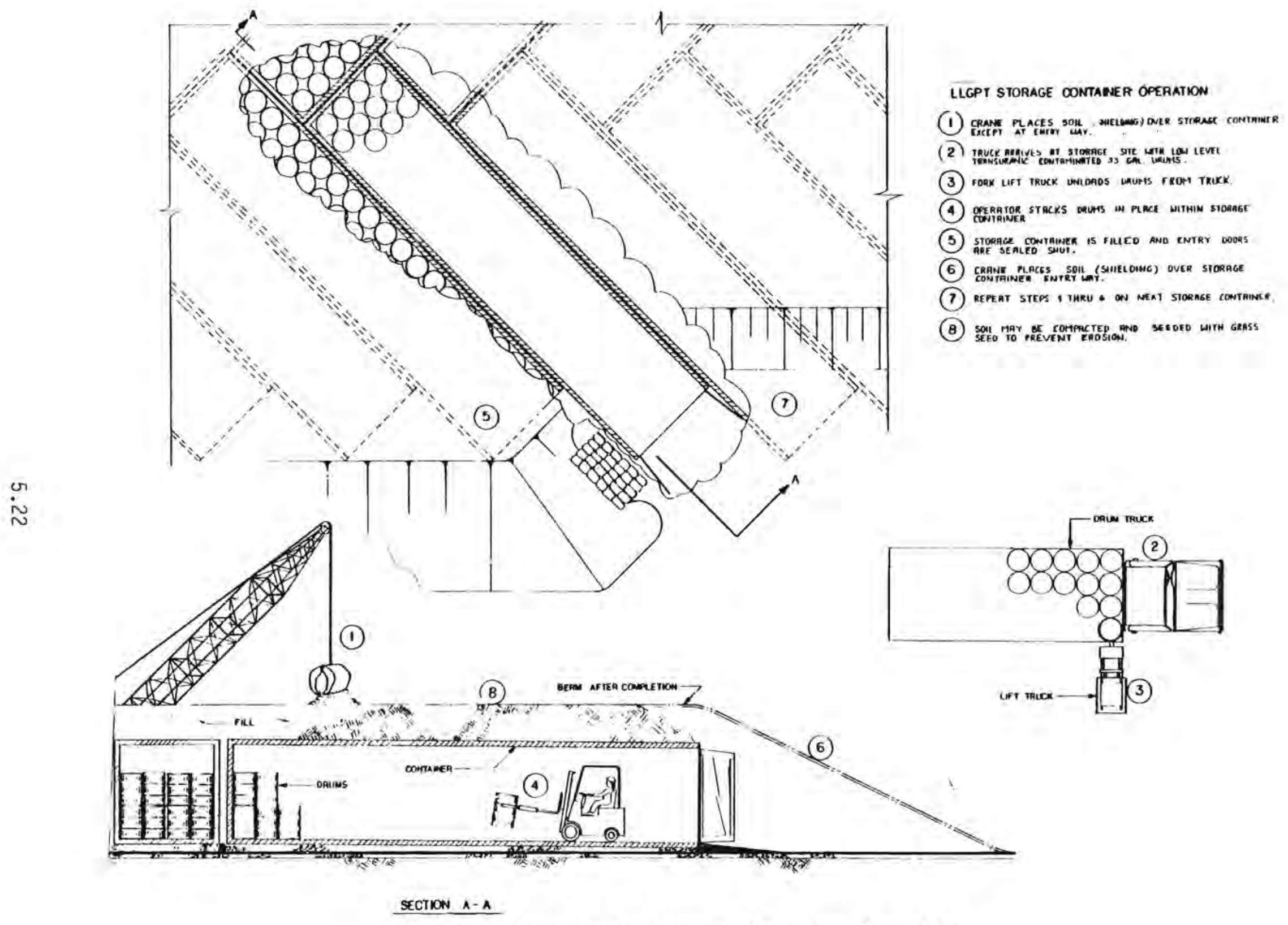

FIGURE 5.9. CHTRU Storage Container Operation 
Standard cargo containers are utilized, being readily available, sealable, and able to support an earthen cover for tornado protection. A herringbone pattern is used to allow placement of earthen cover over a full container without interfering with loading operations in an adjacent unit.

Expansion of storage capacity is accomplished by adding modules on roughly an annual basis.

\subsubsection{Remote-Handled Waste Storage}

Spent fuel and solidified HLW are stored in either storage casks or drywells. Remote-handled TRU waste is stored in drywells installed in an engineered berm having properties specifically designed for this application.

Each of these storage concepts is discussed in subsequent paragraphs.

\subsubsection{Metal Casks}

The casks and related equipment being considered for use in the MRS/IS system are discussed in this subsection. The REA 2023 cask is used as the basis for this study while the GNS-Castor cask is also described in detail as a possible backup.

The casks most nearly ready for either storage or dual-purpose use in the U.S. are the REA 2023 and the GNS Castor casks. Both of these casks are in active design/construction phases. Full-scale testing of both casks is planned for late 1982-1983 at the BNFP for uncontaminated-checkout purposes, and at the TVA-Browns Ferry Plant for "warm" checkout.

Cask Description. The REA 2023 cask is described as the design basis cask for this study in Section 5.2.7. A brief description of an alternative cask is provided since both are being evaluated for possible application.

The Gesellschaft für Nuklear Service (GNS) cask is based on shipping casks currently being used in Europe. The $1 \mathrm{C}$ model is a nominal 80 -ton cask with a 28-in. square cavity cross-section (see Figure 5.10). The $1 \mathrm{C}$ design is representative of the entire series from a construction/handling viewpoint. 


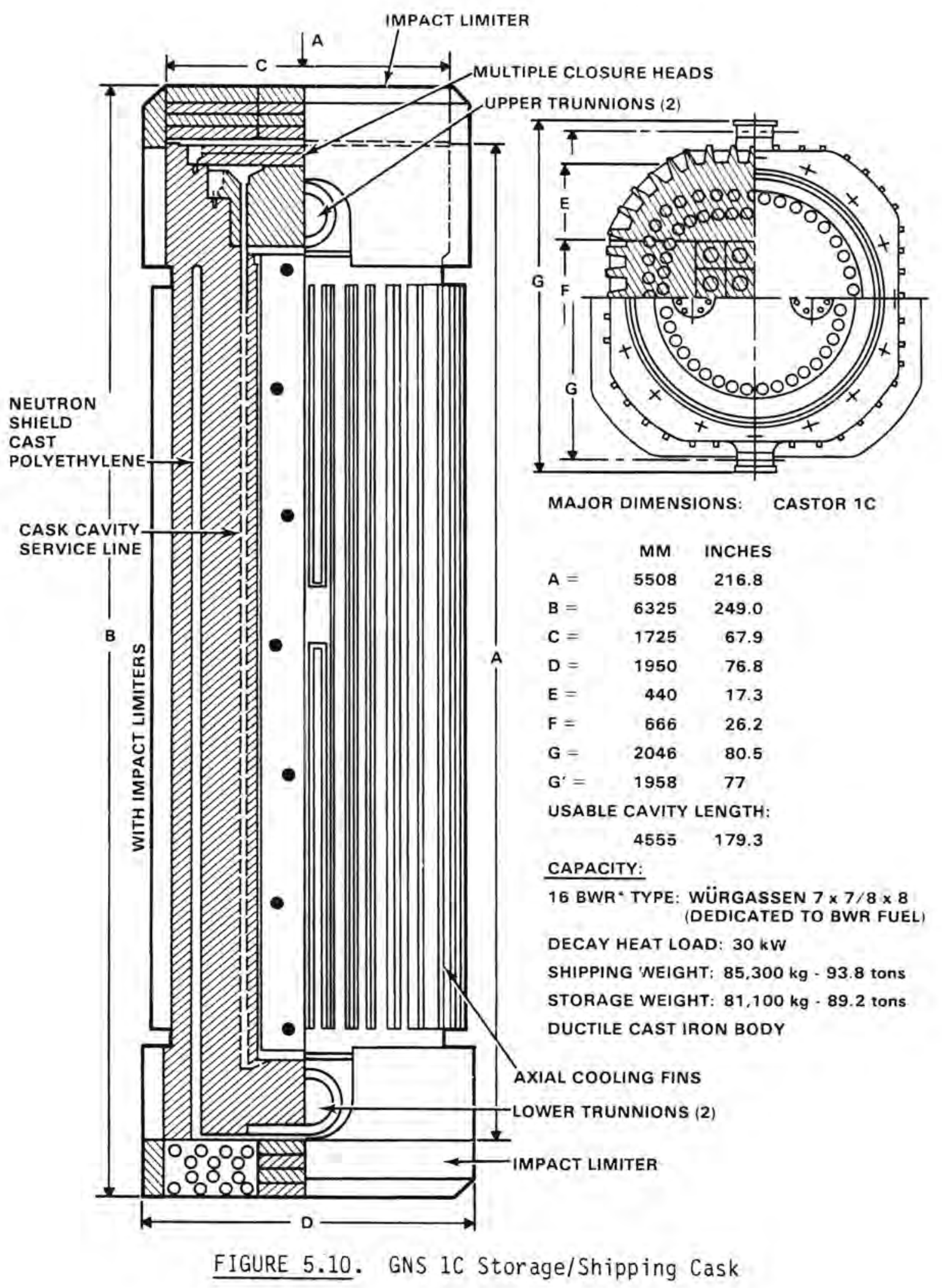


The GNS-Castor cask body construction is unique and represents a potential breakthrough in cost (and possibly fabrication time). The body is a massive iron casting (not a fabricated steel or steel-lead structure). Tests performed in Europe have demonstrated the strength of this cask under simulated drop- and fire-accident conditions. The lack of U.S. experience with this type of construction could have a major impact on licensing. The cast-iron body has integral fins on the cask exterior for heat rejection. The cask outer surface is epoxy, painted over the cast iron. To date, European experience with decontamination after pool immersion has been good. Neutron shielding is provided by a double row of long cylindrical, borated polyethylene channels cast into the body of the cask.

The GNS-Castor cask uses as many as four bolted closure heads for storage purposes (with 11 gasketed/sealed surfaces). The space between each of the closure heads can be monitored for leakage. The internal cavity is filled with helium at 0.6 atmospheres (absolute) pressure. The space between the closure heads is filled with pressurized nitrogen. For storage purposes, air may be used in the internal cavity (particularly if fuel temperatures less than $250^{\circ} \mathrm{C}$ can be ensured). The cask is designed for transporting one-yearold fuel. Further design of the castor-cask series for storage would probably focus on fuel cooled for 5 or more years, thus allowing an increase in storage capacity per cask.

The basic cask storage modules are shown in Figure 5.11 for spent fuel storage, and in Figure 5.12 for storage of canisters of solidified high-level waste. Multiples of these basic modules, as required for the three fuel cycle scenarios, are shown in Figures $5.13,5.14$ and 5.15 .

The handling methods for unloading fuel from truck/rail casks and reloading the fuel into REA casks for on-site storage are depicted in Figure 5.16. The unloading/loading operations are performed underwater in the Cask Unloading Pools (CUP) located in the Fuel Receiving and Storage Station (FRSS). No additional equipment is required for this operation beyond the existing FRSS systems and equipment. 


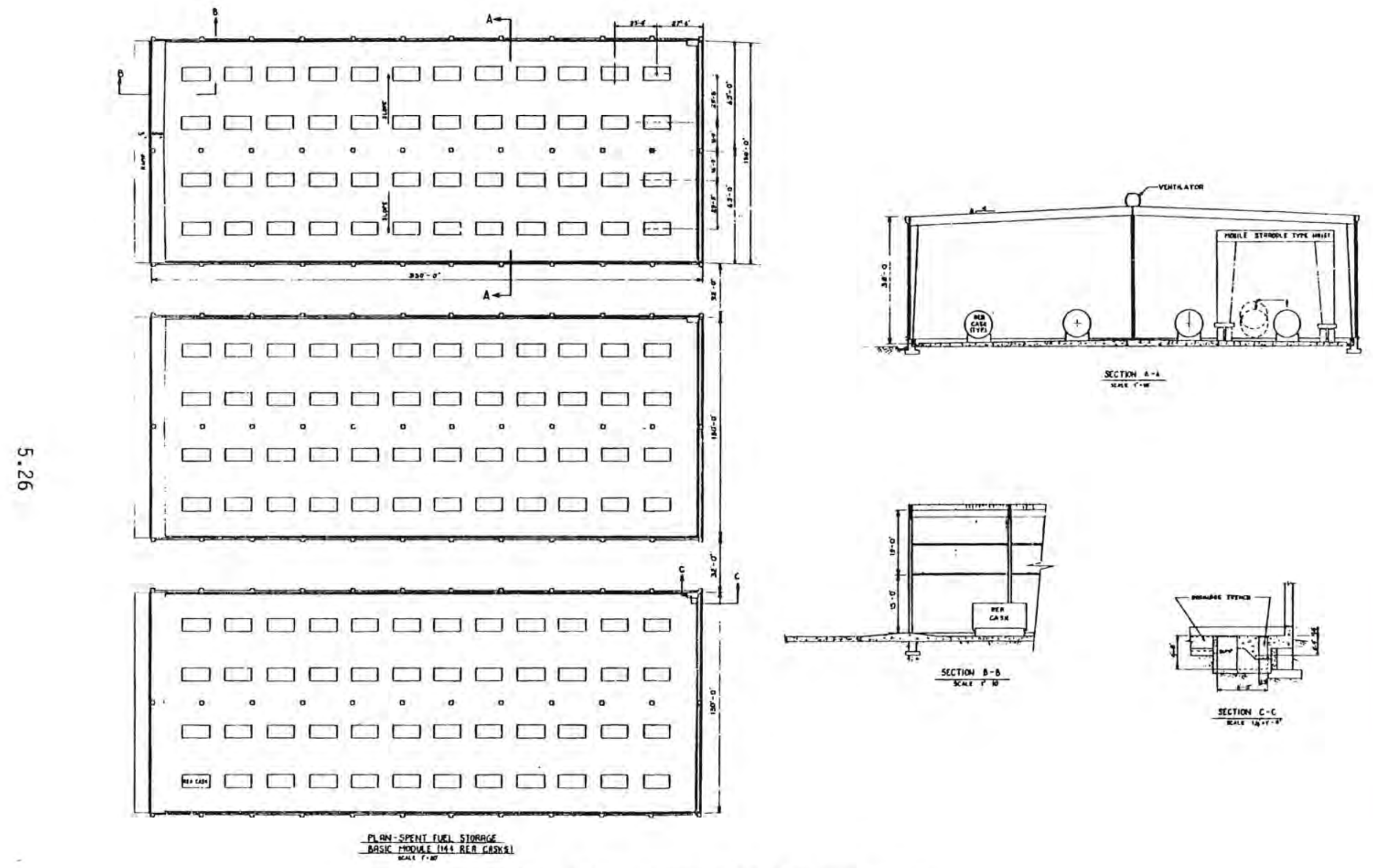

FIGURE 5.11. Spent Fuel Storage Module 


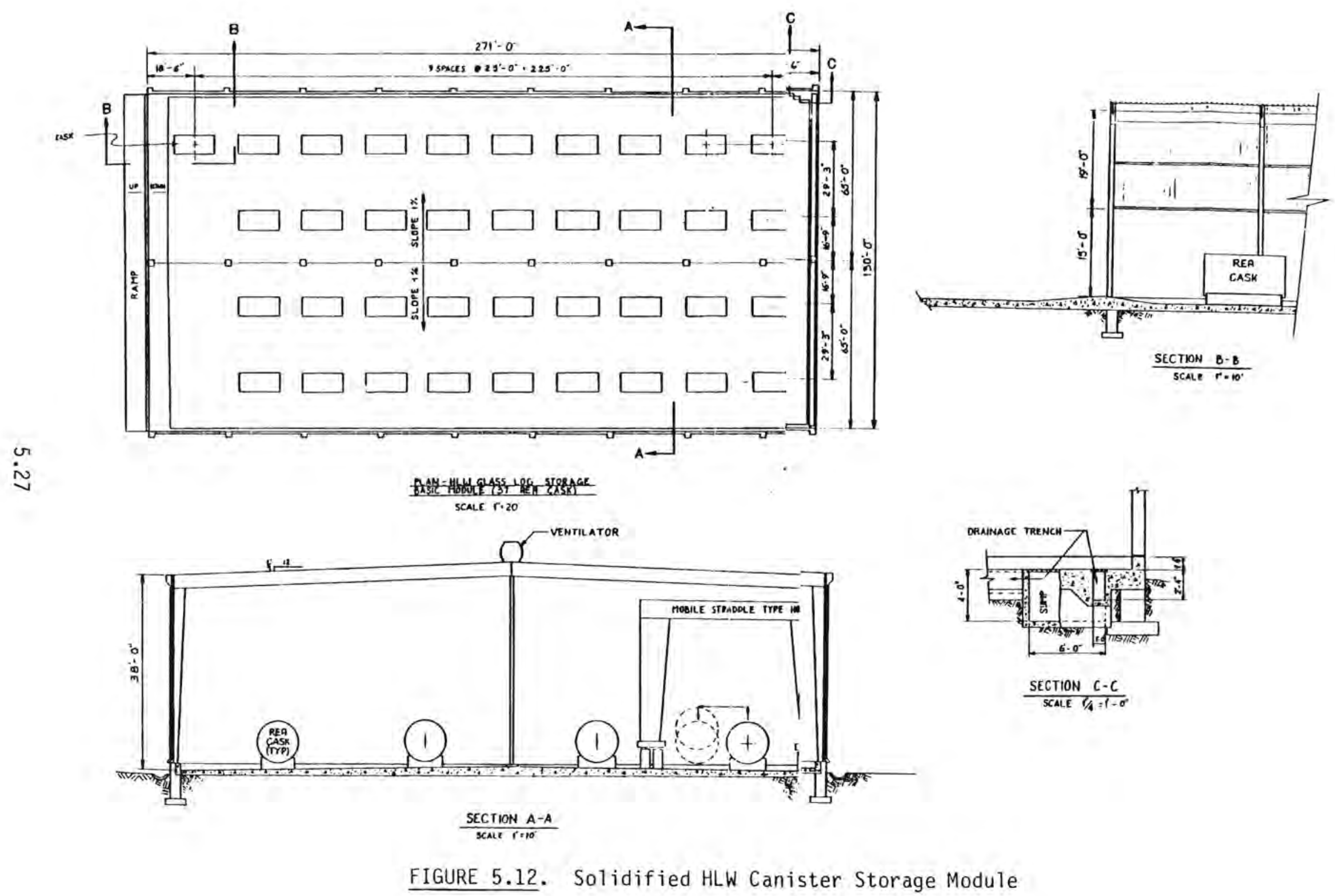




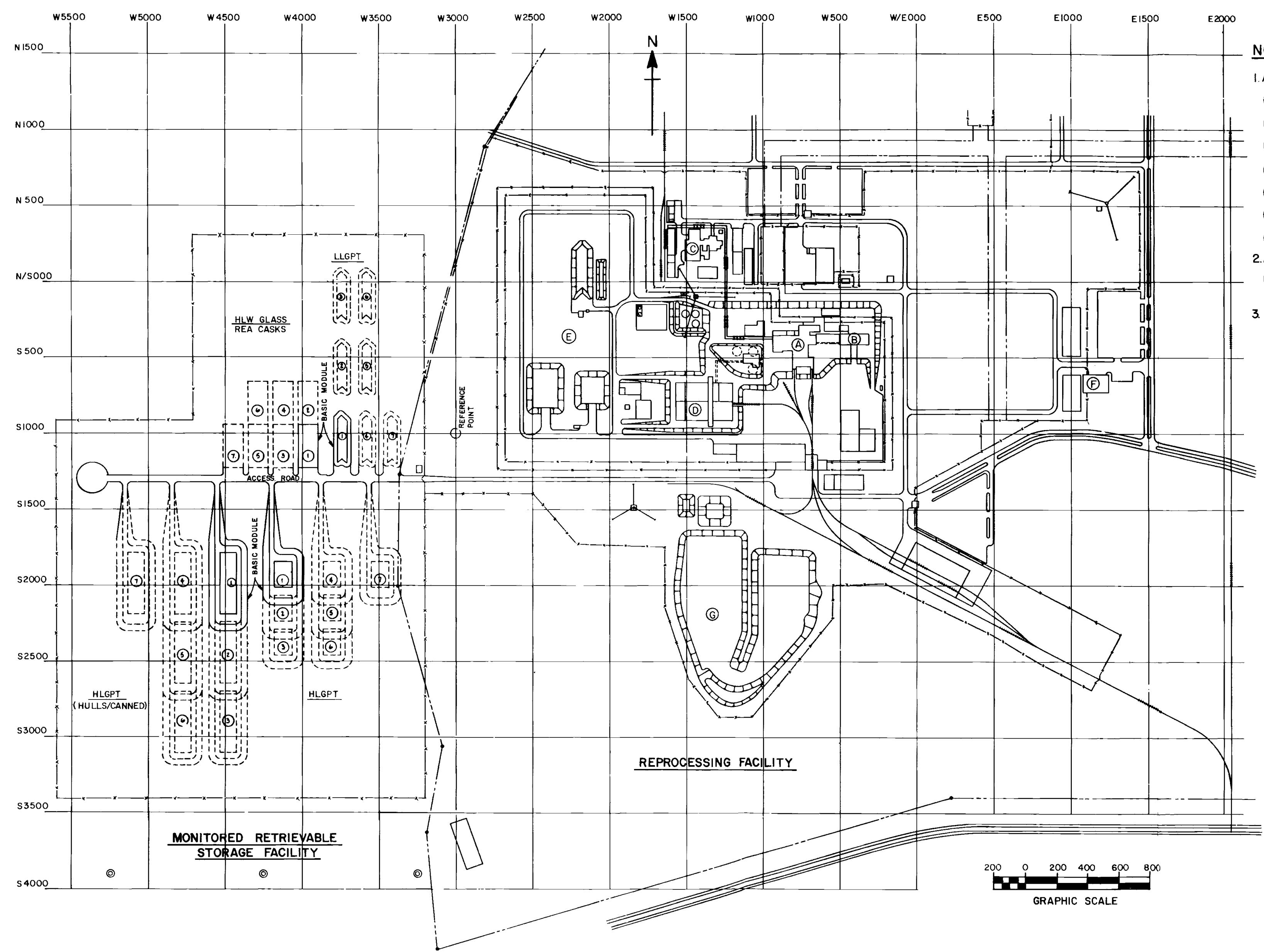

\section{NOTES}

FECESING FACILITY) (A) Separations facilitity

(B) PLUTONIUM PRODUCTS FACILITY (PPF)

(C) URANIUM HEXAFLUORIDE FACILITY $\left(\mathrm{UF}_{6}\right)$

(D) WASTE PROCESSING CENTER (WPC)

(E) SOLID WASTE AREA (SWA)

F administration area

(G) CONDITIONING POND

2.AREA DESIGNATIONS (MRS FACILITY)

THRU (7) REPRESENTS BERM MODULAR THRUIREMENTS

- DESIGNATES PROPOSED OBSERVATION WELLS 


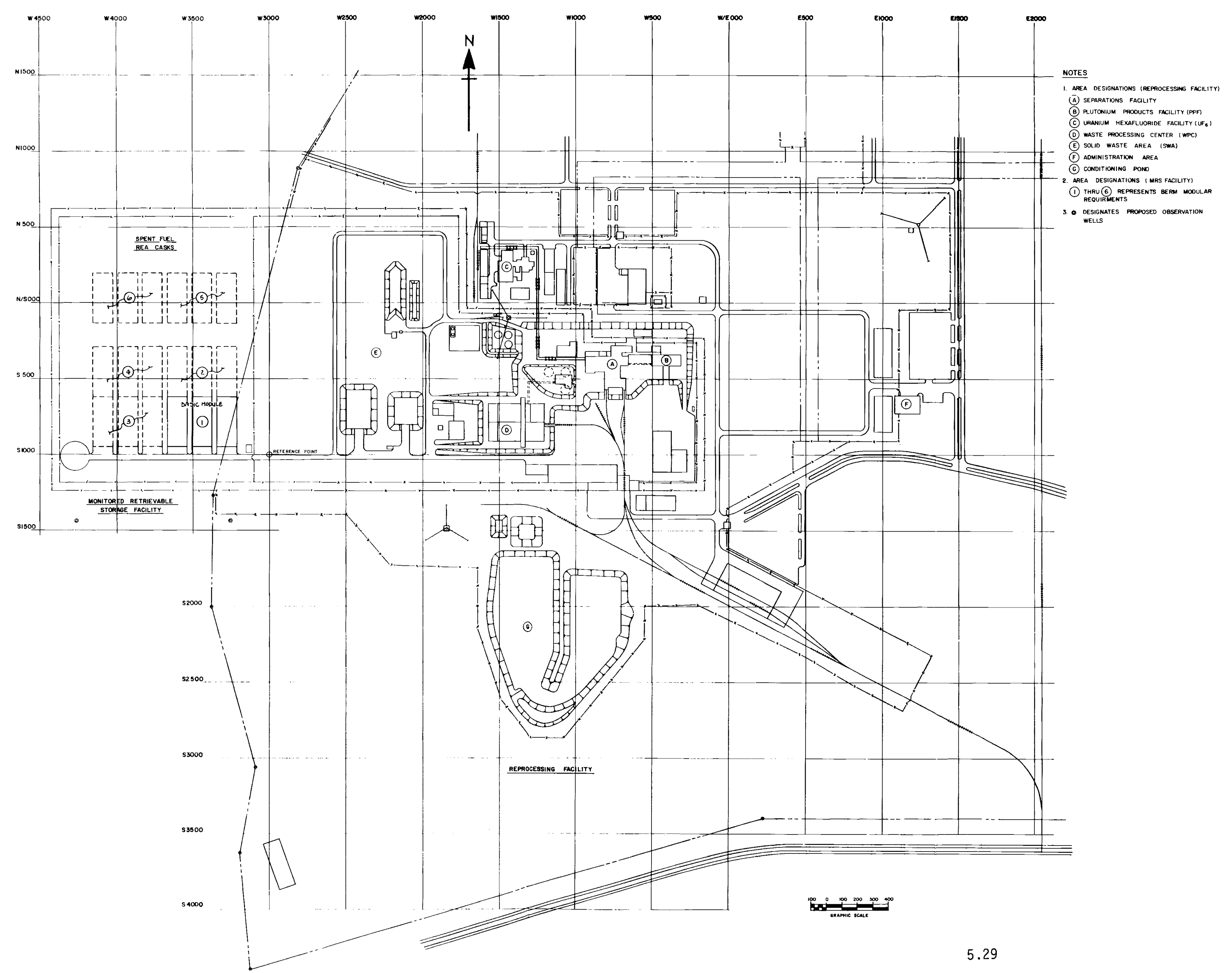

FIGURE 5.14. MRS/IS Facility Co-located with a Reprocessing Plant, Delayed Reprocessing Scenario 


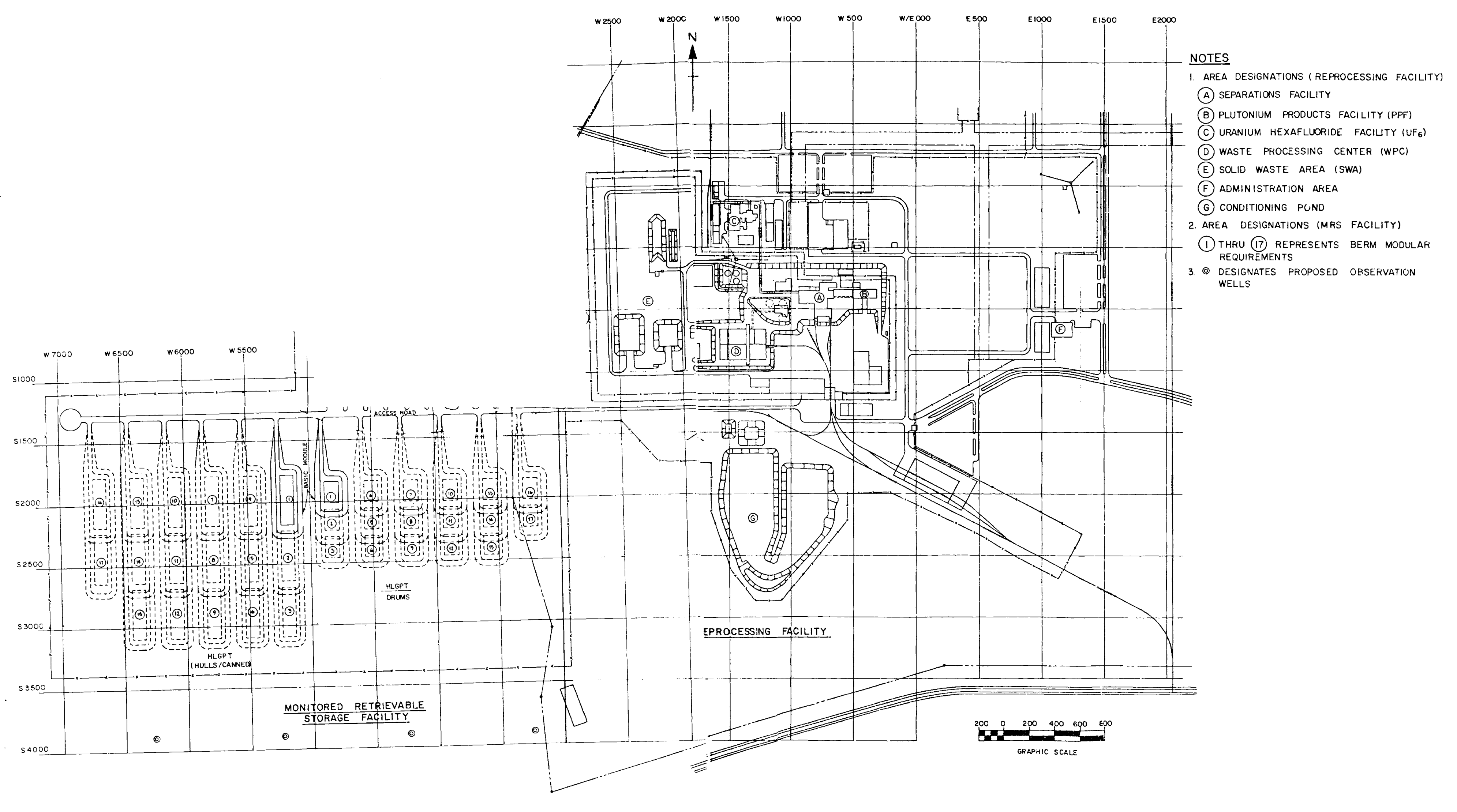




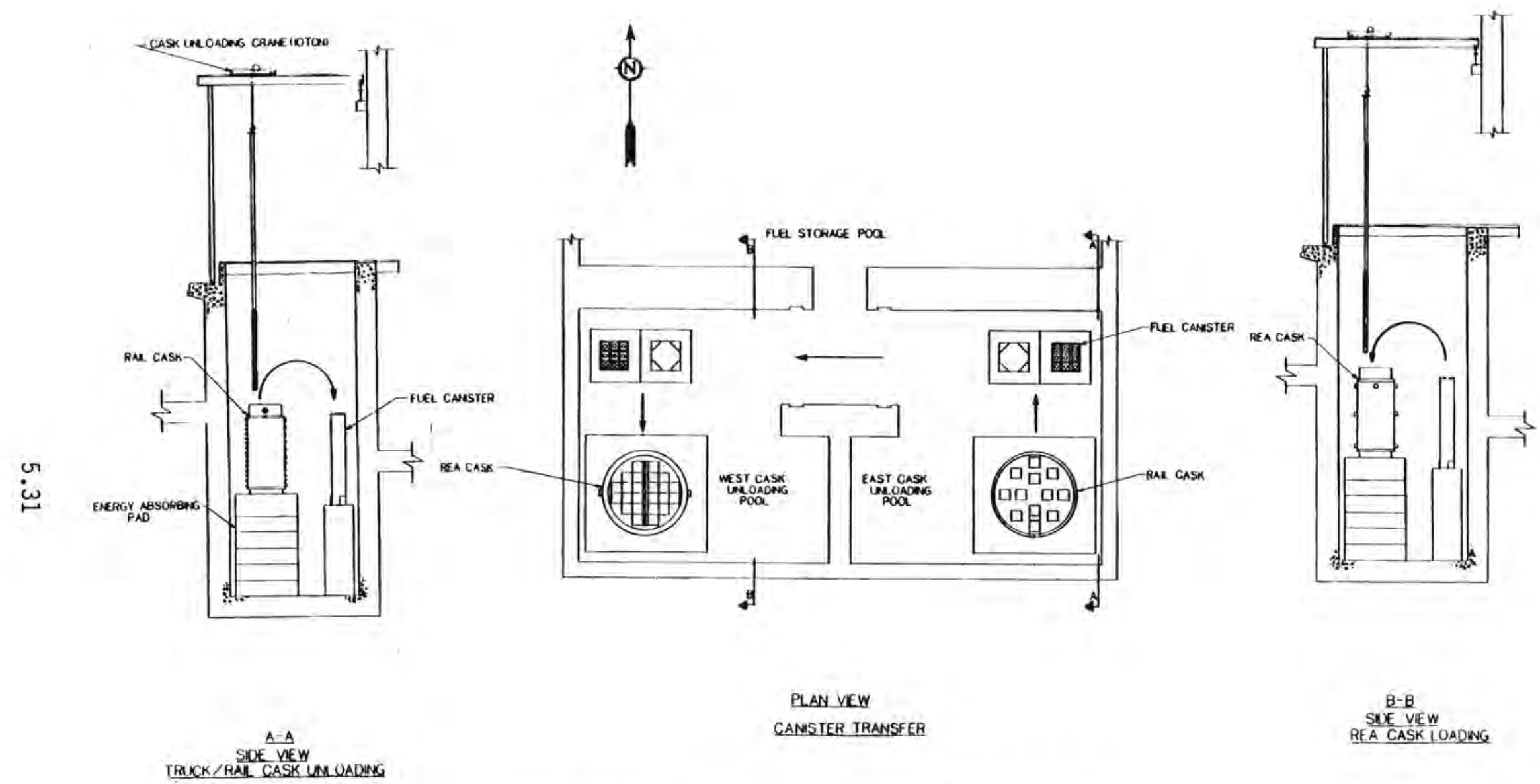

FIGURE 5.16. Cask Unloading/Loading Operation 


\subsubsection{Drywe11s}

The drywells utilized in this concept are installed in a built-up berm. The berm concept provides for modular construction as capacity is needed, and ensures that the "environment" would remain inviolate even in the unlikely event of a package system failure. The confinement barrier philosophy is found in AEC Regulatory Guide 3.18, "Conf inement Barriers and Systems for Fue1 Reprocessing Plants."

Berm Description. As shown on Figure 5.17, a clay pad is laid at the existing grade level and is covered with a layer of relatively large aggregate (sand). The purpose of the clay and sand layers is to break the capillary communication between the unsaturated soil and the berm. The sand layer is then covered with another clay layer to provide the maximum capillary contrast. The remainder of the berm is constructed of a homogeneous sandy clay fill having known ion exchange properties and a pore structure which is more open and free draining than the clay pads.

In this fill, above the clay pads, is laid a horizontal network of monitoring pipes which can be made of any appropriate material, including possibly PVC or polymer glass.

The berm is capped with concrete. The toe of the berm is open, in the manner of an earth-fill dam, to provide an escape route for water which may pass through any breach in the cap. A monitorable surface drainage system is provided for surface runoff from the berm.

Holes are excavated in the berm, and corrugated drywells with solid bottoms are set with aggregate uniform sand, separating the metallic drywell (galvanized steel) from the soil. The purpose of the uniform sand in this case is to 1) break the capillary communication between the drywell casing itself and the soil and 2) insulate the metal from the acidic soil. The drywell may be equipped with a dip-leg for monitoring purposes, which is in turn equipped with a valve and a pressure gauge. An accumulation of water or change in activity level inside the drywell can be detected via this route. Beside each storage drywell is a monitoring drywell which, coupled with the underlying pipe network, gives a three-dimensional "fix" on any leaked radioactivity. 

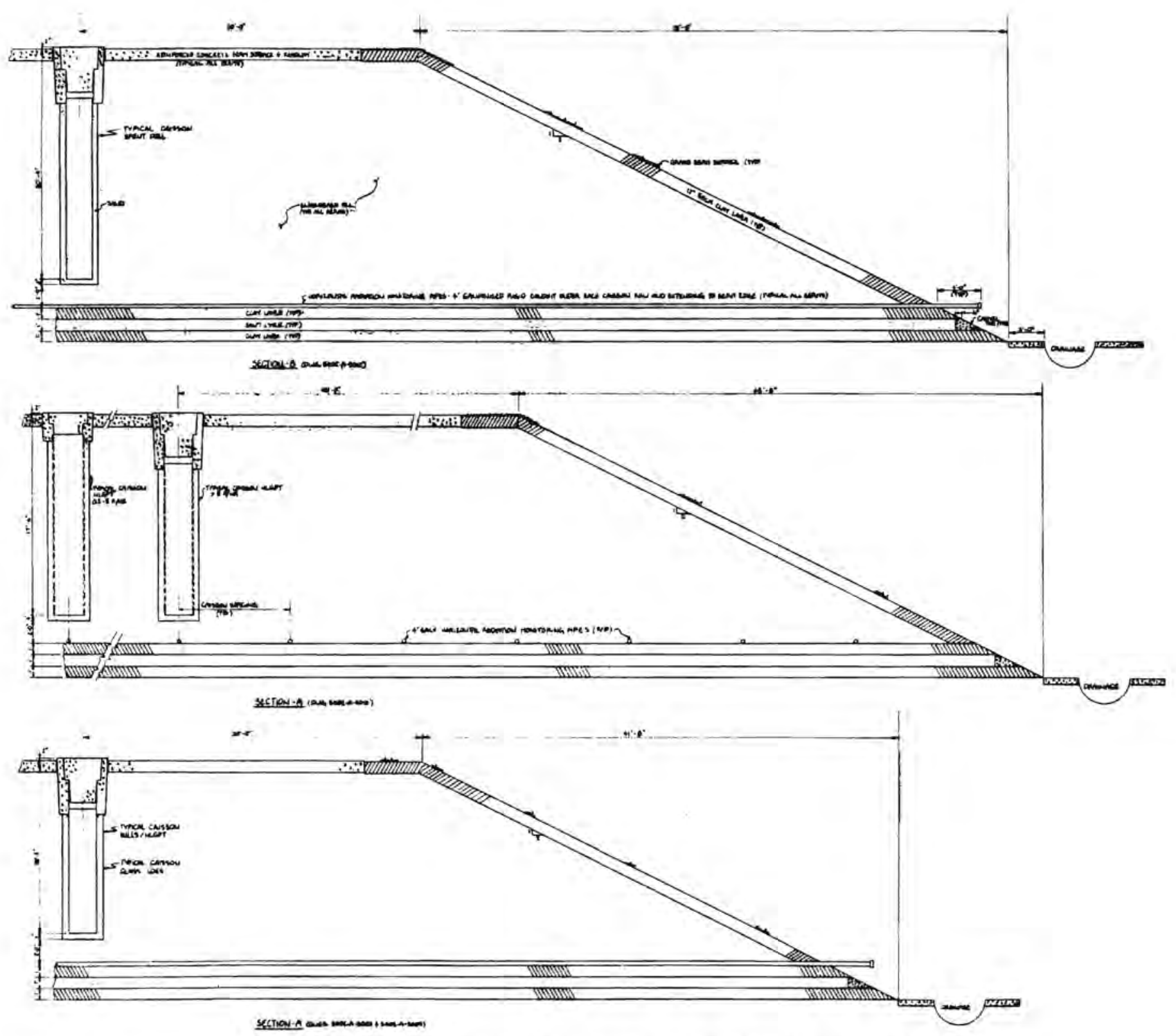

FIGURE 5.17. Cross-Sections of a Typical Berm Module 
Even if an unidentified series of events did result in nuclides reaching the outside of the drywell and enough water were available around the drywell, the worst case movement of water and representative nuclides would not provide any immediate or nonmonitored detrimental consequences. The berm as designed isolates any contaminants from man while allowing detection through the threedimensional drywel1 monitoring network. The minimum time for water leaving the drywe 11 to reach the surface outflow system is 145 days. During that time, the event is monitorable by via neutron sondes in the three-dimensional drywell network. A drywell leak of at least $3490 \mathrm{gal}$ is required, which is a depth in the drywell of about 198 in. The mean annual rainfall at the BNFP is $55 \mathrm{in.}$. per year, and the maximum intensity is $11 \mathrm{in}$. per hour for a 5-minute expected duration. Even if a drywell remained uncovered during the probable maximum rainfall, the volume of water required would not be available.

Estimates of the time required for cesium and plutonium to first appear in the surface drainage system are 113 and 2820 years, respectively. Such times indicate the berm structure's effectiveness in localizing any sorbable nuclides.

\section{Drywell Storage}

Several options are presented for sizing the storage areas and drywells. One canister per drywe1i (with one PWR/two BWR spent fuel assemblies $=0.38$ to 0.46 MTU/hole) is the most conservative choice. It offers the most conservative design from a thermal standpoint and simultaneously offers the reprocessing plant operator the greatest flexibility in selection of fuel assemblies for reprocessing. It is also probably the most costly since it resuits in the greatest number of holes.

At the opposite end of the loading spectrum is a $3 / 7$ spent fuel canister (three PWR/seven BWR assemblies $=1.33 \mathrm{MTU} / \mathrm{hole}$ ). This 1 arger canister is the recommended approach since it is anticipated that the actual age of the spent fuel will be significantly older than 10 years. Criticality concerns can be overcome by either poisoning the can (i.e., use of Boral or similar neutron poison used as a fuel divider in the can) or taking credit for fuel burnup. 
The latter approach has been approved for reactor high-density spent fuel racks. Preliminary calculations indicate that the proposed $250^{\circ} \mathrm{C}$ limit for fuel cladding temperature will not be exceeded using a $3 / 7$ canister, even assuming a worst-case, 10-year-old fuel with 35,000 to 40,000 MWd/MTU burnup.

The holes drilled for the drywells are positioned on a square pitch to enable the placement of aisles for facility handling operations. A minimum of $10 \mathrm{ft}$ is assumed to permit movement of the cask transport vehicle and to preclude exceeding soil loading limitations.

Similar berms are utilized for solidified HLW and remote-handled TRU wastes. The modular berm sizes and shapes for storage of spent fuel, HLW, and RHTRU are illustrated in Figures 5.18, 5.19, and 5.20.

\subsubsection{Service Facilities}

Most of the necessary service facilities to support the MRS at BNFP are currently available as part of the reprocessing facility. These services include utilities (steam, eTectricity, water, etc.), connecting highway and railroad lines, administration buildings, a security and safeguards system, health physics and environmental monitoring, an analytical 1aboratory area, a maintenance and machine shop area with supporting warehouse, and a completed fuel receiving and storage area. At this time, however, neither a cask fleet servicing facility for the transportation vehicles (a conceptual design of such a facility has been completed) nor hot laundry facilities are available on the site.

\subsection{MRS/IS STAND-ALONE FACILITY}

The MRS/IS facility described in this section is a stand-alone facility capable of receiving and storing PWR and BWR spent fuel assemblies, canisters containing solidified HLW, and various forms of TRU waste contained in drums, canisters, and boxes. The facility is divided into three principal areas: the first handles and stores the spent fuel and solidified HLW; the second handles and stores all the TRU waste including canistered hulls; and the third is the support facilities. 


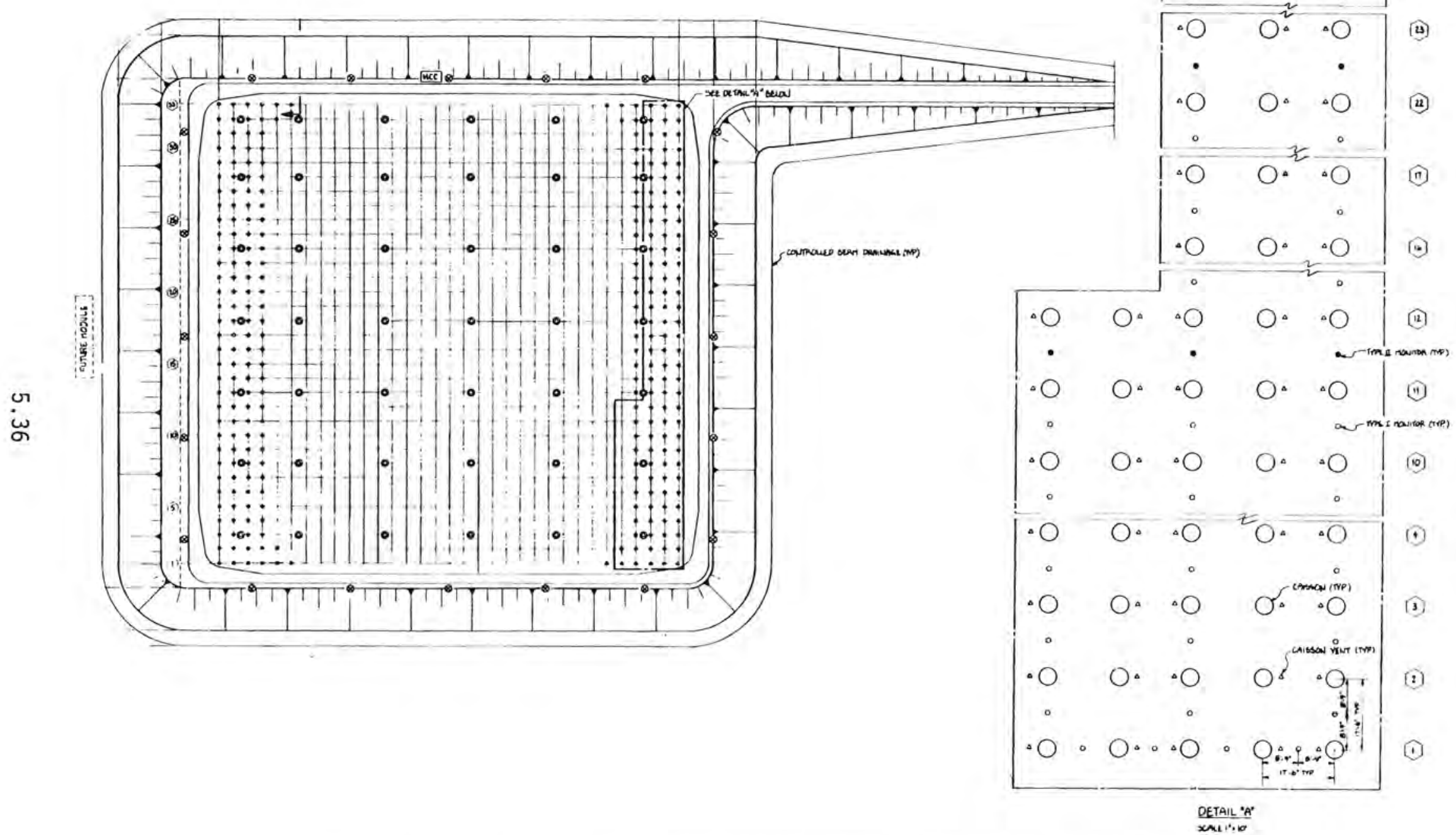

FIGURE 5.18. Typical Berm Module for Drywe11 Storage of Spent Fuel 


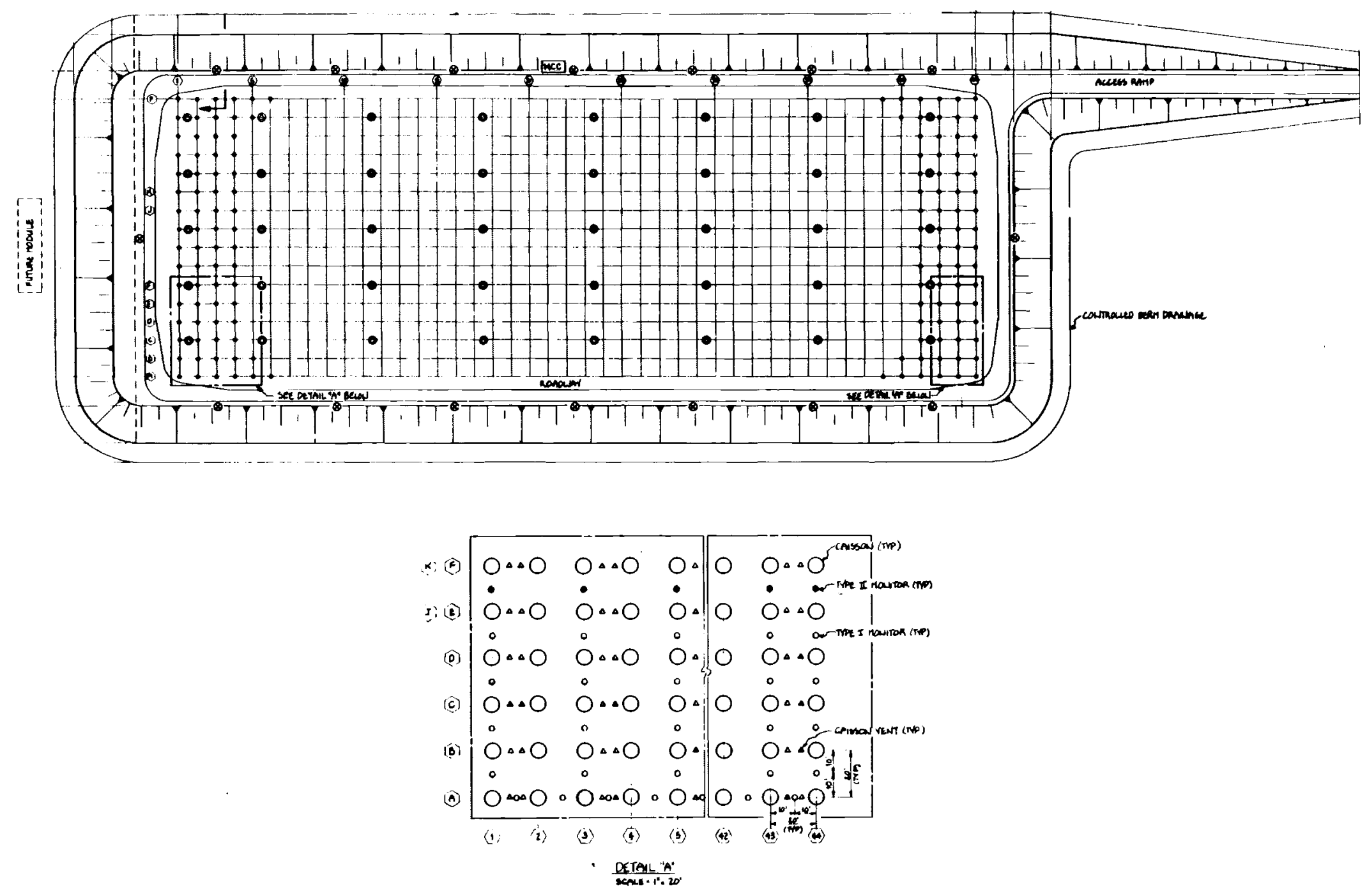

FIGURE 5.19. Typical Berm Module for Drywell Storage of HLW 


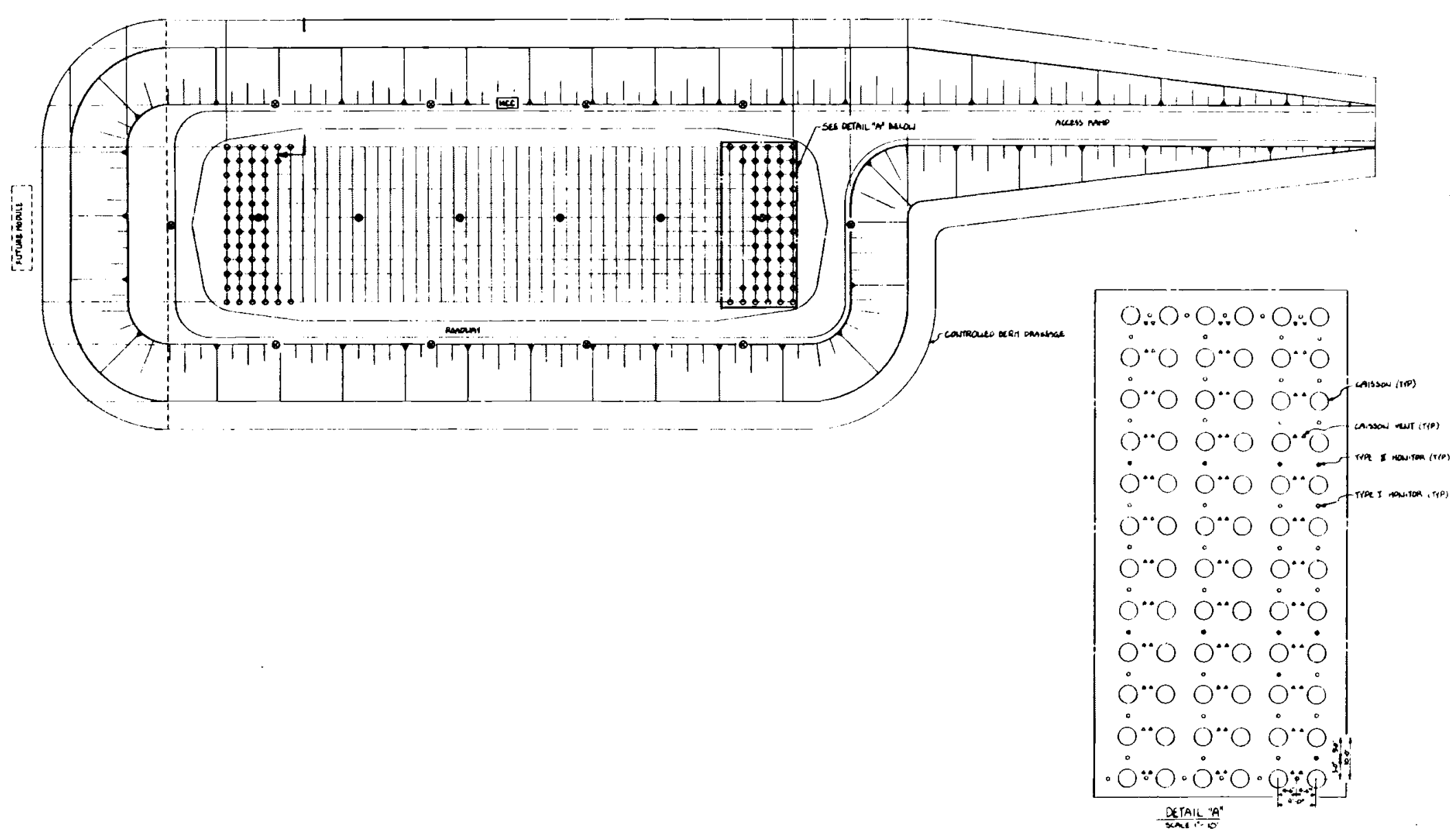

FIGURE 5.20. Typical Berm Module for Drywell Storage of RHTRU Wastes 
Two concepts for the spent fuel and HLW storage area are considered. The first concept uses metal storage casks, and the second uses surface drywells. It is assumed that the casks are not transportable, although, in the future, they may be made transportable with the addition of certain safety equipment. The drywell considered is the reference design identified in Section 5.2.2. Both storage concepts require an onsite receiving and shipping facility. The facility accommodates both rail and truck shipments and uses a wet handing system to unload the spent fuel or HLW from the shipping casks.

The second storage area (TRU waste) of the facility is divided into three sections. The first receives contact-handled TRU waste (CHTRU) and stores it in prefabricated buildings. Because the radiation and decay heat levels are low, the construction of the building is relatively light. The second section stores remote-handled TRU waste (RHTRU) in heavier concrete vaults. These vaults provide greater radiological protection than the buildings in the first section but do not require any special features for heat removal. The third section handles hulls and hardware in canisters. This waste requires substantial radiological protection and heat removal capability and is placed in drywells located in earthen berms.

The support facilities include all the buildings, structures, and systems needed to maintain operation of the MRS/IS facility, including the administration building, the process steam plant, and the emergency vehicle/fire truck station.

The designs of the spent fuel/HLW and TRU waste areas are modular. This allows for incremental expansion of the handling facilities and storage areas to accommodate the three scenarios (reference, delayed reprocessing, delayed disposa 1).

\subsubsection{Receiving and Handling Facility}

The stand-alone MRS/IS concept requires the construction of receiving and handling facilities for spent fuel/HLW and TRU wastes. The spent fuel/HLW receiving and handling facilities are very similar no matter which storage 
concept is being used. The major differences are related to packaging and interfacing with different transfer systems. The same facilities for receiving and handiing TRU wastes are utilized with either a cask or drywell storage concept.

\subsubsection{Cask MRS/IS Spent Fuel/HLW Receiving and Handling}

The receiving and handling system for the cask version of the MRS/IS facility has three principal functions. In the case where spent fuel or solidified HLW enters the MRS/IS facility, the functions are:

1. To accept (receive and inspect) rail and truck casks containing spent fuel or solidified HLW.

2. To transfer spent fuel or solidified HLW from the rail or truck transport casks into storage casks.

3. To deliver loaded storage casks to the transfer system for transport to the cask storage area.

When spent fuel or solidified HLW is retrieved from the storage area for shipment to a reprocessing plant or repository, the facility functions are:

1. To accept loaded storage casks from the transfer system.

2. To unload spent fuel or solidified HLW from the storage cask into a rail or truck transport cask.

3. To prepare loaded rail and truck casks for shipment.

Functional flow diagrams which provide detailed breakdowns of the principal facility functions are given in Figures 5.21 and 5.22.

The following description of the receiving and handling system is for material entering the MRS/IS facility. As shown in Figure 5.22, the system operation is almost reversed when material is retrieved and shipped out of the facility. The receiving and handling system is made up of the following subsystems or areas:

- receiving/inspection area

- carrier preparation/wash-down area

- carrier wash-down/cask unloading area

- cask wash-down/cooling pit 


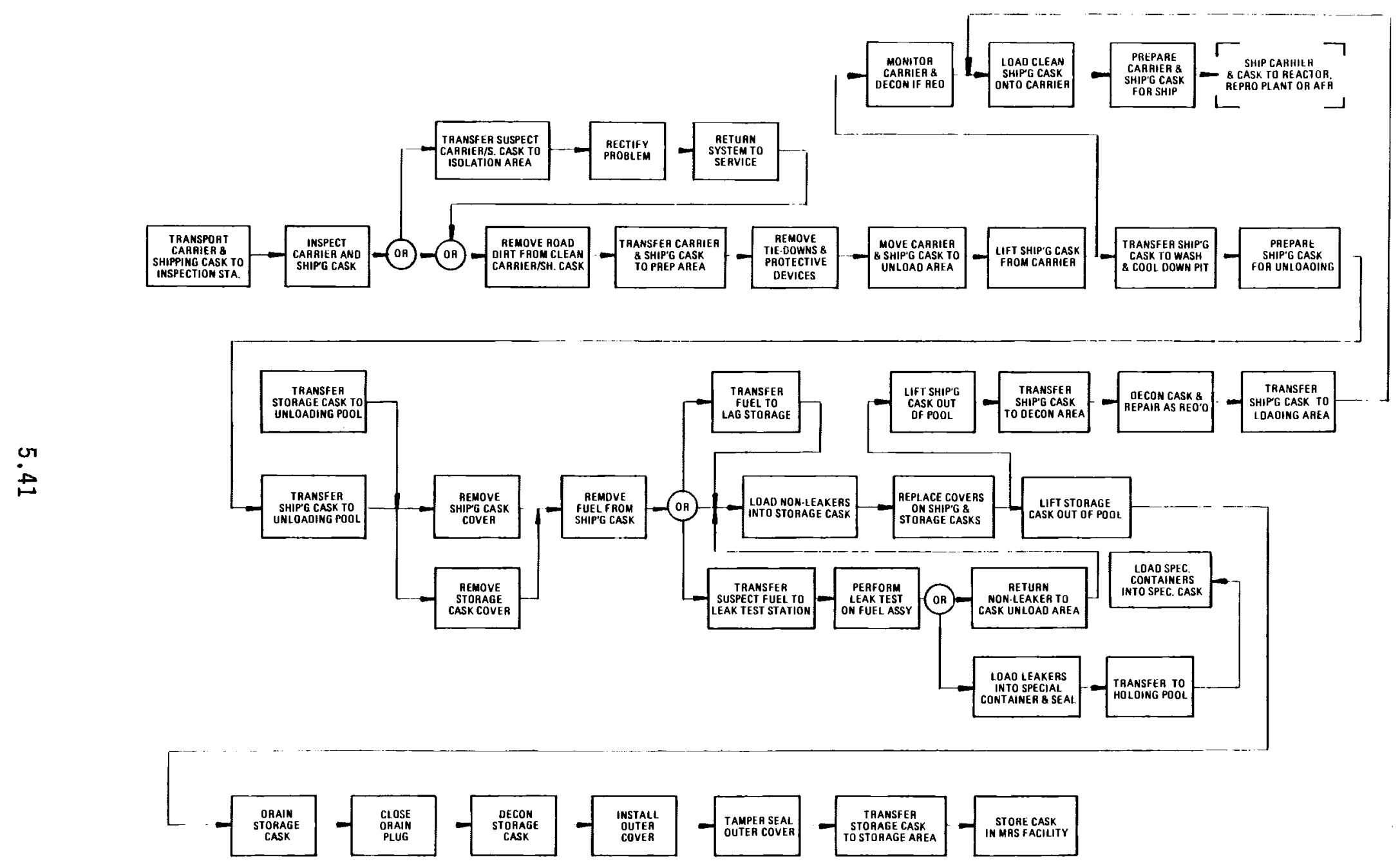

FIGURE 5.21. Spent Fuel/HLW Receiving and Storage Flow Diagram 


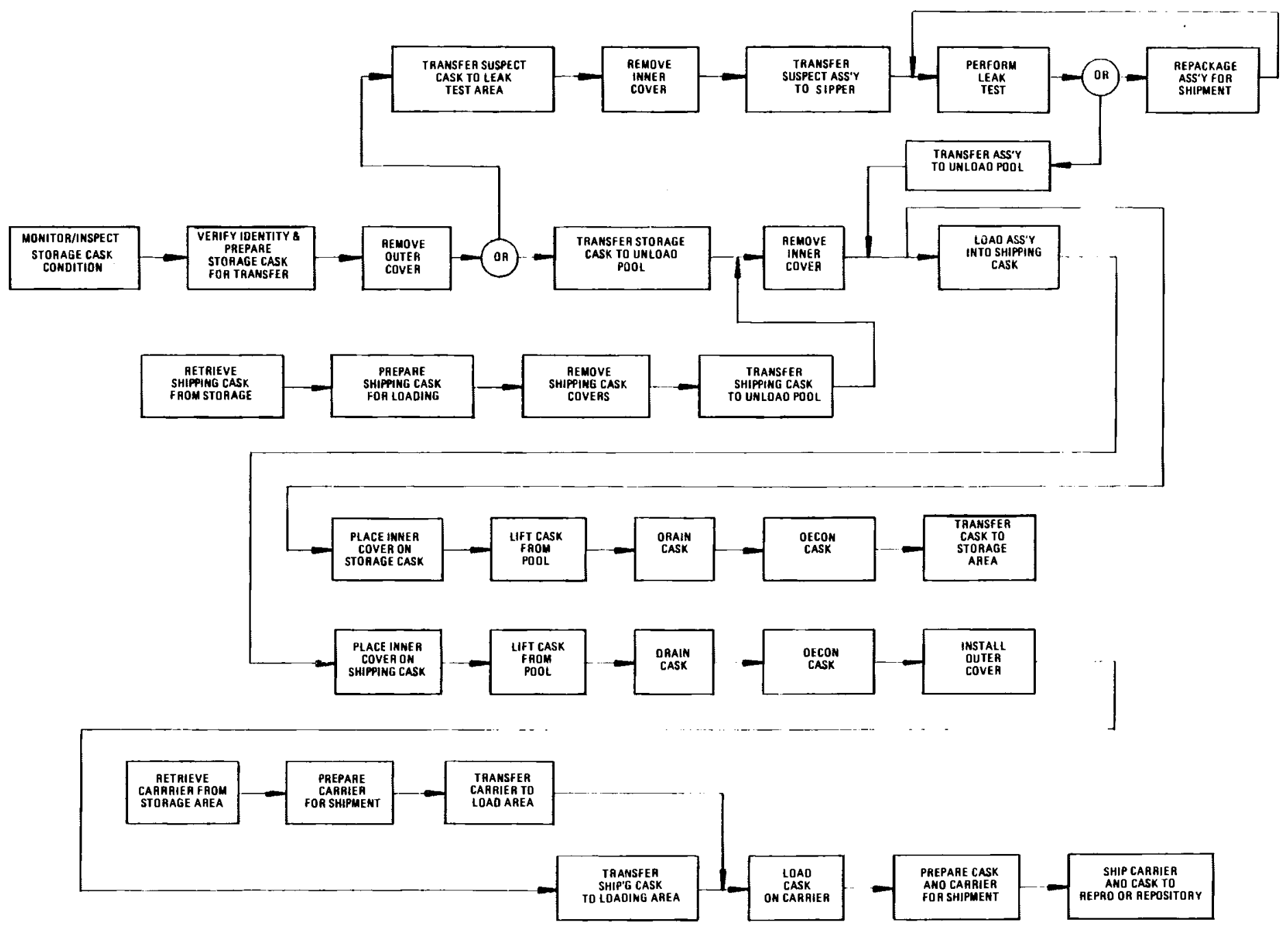

FIGURE 5.22. Retrieval from Storage and Shipment to Repository or Reprocessing Plant 
- spent fuel/solidified HLW unloading/transfer pool

- transport cask decontamination pit

- hot cell/lag storage area

- support areas and systems.

One module in the receiving and handling building contains two truck bays, one rail bay, a fuel/HLW unloading/transfer pool, the cooling and decontamination pits, and a cask storage area. The receiving/inspection area is located at the site boundary. The area is paved to facilitate access for the carriers. Lighting is provided for night operation and sheds for protection of personnel against inclement weather. Rail and truck carriers are stationed in this area while awaiting document processing and are then inspected for contamination and damage. Any carriers suspected of having excessive damage or sabotage are immediately moved to the suspect truck and rail car storage area. After the receiving inspection is complete, carriers are moved to the spent fuel and solidified HLW receiving facility or to the rail car or truck parking areas.

Figure 5.23 is a plan view of the spent fuel and HLW handling facility. This building is approximately $450 \times 430 \mathrm{ft}$ and contains the remainder of the receiving and handling system.

After the receiving inspection is complete, the cask and carrier are moved into the carrier preparation/wash-down area, where road dirt is removed from the cask and carrier and tie-downs and other protective devices are taken away. The area is an enclosed space approximately $105 \mathrm{ft}$ wide, $56 \mathrm{ft}$ long, and $42 \mathrm{ft}$ high. It is equipped with sealable doors at the entrance for air control. The facility is made up of modules, with each module having two truck bays and one rail bay. The rail bay can accommodate a truck if necessary. Each bay is equipped with a 10-ton crane and has storage space for the cask accessories and peripheral equipment and the lifting yokes and accessories.

Next, the cask and carrier are moved to the carrier wash-down cask unloading area, where the cask is lifted from the carrier. Each module is equipped with a 125-ton bridge crane which lifts the cask from the carrier and transfers it to the cask wash-down/cooling pit. 


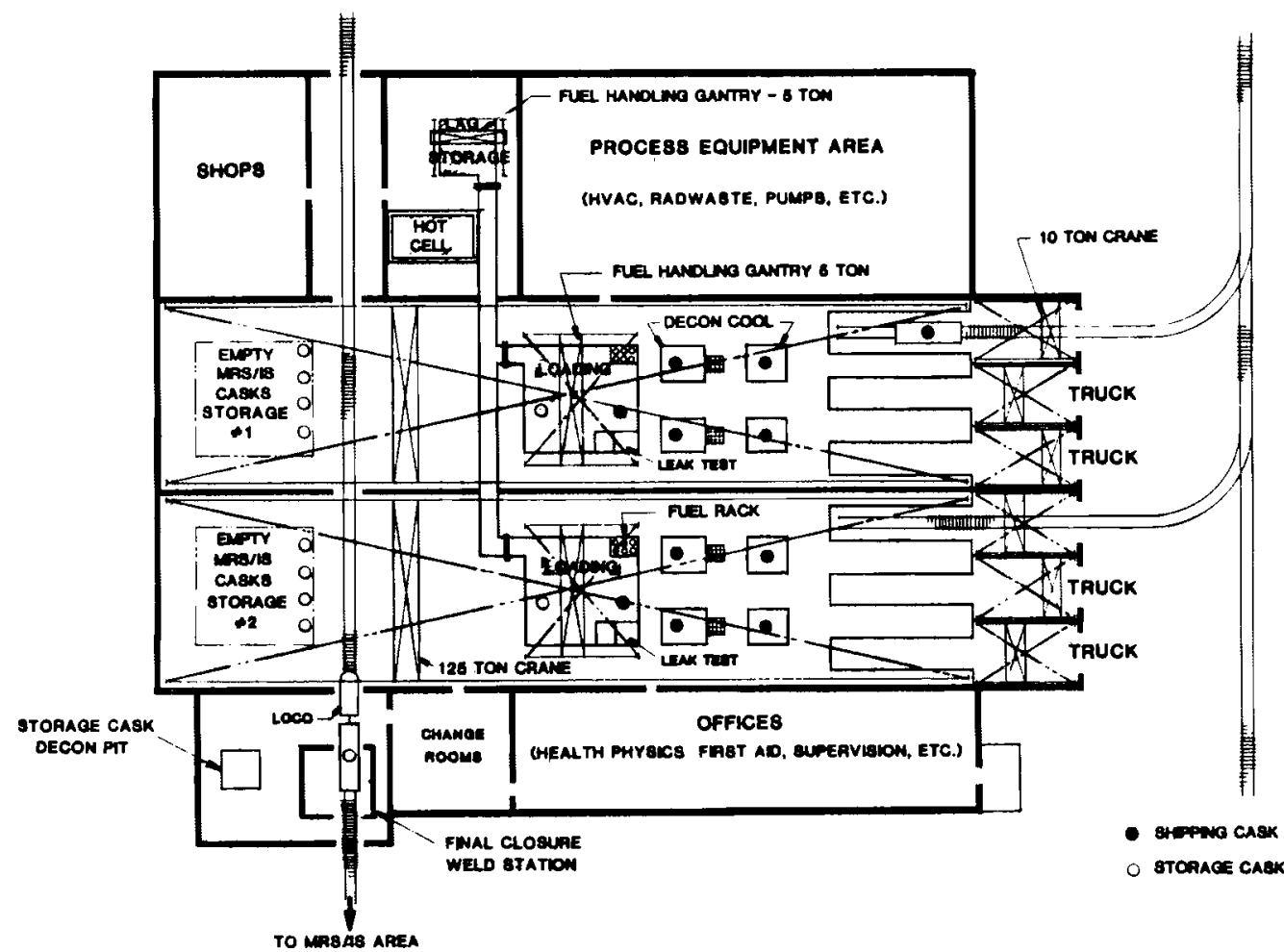

FIGURE 5.23. MRS/IS Facility Spent Fuel and High-Level Waste Handling Building Plan

In the cask wash-down/cooling pit, the external surface of the cask is cleaned, the cask interior is vented to the off-gas system, and the cask is cooled using first steam and then water. During this cooldown, the cask temperatures and contamination levels are periodically monitored. When cooldown is complete, the outer cask cover is removed and the cask transferred (by crane) to the loading/unloading pool.

The wash-down/cooling pit is made of reinforced concrete and is 20 - $\mathrm{ft}$ square and 25-ft deep. Each module has two pits. Each pit is equipped with flexible couplings for venting the gas inside a cask to the off-gas system, is seismically qualified, and can withstand the loads caused by accidental dropping of a rail or truck transport cask into the pit.

In the fuel loading/unloading pool, the transport cask is lowered into the water, the inner cover is removed, the cask is lowered further down into 
the water, and the spent fuel assemblies or waste canisters are unloaded and placed into the storage cask. Fuel unloading continues in this manner until the storage cask is full.

Each module has one loading/unloading pool. It is made of reinforced concrete and is approximately 60-ft long by 57-ft wide by 50-ft deep at the deepest point. Storage and transport casks are loaded into the pool by the traveling 125-ton overhead bridge crane. The cask grappling system is equipped with redundant yokes to ensure that a cask cannot be dropped while it is being transported. Transfer of fuel assemblies or waste canisters is handled by a 5 -ton overhead gantry crane.

The pool is designed with storage shelves for cask hardware (including the inner cover) and has a leak test (sipping) system. A rack for temporary storage of fuel assemblies or canisters is also included. The shelves, racks, and bottom of the pool are fitted with energy-absorbing pads or grills. The pool is designed so that $10 \mathrm{ft}$ of water cover the assembly or canister being handled at all times. A pool water clean-up system maintains the water radioactivity at acceptable levels.

To complement the handling system, an underwater television camera is provided. This permits easy identification and inspection of received material. An underwater vacuum system is also provided to collect any loose debris or scale that may fall from the cask or its contents. Positive means (e.g., locks or stops) are provided to prevent fuel assemblies or canisters from being placed in critical configurations and to prevent movement of casks above fuel assemblies or canisters.

The transport cask is placed in the decontamination pit prior to being reloaded onto a carrier for return to the reactor or reprocessing plant. The cask interior and exterior are washed with decontaminating solutions, and the cask covers are replaced.

The decontamination pit is approximately 23- $\mathrm{ft}$ square and is built of reinforced concrete. It is equipped with high-pressure hoses for spraying detergent and rinsing radiation monitoring instrumentation, a cleaning solution drain and disposal system, and instrumentation for leak-checking the 
assembled cask. The bottom of the pit has an energy-absorbing pad, and air and helium supply lines are available for drying and leak testing. Each module has two decontamination pits.

Loading of clean casks onto a carrier is performed in the cask loading bay using the 125-ton bridge crane.

The hot cell is designed to accommodate radioactive equipment requiring maintenance or repair and to encapsulate leaking spent fuel assemblies or solidified HLW canisters. Although the MRS/IS facility will not, as a general rule, accept leaking assemblies, some fuel or canisters may be damaged in transit, during handling, or in storage, and a facility (hot cell) for repair or recanistering must be available.

The hot cell is constructed of reinforced concrete and is approximately $20 \mathrm{ft}$ wide, $40 \mathrm{ft}$ long, and $25 \mathrm{ft}$ high. The walls are 36- to 48-in. thick, and all windows are fitted with leaded, oil-filled glass. The hot cell contains two remote control manipulators, a 5-ton crane, television cameras, and various jigs and fixtures required for repair or recanistering.

Fuel assemblies are transported to the hot cell from the pool by a transfer buggy that runs the length of the canal from the lag storage pool to the loading/unloading pools. Spent fuel assemblies or HLW canisters enter the hot cell through an air lock in the floor of the cell. The assembly or canister is surrounded by a shield sleeve which is lowered into the canal. The floor port is opened, the assembly or canister drawn up into the cell, and the port closed.

The lag storage pool is made of reinforced concrete and is 30-ft square and 25-ft deep. It provides temporary storage for BWR assemblies, PWR assemblies, or solidified HLW canisters. Storage for about 10 weeks worth of HLW canisters handling at the peak facility handing rate is provided.

The support areas and systems portion of the receiving and handling facility consist of the following subsystems:

- HVAC

- electrical power and lighting system

- fire protection system 
- radiation monitoring system

- radwaste system

- decontamination system

- utility piping system

- process instrumentation system

- control room area

- storage cask receiving and storage areas

- maintenance shops

- health physics areas

- administration/employee service area.

The receiving and handling facility accommodates the three fuel cycle scenarios by varying the number of modules and/or the number of shifts of workers to achieve the desired capacity. The plant handling rates for spent fuel are given in Table 5.4, and the rates for solidified HLW are given in Table 5.5. As indicated in the tables, the same handling rate is available using fewer modules and more shifts. Because of the high capital cost of the modules, use of more shifts is felt to be the more economical option for attaining the desired handling rate.

TABLE 5.4. Receiving and Handling Facility Handling Rates for Spent Fuel (MTU/yr)

\begin{tabular}{crrrr} 
No. of Modules & \multicolumn{3}{c}{ No. of Shifts } \\
\cline { 5 - 5 } & $\frac{1}{1}$ & $\frac{2}{370}$ & 339 & 508 \\
2 & 339 & 678 & 1016 \\
3 & 508 & 1016 & 1524
\end{tabular}

TABLE 5.5. Receiving and Handling Facility Handling Rates for Solidified HLW (MTU//yr)

\begin{tabular}{crrrr} 
No. of Modules & \multicolumn{3}{c}{ No. of Shifts } \\
\cline { 3 - 5 } 1 & $\frac{1}{764}$ & $\frac{2}{1529}$ & $\frac{3}{2293}$ \\
2 & 1529 & 3057 & 4586
\end{tabular}


5.4.1.2 Drywell MRS/IS Spent Fuel/HLW Receiving, Handling and Packaging

The facilities for receiving and handling spent fuel and HLW at the drywell MRS/IS are essentially the same as those described in 5.4.1.1. The hot cell described in 5.4.1.1 is also used for welding the support ring on the HLW canisters. This ring supports the canister in the drywell encasement.

In addition, the drywell MRS/IS facilities for the delayed reprocessing scenario are capable of packaging spent fuel into sealed metal canisters. This is accomplished in the weld and test cell, which is sized to accommodate the packaging and testing functions for a $2.1 \mathrm{MTHM} /$ day throughput on a 5-day week single shift basis. Shifts and cells are added as required to meet the anticipated flow of spent fuel. An operating gallery, located parallel and adjacent to the weld and test cell extends the length and height of the cell to allow direct viewing (via shield windows) for manipulator handling of assemblies and HLW canisters and for performing maintenance operations. Space is provided for personnel and auxiliary equipment in support of the handling and packaging operations. There is a package loadout room at grade level into which transport vehicles will enter to receive packages.

\subsubsection{TRU Waste Receiving and Handling.}

At the MRS/IS stand-alone site, all incoming TRU waste is routed through the TRU waste receiving facility. The receiving facility is divided into the CHTRU and RHTRU receiving facility and the spent fuel residue receiving facility. A further division is made according to mode of transportation, i.e.. rail car or truck. Waste containers arriving by rail are transferred at the receiving facility to site transporters.

A plan view of the proposed TRU waste receiving facility is shown in Figure 5.24. The major portion of the facility is devoted to receiving and transfer of the fuel residue canisters. This part of the facility contains the receiving bays, the unloading and transfer pool, and the load-out station, together with the associated process, radwaste, and hot-cell facilities. The whole area is serviced by a 100-ton bridge crane. A 5-ton gantry crane is provided at the pool for handling fuel residue canisters. 


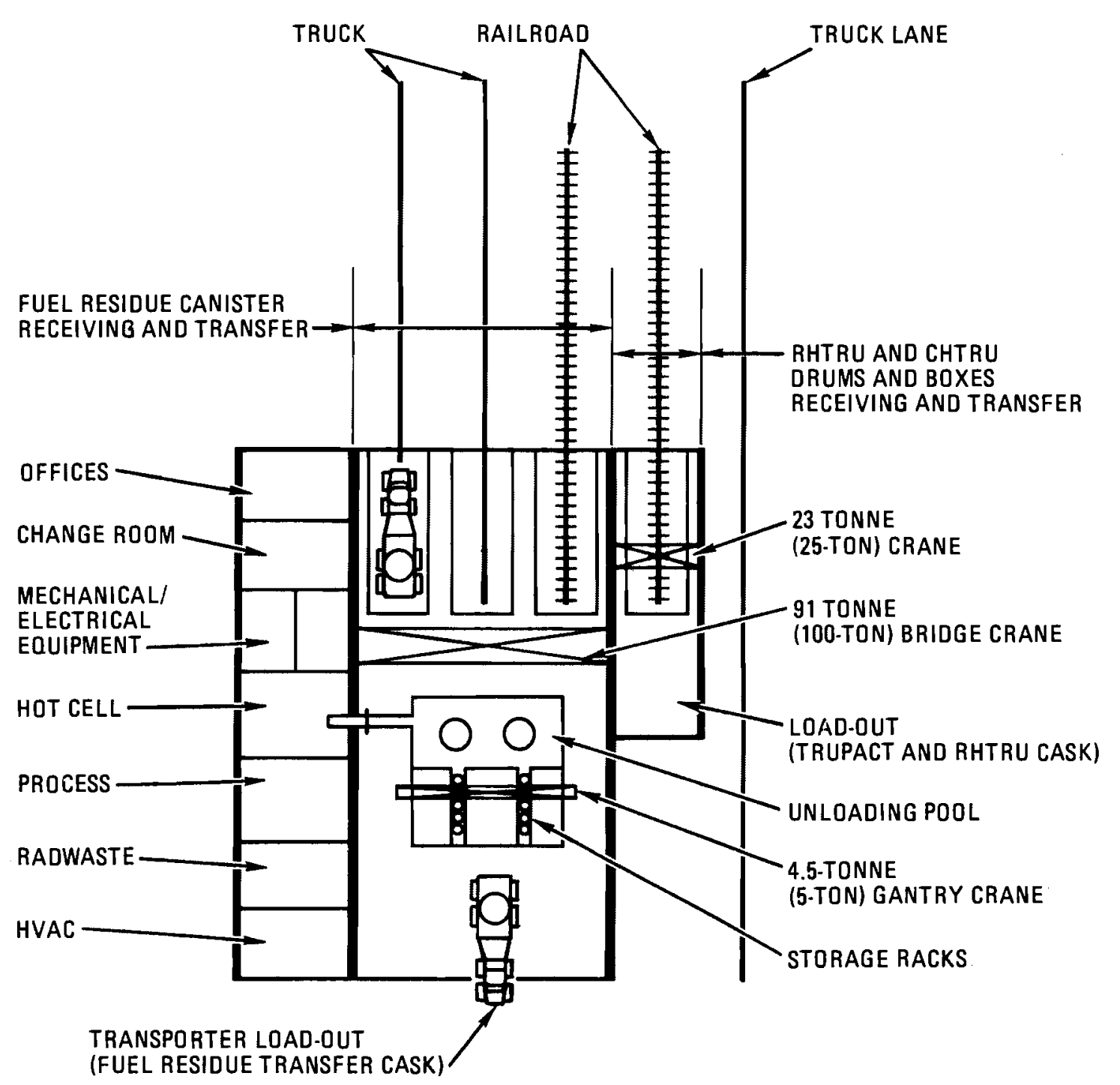

\section{FIGURE 5.24. TRU Waste Receiving and Transfer Facility}

An adjoining building houses the receiving and transfer area for RHTRU and CHTRU drums and boxes. A 25-ton crane is provided for transfer of RHTRU multidrum shipping casks and CHTRU TRUPACT shipping containers from incoming rail cars to site truck transporters for delivery to their storage building.

The required handling rate varies considerably, depending on the particular timetable for availability of reprocessing and disposal facilities. The handling capacity of the receiving facility is adequately sized for the initial waste storage requirements by operating on a single work shift basis and can be increased to the peak handling requirements by operating with second and third shifts. 


\subsubsection{Contact-Handled Waste Storage}

Indoor interim storage of CHTRU waste is a simple concept. A traditional warehouse is sufficient to meet storage needs, and because the shielding requirements are so low, there is no need for special handling equipment.

Variations in the concept are mostly in the choice of structural materials. A precast concrete indoor storage facility has been selected as the reference concept. This comprises a modular, thin-slab, precast, reinforced-concrete structure designed to store CHTRU waste in 208-1iter (55-gal) carbon steel drums and $4 \times 6 \times 6 \mathrm{ft}$ steel boxes. The structure is divided into storage cells. Each cell is $40 \mathrm{ft}$ wide by $70 \mathrm{ft}$ long and has the capacity to store 4200 drums.

Figure 5.25 illustrates the facility expanded to include 10 storage cells, for a capacity of 42,000 drums. The cells are constructed on both sides of a central corridor and have large sliding doors for access. Forced-air ventilation is not required for the stored waste; natural air circulation is provided by roof vents and cell wall openings. Monitoring systems are installed to sample the air within the cells.

Transportation of CHTRU waste to the MRS/IS site is anticipated to be by TRUPACT containers. TRUPACT containers arriving by rail are transferred at the TRU waste receiving area to a site transporter (low-boy truck) for delivery to the storage building. Truck-borne TRUPACT containers are routed directly to the storage building. Transfer of the waste drums and boxes to the storage cells is made by forklift truck.

\subsubsection{Remote-Handled Waste Storage}

The stand-alone MRS/IS facility stores a variety of remote-handled wastes, which include:

- spent fuel

- solidified HLW

- RHTRU waste drums

- RHTRU and fuel residue canisters.

Two methods of storage for spent fuel and HLW are considered, large metal casks and subsurface drywells. Two methods of storage for RHTRU are also 


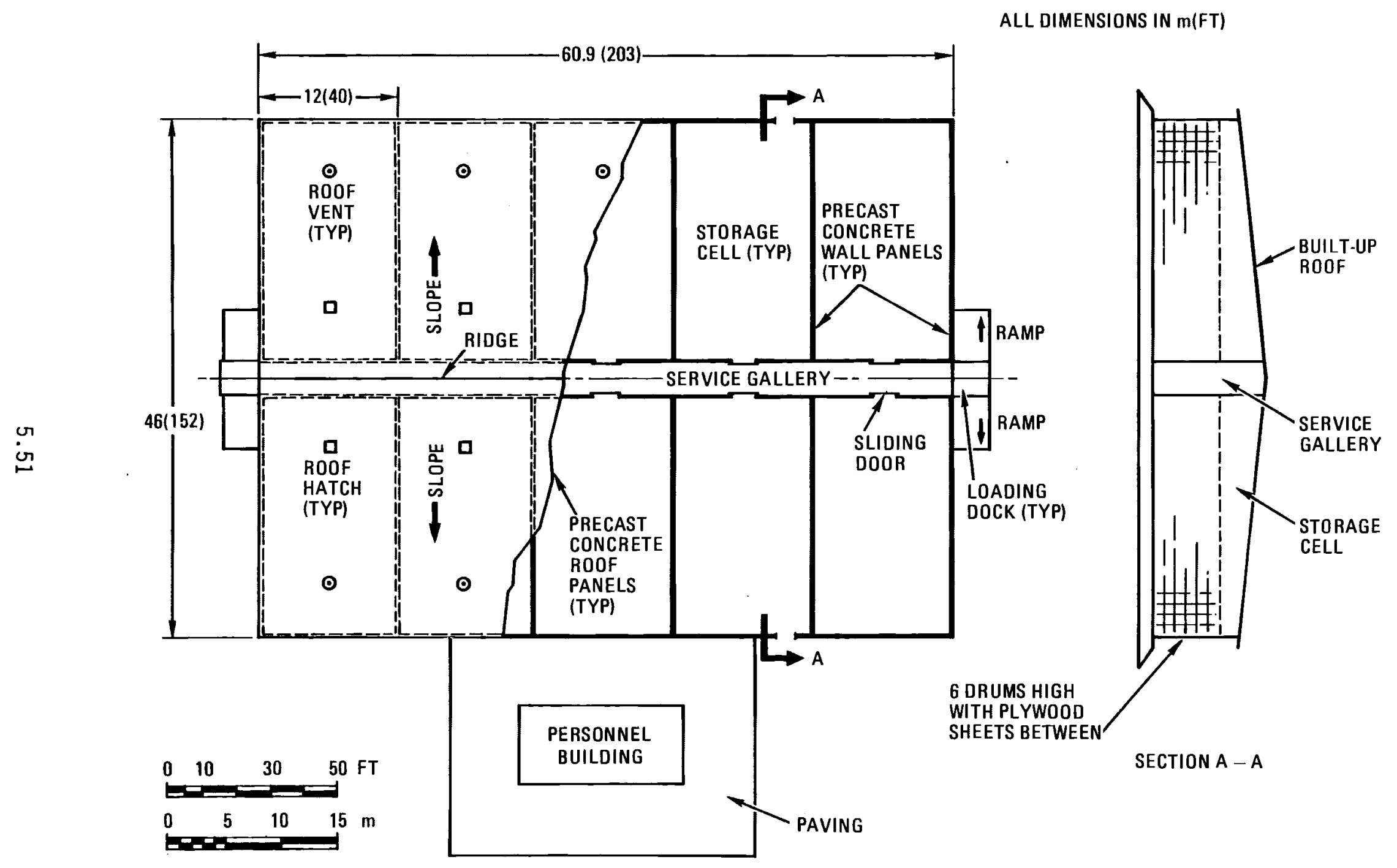

FIGURE 5.25. Indoor Storage Facility for CHTRU Waste 
considered, a shielded vault for drum storage and caissons in a built-up berm for canisters. Each of these methods is described in a succeeding subsection.

\subsubsection{Metal Casks}

Spent fuel and HLW is stored in large metal casks which are described in Section 5.2.1. In the storage area, the casks are stored upright on large concrete pads, which provide for maximum heat transfer. The dimensions of the pad and the spacing of the casks on the pad are shown in Figure 5.26. Each pad has a rail line to accommodate the rail car. Because the spent fuel assemblies are placed intact in the storage casks and the fuel will be at least 10-yr old, calculations performed by REA indicate that the peak fuel cladding temperatures will be below $250^{\circ} \mathrm{C}\left(485^{\circ} \mathrm{F}\right)$. In the case of solidified $H L W$, the thermal load in the cask is approximately $30 \mathrm{~kW}$. Detailed heat transfer calculations need to be performed to demonstrate that the temperature limits on the glass and canister wall can be met.

Each pad holds 204 casks. The numbers of casks and pads required for the three scenarios are given in Table 5.6. In all cases, the first pad is set in place during initial construction of the receiving and handling facility. In the reference case, the second pad is needed on line in 1995; the delayed reprocessing scenario requires additional pads in 1993, 1995, and 1997. The most severe pad construction schedule is required by the delayed disposal scenario, in which new pads are needed in 1995, 1999, 2002, 2004, 2006, 2007, 2009, 2010, and 2011 .

The casks are positioned on the pads using the cask transfer system. The function of the transfer system is to transport storage casks between the receiving and handling facility and the storage area. To accomplish this, a system with a rail transport car and a mobile crane is used. Fully loaded storage casks are removed from the loading pool, drained, and dried. The cask is then placed on a low-bed rail car, which is pulled by a small locomotive to the final closure weld station. Following welding, the cask is tamper-sealed, identified, and transported to the storage area. The time to transport the cask from the weld station to the MRS/IS area is estimated to be less than 20 minutes. At the storage area, the cask is lifted from the rail car using a 125-ton-capacity mobile crane and is placed on the concrete storage pad. 


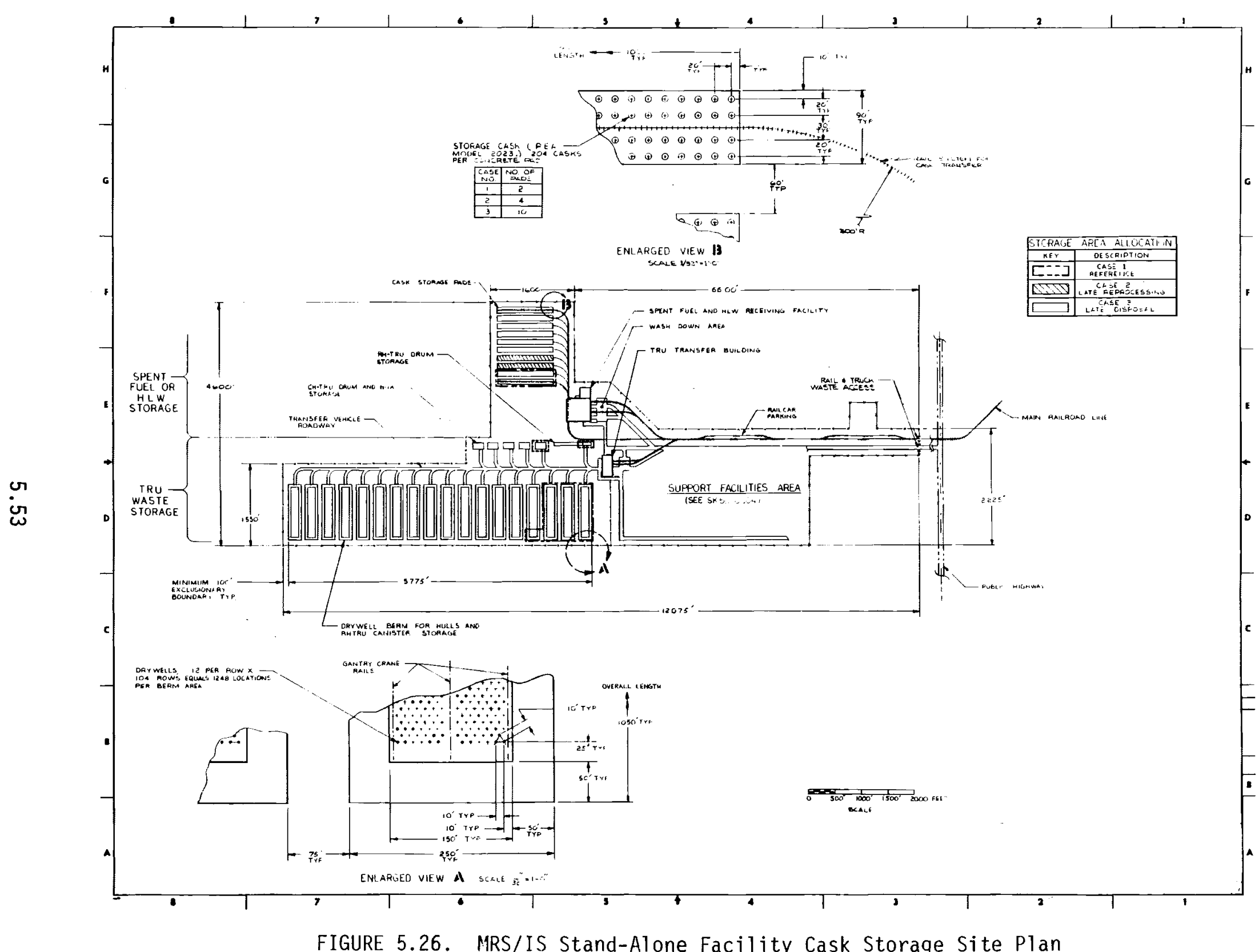


TABLE 5.6. Number of Casks and Pads Required for Study Scenarios

\begin{tabular}{lccc}
\multicolumn{1}{c}{ Scenario } & No. Casks & No. Pads \\
Reference & 350 & & 2 \\
Delayed reprocessing & 769 & & 4 \\
Delayed disposal & 2112 & & 10
\end{tabular}

The cask is tied down, and initial measurements of temperature and radioactivity levels are made. The rail car is returned to the handling facility for another cask.

\subsubsection{Drywe11s}

An alternative system for storing spent fuel and $H L W$ is in drywells which are described in Section 5.2.2. The primary function of the storage system is to provide shielded, passively cooled, below-ground storage for spent fuel and solidified HLW packages. The storage system consists of the canistered spent fuel or solidified HLW and the drywell storage field.

Spent LWR fuel is stored in canisters sized for either one PWR or three BWR fuel assemblies. Because the fuel cladding is considered the primary containment for the spent fuel, the canister provides an additional barrier as well as a means of handling the fuel assemblies in and out of the drywells. Solidified HLW in the form of borosilicate glass arrives at the facility already in a canister and therefore does not require packaging. The conceptual design for the canister package is shown in Figure 5.27.

The drywell storage field consists of vertical steel encasements with a 305-mm (12-in.) blanket of concrete buried in the ground in a rectangular array. The center-to-center spacing of the drywells is determined by the heat output of the waste package, the maximum allowable waste temperature, and the heat transfer properties of the soil. A conceptual site plan for an open-field drywell storage facility is shown in Figure 5.28. It is sized for solidified HLW packages with a $3-\mathrm{KW}$ heat output, with drywell spacing suitable for dry, low-thermal-conductivity soil. Similar spacing is assumed to be required to maintain spent fuel cladding temperatures at or below $250^{\circ} \mathrm{C}$ $\left(482^{\circ} \mathrm{F}\right.$ ) for 10 -year-old fuel. 


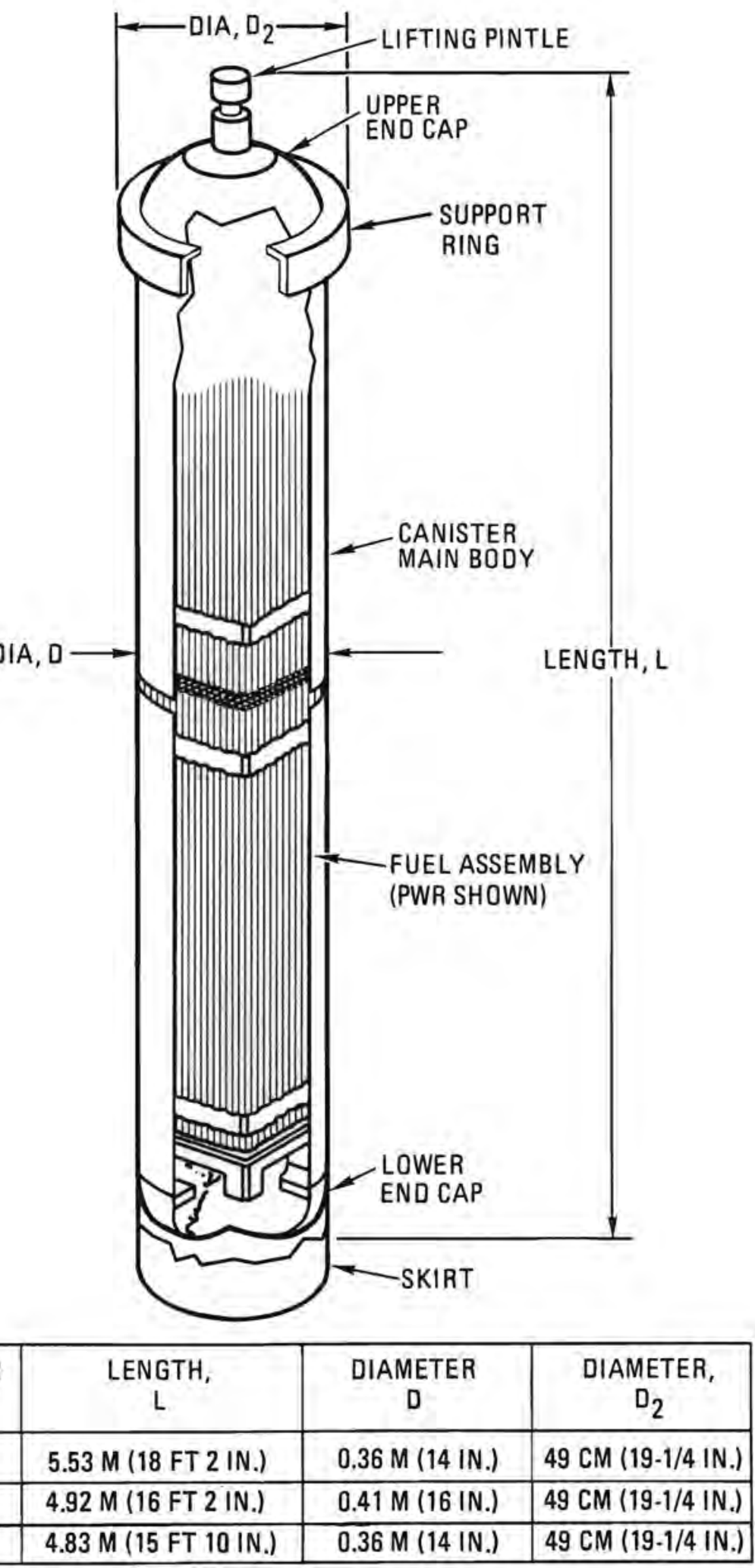

FIGURE 5.27. Spent Fuel Canister for Open-Field Dry Well Storage 


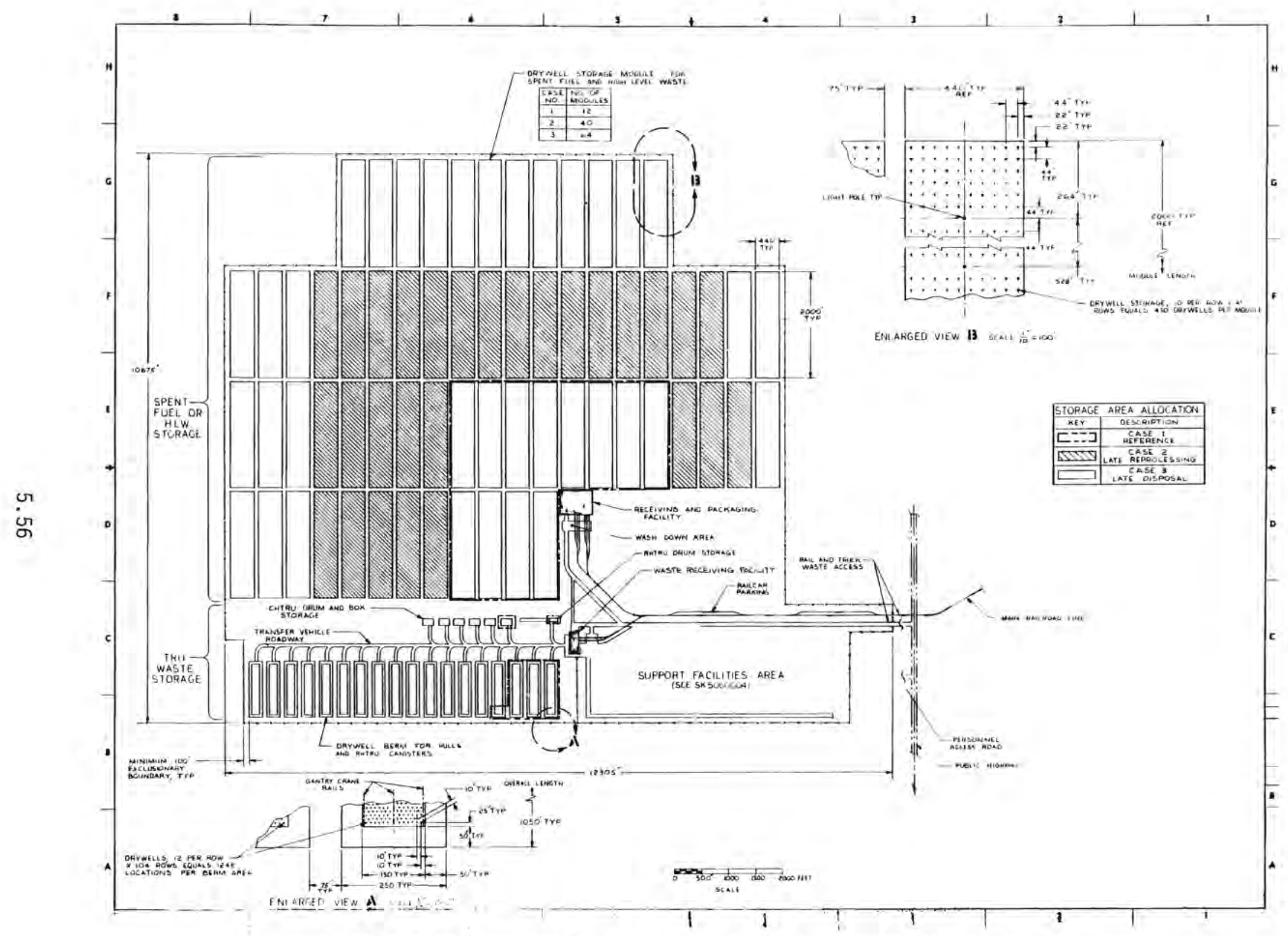

FIGURE 5.28. MRS/IS Stand-Alone Facility Drywell Storage Site Plan 
The waste canisters are transferred to and loaded into the drywells using the transfer system, which consists of a transporter cask attached to a transporter vehicle. The primary functions of the transfer system for the drywell storage concept are to collect waste packages of spent fuel or HLW from the receiving and packaging facility load-out station, transport them to the storage field, position the transfer cask over the drywe11, and place the canisters in the drywell encasement.

The transporter cask contains the waste package while providing continuous cooling and shielding during the transfer operation. The package is shielded by a vertical, cylindrical, bottom-loading cask complete with a hoisting mechanism and a grapple device to permit vertical loading and retrieval of the canister. The cask bottom section, including a cask closure gate and a retractable radiation shield sleeve, interfaces with the drywell for transfer of the package into the drywell. The cask and the shield sleeve will limit the radiation dose rate to no greater than $0.25 \mathrm{mrem} / \mathrm{h}$ at a distance of $6 \mathrm{~m}(20 \mathrm{ft})$ for the entire transfer operation. The bottom of the cask has a sealing device (such as an inflatable seal) to provide complete containment of the package during placement by direct contact with the drywell closure flange. Closed-circuit television cameras and monitors and other viewing devices inside the cask will verify package identity and control package placement and retrieval.

The transporter vehicle transports waste packages from the receiving and packaging building load-out station and places them in drywells at a specified rate per single-shift day. The 150-ton vehicle operates on engineered roadways in the drywell storage areas on large earthmover pneumatic tires at approximately $16 \mathrm{~km} / \mathrm{h}$ (10 miles/h).

Positioning mechanisms adjust the cask vertically, horizontally, and angularly to align with the drywell centerline. A sand placement and removal system deposits and removes sand, which provides vertical shielding. The package and sand shielding material is transported to the storage area. The canister is placed in three steps:

1. Drywell preparation is accomplished by removing the temporary cover and inspecting, cleaning, and removing the closure plate. 
2. Package placement occurs by aligning the transporter cask with the drywell center line and lowering the cask and seal to the drywell. The cask bottom gate is opened and the radiation shield lowered into the drywell. The canister is lowered into the drywell, and sand is discharged into the space above the canister.

3. Placement is completed when the sand fill is completed, the radiation sleeve retracted, the cask bottom gate closed, and the cask raised from the drywell. The top of the drywell is cleaned, and the top closure is placed and welded. Instrument installation is completed, and the sample valve is secured.

The packages may be retrieved anytime during the storage period. Package retrieval is generally the reverse of storage, using the same transporter vehicle.

\subsubsection{Storage Vaults}

Indoor shielded storage of RHTRU waste drums calls for construction of heavily shielded storage vaults. Because of the possibility of high dose rates, the concept requires remote operation for handling and placement of the RHTRU waste. The indoor storage vault is designed for RHTRU packaged in drums. The relatively few RHTRU canisters would be stored in the same facility as the spent fuel residue canister.

The basic storage module for indoor storage of RHTRU waste is a structure which has a capacity of 5000 drums (10 cells, 500 drums per cell). The general arrangement and section views of the storage building expanded to a capacity of 20,000 drums ( 40 cells) are shown in Figure 5.29 .

The module has two main operating areas: 1) the service area, which comprises the cask receiving room, control room, and offices, and 2) the storage area, which comprises a series of adjacent twin cells separated by structural partitions. The storage portion of each cell is $20 \mathrm{ft}$ square and $17 \mathrm{ft}$ high. An additional $12 \mathrm{ft}$ above the cells is needed for crane operation.

The RHTRU drum cask is delivered into the cask receiving room on a low-boy truck or tractor-trailer. Unloading, moving, and stacking of the RHTRU waste drums are accomplished with a remotely operated bridge crane. 

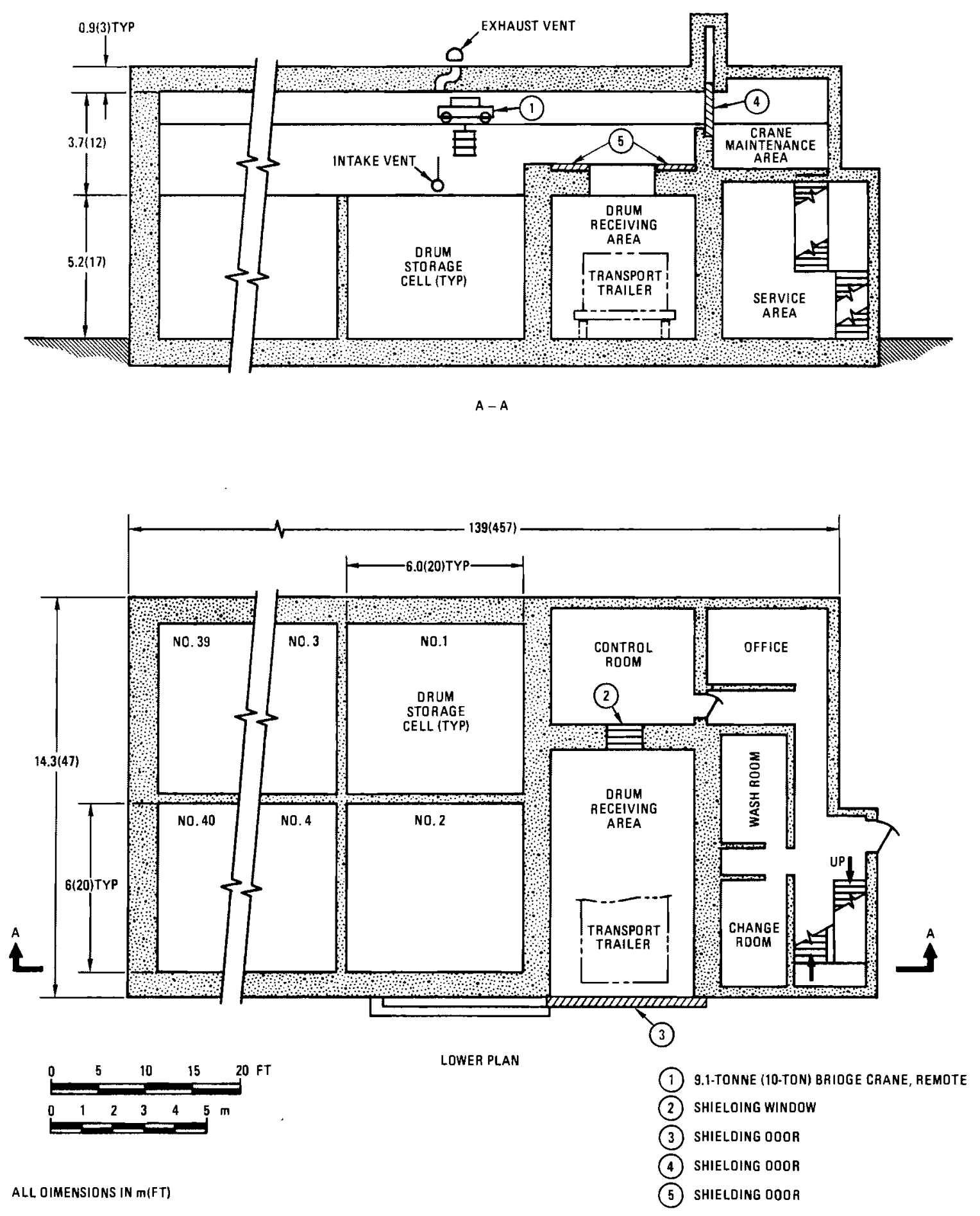

FIGURE 5.29. Indoor Storage Facility for RHTRU Waste 
To permit quick unloading, a drum surge area is provided at the upper level, directly above the control room, so that about 90 drums may accumulate. The 10-ton bridge crane is remotely operated from the control room, which contains television monitors. The crane runs over the entire length of the storage area and transports the drums using a vacuum-operated lifting device. Positioning, viewing, and unloading of drums is aided by two television cameras carried by the crane at bridge level and by spotlights that illuminate the entire work area. When the crane requires maintenance, it can be moved to the crane maintenance area, which is separated from the storage area by a guillotine-type shielding door. Air circulation through the storage area is provided by ventilation openings located in the roof and walls of each cell. Monitoring systems are installed to sample the air within the cells.

Shipping casks containing drums of RHTRU waste drums and arriving by rail are transferred at the TRU waste receiving facility to a site transporter for delivery to the RHTRU storage building. Truck-borne shipping casks are routed directly. The storage facility provides equipment for the remote transfer of the RHTRU waste drums from their shielded shipping casks to their shielded storage cells.

\subsubsection{Storage Berms}

The RHTRU and fuel residue canisters are stored in drywells similar to those described in Section 5.2 .2 or in drywells located in berms as described in Section 5.3.3.2. The choice is dependent on site conditions. Berm storage of the RHTRU and fuel residue canisters is assumed for the stand-alone MRS/IS facility.

The site transfer cask provides continuous shielding of the fuel residue canister during transfer from the TRU waste receiving facility to the storage berm. The transfer cask is transported by a site tractor-trailer combination and comprises a heavily shielded bottom-loading cask equipped with isolation valve and internal hoist and grapple mechanisms.

\subsubsection{Service Facilities}

The MRS/IS support facilities include all buildings, structures, and utility and other systems required to support the spent fuel/HLW and TRU waste 
handling and storage areas. The location of the support facilities is shown in Figures 5.26 and 5.28. A plot plan of the building arrangement within the support facilities area is shown in Figure 5.30. The support facilities area, including vehicular and rail access routes, is placed so as to maintain the operation of the adjoining spent fuel/HLW and TRU waste areas and to maximize site security and safety under emergency situations.

The buildings and structures in the MRS/IS support facilities area are:

- administration, industrial relations, and cafeteria building

- security and gatehouse building

- firehouse, clinic, and emergency vehicle building

- visitor center

- environment and instrument laboratory building

- laundry

- warehouse

- general maintenance building

- locomotive maintenance building

- truck and rail car inspection area

- standby power building and electric substation

- compressor and chiller building

- cooling tower

- steam plant building

- coal thawing and unloading building

- coal storage building.

The design requirements for these buildings, systems, and the projected staffing levels are presented in Sections 2.1.1 through 2.1.16 of Reference 1. The utility and service support systems required for the MRS/IS facility are:

- electric power system, including the primary, standby, and uninterruptible supplies

- water supply system, including yard piping, pumps, and water treatment system

- sewage treatment system 


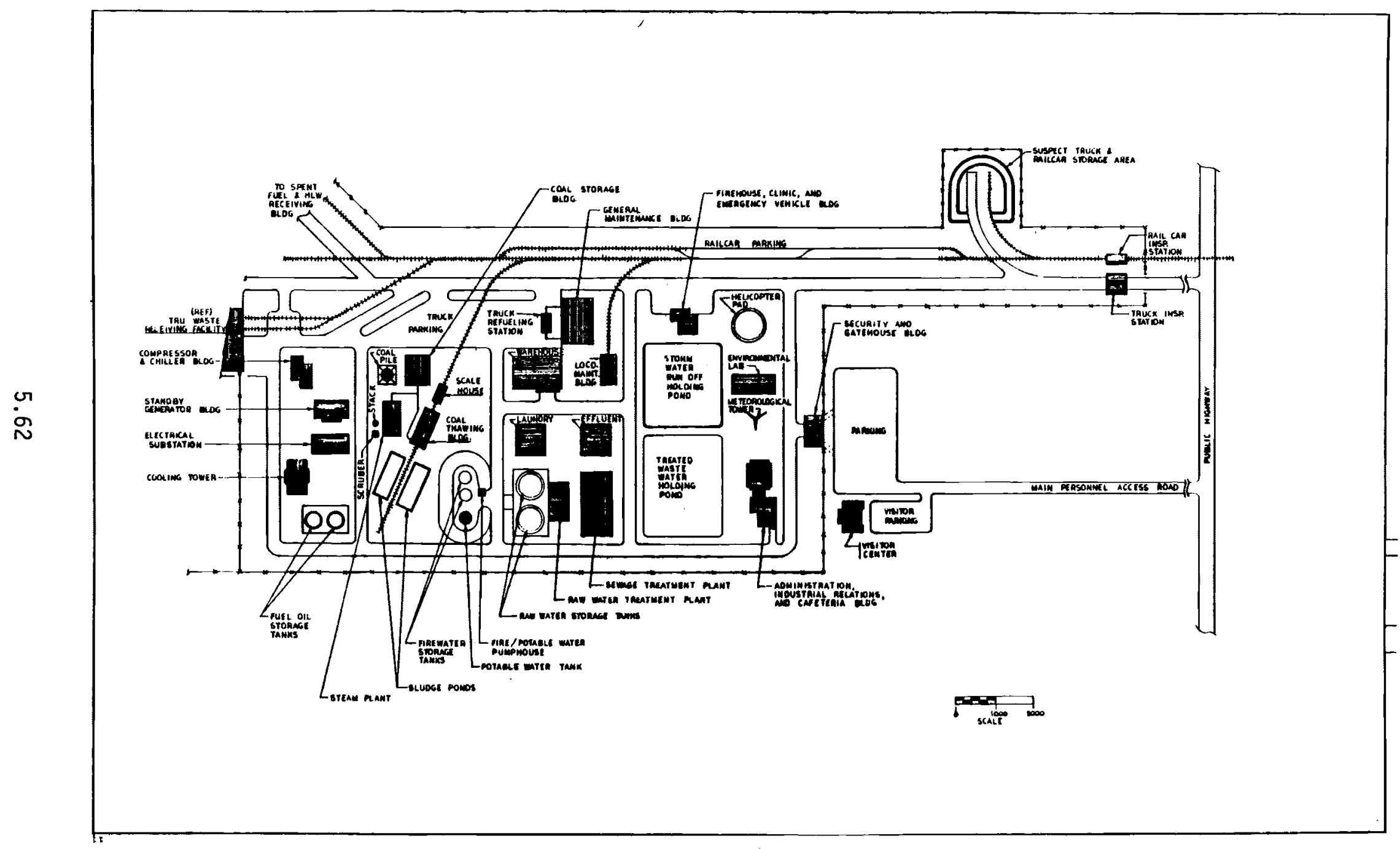

FIGURE 5.30. Support Facilities Area Site Plan 
- compressed air distribution system

- chilled water distribution system

- steam distribution system

- fire water/potable water system.

\subsection{MRS/IS FACILITY CO-LOCATED WITH A REPOSITORY}

The MRS/IS facility described in this section comprises a waste handling facility where the incoming waste shipments are received and the individual fuel assemblies/HLW canisters/TRU containers are examined and decontaminated and/or repackaged as appropriate before transfer to the storage areas. The MRS/IS facility also contains storage areas where the spent fuel assemblies and HLW canisters are stored in either large metal storage casks standing on support pads or in subsurface drywells with the surrounding soil providing shielding. Remote-handled TRU wastes (RHTRU) are stored in concrete casks standing on support pads in the storage areas, and contact-handled TRU wastes (CHTRU) are stored in a surface warehouse. Transfer of the stored wastes from the storage areas to the repository is accomplished after the repository is opened.

\subsubsection{Receiving and Handling Facility}

The waste handling facility (WHF), illustrated in Figure 5.31, is used to receive, examine, and prepare for storage both remote-handled and contacthandled waste. It provides space and systems so the process functions can be accomplished effectively and safely as well as providing the necessary support activities and functions. Its requirements are basically independent of the storage concept used (i.e., surface casks or subsurface drywells). However, requirements and/or size or capacity will vary with the various fuel cycle and transportation scenarios. Also, if the drywell storage concept is adopted, additional provisions and capabilities will be required to overpack all fuel elements on a production basis in the WHF. The building is the sealedconfinement type with ventilation systems adequate to prevent exposure of the public to radiation doses in excess of allowable limits. 


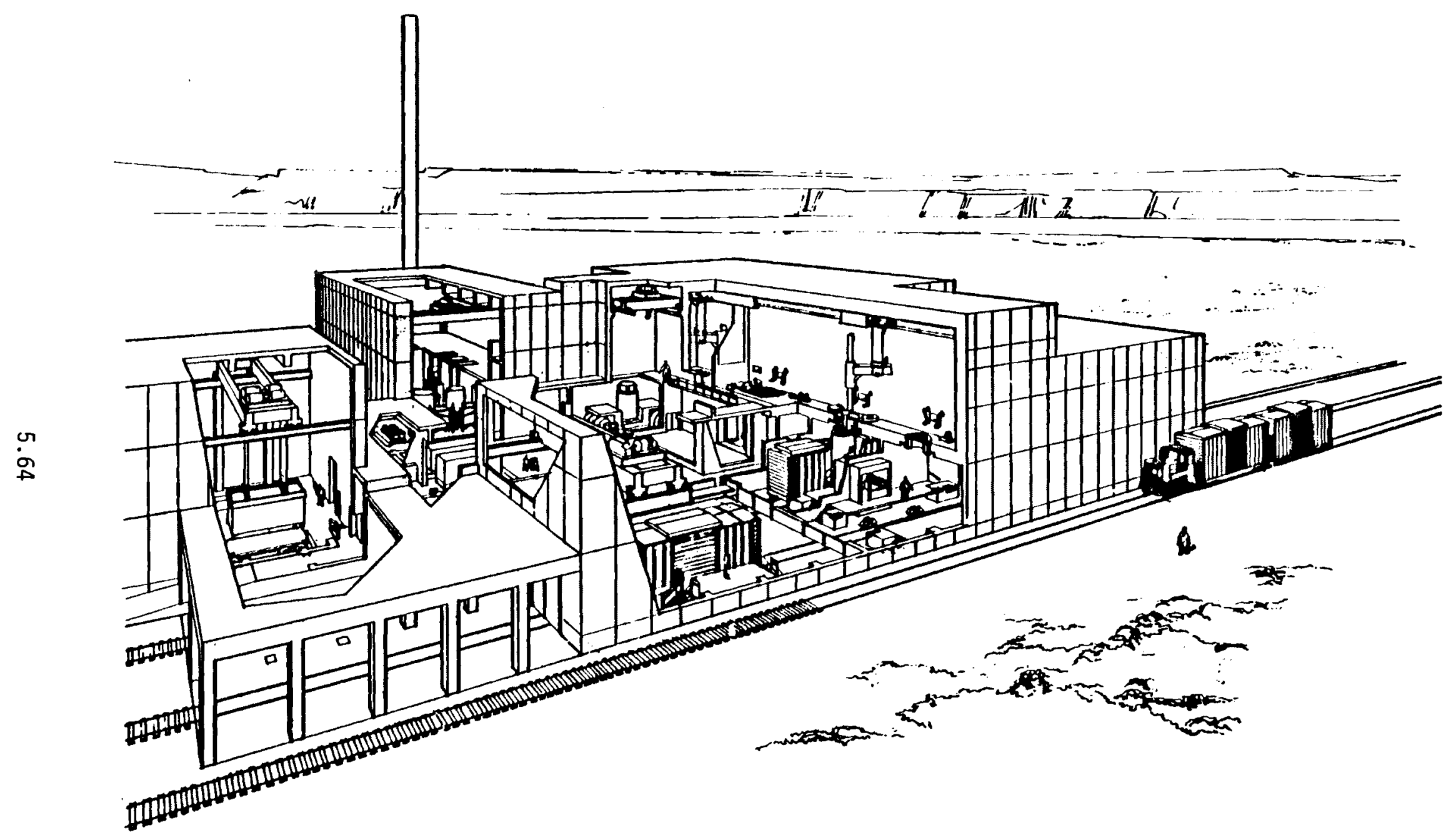

FIGURE 5.31. Waste Handling Facility 
The core of the WHF (Figures $5.32,5.33$ and 5.34 ) is designed for the handling and transfer of waste packages that require remote handling. This is done in a series of hot cells located on an upper level and flanked by operating and service galleries. On the ground floor, beneath this group, the shipping cask unloading area provides a space in which the incoming cask is upended and connected to the shielding sleeve from the primary hot cell, thus providing a confined route for transfer of fuel, canisters or drums from the cask to the primary hot cell. Below the secondary cell is another transfer corridor for loading the casks to be transferred to storage.

The second waste handling area in the facility is for waste packages that can be contact-handled. After preliminary inspection and washdown, the drums or containers are removed from the carriers; inspected for damage, radiation and surface contamination; decontaminated or modified if necessary; and placed on pallets as appropriate for transfer to storage.

The building support areas include radwaste treatment facilities, ventilation and filter rooms, mechanical and electrical rooms, service areas, and administrative areas.

Two separate ventilating systems are furnished in the building: the confinement system for the waste handling areas, and a standard ventilating system for support and administrative areas. The confinement system supplies fresh air to the negative pressure zones of the waste handling areas and exhausts it through a filter system (which includes HEPA filters) to the stack.

The cask receiving and shipping portion of the facility can accommodate at least two rail cars or trucks at any given time. Shipping casks transported either by rail or by truck are inspected, cooled and, they and their contents are transported to the transfer or packaging portion of the facility. This portion of the facility consists of two basic areas: 1) cask carrier preparation and 2) cask and material transfers or unloading. The preparation activities are carried out in enclosed spaces that also serve as air locks for truck and rail car entry into the transfer area. This portion of the facility has the process functions shown in Figure 5.35 . 


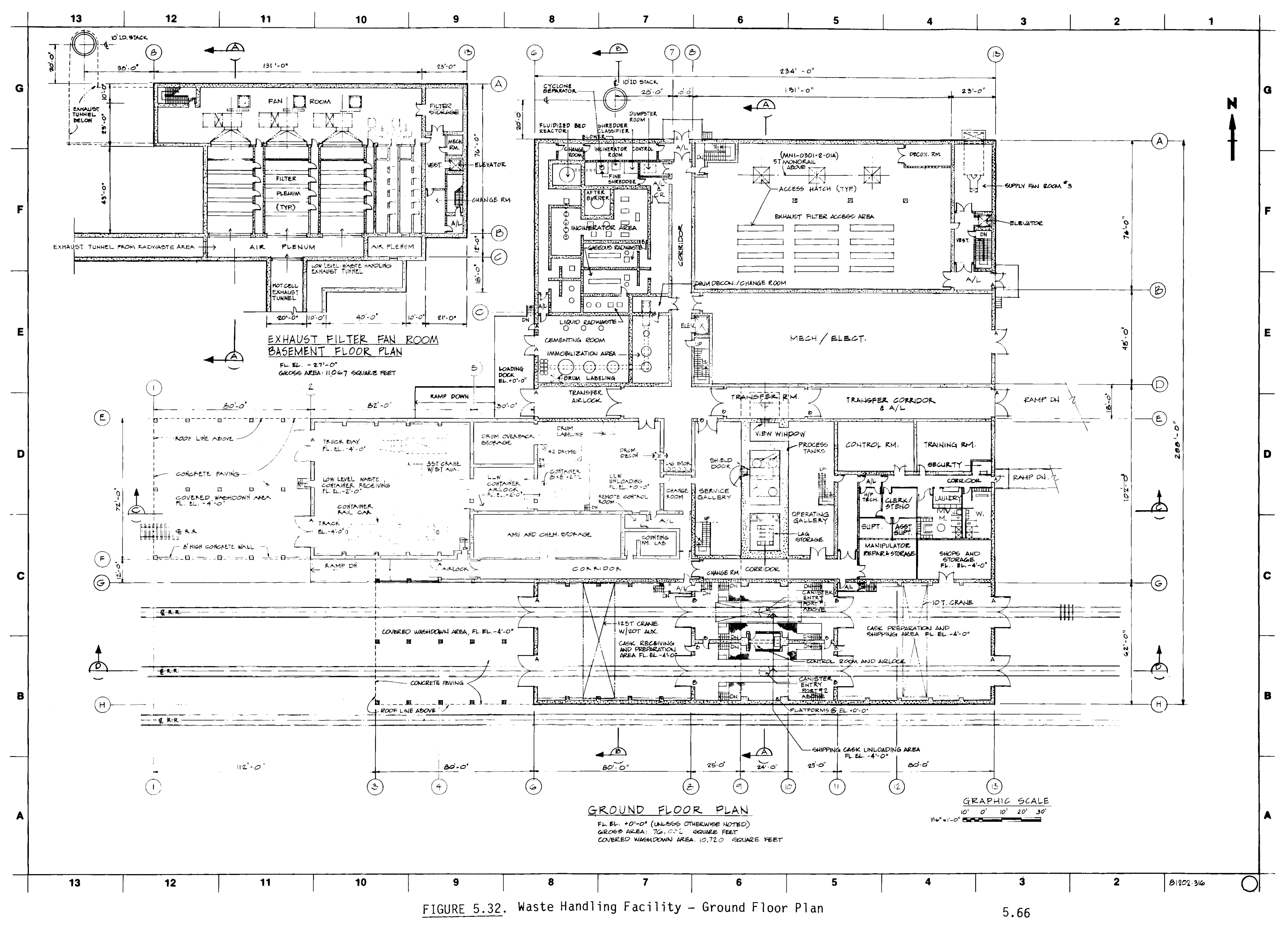




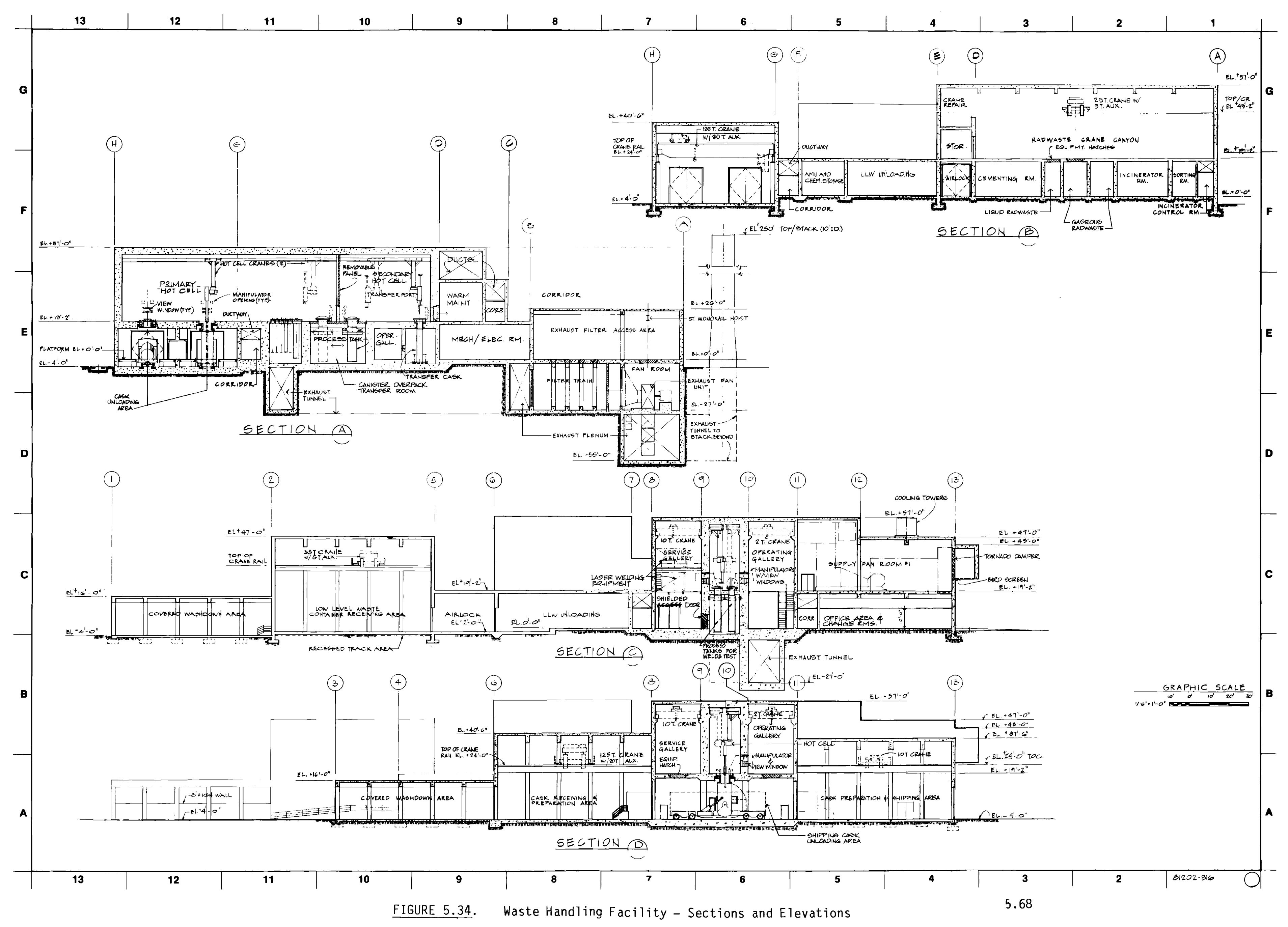




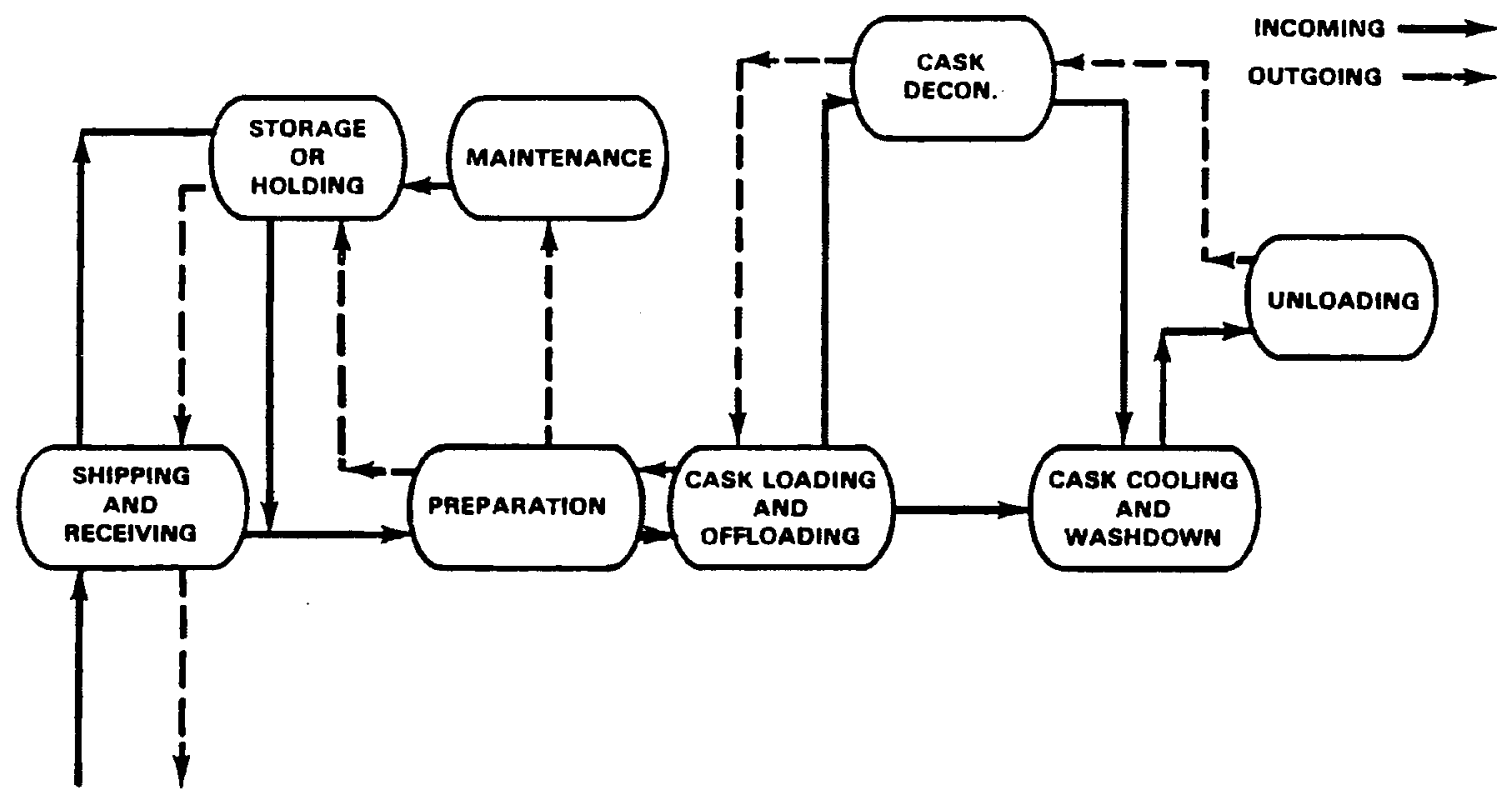

FIGURE 5.35. Cask Receiving and Handling

If the cask is shipped in a horizontal position it is raised to vertical position on the transporter or set in a vertical position on a special car. Then it is moved beneath the primary hot cell and mated with a shielded collar lowered from the cell. After removal of the shielding plugs from the hot cell and the cask, each canister or fuel bundle is raised up into the hot cell. After the fuel bundle or waste canister is checked as necessary, it is stored temporarily in a lag storage location or is placed in one of the process tank areas or cells. These areas have the capability of enclosing fuel bundles or canisters in an overpack, inspecting spent fuel or completed waste packages (both helium-leak and ultrasonically tested for structural soundness), and decontaminating if necessary. Clean canisters and packages are transferred from the primary process cells to the secondary (and clean) hot cell. From there the completed waste package is lowered through shielding collars into a storage cask, which can be sealed and made ready for transfer to storage area.

Remotely operated cranes, manipulators or devices are used to perform the following functions in the transfer and packaging hot cells:

- remove and replace shielding plugs for cell ports

- unlock/lock and remove/replace cask shield plugs 
- extract material packages from shipping cask, move them to and through the hot cells, place them in transfer or storage casks; also the reverse of the above sequence

\subsubsection{Transfer and Storage of Contact-Handled Waste - TRUSS Facility}

The Transuranic Surface Storage (TRUSS) facility, shown in Figure 5.36, is an above-ground, warehouse-type building designed to optimize life cycle costs for CHTRU drum and steel box storage while maintaining safety, security, and storage environment requirements. The facility provides indoor container storage in clean, dry conditions. State-of-the-art handling and storage methods permit efficient operation with forklifts and a minimum of operating personnel. Containers on pallets are transported to the TRUSS facility by forklift, truck or rail. The necessary segregation of TRU waste types is accomplished within the facility by zoning with interior walls and aisles, or by covering arrays of similar containers with fire-retardant covers. The facility is sized to accommodate primarily the drummed and boxed CHTRU waste generated between start-up of the reprocessing plant and start-up of the co-located repository, Table 5.7 .

A precast concrete building is used for the TRUSS facility to meet requirements of containment and protection. A fairly tight building with an inward-directed air flow provides reasonable assurance of meeting this objective. This type structure also provides ample protection from plausible natural events. Floor and loading bay areas are designed to accommodate the handling equipment and containers.

Deliveries to the TRUSS facility are normally made by truck from the WHF and are received in an enclosed loading bay which fully contains the delivery trucks or trailers. The loading docks in these bays match the height of truck or trailer beds to permit forklift unloading and storage operations. Fifty-five-gallon drums are handled by forklifts equipped with drum handling tongs, and stacked in rectangular modules in designated areas in the building. Drums are stacked no more than 5 layers high, but the storage arrays may be any convenient length or width. Forklifts configured with regular tines handle TRU boxes and preassembled 6- or 12-packs of 55-gallon drums. 


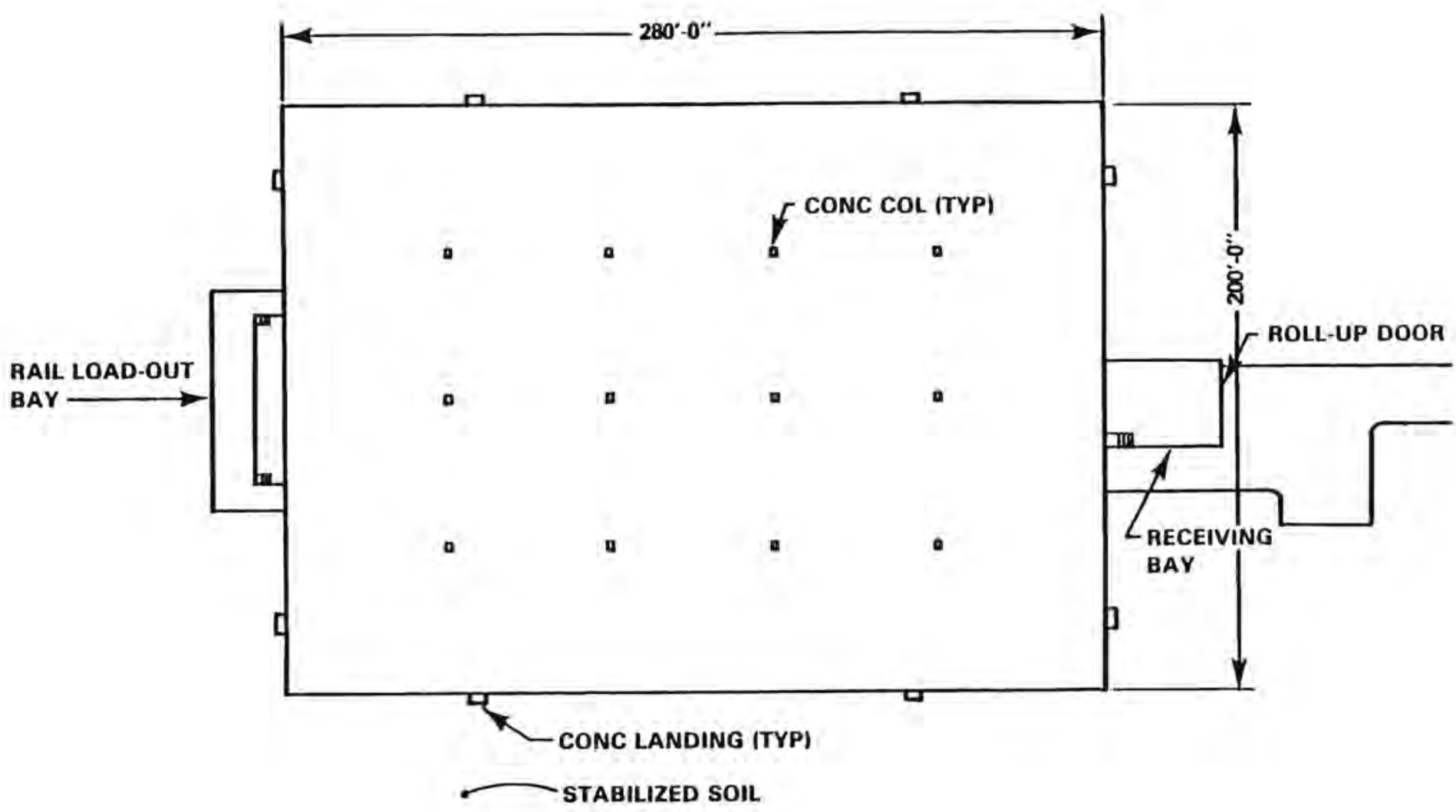

PLAN

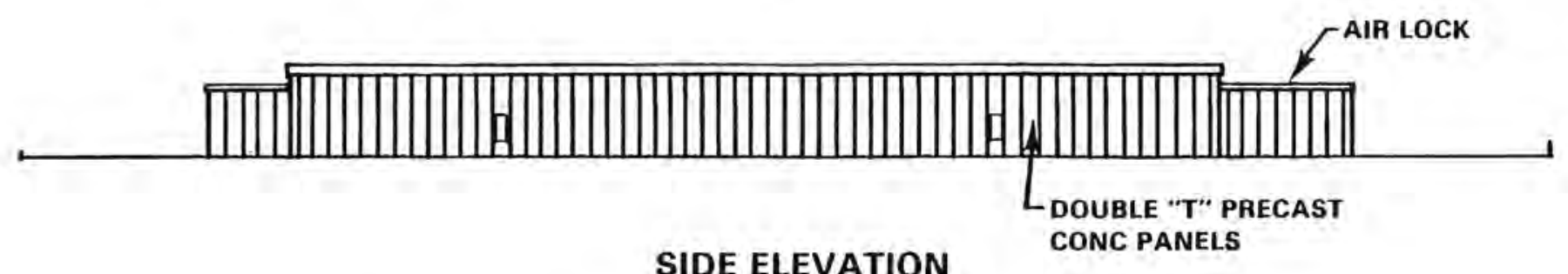

FIGURE 5.36. Transuranic Surface Storage Facility 
TABLE 5.7. MRS/IS Reference Scenario Storage Requirements

\begin{tabular}{|c|c|c|c|c|}
\hline & MTHM & Containers & $\begin{array}{l}\text { Casks } \\
\text { Required }\end{array}$ & Comments \\
\hline$H L W-1 \mathrm{ft}$ dia, $\times 10 \mathrm{ft}$ & 10,500 & 4,900 & 350 & $\begin{array}{l}\text { REA-2023 cask, } 14 \\
\text { canisters per cask }\end{array}$ \\
\hline RHTRU $-2 \mathrm{ft}$ dia. $\times 10 \mathrm{ft}$ & & 3,845 & 1,282 & $\begin{array}{l}\text { Concrete cask, } \\
\text { average } 3 \text { containers } \\
\text { per cask }\end{array}$ \\
\hline RHTRU-55 gal & & 4,486 & 408 & $\begin{array}{l}\text { Concrete cask, } 12 \\
\text { drums per cask }\end{array}$ \\
\hline CHTRU-55 gat ${ }^{(\mathrm{a})}$ & & 34,076 & & \\
\hline CHTRU-4 $\mathrm{ft} \times 6 \mathrm{ft} \times 6 \mathrm{ft}^{(\mathrm{b})}$ & & 286 & & \\
\hline
\end{tabular}

(a) Stacked four high, $-35,000 \mathrm{ft}^{2}$ required.

(b) Stacked two high, $\sim 3,500 \mathrm{ft}^{2}$ required.

The relative humidity inside the TRUSS facility is below critical levels for the vast majority of the storage periods, even without mechanical dehumidification equipment or heating.

Radiation monitoring and alarm systems are provided in the TRUSS building, in the ventilation stack, and exterior to the building, to detect any inadvertent releases.

\subsubsection{Transfer and Storage of Remote-Handled Wastes - Casks}

Two different types of storage casks are used. The REA is the reference cask for fuel and HLW storage. This cask is compatible with loading and unloading procedures which are common to reactor and reprocessing plants. The cask can be handled and stored in either a horizontal or vertical attitude. The cask design permits continuous monitoring of both primary and secondary containment.

For storage of RHTRU, concrete casks, as shown in Figure 5.37, are used. The concrete casks are up to $9 \mathrm{ft}$ in diameter by $16 \mathrm{ft}$ long and weigh up to 90 tons. Different bore sizes and shielding thicknesses are used to accommodate different cask payloads, which varry from one 2-ft diameter by 10-ft long RHTRU canister to twelve 55-gallon drums. 


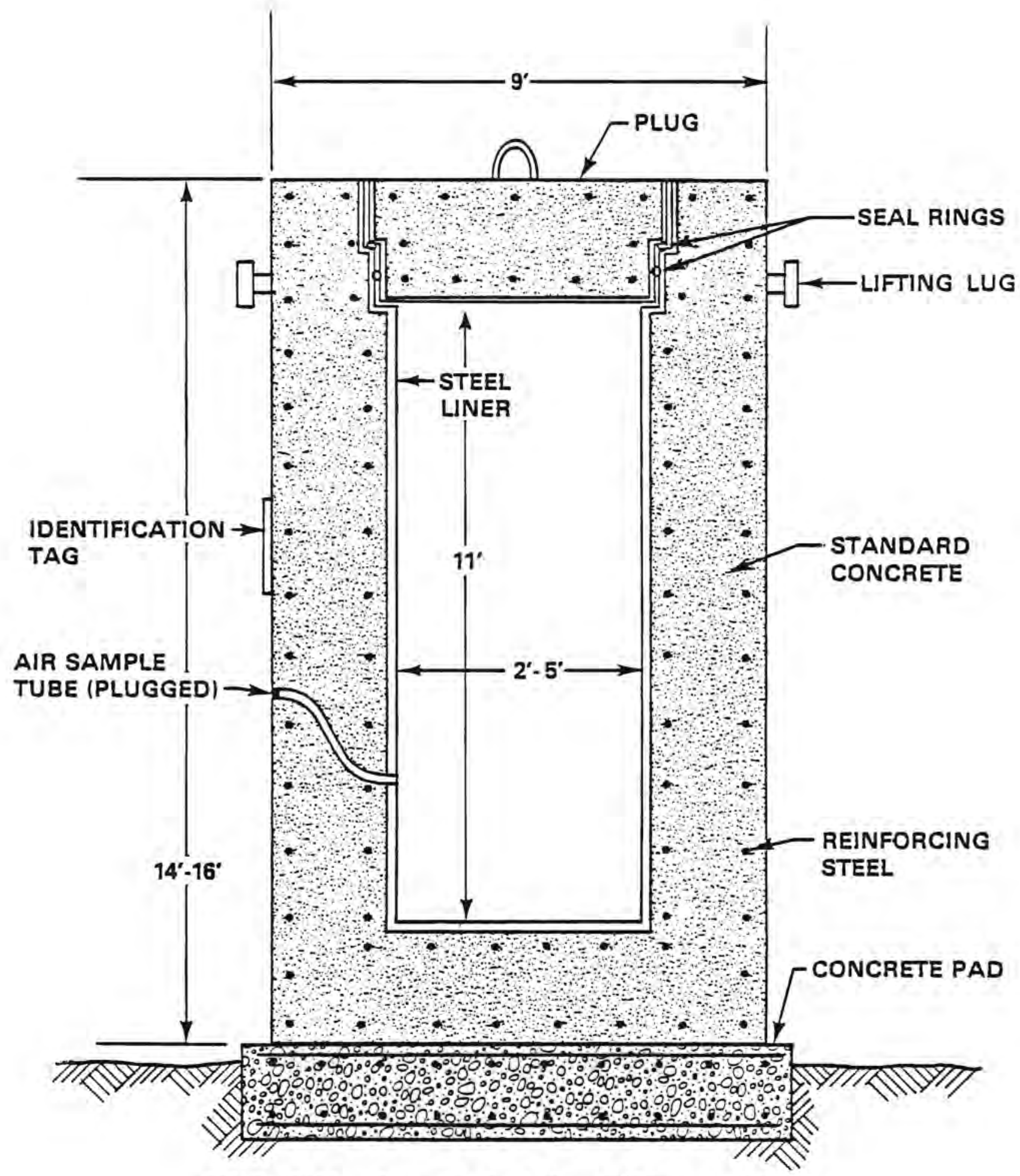

FIGURE 5.37. Concrete Cask for RHTRU Waste Storage 
The same handling, unloading and storage system is used for all casks. This system uses above-ground storage on reinforced concrete pads. A typical storage yard is $200 \mathrm{ft}$ by 1850 feet and accommodates about 1000 casks on a nominal 20-ft spacing.

\subsubsection{Surface Cask Storage}

After a cask storage unit is filled in the WHF, it is loaded onto a pneumatic-tired transport trailer and towed into the cask storage area by a wheel tractor. The storage area is served by a mobile yard gantry crane, which spans two rows of storage units with an aisle between the rows for transport trailer access. This allows the gantry crane to unload a storage unit on either side of the transport trailer, as shown in Figure 5.38. In the storage area, the transport trailer meets the yard gantry crane at the placement site. The gantry crane attaches to the storage unit by means of a cab-controlled power-operated load grab, lifts the cask unit clear of the trailer bed and places the unit in final position on its preconstructed concrete foundation pad. While performing the unloading operation, the gantry crane stands on power-operated stabilizing jacks and operates as a fixed gantry.

The transport and yard gantry crane system can retrieve any storage unit from any position in the storage area by reversing the procedure of the normal delivery. The storage area aisles provide unlimited access to any single storage unit, and retrieval cycle time is comparable to the delivery-placement cycle time.

For the waste casks, the storage area is subdivided into lots of $\sim 1000$

storage units. The array spacing within each lot, to provide $400 \mathrm{ft}^{2}$ for each storage unit in conformance with design limitations for handling operations is as follows (center-to-center of storage units):

- parallel to travel of transport trailer and yard gantry crane spacing alternately $21 \mathrm{ft}$ to $27 \mathrm{ft}$.

- transverse to travel of transport trailer and yard gantry crane spacing nominally $16 \mathrm{ft} 8 \mathrm{in}$.

The above arrangement and spacings are based on the reference 8 to $9 \mathrm{ft}$ diameter casks, but they can be modified to accommodate casks of different 


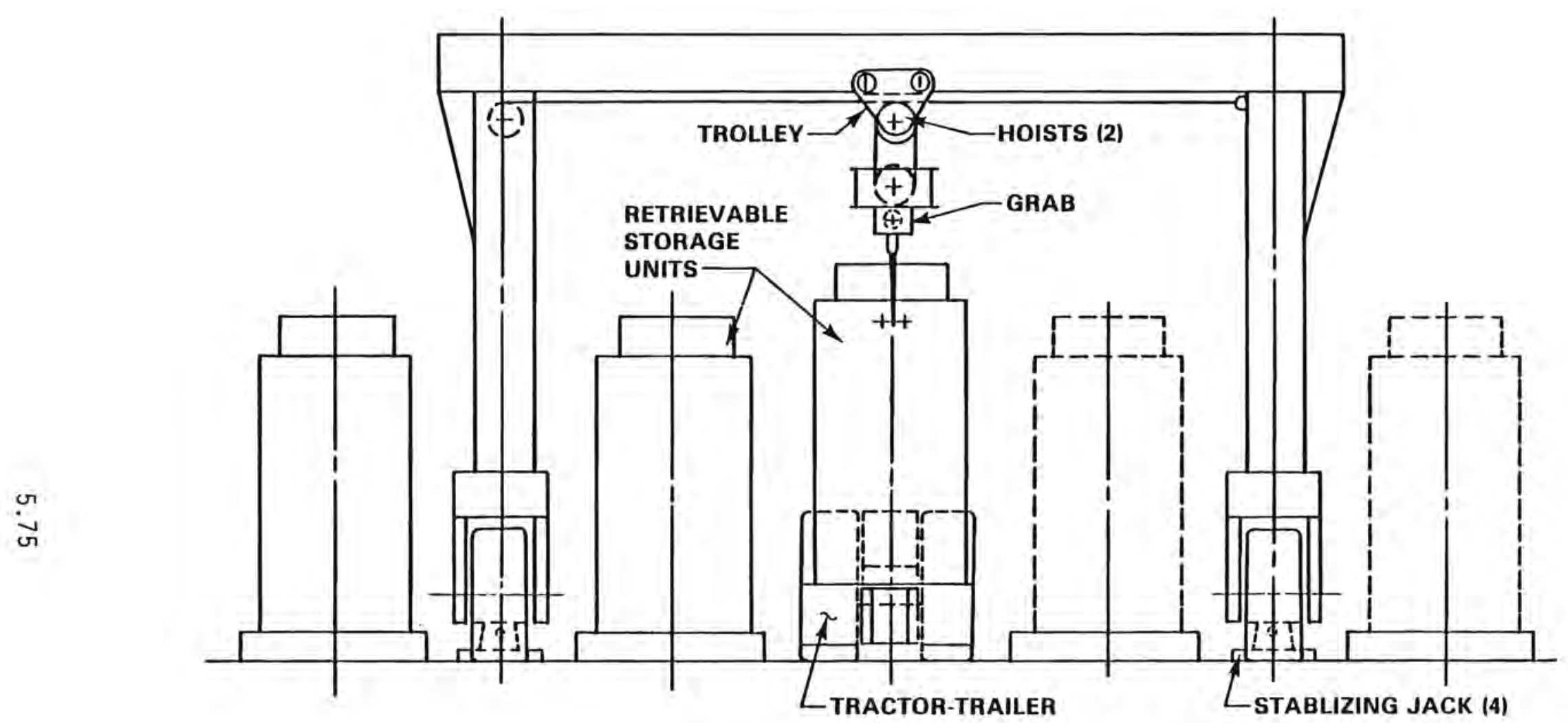

FIGURE 5.38. Yard Gantry Crane 
sizes (within reasonable limits). Different cask sizes would only change the internal array arrangement and not the land usage of the storage system.

The initial storage area fence will enclose an area capable of storing waste through the year 1995. Initial construction wi11 consist of about 100 foundation pads, which is the number required for the first 5 years of facility operation for the reference scenario.

Foundation pads for support of the waste storage units are poured in place. The pads are octagonal, circular or three smaller square reinforced concrete slabs on grade, approximately 18 inches thick. After construction of the initial 100 pads, they will be built in quantities dictated by the placement schedule.

The area between storage pads, and the lightly traveled portions of the wide aisles between lots, are treated with defoliant, graded, and surfaced with 8 inches of crushed rock. This surface is considered adequate for travel by the transport equipment and yard gantry crane equipped with wide base earthmovertype pneumatic tires, and for use by surveillance and maintenance vehicles. The main roadway portions of aisles, where repeated and heavy traffic is expected, and feeder and collector roadways traveled by the transport equipment are 10 inches of compacted aggregate over a prepared and compacted subgrade.

The transport trailer is a 110-ton capacity, low-bed, four-wheel trailer, running on wide base earthmover-type pneumatic tires. The tractor for the transport trailer is a four wheel, pneumatic-tired, diesel-engined unit which has electric power and lighting to allow night operation in the storage area. The mobile yard gantry crane is a self-contained, self-propelled, straddle-type lifting system, with rated lifting capacity of 110 tons when stationary on stabilizing jacks. Initial equipment complement is one tractor, trailer and mobile yard crane.

\subsubsection{Transfer and Storage of Remote-Handled Wastes - Drywe11s}

Below-grade drywells could be used for the interim storage of waste requiring major shielding and isolation. If RHTRU waste packages of a configuration not compatible with drywell dimensional limits are received, they could be stored in concrete casks as previously discussed. 
Dry well passive storage consists of the reference drywell (described in Section 5.2.2) extending about $24 \mathrm{ft}$ into the ground. The ground provides shielding from radiation and permits dry heat dispersion by conduction through the surrounding soil to the atmosphere. The bottom of the pipe is sealed by welding and the top of the drywell is sealed by gasketing or welding. A small sealed tube is provided for periodic sampling of the drywell interior for airborne activity.

After a drywell package, which would typically contain three BWR fuel eTements, one PWR fuel element or one HLW canister, is either prepared or checked out in the WHF, it and sand shielding material are transported to the storage area in a shielded cask transporter vehicle.

The transporter is supported by and travels on 1arge earthmover-type pneumatic tires. The fuel and HLW canisters are shielded by a vertical, cylindrical bottom-loading cask mounted on the transporter. The cask is complete with a hoisting mechanism and a grapple device to permit vertical loading and retrieval of the canister. The transporter is equipped with positioning mechanisms for vertical, horizontal, and angular adjustment of the cask for alignment with the drywell centerline, and is capable of handiing a package with maximum dimensions of about $18 \mathrm{ft} 6$ inches in length and 16 inches in diameter. The heaviest package weight is $\sim 3850$ pounds. The sequence of the canister placement, as illustrated in Figure 5.39 , is accomplished in three major steps: drywe11 preparation, package placement, and drywell closure.

The storage area consists of a rectangular array of the reference drywells buried in the ground, with a uniform 17-ft center-to-center spacing for spent fuel assemblies and a 44-ft spacing for HLW canisters. The initial storage field for fuel contains about 1110 drywells, with primary and secondary road systems for package transport, support equipment, and security vehicles.

The storage area is expandable by modular construction of drywells to ensure a minimum availability of 1 year of storage capacity in advance of ongoing storage operations. It is assumed that the soil will effectively transfer $1 \mathrm{~kW} / \mathrm{hr}$ of thermal decay heat from the spent fuel packages to the 


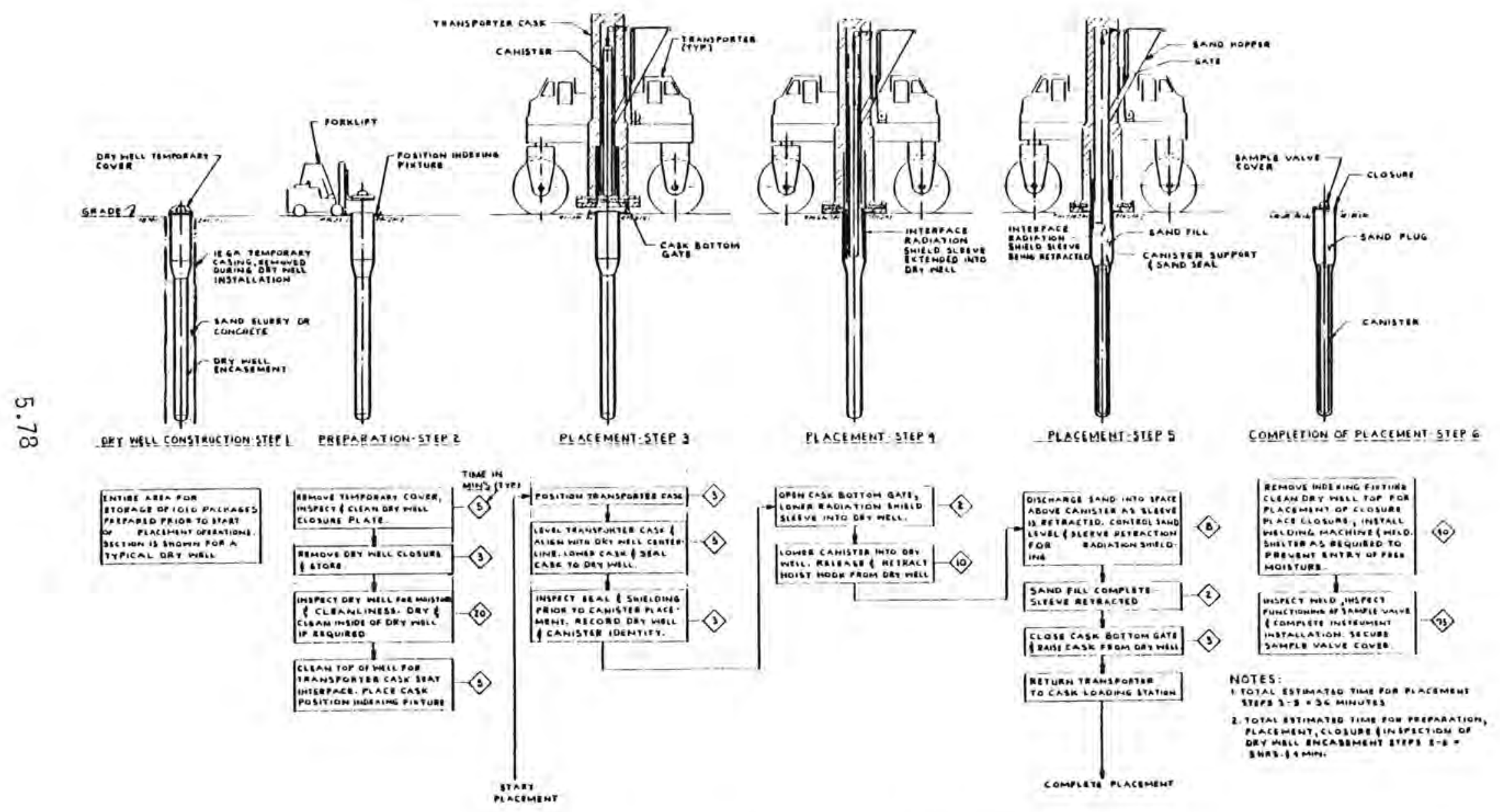

FIGURE 5.39. Drywell Canister Unloading Sequence 
atmosphere on a 17-ft spacing. However, to facilitate the transfer of the $2.3 \mathrm{~kW} / \mathrm{hr}$ decay heat from the HLW packages, an 11- to 12-inch blanket of a more highly conductive material (e.g., concrete) is placed around the drywe11 encasements that are on 44-ft spacings.

\subsubsection{Service Facilities}

In addition to the WHF and the storage areas, other support and servicing buildings and facilities as shown in Figure 5.40 are provided for the efficient and safe operation of the MRS/IS facility, first in its role as interim storage and later as the basic surface facility for the co-located repository. Because of the existence and close proximity to various site services such as fire and emergency vehicles, no site-specific facilities are provided for these. The major facilities provided are:

Administration Building. A one-story bujlding of 6000 to $8000 \mathrm{ft}^{2}$ provides office and storage space for the onsite administration, quality assurance, safety, and engineering personnel. Overal1 administrative functions are conducted in other existing site buildings.

Maintenance Building. A one-story building of about 15,000 $\mathrm{ft}^{2}$ provides the supporting shops and associated shop storage for the MRS/IS operation.

Material Warehouse Building. The material warehouse, a building of varying heights, consists of two functional portions: a high bay building of about $50 \mathrm{ft}$ high and a low bay for administrative and small equipment storage. The total building has an area of about $20,000 \mathrm{ft}^{2}$. The high bay portion of the building has a bridge crane for handling operating supplies and spare equipment for the WHF and other support buildings. Forklift truck access is provided for stacked pallet racks and floor storage areas. Also, areas are provided for outdoor storage of large equipment items.

Gate Houses. There are two, one-story gate house buildings for the area. The first provides a security check area for entering employees and visitors and the second is for rail car and truck shipments. Truck inspection and rail car inspection pits are provided adjacent to the second guard station. 


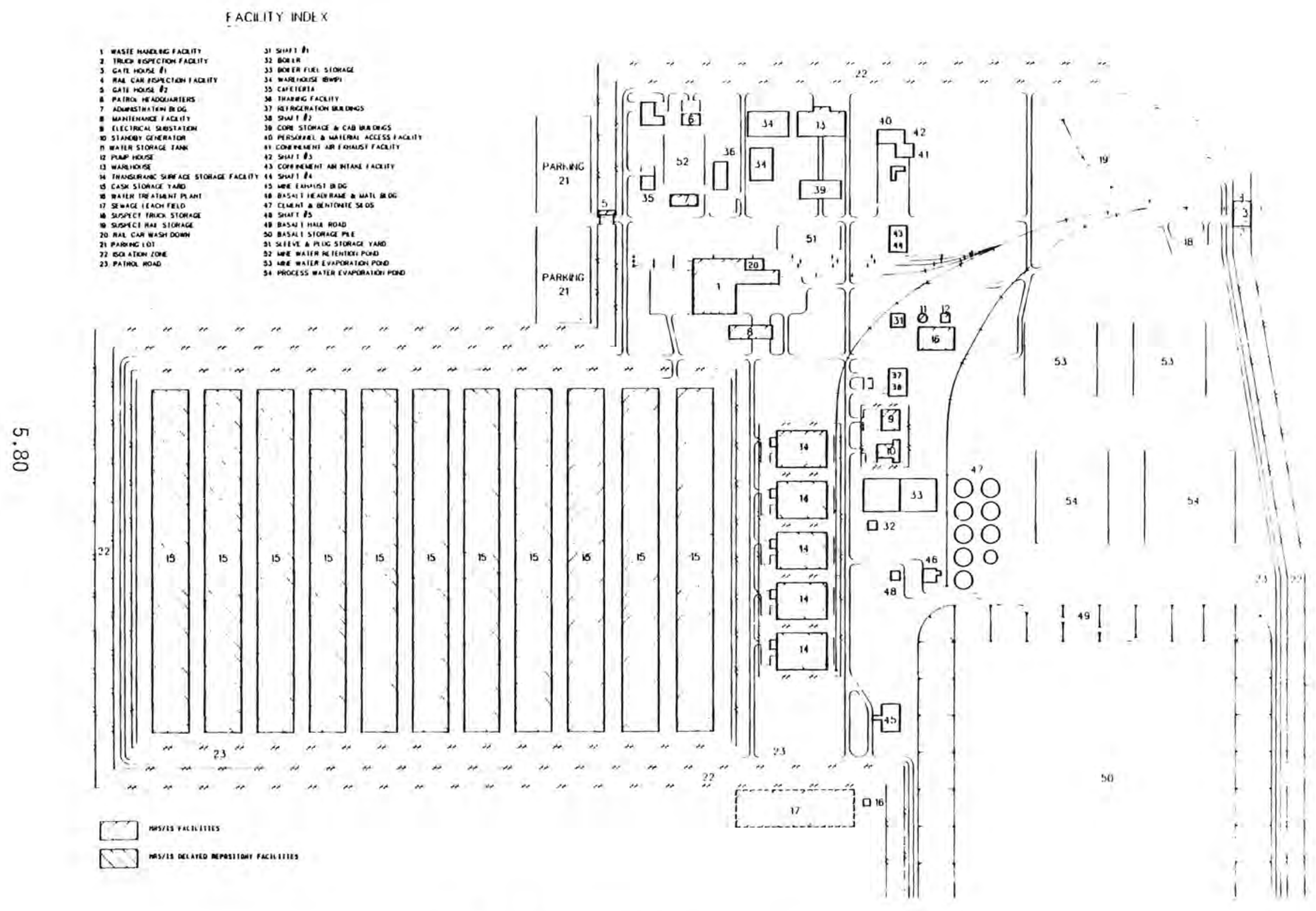

FIGURE 5.40. MRS/IS/Repository Arrangement 


\subsubsection{Service Utilities and Systems}

Water, electrical power, roads and railways to the MRS/IS facility are assumed to be available from sources on the site. Descriptions of these utility systems plus several in-area systems are given below.

Water Supply. Water will be supplied from an existing export line pumping station. This water supply delivers water to the required in-plant systems; these include the raw water system, water treatment, water storage, water distribution and the fire protection system. A water treatment plant is provided for a sanitary water supply. Distribution pumps will maintain a 100 psig normal distribution network for sanitary and process use. The fire protection system will include a 250,000-gallon water tank and two fire pumps discharging into the facility water distribution network supplying fire hydrants, sprinkler systems and fire hoses. One pump will be electric-motordriven and one will be diesel-engine-driven.

Electrical Power Systems. Normal and emergency standby power systems will be provided. Offsite power will be obtained at 115 or $230 \mathrm{kV}$ and will be brought to a new substation that will reduce the voltage to $13.8 \mathrm{kV}$. Dual electrical feed systems to the substation are planned for maximum reliability. From the main substation the power will be distributed to the various building and centers via $13.8 \mathrm{kV}$ direct burial cables.

Emergency standby power will be provided to vital systems by means of a turbine generator set. An essential function of this system is to restore power to those essential loads which must maintain safety functions but can accept short duration interruption in power. Uninterruptable power will be supplied by batteries to those systems that cannot accept short duration interruptions.

Sanitary Waste Disposal System. A sanitary waste disposal system is provided to collect, treat, and dispose of a maximum flow of 10,000 gallons/day of sanitary waste generated at the proposed facility. Sewage collection is through an underground gravity pipe system. The sewer pipe is laid under 4-1/2 feet of earth cover for frost protection. Sewage is treated in a prepacked, extended aeration, biological treatment plant which meets all 
local, state and federal effluent discharge standards. Effluents from the treatment plant are discharged to an offsite subsurface tile drainage field. Wastes from potentially radioactively contaminated sources are not discharged to the sanitary waste disposal system, but are treated within the facility waste treatment system.

Communications and Fire Alarm System. Communication systems for the facility include a PA system, a plant intercom system, and telephone systems for both inside and outside calls. Security communications are handled primarily by the site radio system. Evacuation, radiation alert, and fire alarm systems also are provided.

Radiation Monitoring and Surveillance. Radiation monitoring is conducted both inside and outside the buildings and in the storage yards to assure that radiation levels and airborne particulate levels on or about the facility or area do not exceed preset limits. Monitors located in areas frequented by onsite personnel have local alarm capability. Other monitors and monitoring devices are under continuous surveillance at the environmental console or are periodically checked by health physics personnel.

Area and perimeter monitoring are accomplished with continuous air monitors (CAMs) and ion-chamber-type dosimeters strategically placed around the outside boundary of the site to provide continuous monitoring of the immobilized spent fuel and remote handled wastes. The heaviest concentration of units is located downwind from the facility. The CAMs are of the fixed-filter type and designed to withstand exposure to adverse elements of the environment.

Radiation monitors are placed strategically around the outside boundary of the site. The heaviest concentration of units is located downwind of the prevailing winds. Three types of monitors are used: area gamma monitors, beta-gamma particulate monitors, and thermoluminescent dosimeters.

\section{REFERENCE}

1. GA-1981. Monitored Retrievable Storage Tunnel Rack Concept, Volume 3: Support Facilities, DOE Report GA-A106370, General Atomic Company, August 1981. 


\subsection{STUDY RESULTS}

The results of the studies made on conceptual MRS/IS facilities that are located at each of three sites and that handle the quantities of radioactive waste identified in the three principal fuel cycle scenarios are presented in this section. The life-cycle cost for each of the three concepts and the advantages and disadvantages of each concept are summarized in Section 6.1. A number of more generic topics are discussed in Section 6.2; including licensing and safety, environment, transportation, and socioeconomic considerations, relations to other facilities, advantages/disadvantages of utilizing an existing federal site, and the technical status of postulated system components and projected research and development needs.

\subsection{COMPARISON OF THE THREE MRS/IS FACILITY CONCEPTS}

The construction and operating schedules for the MRS/IS facilities, a summary of the cost assumptions used in the study, and a comparison of the total system costs, and cash flows for the three types of facilities considered in this study are presented in this section. Also presented are discussions of the advantages and disadvantages of each concept.

\subsubsection{Construction and Operating Schedules}

Construction schedules for the three MRS/IS facilities are shown in Figure 6.1. The schedules for the stand-alone version and the version co-located with a repository are similar-the total time from receipt of funding authorization to start-up is 6 and $51 / 2$ years, respectively. In the case of an MRS/IS facility co-located with a reprocessing plant the total time span is considerably shorter (about $31 / 2$ years). It has been assumed that the first reprocessing plant will be licensed to start operation in 1989 and that the MRS/IS facility will share much of the handling equipment with the reprocessing plant.

The construction schedules given above indicate that an MRS/IS could be operational about 1988-1990. However, these construction schedules, developed by the study contractors, do not include the additional time needed for such things as: 1) selection and qualification of a site, 2) the conceptual design 


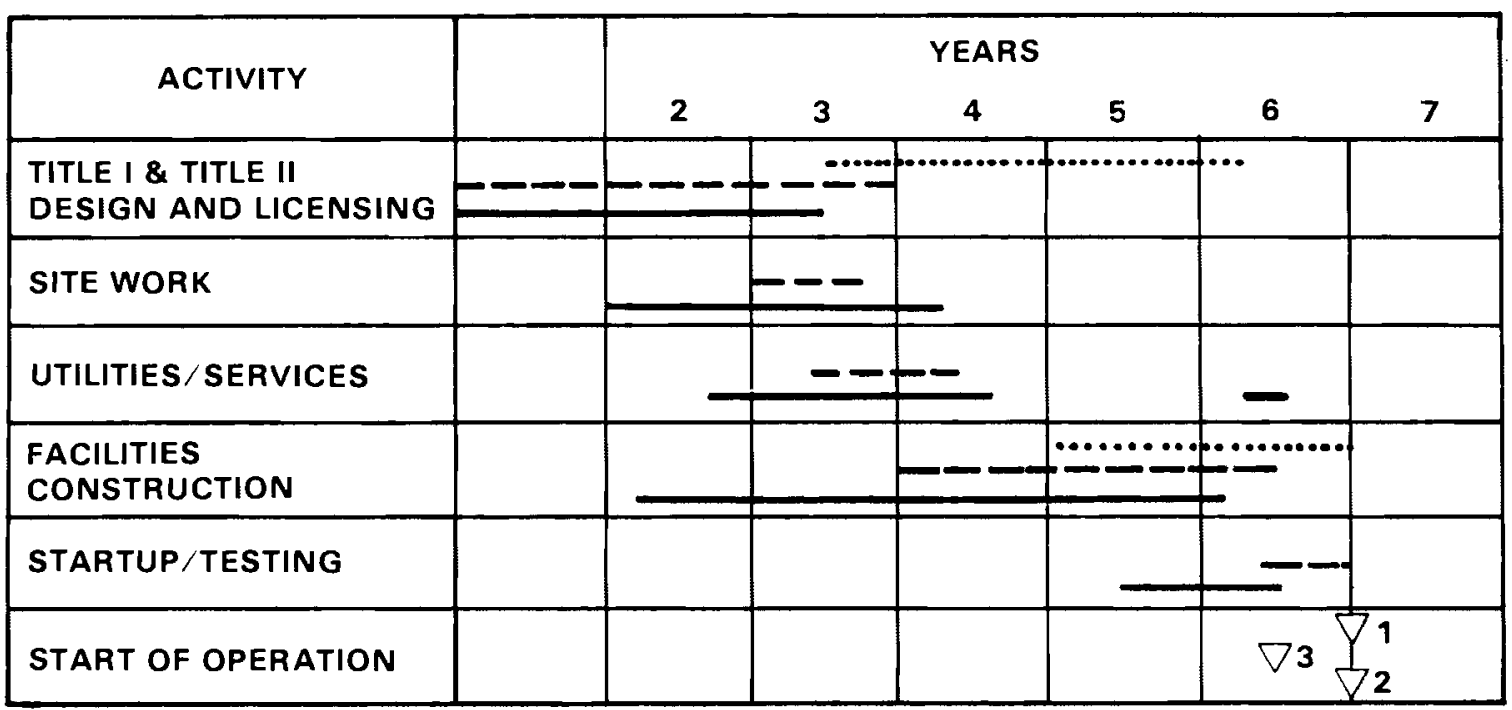

......... 1 SITE CO-LOCATED AT REPROCESSING PLANT

- - 2 STAND-ALONE SITE

3 SITE CO-LOCATED AT REPOSITORY

FIGURE 6.1. MRS/IS Facilities Construction Schedule Comparisons

for concept selection, 3) Congressional funding authorization, and

4) qualification and selection of an architect engineer for the detailed design. Inclusion of these factors will add approximately 5 years to the schedule, resulting in an earlier startup date for an MRS/IS of 1994 or 1995. Since these factors could vary with the site, they were eliminated from the study and a startup date of 1990 selected for all versions of the MRS/IS facility.

Figures $6.2,6.3$, and 6.4 contain the life cycles (timeline schedules for construction, operation, and decommissioning) of MRS/IS facility concepts for this reference scenario, the delayed reprocessing scenario, and the delayed disposal scenario, respectively. The inventories of spent fuel and HLW requiring storage in an MRS/IS facility are illustrated in Figure 6.5 as a function of time, for each of the three scenarios.

The MRS/IS facility co-located at a reprocessing plant shares much of its handling and support equipment with the reprocessing plant. Thus its capital costs are mainly those of storage equipment, and its construction period is appreciably shorter than for the other concepts. Similarly, the cost and time for decommissioning are shorter than for the stand-alone concept. 


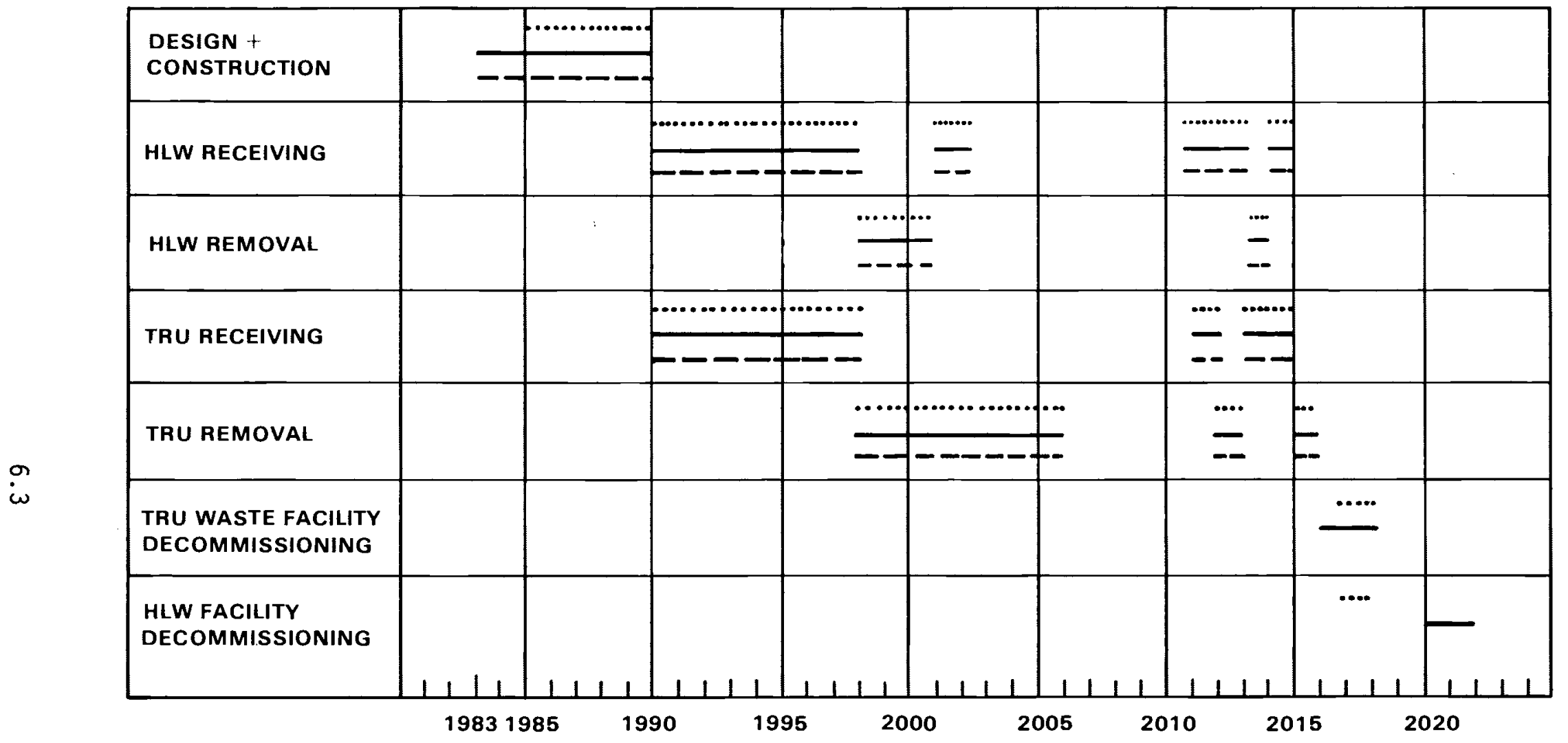

........... SITE CO-LOCATED AT REPROCESSING PLANT

STAND-ALONE SITE

- - SITE CO-LOCATED AT REPOSITORY

FIGURE 6.2. MRS/IS Life Cycles for Reference Scenario 


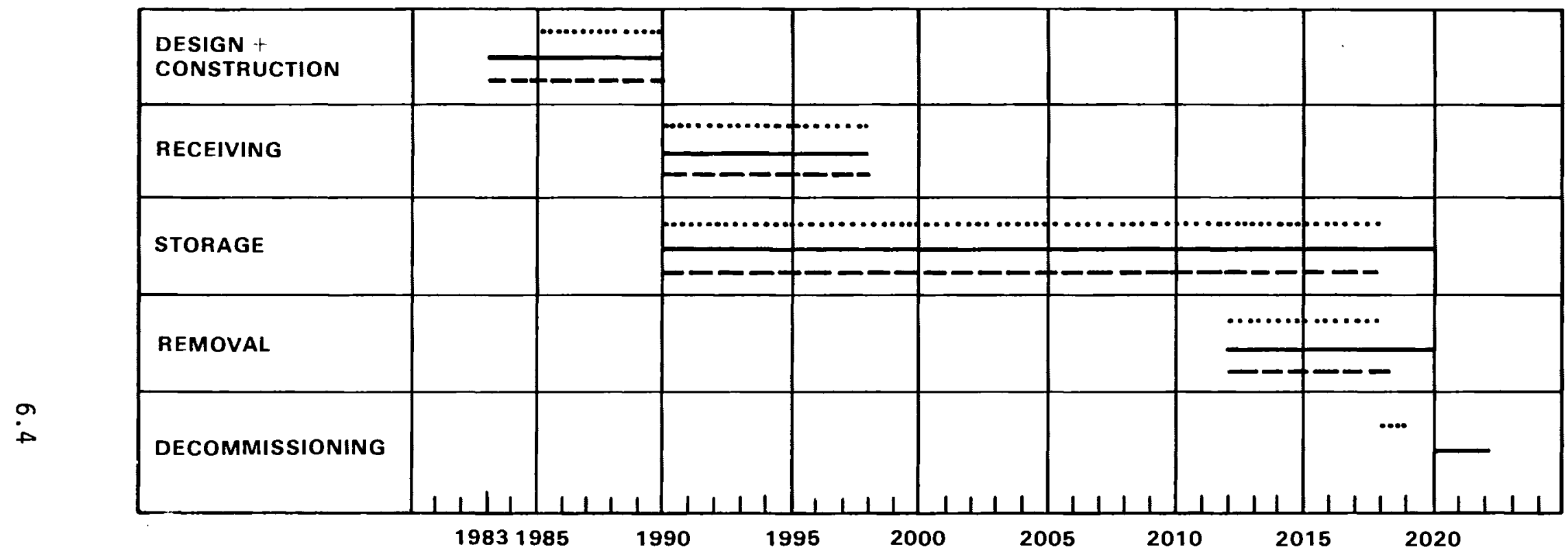

......... SITE CO-LOCATED AT REPROCESSING PLANT

$\longrightarrow$ STAND-ALONE SITE

- - SITE CO-LOCATED AT REPOSITORY

FIGURE 6.3. MRS/IS Life Cycles for Delayed Reprocessing Scenario 


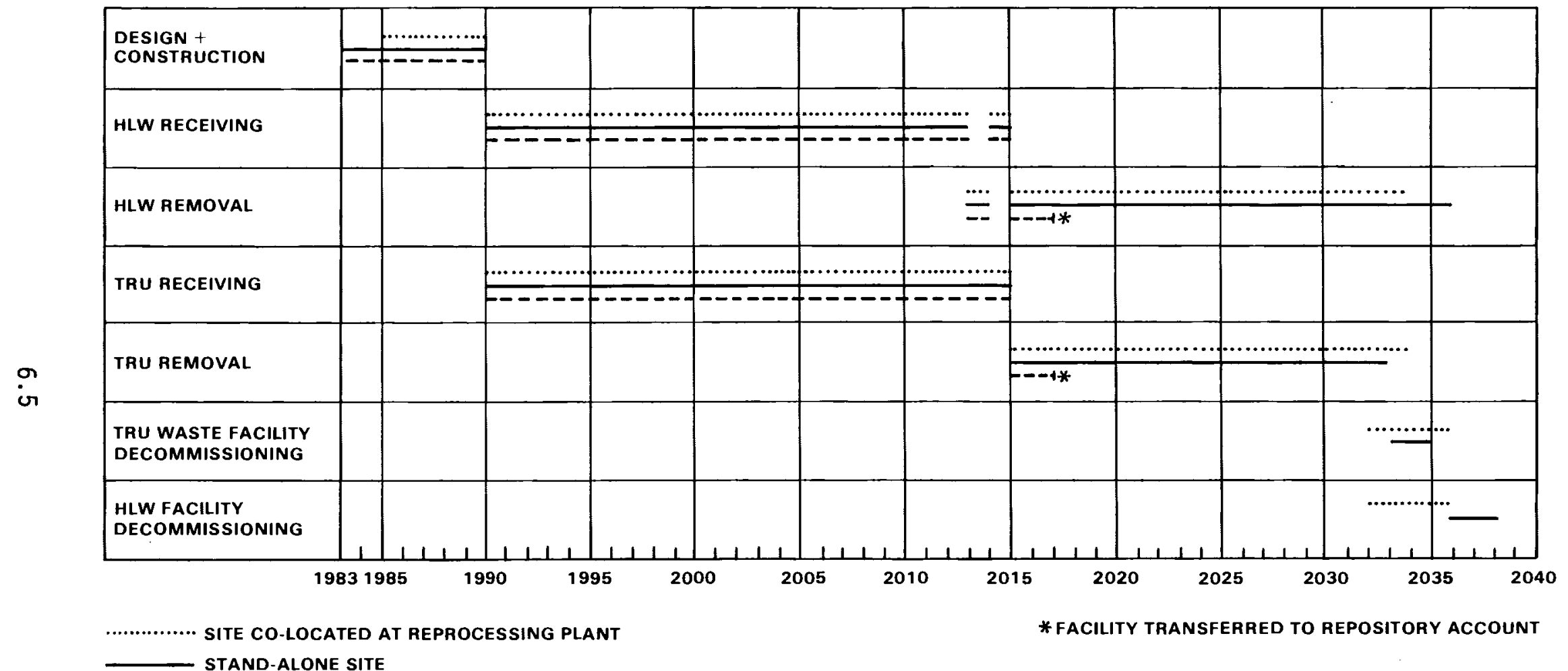

\section{STAND-ALONE SITE}

- - - SITE CO-LOCATED AT REPOSITORY

FIGURE 6.4. MRS/IS Life Cycles for Delayed Disposal Scenario 


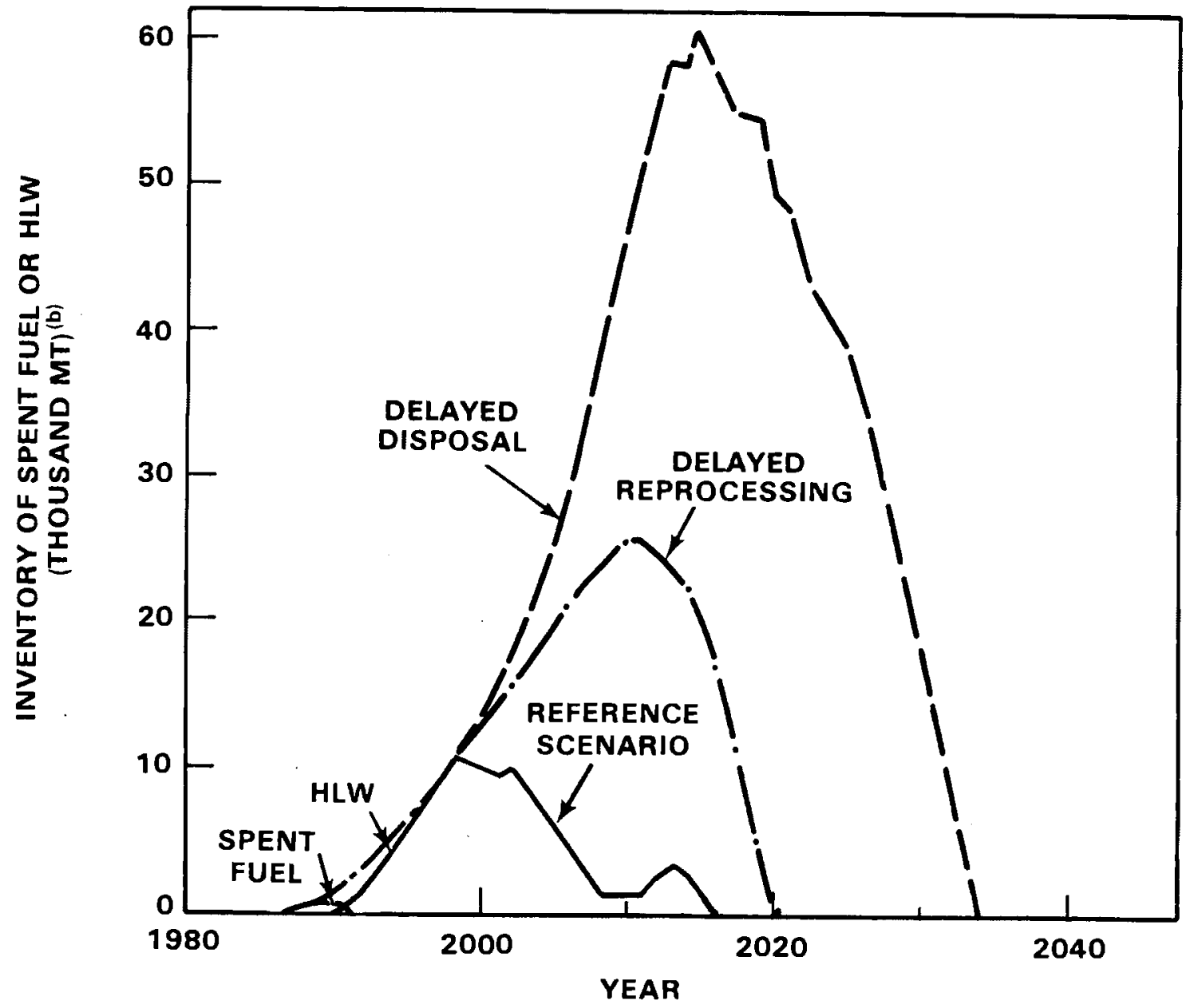

FIGURE 6.5. Inventories of Spent Fuel and HLW Requiring Storage ${ }^{(a)}$

(a) These scenarios represent maximum capacities and do not include any moderating effects of extended burnup operation, rod consolidation, or private AFRs.

(b) To convert from MTHM to fuel assemblies or HLW canisters, divide the MTHM values by 0.18 MTHM/BWR, 0.42 MTHM//PWR, 2.143 MTHM/canister.

The stand-alone facility has no opportunity for sharing of facilities; hence the capital and operating costs tend to be higher, and both the construction and decommissioning periods are longer than for the two co-located concepts. To compensate for the tendency to higher costs, a somewhat lower fuel/waste handling capacity is assumed for the stand-alone 
facility than for the other concepts. The lower handling capacity does not affect the rate of loading wastes and spent fuel into the storage facility, but does result in some "stretch out" of the unloading period, with consequent lengthening of the effective life of the facility.

The MRS/IS facility co-located with a repository is constructed as a complete, independent fuel/waste handling and storage facility. However, the handling equipment is designed to be compatible with use as the surface handling facility for the repository, and the MRS/IS support facilities are shared with the repository after the repository is opened. Thus, when the effective life of the storage facility is over, the handling equipment is transferred to the repository account and is not subject to decommissioning until the repository is closed. The storage facilities may either be continued in service as "lag storage" for the repository, or decommissioned with salvage value of the casks compensating for decommissioning costs.

The life cycles for the three MRS/IS facility concepts have been developed from the data in Appendix B.1. Because of the "rules" used in the computer program that generated the MRS/IS mass flow rates some small anomalies appear in the operating schedules. For example, in the reference scenario the MRS/IS plant is, as a general rule, being emptied in the years 2013 through 2020. However, as shown in Figure 6.2, the MRS/IS facility has a net receipt of HLW in the year 2014 followed in 2015 by more removal of HLW from storage. It is expected that arrangements would be made to continue unloading the storage facility once it has begun so as to minimize transfers of material between the MRS/IS facility, the reprocessing plant, and the repository.

It must also be noted that since the facilities commence operation in 1990, no spent fuel enters the MRS/IS facility in the reference or delayed disposal scenarios. In the delayed reprocessing scenario, the peak MRS/IS spent fuel inventory shown in Table B.5 (Appendix B) is reduced to 7547 MTHM. It is assumed that spent fuel would be stored at reactor sites (in metal casks, for example) or at an emergency storage site during the period 1985 through 1989. 


\subsubsection{Total System Costs}

A comparison of the total system costs for three MRS/IS facility concepts considered in this study is presented in Table 6.1. The costs for both cask and dry-well versions of the facilities are included and the costs are separated into capital costs, operating costs and incremental transportation costs (see Section 6.2.3 for a discussion of transportation costs).

The capital costs which include the costs of all structures and the storage system (casks or drywells and their associated equipment) is highest for the stand-alone facility. This is due to the fact that both co-located facilities share handling and support facilities with the reprocessing plant or repository. The facility co-located with a reprocessing plant, in particular, shares existing facilities with the Barnwell reprocessing plant, and it is assumed that the same cost division could be used for future reprocessing plants with MRS/IS facilities. The differences between the stand-alone and repository-co-located concepts are smaller (about 25 percent), apparently due to differences in the level of support facilities, the fact that 7-day/24-hour operation is assumed for the repository concept versus 5-day/ 24-hour operation for the stand-alone version, and in the base cost estimates for the handling and receiving building. In the repository-co-located concept it is assumed that the entire handling facility is constructed prior to startup of the MRS/IS facility and would be large enough to satisfy both the storage facility and repository handling rate requirements. After the storage facility ceases operation the handling facility is devoted exclusively to repository handling.

In all concepts, the facilities with drywells have lower capital costs than those with casks. This is due to the difference in cost between casks and drywells and can be seen in Table 6.1.

In general, the capital costs for the delayed disposal scenario are larger than those for the delayed reprocessing scenario which in turn are larger than those for the reference scenario. The exception is the drywe 11 MRS/IS facility co-located with the reprocessing plant. The increased costs are due to both the increasing size of the storage facilities required for the 
TABLE 6.1. Total System Costs for MRS/IS Facilities

(millions of mid-82 dollars)

\begin{tabular}{|c|c|c|c|c|c|c|c|}
\hline Scenario & $\begin{array}{l}\text { MRS/IS } \\
\text { Concept }\end{array}$ & $\begin{array}{r}\text { Cap } \\
\text { Facility }\end{array}$ & $\frac{\text { tal }}{\text { Storage }}$ & Operating & $\begin{array}{c}\text { Incremental } \\
\text { Transportation }\end{array}$ & $\begin{array}{r}\text { Total } \\
\text { System } \\
\text { Costs } \\
\end{array}$ & $\begin{array}{c}\text { Discounted } \\
\text { Total } \\
\end{array}$ \\
\hline \multirow[t]{3}{*}{ Reference } & $\begin{array}{l}\text { Co-located Reprocessing } \\
\text { Cask } \\
\text { Drywell }\end{array}$ & $\begin{array}{r}6 \\
11\end{array}$ & $\begin{array}{l}320 \\
184\end{array}$ & $\begin{array}{l}53 \\
82\end{array}$ & - & $\begin{array}{l}379 \\
277\end{array}$ & $\begin{array}{l}300 \\
213\end{array}$ \\
\hline & $\begin{array}{l}\text { Stand-Alone } \\
\text { Cask } \\
\text { Drywell }\end{array}$ & $\begin{array}{l}318 \\
322\end{array}$ & $\begin{array}{l}396 \\
140\end{array}$ & $\begin{array}{l}466 \\
502\end{array}$ & $\begin{array}{l}160 \\
160\end{array}$ & $\begin{array}{l}1340 \\
1124\end{array}$ & $\begin{array}{r}1026 \\
846\end{array}$ \\
\hline & $\begin{array}{l}\text { Co-located Repository } \\
\text { Cask } \\
\text { Drywell }\end{array}$ & $\begin{array}{l}178 \\
180\end{array}$ & $\begin{array}{l}353 \\
138\end{array}$ & $\begin{array}{l}200 \\
200\end{array}$ & - & $\begin{array}{l}731 \\
518\end{array}$ & $\begin{array}{l}578 \\
412\end{array}$ \\
\hline \multirow[t]{3}{*}{$\begin{array}{l}\text { Delayed } \\
\text { Reprocessing }\end{array}$} & $\begin{array}{l}\text { Co-located Reprocessing } \\
\text { Cask } \\
\text { Drywell }\end{array}$ & $\begin{array}{l}3 \\
7\end{array}$ & $\begin{array}{l}783 \\
137\end{array}$ & $\begin{array}{r}53 \\
196\end{array}$ & $\begin{array}{l}-- \\
--\end{array}$ & $\begin{array}{l}839 \\
340\end{array}$ & $\begin{array}{l}654 \\
257\end{array}$ \\
\hline & $\begin{array}{l}\text { Stand-Alone } \\
\text { Cask } \\
\text { Drywell }\end{array}$ & $\begin{array}{l}460 \\
527\end{array}$ & $\begin{array}{l}650 \\
198\end{array}$ & $\begin{array}{l}417 \\
593\end{array}$ & $\begin{array}{l}195 \\
195\end{array}$ & $\begin{array}{l}1722 \\
1513\end{array}$ & $\begin{array}{l}1335 \\
1151\end{array}$ \\
\hline & $\begin{array}{l}\text { Co-located Repository } \\
\text { Cask } \\
\text { Drywell }\end{array}$ & $\begin{array}{l}176 \\
176\end{array}$ & $\begin{array}{l}676 \\
302\end{array}$ & $\begin{array}{l}212 \\
302\end{array}$ & $\begin{array}{l}1193 \\
1193\end{array}$ & $\begin{array}{l}2257 \\
1973\end{array}$ & $\begin{array}{l}1592 \\
1376\end{array}$ \\
\hline \multirow[t]{3}{*}{$\begin{array}{l}\text { Delayed } \\
\text { Disposal }\end{array}$} & $\begin{array}{l}\text { Co-located Reprocessing } \\
\text { Cask } \\
\text { Drywell }\end{array}$ & $\begin{array}{l}38 \\
66\end{array}$ & $\begin{array}{l}1919 \\
1103\end{array}$ & $\begin{array}{l}268 \\
545\end{array}$ & -- & $\begin{array}{l}2224 \\
1713\end{array}$ & $\begin{array}{l}1425 \\
1032\end{array}$ \\
\hline & $\begin{array}{l}\text { Stand-A lone } \\
\text { Cask } \\
\text { Drywell }\end{array}$ & $\begin{array}{l}411 \\
415\end{array}$ & $\begin{array}{r}2225 \\
763\end{array}$ & $\begin{array}{l}1044 \\
1116\end{array}$ & $\begin{array}{l}696 \\
696\end{array}$ & $\begin{array}{l}4376 \\
2989\end{array}$ & $\begin{array}{l}2834 \\
1994\end{array}$ \\
\hline & $\begin{array}{l}\text { Co-located Repository } \\
\text { Cask } \\
\text { Drywell }\end{array}$ & $\begin{array}{l}188 \\
190\end{array}$ & $\begin{array}{r}2037 \\
784\end{array}$ & $\begin{array}{l}262 \\
262\end{array}$ & -- & $\begin{array}{l}2487 \\
1235\end{array}$ & $\begin{array}{r}1660 \\
868\end{array}$ \\
\hline
\end{tabular}


delayed scenarios and the additional handling facilities required at the reprocessing-co-located and stand-alone facilities (the repository-co-located version uses the same handling facility for all three cases). The cost reduction for the reprocessing plant drywell MRS/IS facility is due to the larger capacity drywell assumed for that concept, which is assumed to hold three PWR elements or seven BWR elements as opposed to the one PWR/three BWR element-capacity drywells used in the other two concepts.

The reprocessing plant-co-located MRS/IS facility also exhibits lower operating costs than the other two versions for the reference and the delayed reprocessing scenarios. In the delayed disposal scenario, the repositoryco-located MRS/IS facility has the lowest operating costs although they are approximately the same as the reprocessing-co-located concept costs. The stand-alone concept has appreciably higher operating costs in all three scenarios.

These differences in operating costs are due to the assumptions made with respect to sharing of costs with the reprocessing plant or repository. In the former concept it is assumed that MRS/IS facility operating costs are with the reprocessing plant from the startup of the storage MRS/IS facility. In the repository-co-located concept it is assumed that the full operating costs are borne by the storage facility until the repository comes on line. Between that date and 2016, the storage facility would bear about one-half of the operating cost (the other half being charged to the repository). After 2016 , it is assumed that all operating costs would be charged to the repository operations.

The stand-alone concept incurs 100 percent of the operating cost throughout its lifetime. The differences between it and the other two concepts are particularly marked in the delayed disposal scenario where the MRS/IS is operating for a period of 46 years. The stand-alone facility operating costs also include the full decommissioning costs (10 percent of the total capital costs, less casks is assumed). The repository-co-located facility decommissioning costs are assumed to be zero (the repository bears the full cost of the eventual decommissioning). The reprocessing-co-located facility decommissioning costs are lower than those for the stand-alone 
facility because of the lower capital costs (essentially only the storage facilities are decommissioned).

In all studies it is assumed that the scrap value of the casks is at least equal to the decommissioning cost.

The storage facility co-located with the reprocessing plant does not have any incremental transportation costs for any of the three scenarios studied. The concept co-located with the repository has an incremental cost only in the delayed reprocessing scenario where spent fuel is shipped 2500 miles to the MRS/IS facility(a) and then 2500 miles back to the reprocessing plant once space becomes available at the plant. In this case, the transportation costs are a large portion of the total undiscounted cost (about 55 to 60 percent). The stand-alone MRS/IS facility has incremental transportation costs in all cases. They range from 11 to 23 percent of the total undiscounted cost.

\subsubsection{Technical Merits of Casks Versus Drywells}

The technical merits of casks and drywells are evaluated in this section for the three major functions of the MRS/IS facility: a) receipt, handling, and packaging; b) transfer; and c) storage.

Because the storage cask is loaded at the MRS/IS facility, it has no advantage over the drywell in the receiving and handling functions. It does have an advantage in packaging spent fuel since no canister is required. If the storage casks were transportable, they would be loaded with spent fuel at the reactor site and with HLW at the reprocessing plant, thus eliminating the need for a transfer system, increasing material handling capacity, and greatly reducing personnel requirements at the MRS/IS facility.

The transfer system for casks has merit over drywells because the transfer to storage is accomplished in larger quantities of material per transfer and in the final storage configuration. The drywell concept requires

(a) Only 2000 miles of the trip to the storage facility are counted in assessing incremental transportation charges; since a 500-mile trip to the reprocessing plant would have been incurred without the storage facility. 
single canister transfer and involves several operations at the storage site before the material is in the storage configuration.

The storage system for casks has advantages over drywells in the monitoring, and heat dissipation functions. Monitoring of casks for leakage can be done both visually and with radiation contamination surveys whereas drywells cannot be visually inspected and must rely on secondary methods to determine the status of canisters and encasements. Casks are capable of dissipating heat better than drywells since both conduction and convection are enhanced by the material involved. If the thermal criterion for spent fuel is set too, low drywells may be unable to cool the fuel sufficiently without complex cooling systems.

In summary, transportable storage casks have a definite technical advantage over drywells in all major functions of the MRS/IS facility.

\subsubsection{Possibilities for Life-Cycle Cost Reductions}

Several possibilities exist for reducing the costs of an MRS/IS facility, including consolidation of spent fuel assemblies and utilization of the large metal storage casks for transport between the source site and the storage site.

\subsubsection{Consolidation of Spent Fuel Assemblies}

Consolidating spent fuel assemblies into closely packed arrays within containers results in packing the equivalent of two assemblies into the space formerly occupied by one assembly. Cost components affected by consolidation are transportation, storage containers and storage pads, and staff labor. The number of spent fuel shipments is reduced by half, as is the number of metal casks or drywells required to store the spent fuel. Staff labor is reduced since the number of units to be handled is also reduced by half.

Consolidation is most effective for the delayed reprocessing scenario since that scenario deals almost exclusively with spent fuel.

\subsubsection{Shipment in Large Metal Storage Casks}

In the three principal scenarios, the spent fuel and HLW canisters are assumed to be shipped 50 percent by volume by truck and 50 percent by volume by rail. If it were possible to license the reference metal storage cask for 
shipment of spent fuel and HLW canisters, the number of shipments could be greatly reduced. As with consolidation of fuel, use of the storage cask for shipment is most cost effective when there are large quantities of spent fuel to transport, as in the delayed reprocessing scenario.

Shipment of the ratioactive wastes in the large storage casks would also reduce facility capital costs by eliminating the need for a handling facility, since the casks would be loaded and sealed at the source site. All that would be required at the storage site is a receiving station for removing the casks from the rail cars and a transporter system for placing the casks in the storage array.

\subsubsection{Advantages/Disadvantages of the Three MRS/IS Facility Concepts}

Each of the three concepts examined in this study has certain advantages and disadvantages relative to the other two concepts. These advantages and disadvantages are discussed in this section.

\subsubsection{MRS/IS/Reprocessing Plant}

Co-location with a reprocessing plant reduces the capital cost of the MRS/IS facility since the receiving and handing station and other supporting facilities at the reprocessing plant can also serve the storage facility.

Since the site is already approved for nuclear applications, the time required to obtain the necessary permits and 1 icenses should be reduced, as compared with a new site. Thus, authorization, construction and utilization of the storage facility could be accomplished at an earlier date.

The incremental transportation links for this concept (transport in addition to the normal reactor-to-reprocessor-to-repository links) are zero, minimizing waste management transportation costs.

Storage at the reprocessing plant may be publicly perceived as likely to become permanent disposal, and could, therefore, receive substantial public opposition.

\subsubsection{MRS/IS Stand-Alone}

The stand-alone facility can be sited in many places, since the location does not have to be suitable for either a reprocessing plant or a geologic 
repository. Thus, selection of a site and the obtaining of necessary permits and licenses might be accomplished more quickly, compared with a repository-based site.

The incremental transportation links for this concept are longer than the repository concept except for the delayed reprocessing scenario.

Storage at the stand-alone facility may also be publicly perceived as likely to become permanent disposal and could, therefore, receive substantial public opposition.

\section{1 .5 .3 MRS/IS/Repository}

Co-location with a geologic repository reduces the overall capital investment in the waste management system since the waste handiing facility and its supporting facilities become the surface installations for the repository. Using these facilities over the life span of the repository approximately doubles the useful life of the structures and permits amortization of the capital costs over a longer time period.

Except for the delayed reprocessing scenario, the incremental transportation links are zero, thus minimizing waste management transportation costs.

The stored materials are transferred directly from storage to the repository without leaving the site, thereby minimizing the potentia? for transportation accidents and the possible exposure of the public that could otherwise result from such accidents.

\subsection{OTHER GENERIC CONSIDERATIONS}

A number of areas requiring consideration when developing a conceptual design for an MRS/IS facility are essentially independent of the particular facility concept. These areas are discussed generically in the following subsections. 


\subsubsection{Licensing and Safety Considerations}

The rules, regulations, and regulatory guides generally applicable to an MRS/IS facility are identified in Section 6.2.1.1. A discussion of a number of possible safety issues related to MRS/IS facilities is presented in Section 6.2.1.2.

\subsubsection{Licensing}

The various bills before Congress all require that the MRS/IS facility be licensed by the Nuclear Regulatory Commission under the appropriate parts of Title 10, Code of Federal Regulations (10 CFR). Principal among these is Part 72, which deals specifically with storage of spent nuclear reactor fuel and other radioactive materials in facilities independent of the reactor. Other parts of 10 CFR relevant to the design, construction, and operation of an MRS/IS facility include:

10 CFR 20 - Standards for Protection Against Radiation

10 CFR 50 - Appendix B (Quality Assurance) and Appendix E (Emergency Planning)

10 CFR 51 - Licensing and Regulatory Policy and Procedures for Environmental Protection

10 CFR 60 - Disposal of High-Level Radioactive Wastes in Geologic Repositories

10 CFR 70 - Domestic Licensing of Special Nuclear Material

10 CFR 71 - Packaging of Radioactive Materials for Transport

10 CFR 73 - Physical Protection of Plants and Materials

10 CFR 100 - Appendix A, Seismic and Geologic Siting Criteria

10 CFR 170 - Fees for Facilities and Materials Licenses and Other Regulatory Services.

Part 72, "Licensing Requirements for the Storage of Spent Fuel in an Independent Spent Fuel Storage Installation," contains a number of sections dealing with required licensing documentation. These sections are: 
10 CFR 72.14 - License Application

10 CFR 72.15 - Safety Analys is Report

10 CFR 72.18 - Decommissioning Plan

10 CFR 72.19 - Emergency Plan

10 CFR 72.20 - Environmental Report

10 CFR 72.35 - Report of ISFSI Design and Procedure Changes

10 CFR 72.36 - Application for Transfer of License

10 CFR 72.38 - Application for Termination of License

10 CFR 72.39 - Amendment to License

10 CFR 72.80 - Quality Assurance Program

10 CFR 72.81 - Physical Security Plan

10 CFR 72.82 - Design for Physical Protection

10 CFR 72.83 - Safeguards Contingency $P 1$ an

10 CFR 72.84 - Changes to Physical Security and Contingency Plans

10 CFR 72.92 - Personnel Training Program.

In addition to the regulations already mentioned, several Regulatory Guides have been issued that provide specific guidance for potential licenses. Principal among these are:

- Reg. Guide 3.48, Standard Format and Content for the Safety Analys is Report for an Independent Spent Fuel Installation (dry storage).

- Reg. Guide 3.50, Guidance on Preparing a License Application to Store Spent Fuel in an Independent Spent Fuel Storage Installation.

- Reg. Guide 3.53, Applicability of Existing Regulatory Guides to the Design and Operation of an Independent Spent Fuel Storage Installation.

Depending upon the location of the facility, there may be permits and/or licenses required by state and local agencies. A 11 required licenses and permits must be identified and a schedule established to ensure the availability of necessary information and the timely submission of applications for the necessary licenses/permits. 


\subsubsection{Safety}

The principal concerns at the MRS/IS facility in regard to safety deal with the handling of the nuclear waste or spent fuel. Considerations for facility safety include layout, design, construction, and, in particular, proper design for nuclear materials handling, such as the use of work zones to limit personnel exposure to radiation, the use of an adequate facility security system, and the use of high safety factors and significant redundance for all systems that receive, handle, and store the nuclear waste.

Containment and filtering is provided to minimize the potential for release of radioactive materials. Criticality incidents and radiation exposure are prevented by careful attention to design concepts and configuration. Comprehensive fire detection and protection equipment are used throughout the entire facility. Potential noise excesses are controlled by equipment isolation, sound-absorbent material, and personnel protection where required. Personnel exposure to high temperatures is reduced by ventilation, air-conditioning and worker protection where required. All facilities are designed to withstand the effects of natural phenomena as appropriate for the safety classification of the individual facility.

Systems and operational procedures are used in the MRS/IS facility to protect facility personnel and the public from nuclear radiation and contamination and to protect against industrial accidents. Three circumstances are considered-normal operating conditions; abnormal operating conditions; and conditions resulting from improbable events.

Normal Facility Operation. Containers of wastes are received, handled, stored and eventually retrieved on a routine basis. Protection from radioactivity is provided by the integrity of the waste form and its container and cask, or by the isolation provided for in the waste handling building and in the storage modes.

During normal operations, insignificant quantities of airborne radioactivity could be released into the atmosphere. In any event, exposure of the public shall not be greater than that allowed by 10 CFR 20 and 
Appendix I to 10 CFR 50. Engineered conf inement systems prevent major releases of radioactivity from the waste handling building or from the storage areas.

The waste handling facility is treated as a "controlled area" in which building ventilation pressure(s) is maintained below ambient atmospheric or adjacent area pressure, thus ensuring that possible leakage through the walls is into, not outward from, any potential source of contamination. Additionally, all exhaust air from the building is passed through filter systems that include high-efficiency particulate air (HEPA) filters and then released through a stack. The stack height is established according to atmospheric conditions at the site; dispersion provides sufficient dilution to ensure that any radioactivity reaching ground level is at or below permissible concentrations.

Abnormal Operating Conditions. Anticipated occurrences that could result from equipment failures, operator errors, or unplanned process variations during the operating life of the facilities are considered in a Failure Modes and Effects Analysis (FMEA) for cask storage and for drywell storage.

The FMEA indicates that significant failure modes for the storage cask concept fall into two major categories: 1) damage to a cask containing spent fuel assemblies, resulting in radionuclide release, and 2) damage to bare spent fuel assemblies being transferred from a shipping cask to a storage cask. A qualitative evaluation of these failure modes identified no postulated events that would pose any significant risk to the health and safety of the public.

The FMEA of the drywell concept was performed only for the interface and storage facilities. The results indicate that potential for radionuclide release is principally associated with transporter failures or accidents. The dominant condition appears to be the movement of the transporter while the canister is partially in place, leading to actual shearing of the canister. 
Improbable Events. Although they have a very low probability of occurring, some upper-limit accidents or improbable events justify the incorporation of additional design features to further reduce the probability of their occurrence or to mitigate their effects. Improbable events considered include earthquakes, high winds and tornadoes, and floods. Risks due to these natural phenomena are assessed and adequate design provisions made for them. The frequency of natural phenomena such as earthquakes and tornadoes is too low to have any significant impact on the safety of the facility.

The rare, non-design basis occurrences that could result in severe consequences, such as a plane crash or a meteorite impact are not examined in this study. Multiple failures of certain subsystems and equipment following the more credible initiating events could also result in large radiological effects. However, the quantification of event trees for such initiating events would show very low branch sequence probabilities for any large radionuclide releases that might be associated with the events.

\subsubsection{Environmental Considerations}

The construction, operation, and decommissioning of an MRS/IS facility raise a number of environmental issues. Although most of these issues are encountered elsewhere within the nuclear industry (e.g., construction and operation of a reactor facility), they must still be carefully addressed. The environmental considerations relevant to an MRS/IS facility are generically discussed in Section 6.2.2.1 and the particular considerations specific to each of the siting alternatives are addressed in Section 6.2.2.2.

\subsubsection{Generic Environmental Considerations}

Construction, operation, and decommissioning of an MRS/IS facility by the federal government must comply with the National Environmental Policy Act (NEPA). These activities will almost certainly be viewed as major federal actions requiring the preparation of an environmental impact statement (EIS) in accordance with the regulations of the Council on Environmental Quality (CEQ). In reality, two EISs may be prepared, one covering construction and operation of the facility and the other covering decommissioning. In 
addition, since the facility is to be licensed by the U.S. Nuclear Regulatory Commission (NRC), a safety analysis report (SAR) covering operation of the facility will be required. Together, these documents will include descriptions of the facility and alternatives to the facility; the environmental impacts of constructing, operating, and decommissioning the facility; and the measures taken to monitor and assure environmental safety.

The potential environmental impacts associated with the various phases of the MRS/IS facility life, which will require consideration during preparation of the EISs, are discussed briefly in the following paragraphs.

Environmental Impacts During Construction. The potential environmental impacts of construction of an MRS/IS facility are similar to those of any major construction project, except that the MRS/IS construction work force at any time is likely to be relatively small (i.e., several hundred people). Therefore, the impacts normally associated with the presence of extra temporary workers or with many people concentrated in a small geographic area will be minimal. Some of the environmental impacts from construction will be:

- removal of the 1 and from production or other uses

- possible removal of timber from the land

- irreversible use of some construction materials

- irreversible use of fuels and electricity

- occasional minor traffic congestion

- dust from construction activities

- noise from construction activities

- minor socioeconomic impacts.

Environmental Impacts During Operation. Radioactive materials, including spent fuel, will be handled during operation of the MRS/IS facility. Appropriate measures will be taken at all times to avoid criticality and the possibility of any other accident, as well as to minimize occupational or public radiation dose from routine radioactive waste handling activities. Probably the most significant environmental impact from operation of the facility will be the large number of shipments of radioactive material to and from the facility. 
The possible impacts from operation include:

- potential occupational radiation doses to workers at the facility

- substantial freight traffic hauling radioactive shipments to and from the facility

- potential low level public radiation doses due to transportation activities

- low probability of accidental offsite releases of radioactivity.

Environmental Impacts During Decommissioning. Before decommissioning of the facility begins, all packaged radioactive waste materials will be removed and placed in a repository, leaving only minimal amounts of radioactivity to be removed during decommissioning. Significant quantities of construction materials (e.g., iron) could be reclaimed. The decommissioning work force will be small, so socioeconomic impacts will be small. Some of the impacts from decommissioning will be:

- small occupational radiation doses from decommissioning activities

- small public radiation doses from the transportation of radioactive wastes to low-level waste burial grounds

- some noise

- traffic to and from land fills.

Because the storage facilities are expected to be essentially uncontaminated, or readily decontaminated at the time of decommissioning, only the last of the listed impacts is expected to be significant.

\subsubsection{Environmental Considerations Specific to Siting Concepts}

As stated previously, environmental considerations relevant to an MRS/IS facility are principally routine issues. Owing to the high integrity of the containers and storage facilities, the expected impact on the environment is minimal. However, unique environmental considerations exist for each of the specific siting concepts considered in this study. Those considerations for each siting concepts that merit particular discussion are covered in the following paragraphs. 
Co-location with Reprocessing Facility. The particular environmental considerations of concern for the MRS/IS facility co-located with a reprocessing facility are site surface drainage and groundwater monitoring.

Surface drainage for the reprocessing facility site is accommodated by runoff through natural drainage features. Construction of the reprocessing facility resulted in hardening of surface features and construction of engineered drainage, increasing the rate of runoff of drainage for the southerly portion of the site to the upper limit that could be handled by the natural system. Construction of the MRS/IS facility requires further surface hardening and engineered drainage. To prevent erosion that has the potential for destruction of important site features and facilities, runoff control features include drainage ditches, rip-raps, engineered ponds, and construction of an outfall to a local creek. The construction of runoff control features will require obtaining a National Pollutant Discharge Elimination System (NPDES) permit for the discharge point into the creek.

The berm structures are resistant to penetration by surface moisture and are protected from discharge of potentially radioactively contaminated liquid into the ground by a relatively impervious underlayer. To further ensure that moisture in the storage structures is diverted from infusion into groundwater, drainage is promoted by drain lines which penetrate the structures.

Several programs of monitoring and sampling will be pursued to provide early detection of leaks of radioactive material so that appropriate corrective measures may be taken. In addition, the installation of one or more groundwater observation wells will permit routine determination of groundwater contamination levels (or absence thereof). The number and placement of such wells will be determined by the hydrological properties of the site and by the proposed monitoring and sampling program.

Stand-Alone MRS Facility. The particular environmental considerations of concern for the stand-alone MRS/IS facility depend upon the site chosen for the facility. The stand-alone MRS/IS facility could be located in most states of the U.S., because it does not use the geological features of the site as one of the radionuclide containment boundaries. In reality, however, the 
characteristics of a particular site may have an impact on the design and operation of the facility. In addition, the licensing of a particular site for storage of radioactive material may be more or less difficult depending upon the seismic or meteorological conditions of the site.

Environmental considerations that would be taken into account during the site selection process for the stand-alone MRS/IS facility include the following:

- good drainage and a low water table

- adequate surface area

- adequate protection of environmental quality of the area

- satisfactory meteorological conditions

- good transportation access.

These factors would be weighed against other factors relevant to site selection in order to determine the desirability of any given site. Clearly, the siting process would not permit the selection of a site that would result in unacceptable impacts to the environment.

The major difference relevant to environmental concerns between the stand-alone siting of an MRS/IS facility and the co-location of the facility with other nuclear facilities is the need for additional transportation. The use of a stand-alone MRS/IS requires at least one additional transportation step within the nuclear waste management system. This step results in additional radiation exposures of both the public and the work force even though no significant release of activity is expected. However, these extra exposures are well below the expected background doses and within allowable regulatory standards.

Both MRS/IS technologies (i.e., cask and drywell storage) require the shipping of significant quantities of construction materials (to support both the handling and storage facilities) as well as the nuclear waste itself. The need for highway and rail construction, however, depends on the site chosen. The cask MRS/IS facility may require a greater number of transportation links because of the need to import the storage casks. (Concrete materials required for drywells will most likely be available locally.) In any event, the 
traffic flows required are not unusual for many industrial facilities and, thus, their transportation impacts are not considered to be of particular concern.

Co-location with Repository. The assumed location of the MRS/IS facility co-located with a geologic repository is within the boundaries of a federal reservation in the semiarid western part of the U.S.

The major environmental concern at the site is the disruption of the fragile native vegetation that would result from construction and operation of the MRS/IS facility. This disruption, coupled with the low precipitation and the occasional high winds characteristic of the site, is likely to lead to substantial fugitive dust emissions from time to time. In site areas disturbed by construction activities or fires, scarcity of grass allows the invasion of tumbleweed and cheatgrass, displacing the native vegetation.

Hydrological considerations are of little concern at the site. Annual precipitation is low. Groundwater levels on the site are on the order of hundreds of feet below the surface. Past and current hydrological investigations provide a solid understanding of the site's hydrological characteristics.

Impacts on local populations from activities at the MRS/IS facility are also of little concern. The activities associated with the facility would be carried out at a location that is isolated from the local population centers. In addition, location within the boundaries of the federal reservation ensures against the encroachment of new communities.

Finally, the reservation is already equipped with the necessary infrastructure (transportation facilities, services, etc.) to support the MRS/IS facility. No extensive new infrastructure additions which could result in environmental disruptions will be required for the facility.

\subsubsection{Transportation Considerations}

Transportation is an important element in implementating of the MRS/IS concept. The major bases and assumptions for transportation in this study are 
summarized in Section 3.3.2 and given in detail in Appendix B.3. Pertinent background and the impacts of transportation on an MRS/IS facility are discussed in this section.

\subsubsection{Transport Licensing Considerations}

The transport of radioactive materials is regulated by the Department of Transportation (49 CFR 171-181) and the Nuclear Regulatory Commission (10 CFR 71). The regulations classify radioactive material transport into several categories according to quantities and/or toxicity of the radionuclides present. Spent fuel and high-level waste are in the category of Type B, large quantities (or the category with the most amount of radionuclides), and many or all of the transuranic wastes will be in the same category. The principal performance requirement for transport of these materials regards containment, which is generally provided by the outer transportation packaging (i.e., the cask). Type B large quantities require that containment of radioactive materials be maintained for normal conditions encountered during transport, for which there are specified physical tests that a package must endure. More important, the containment by the transport cask must be maintained under accident conditions, for which there are severe physical tests that the outer packaging must endure without loss of containment. The most important of these tests are, in the following sequence to the same cask: impact, puncture, fire, and submersion under water. All licensed casks must be capable of passing these tests. These tests are sufficiently severe that they encompass the performance needs for all but the most severe accidents, for which the probability of occurrence is very low. Thus, the primary purpose of a canister, if present, for transport of Type $B$ radioactive materials is for handling and contamination control for routine operations.

For most shipments containing more than $20 \mathrm{Ci}$ of plutonium, (which would include the three materials of concern here), the regulations that require the packaging system (i.e., outer cask and inner packagings) must retain two levels of containment if the total package is exposed to the severe regulatory test conditions. The NRC regulations specifically exempt spent fuel from this 
requirement and allow for possible NRC exemption of other materials. It remains to be determined whether this rule is to be applied to high-level and transuranic wastes. If it does apply, the waste canister (full of its contents) or an overpack canister must provide the second level of containment; if the rule does not apply to these waste shipments (i.e., these materials would be exempt from the double containment category), the canister need not endure the tests on the total cask-plus contents. In any case, the canister may be much less rugged than the cask, which must absorb nearly all of the accident environment. In this study, it is assumed that, if needed, the canisters as described for high-level and transuranic wastes will provide the second level of containment.

As stated above, the transport cask must be shown to withstand the severe regulatory dynamic tests without loss of containment and with only modest loss of shielding effectiveness. These conditions are much more severe than the requirements for storage or handling at an MRS/IS or at any other fuel cycle facility.

Most of the reference transport casks used in this study (designated by NAC-1, IF-300, CNS-14-170, CNS-7-100) have been shown to meet these regulatory tests for their respective cargoes. (a) The design of the two casks used in this study to transport fuel cladding hulls (designated HLW-T and HLW-R) and the packaging to transport CHTRU wastes (TRUPACT) are not yet completed, but they are being designed for transport licensability, and it is assumed here that they will be licensable for their respective purposes designated in this study. The reference metal storage cask in this study is designed for storage and used only for storage in this study. There is a financial incentive for these casks to also be used for transport in the metal storage cask concept. Their design may require modifications and or additions (e.g., impact limiters, special tie-downs, etc.) to be licensed for this use. Their licensing would also require considerable effort and perhaps several years.

(a) The NAC-1 and IF-300 casks are licensed to carry spent fuel. It is assumed here that with appropriate internal spacers they are licensable to carry high-level waste. The CNS-14-170 and $\mathrm{CN}-7-100$ casks are licensed to carry type $B$ radioactive materials. It is assumed here that the ir licenses apply to transuranic wastes. 
Another storage cask concept that could be considered for transporting is the GNS Castor Cask which is licensed for transportation in Europe. Licensing requirements in Europe are based on IAEA transportation standards which are the same in principle as those in the U.S. Thus it seems very likely that a storage cask design can be developed for transport in the U.S.

\section{Transportation Assumptions}

The bases and assumptions for of fsite transportation of the waste materials are summarized in Section 3.3.2 and given in detail in Appendix B.3. The reference shipping systems selected, with 50 percent by volume of each waste category shipped by rail and 50 percent by truck, are given in Table 6.2. The overall sizes of the spent fuel and waste canisters for transport are summarized in Table 6.3.

The offsite transport scenarios for the three MRS/IS site evaluations are summarized in Figure 6.6. The transportation links are either $500 \mathrm{mi}$ (800 km) or $2500 \mathrm{mi}(4030 \mathrm{~km})$ depending upon the site location for the repository. The offsite transportation links for the three principal scenarios are given in Figure 6.6 for each of the three study locations of the MRS/IS site. As indicated, all offsite transportation links for each scenario are not identical. Note that for this study the mixed-oxide fuel fabrication plant is always co-located with the fuel reprocessing plant in the east, the geologic disposal repository is located in the west $(2500 \mathrm{miles}$ from the other fuel cycle facilities), and the reactors are located in the east (500 miles from other fuel cycle facilities).

\section{Transport Costs}

Transportation is a significant cost element in the operation of an MRS/IS system. However, it is also a significant cost element in operaion of a fuel cycle that does not require an MRS/IS. The main interest for offsite transportation costs in this study is to determine those costs for an MRS/IS system that are incremental to those for a recycle fuel cycle where an MRS/IS is not needed (i.e., reprocessing and Mox fuel refabrication, and geologic repository capabilities are operating). These would be the incremental transport costs associated with operating an MRS/IS system. The transportation links for spent fuel, high-level and transuranic wastes which are required in 
TABLE 6.2 Reference Shipping Systems Selected for This Study

\begin{tabular}{|c|c|c|c|}
\hline Material & $\begin{array}{l}\text { Shipping } \\
\text { Mode } \\
\end{array}$ & $\begin{array}{r}\text { Shipping } \\
\text { Container } \\
\end{array}$ & $\begin{array}{c}\text { Waste Packages } \\
\text { Per } \\
\text { Shipment } \\
\end{array}$ \\
\hline \multirow[t]{2}{*}{ Spent fuel } & Truck & $N A C-1$ & $\begin{array}{l}1 \text { PWR or } \\
2 \text { BWR }\end{array}$ \\
\hline & Rail & IF -300 & $\begin{array}{l}7 \mathrm{PWR} \text { or } \\
18 \mathrm{BWR}\end{array}$ \\
\hline \multirow[t]{2}{*}{$\begin{array}{l}\text { High-level } \\
\text { wastes }\end{array}$} & Truck & $N A C-1$ & 1 canister \\
\hline & Rail & IF -300 & 5 canisters \\
\hline \multirow[t]{2}{*}{$\begin{array}{l}\text { RHTRU special } \\
\text { canister }\end{array}$} & Truck & $H L W-T$ & 1 canisters \\
\hline & Rail & $H L W-R$ & 5 canisters \\
\hline \multirow{2}{*}{$\begin{array}{l}\text { RHTRU drums } \\
>5 \mathrm{R} / \mathrm{hr}\end{array}$} & Truck & CNS 7-100 & 7 drums \\
\hline & $\operatorname{Rail}(a)$ & CNS 7-100 & 21 drums \\
\hline \multirow{2}{*}{$\begin{array}{l}\text { RHTRU drums } \\
<5 \mathrm{R} / \mathrm{hr}\end{array}$} & Truck & CNS $14-170$ & 14 drums \\
\hline & $\operatorname{Rail}(a)$ & CNS $14-170$ & 42 drums \\
\hline \multirow[t]{2}{*}{ CHTRU wastes } & Truck & TRU-PACT & $\begin{array}{l}36 \text { drums or } \\
3 \text { boxes }\end{array}$ \\
\hline & Rail & TRU-PACT & $\begin{array}{l}72 \text { drums or } \\
6 \text { boxes }\end{array}$ \\
\hline
\end{tabular}

(a) It is assumed that three of these shipping containers are transported per rail car.

(b) Assumes two truck TRUPACT versions are transported per rail car. 
TABLE 6.3. Reference Canister Sizes and Weights for offsite Transportation

\begin{tabular}{|c|c|c|c|}
\hline Fuel Cycle Material & Dimensions, $\mathrm{m}$ & $\begin{array}{c}\text { Net } \\
\text { Capacity, } \mathrm{m}^{3}\left(\mathrm{ft} \mathrm{t}^{3}\right) \\
\end{array}$ & 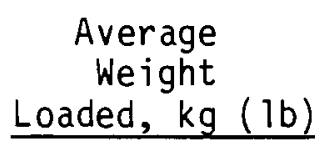 \\
\hline $\begin{array}{l}\text { Spent fuel } \\
\text { PWR assembly } \\
\text { BWR assembly }\end{array}$ & $\begin{array}{l}N A \\
\text { NA }\end{array}$ & $\begin{array}{l}N A \\
N A\end{array}$ & $\begin{array}{l}658(1448) \\
284(625)\end{array}$ \\
\hline $\begin{array}{l}\text { Solidifed high-level } \\
\text { waste canister }\end{array}$ & $0.31 \mathrm{D} \times 3.1$ & $0.17(6.0)$ & $1050(2310)$ \\
\hline $\begin{array}{l}\text { RHTRU wastes } \\
\text { Hulls canister } \\
210 \mathrm{~L}(55 \mathrm{gal}) \text { drum }\end{array}$ & $\begin{array}{l}0.62 D \times 3.1 \\
0.62 D \times 0.92\end{array}$ & $\begin{array}{l}0.75(2.6) \\
0.17(6.0)\end{array}$ & $3500(7700)$ \\
\hline $\begin{array}{l}\text { CHTRU wastes } \\
210 L(55-g a l) \text { drum } \\
\text { Metal box }\end{array}$ & $\begin{array}{l}0.62 \mathrm{D} \times 0.92 \\
1.2 \times 1.9 \times 1.9\end{array}$ & $\begin{array}{l}0.19(6.7) \\
3.5(123.6)\end{array}$ & $\begin{aligned} 300 & (660) \\
4000 & (8800)\end{aligned}$ \\
\hline
\end{tabular}

a recycle fuel cycle that does not utilize an MRS/IS facility are the same as those shown in Figure 6.6(a) for an MRS/IS facility located at a fuel reprocessing plant.

Thus, the incremental offsite transportation links attributed to operation of an MRS/IS facility are the differences between those in Figure 6.6(b) and $6.6(\mathrm{c})$ and those in Figure 6.6(a). These transportation links and the incremental links for the three scenarios for each of the three MRS/IS facility site locations, are tabulated in Table 6.4. There is one incremental 500-mile transportation link for each scenario for the stand-alone facility, there are no incremental links for the facility at a fuel reprocessing plant, and there are incremental links (two long ones) for only the delayed reprocessing scenario with the MRS/IS facility located at the repository. Thus incremental offsite transportation costs for the MRS/IS facility at the fuel reprocessing plant are zero, they are modest for each scenario for the stand-alone facility, and for the MRS/IS facility at the repository they are zero for two scenarios and significant for the delayed reprocessing scenario. 


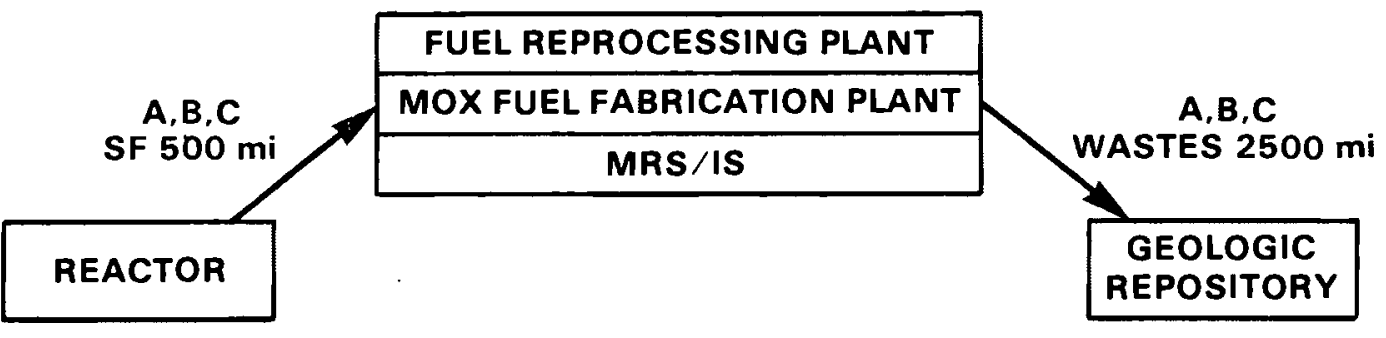

a. SPENT FUEL AND WASTE FLOW FOR AN MRS/IS AT A REPROCESSING PLANT

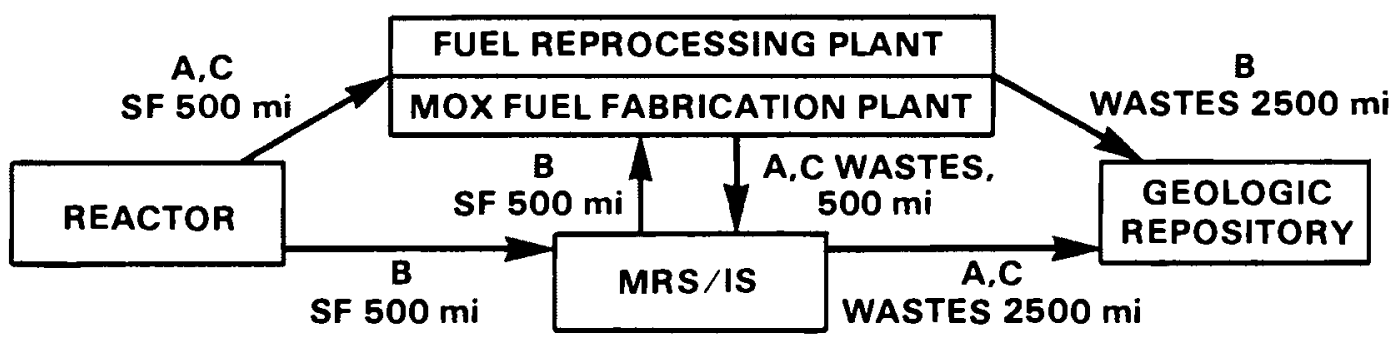

b. SPENT FUEL AND WASTE FLOW FOR A STAND-ALONE MRS/IS

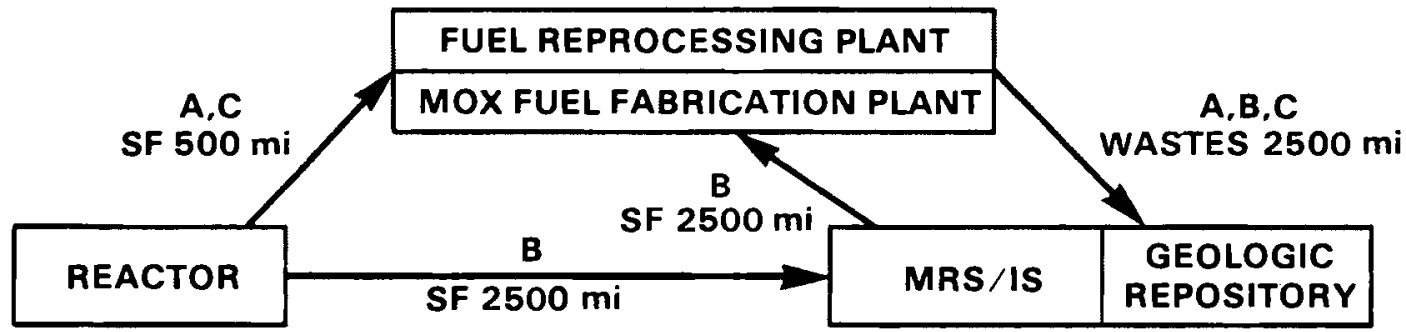

c. SPENT FUEL AND WASTE FLOW FOR AN MRS/IS AT A REPOSITORY

LEGEND: A = REFERENCE SCENARIO

$B=$ SCENARIO WITH DELAYED REPROCESSING

C = SCENARIO WITH DELAYED REPOSITORY

SF = SPENT FUEL

WASTES $=$ HIGH-LEVEL AND TRANSURANIC WASTES

FIGURE 6.6. Spent Fuel and Waste Flow Routes for an MRS/IS Facility 
TABLE 6.4. Transportation Link Comparisons

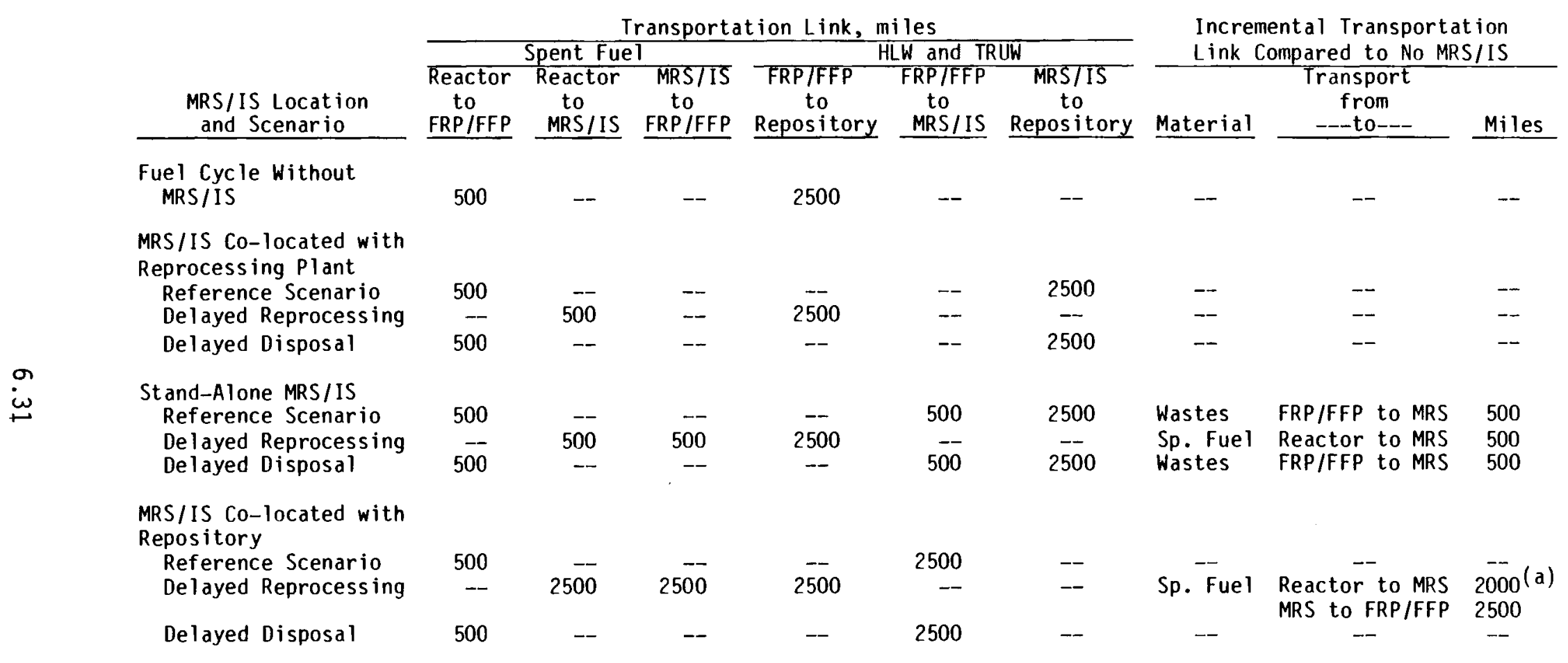

(a) Difference in trip length between 2500 miles and 500 miles. 
These life-cycle costs, taken from Section 6.1, are summarized in Table 6.5. Also shown for information are the anticipated costs for offsite transportation without an MRS/IS facility.

Savings in transportation costs can be achieved when using metal storage casks if the casks are also suitable for transportation. These reductions improve the overall costs of the metal cask concept but not enough to reach the level of the drywell concept. The dual-purpose casks reduce the offsite transportation costs, but also reduce significantly the capital and operating costs for the MRS/IS, by eliminating the need or the spent fuel and waste transfer facility.

Transportation costs are evaluated for the stand-alone MRS/IS if the amounts of materials shipped by rail were increased from 50 percent to 80 percent. As shown in Table 6.6 , rail shipments are slightly more costeffective for spent fuel and truck shipments are more cost-effective for shipping the wastes. Changing the rail/truck split impacts the MRS/IS facility since the number of rail and truck receiving bays is dependent on the rate of rail and truck shipments. An increase in rail shipments will reduce

TABLE 6.5. Life-Cycle Offsite Transportation Costs for Waste Management System (millions of mid-1982 dollars, undiscounted)

\begin{tabular}{|c|c|c|c|}
\hline $\begin{array}{l}\text { MRS/IS Facility Location } \\
\text { and Scenario } \\
\end{array}$ & $\begin{array}{l}\text { Costs Without } \\
\text { MRS/IS Facility } \\
\end{array}$ & $\begin{array}{l}\text { Costs With } \\
\text { MRS/IS Facility }\end{array}$ & $\begin{array}{c}\text { Incremental } \\
\text { Cost With } \\
\text { MRS/IS Facility } \\
\end{array}$ \\
\hline $\begin{array}{l}\text { MRS/IS/Reprocessor } \\
\text { Reference Scenario } \\
\text { Delayed Reprocessing } \\
\text { Delayed Disposal }\end{array}$ & $\begin{array}{r}462 \\
230 \\
2119\end{array}$ & $\begin{array}{r}462 \\
230 \\
2119\end{array}$ & $\begin{array}{l}0 \\
0 \\
0\end{array}$ \\
\hline $\begin{array}{l}\text { MRS/IS Stand-Alone } \\
\text { Reference Scenario } \\
\text { Delayed Reprocessing } \\
\text { Delayed Disposal }\end{array}$ & $\begin{array}{r}462 \\
230 \\
2119\end{array}$ & $\begin{array}{r}622 \\
425 \\
2815\end{array}$ & $\begin{array}{l}160 \\
195 \\
696\end{array}$ \\
\hline $\begin{array}{l}\text { MRS/IS/Repository } \\
\text { Reference Scenario } \\
\text { Delayed Reprocessing } \\
\text { Delayed Disposal }\end{array}$ & $\begin{array}{r}462 \\
230 \\
2119\end{array}$ & $\begin{array}{r}462 \\
1423 \\
2119\end{array}$ & $\begin{array}{r}0 \\
1193 \\
0\end{array}$ \\
\hline
\end{tabular}


TABLE 6.6. Sensitivity of Transportation Costs to Rail/Truck Split

\begin{tabular}{|c|c|c|c|}
\hline Scenario & $\begin{array}{l}\text { Transportation Cost for } \\
\text { 50/50 Rail/Truck Split } \\
\text { (\$ million, mid-1982) } \\
\end{array}$ & $\begin{array}{r}\text { Transpo } \\
\text { Increase/ } \\
80 \text { Rail/ } \\
20 \text { Truck } \\
\end{array}$ & $\begin{array}{l}\text { ion Cost } \\
\text { rease> } \\
20 \text { Raill } \\
80 \text { Truck }\end{array}$ \\
\hline Reference & 622 & 10 & $\langle 13\rangle$ \\
\hline Delayed reprocessing & 425 & $\langle 5\rangle$ & 16 \\
\hline Delayed disposal & 2815 & 4 & $\langle 18\rangle$ \\
\hline
\end{tabular}

facility costs, and an increase in truck shipments will increase facility costs because of the large number of shipments to be handled.

There are several of other considerations that could tend to reduce the transportation costs:

a. design casks for transport of older fuel and wastes

b. design casks for transport of other fuel and wastes

c. for spent fuel, consolidate the fuel

d. for truck shipments, use overweight trucks

e. for train shipments, use special trains

f. design casks and radioactive materials packagings to optimize the pay load

g. security and special equipment costs for HLW.

Items $b$ through $f a l l$ involve increasing the payload per shipment, thereby reducing the number of shipments and the costs. These changes would also reduce facility costs as discussed above. Item a may also be affected by a better and more competitive market condition for transportation. Currently, there is little commercial business in transportation of the materials of concern here, so few packagings or casks are available and there is no incentive for commercial entities to expand their activities. Obviously, a larger market should tend to reduce unit costs. The unit leasing costs used for casks in this study are based on limited information and on short-term lease rates (about 1 month). Indications are that long-term lease rates could 
reduce these costs in the order of a factor of two, which is very significant. In practice, actual lease rates will be negotiated and could vary significantly.

The casks assumed for use in transport of spent fuel and high-level wastes in this study were designed to transport spent fuel out of the reactor about 120 days. The materials transported in this study are all out of the reactor at least 10 years, and have significantly lower decay heat and radiation levels. These lower radiation levels would allow reduction in gamma shielding thickness. With this reduced shielding and the resultant larger cask cavity for the same outside dimensions and total weight of the cask, the cavity volume and pay load can be increased by as much as 100 percent (for truck casks). Also, if spent fuel were consolidated into half the ir volume, the number of shipments could be reduced by as much as a factor of two.

The truck shipments in this study assumed the use of casks which, when combined with the tractor-trailer, would not exceed the legal limit of 80,000 pounds, beyond which a special permit is required in many states for each shipment. Cost savings may be possible for a truck plus cask that weigh 1.46 times the legal weight transporter assumed in this study. The payload can be increased by a factor of about 7, thereby reducing truck transportation trips and costs for spent fuel or high-level waste by as much as a factor of 5. Additional administrative costs and special permit fees, however, wolild be incurred to process overweight shipment requests. Furthermore, overweight shipments may be limited to certain routes and time of day.

For train shipments, the use of special trains (i.e., those carrying only radioactive materials on several cars) offer the possibility of cost reduction. The use of such trains would generally reduce the travel time and improve the resultant transport logistics and costs. However, the railroads are reluctant to use special trains without increasing the unit transport charges, and a recent court ruling concluded that such higher charges were not legal. This matter remains to be resolved.

When there is sufficient business for transport of the wastes and spent fuel of concern in this study, it would be cost effective to design the 
packagings and canisters to maximize the payload. For example, casks for high-level wastes may be shorter (and larger in diameter) to carry the high-level waste canisters, which are shorter than spent fuel assemblies. The diameters of waste canisters may be adjusted to allow a significant increase in the amount of waste that will fit into the casks. The same concept could apply to packagings for RHTRU wastes.

\subsubsection{Socioeconomic Considerations}

Several nontechnical considerations are important when planning for the development of an MRS/IS facility. Principal among these are the acceptability of the facility to the local and regional populace, and the impacts of facility construction, operation, and eventual closure on the economy of the region.

\subsubsection{Public Acceptability}

The acceptability to the local and regional populace of a facility for the long-term storage of spent fuel, HLW, and TRU wastes is recognized as an important consideration. All bills presently pending in Congress contain mechanisms for consultation with local regional governmental agencies, and with interested Indian tribes, in the selection of sites for waste storage and disposal facilities, and provide the framework for local rejection and Congressional override when appropriate.

The acceptability of an MRS/IS facility may depend strongly on whether the facility is seen as a step toward the eventual solution of the waste disposal question or as simply a delaying action to postpone difficult decisions. A storage facility located on a site selected for a repository is more likely to be favorably received than are facilities located at a reprocessing plant or located separately, since the selection of a repository site is seen as a positive step toward final disposition of the wastes. Locating the storage facility at a reprocessing plant or at a separate location is likely to be perceived as 1) just another delaying action, and 2) possibly becoming a permanent disposition site by failure to proceed with geologic repositories. The reprocessing plant location may be slightly more favorable than a separate facility, since a nuclear installation is already present on the site. 


\subsubsection{Economic Considerations}

Construction, operation, and decommissioning of an MRS/IS facility will have economic impacts on the local community. The labor force necessary to construct the facility is not expected to be large, probably a few hundred workers, and would not present any significant stress to the local community services in most locations. However, location of an MRS/IS facility in regions of low population could significantly burden existing community services. The use of federal impact funds might be required to ensure that sufficient municipal services are available to support the MRS/IS work force. The construction force payroll would contribute to the overall local prosperity, but would not be a major factor. Operation of the facility is expected to require a permanent staff of workers, who would be permanent local residents and would contribute to local business community and the local tax base.

Closure of the facility would result in a loss of permanent jobs in the community, which would be partially mitigated by the employment of a decomissioning staff. The decommissioning staff would be relatively small, and the decommissioning effort would be relatively brief, probably less than 3 years.

Overall, an MRS/IS facility would provide an employment base for a period of 15 to 20 years. If co-located with a repository, the facility staff would continue with repository operations after closure of the storage activities, thus extending the duration of the employment base.

\subsubsection{Relation to Other Facilities}

The monitored retrievable storage/interim storage (MRS/IS) facility, as one part of the overall nuclear fuel cycle system, has interfaces with several other parts of the system, such as the nuclear power stations and the geologic repositories.

\subsubsection{Reactor Power Stations}

As presently conceived, the MRS/IS facility could receive spent fuel from the reactor stations as necessary for the stations to maintain their full core reserve storage capacity. This fuel would be stored until either a 
reprocessing plant is operating, at which time the fuel would be shipped to the reprocessor, or, if the operation of reprocessing plants is delayed until after a geologic repository is available, some or all of the fuel might be emplaced in the repository without reprocessing. In any event, the principal interface between the MRS/IS facility and the reactor stations is the transportation link by which the spent fuel is transported from the reactors to the MRS/IS facility. Thus, it is essential that the facility is capable of receiving, unloading, loading, and decontaminating any of the present generation of spent fuel shipping casks.

\subsubsection{Geologic Repositories}

The main interface with the MRS/IS facility and the geologic repository is the transportation link. Spent fuel, solidified high level waste and transuranic wastes that have been in interim storage are shipped from the MRS/IS facility to the repository for permanent disposal. Depending upon the concept employed, this link may be an onsite transfer or a transcontinental shipment.

\subsubsection{Advantages/Disadvantages of Utilizing an Existing Federal Site}

This section addresses the advantages and disadvantages of using an existing federal site as the location of an MRS/IS facility. Site selection for an MRS/IS facility can be relatively independent of local geologic features and is likely to be made based on other factors. e.g., transportation costs, availability of resources (material and labor), and socioeconomic considerations.

Advantages. Currently active DOE nuclear facilities already have a number of the resource and support facilities required by an MRS/IS facility. Such facilities typically include:

- a work force experienced in constructing and operating nuclear facilities

- an established security force and site boundary

- an in-place municipal service system to support a construction labor force 
- the potential availability of a nearby low-level waste disposal facility

- established local site support systems.

The experience of the local population living in the vicinity of a nuclear facility should result in a minimum of local opposition to nearby MRS/IS facility siting. In fact, the local population may lobby strongly in support of an MRS/IS facility for its occupational opportunities. This may become pronounced as other nuclear programs [e.g., the liquid metal fast breeder reactor (LMFBR) program] are cut back.

The use of existing DOE facilities eliminates many procedural difficulties with land acquisition as well as the political difficulties of purchasing land and relocating an indigeneous population. In many cases, the DOE sites were originally chosen for their remoteness, and use of such sites would have the least adverse effect on the population.

There are significant economic advantages to locating an MRS/IS facility on a site at which a repository will subsequently be located. If both facilities are on adjacent sites, significant economic advantages arise from the ease of transporting waste from storage to the repository, even under the design constraint that the storage and repository facilities be independent. Adjacent siting eliminates much of the transportation cost inherent in using an independently-sited storage facility. Transportation distances are short, and the potential for using economical, but unlicensed, casks is attractive. (Cask economies may arise from the ability to reduce cask shielding or use a dedicated roadway or rail line.)

Disadvantages. The siting of an MRS/IS facility at an existing DOE site may have potential risks and costs. It is likely to arouse public concern that site selection is being made on the basis of convenience (i.e., prior ownership) rather than technical superiority. Although the portion of the public benefiting from MRS/IS economic opportunities may be supportive, others more distant from the site are likely to oppose the site selection, which will add impetus to their opposition to existing activities. 
The two presently identified DOE repository candidate sites are not well located. Because they were originally chosen, in part, for their remoteness, the construction, operating, and transport costs of an MRS/IS facility may be substantially increased. The lack of locally available construction materials, and at the Nevada Site lack of an adequate water supply, is certain to increase construction costs. The remoteness of the site from nuclear reactors and fuel reprocessing plants will contribute to high spent fuel and waste transport costs.

Many current legislative proposals call for MRS facilities to be subjected to the NRC licensing process. Co-locating NRC-licensed commercial waste management facilities with unlicensed nuclear research and development facilities may allow the regulatory authorities to claim jurisdiction over currently unlicensed activities. This risk can be minimized only by maintaining separation between the MRS/IS facility and the existing research and development facilities. Such separation, however, reduces (or eliminates) the ability of the MRS/IS facility to utilize existing facilities and negates some of the advantages of using existing DOE facilities.

Local Site Support Systems. The selection of a federal nuclear site as the location of an MRS/IS facility makes possible the utilization of many support services already available on the site. These services are discussed briefly in this subsection.

Transportation Services. An existing network of rail lines extends to nearly all parts of the site. The site rail network is connected directly to the principal railroads operating in the area, with connections to other major railroads in the U.S. Extension of the existing rail networks to the MRS/IS facility site can be accomplished relatively easily, with the length of new track likely to be in the vicinity of 5 miles or less, depending on the specific site selected.

The site is also served by a network of onsite highways, with connections to major state and interstate highways. Extensions of the existing highway network to the MRS/IS facility site can also be accomplished relatively easily, with the length of roadway to be added likely to be in the vicinity of 5 miles or less, depending on the specific site selected. 
Essential Services. The site is served by a large network of electric power transmission lines. These lines interconnect the principal electricity generating stations in the area and provide an assured source of electrical energy to the site facilities. Extension of the existing site distribution system to the MRS/IS facility site can be accomplished readily.

Water for use at the site would be pumped from a nearby river at an existing pumping station by the installation of new pumps and delivered to the site through a new delivery line. Alternatively, if the demand for water is not too great, wells could be drilled into the underlying aquifer and the necessary water pumped to the surface. In any event, ample water supplies can be made available.

Sludges from the sanitary waste disposal system and from process waste evaporation ponds would be disposed of at existing site sludge disposal facilities.

In view of the close proximity of the MRS/IS facility to existing site waste treatment facilities, and since the quantities of radioactive waste generated within the storage complex are expected to be quite small, extensive systems for treatment of radioactive wastes should not be required at the complex.

The site is served by an existing telephone system which is connected into the national telephone network. Additional communications are available through the plant radio network, under the control of the plant security forces.

Security for the government-owned facilities on the site is provided by the Site Patrol organization. Rapid response to any situations requiring such a response is made possible by a closely integrated communications system, a fleet of emergency response vehicles, and a large force of well-trained personnel. It is expected that security at the MRS/IS facility site would be provided by the Site Patrol organization.

Other Support Services. The existing central stores, employee transport, contaminated laundry service, central heavy equipment and vehicle maintenance, and central computing services already in operation on the Site are available as needed by the MRS/IS facility. 


\subsubsection{Technical Status of System Components}

The methods and systems to be used at a monitored retrievable storage/interim storage (MRS/IS) facility are, for the most part, well within the state-of-the-art and most have either been used or demonstrated at various facilities in the United States or abroad. The status of each of the principal components of an MRS/IS facility is discussed in this section.

\subsubsection{Receiving and Handling}

A considerable amount of experience has been gained in the use of rail and truck casks, both wet and dry, for the transportation of irradiated fuel elements in the United States.

Shipping cask wet unloading and fuel handling storage have been routinely performed at two reprocessing plants and in the spent fuel storage basin at commercial LWRs for a number of years. Dry receiving, unloading and storage have been considered and proposed in a number of different types of facilities ranging from reprocessing plants to repositories. They have been performed at the Nevada Test Site (NTS) in support of both the Spent Fuel Dry Surface Storage Program conducted by ONWI at the E-MAD facility and the disposal demonstration program conducted by the Lawrence Livermore Laboratory at the CLIMAX facility.

Transporter/emplacement systems for use with both casks and drywells of equivalent weight and configuration being considered for the MRS/IS facility have been demonstrated at E-MAD as part of the Spent Fuel Surface Storage Program.

\subsubsection{Storage Casks}

Early cask storage concepts used hollow, reinforced-concrete cylinders to provide storage for spent fuel and HLW cylinders. In the U.S., surface storage casks have been demonstrated at NTS under the spent fuel storage program. More recent cask designs have centered around metal casks and considerable development work is under way at several firms. Although the bulk of the work is proprietary, it can be concluded that the technology for metal casks will soon be adequate to allow the concept to develop into a commercially available and licensable product. 
Three metal casks are now at the stage where prototype units are undergoing final design and fabrication. Table 6.7 contains a brief summary of the specifications for these three casks. In this study, all cask storage designs and calculations are based on the REA-2023.

The spent fuel capacity of the REA cask may be doubled (48 PWR or 104 BWR assemblies) over that shown in Table 6.7 by loading it with consolidated rods. However, exterior cooling fins must be added, and the maximum cladding temperature is expected to rise.

No designs are yet available for the placement of solidified HLW canisters in the REA cask. A new basket would be required to support the 1-ft 0.D. canisters. Because each canister generates about $2.1 \mathrm{~kW}$, it seems reasonable to assume that $14 \mathrm{HLW}$ canisters could be put into one cask without exceeding the 30-kW thermal load limit for the nonfinned cask. This assumption must be confirmed by more detailed heat transfer and shielding calculations and/or experiments.

\section{TABLE 6.7. Storage Cask Specifications}

\begin{tabular}{|c|c|c|c|}
\hline & REA-2023 & $T N-2100$ & CASTOR-V (B and $C)$ \\
\hline Designer/manufacturer & $\begin{array}{l}\text { REA/Brooks and } \\
\text { Perkins (USA) }\end{array}$ & $\begin{array}{l}\text { Transnuk lear } \\
\text { (W. Germany) }\end{array}$ & $\begin{array}{l}\text { GNS } \\
\text { (W. Germany) }\end{array}$ \\
\hline \multicolumn{4}{|l|}{ Capacity } \\
\hline $\begin{array}{l}\text { PWR assemblies } \\
\text { BWR assemblies }\end{array}$ & $\begin{array}{l}24 \\
52\end{array}$ & $\begin{array}{l}21 \\
37\end{array}$ & $\begin{array}{l}20-24 \\
50-52\end{array}$ \\
\hline Weight, loaded (tons) & $87.5-97.5$ & $110-120$ & $100-125$ \\
\hline Age of fuel (yr) & 5 & $5-8$ & 5 \\
\hline Thermal load (kW) & $30(a)$ & 15 & $45-55$ \\
\hline
\end{tabular}

(a) Can be increased to $47 \mathrm{~kW}$ by addition of special fins at the storage site. 


\subsubsection{Drywells}

The technology needed to design and construct drywells is wellestablished. Drywell development programs and projects at NTS, Hanford and the Idaho National Engineering Laboratory (INEL) have all provided experience with procedures and equipment, heat transfer data in soil and confirmation of the feasibility of the method.

The use of drywells has been demonstrated at NTS/E-MAD as part of the Spent Fue 1 Surface Storage Program. Drywells have been used to store HTGR and LMFBR fuels at INEL for over ten years. However, available test data for dry storage have not covered the full range of possible spent fuel performance variables including different fuel manufacturers, reactor types, fuel burnups, air storage environment, etc. Qualified shielding, criticality, and structural analysis models and techniques for dry storage systems are available and well-established. The open-field drywell has direct qualification data from operating experience and demonstrations. With respect to structural analys is for drywell concepts, extensive seismic analysis has already been performed on systems which are directly comparable.

The BNFP drywell design is similar to those for various test holes at federal sites in Nevada, Idaho, and Washington, but differs from the other designs in that the storage drywells are enclosed in an engineered berm, built above the normal ground level. An engineered berm $c$ an be constructed with predictable heat dissipation design characteristics. Moisture and nuclide transport within an engineered berm can also be predicted.

This design package, which formed the basis for the BNFP solid waste storage area design, is complete and has been issued for construction. Concurrentiy, the BNFP SAR has been amended and the concept has undergone NRC licensing review.

\subsubsection{TRU Waste Storage}

Commercial experience in handling and storing TRU waste is limited, due to the delays in startup of commercial fuel reprocessing. Substantial 
experience has been gained, however, in the handling and storing of defense TRU wastes, and numerous design concepts have been considered as storage alternatives.

For the most part, the requirements for handling and storing TRU waste at an MRS/IS site can be satisfied by the available technology. The technical status for the handling and storage methods considered in this report are briefly reviewed below.

Contact-Handled TRU. Above-ground, indoor, unshielded storage of TRU low-level waste on a long-term basis is being successfully used by the national laboratories. The absence of significant heat output or radiation from CHTRU waste makes simple warehouses sufficient for meeting storage needs. No special handling equipment is required for placement or retrieval of the waste drums and boxes. Decommissioning of the facilities involves only routine salvage procedures. Buried storage has been used by national laboratories and the use of buried cargo containers presents no additional technological problems.

Remote-Handled TRU. Above-ground storage of intermediate-level TRU waste requires either a heavily shielded storage building and remote operations or storage casks. Limited experience with this method of storage has been gained at government facilities. The design and construction of suitable, shielded buildings and the necessary remote handling equipment are less sophisticated than that found in existing nuclear facilities. The storage facilities will be free of radioactive contamination after removal of the stored waste, and decommissioning should require only routine salvage procedures.

Fuel Residue. The radioactivity of the fuel residue necessitates remote handling and shielded storage. The interim storage concept involves storing canisters of compacted fuel residue in subsurface drywells or in concrete casks. Some failed equipment (RHTRU) packaged in identical containers may be stored along with the fuel residue. Similar techniques have been used for retrievable storage of radioactive wastes at government installations. Commercial experience with handling and storing fuel residue has been gained at the Nuclear Fuels Services facility in New York. 
Monitoring Systems. Required storage monitoring such as gas sampling and measuring, and temperature measuring systems are al1 we11-developed and can be applied to either storage concept.

\subsubsection{Research and Development Requirements}

As noted above in Section 6.2.1, the general systems and components required at an MRS/IS facility have been developed and demonstrated. It is anticipated that the $R \& D$ requirements will essentially be the same for all MRS/IS facilities no matter where they are located. An exception for the MRS/IS/Repository is that geological, hydrological and geotechnical exploration and data evaluation will be required to assure the facility is located on an acceptable and viable geologic repository site.

Although much of the technology required for the design and construction of an MRS/IS facility is currently available, two areas that pertain to all the storage concepts considered in this study will require development:

(1) generic design and operational criteria including temperature limits for the material stored and (2) monitoring methods and instruments. Criteria must be developed so that an MRS/IS facility can be econonomically designed, operated, and decommissioned in compliance with applicable government regulations. This will involve identification of the specific requirements of an MRS/IS facility, pertinent regulations, and facility operating parameters. Monitoring methods and instrumentation must be developed that will verify the integrity of the storage system during the operational life of the facility. If the integrity of the storage system depends on the integrity of the spent fuel cladding or the HLW canisters, then the monitoring system must verify the condition of the stored contents. Additional development areas specific to transportation, handling, and storage concepts are described in the following sections.

\subsubsection{Transportation}

Additional R\&D efforts will be required to develop:

- licensed truck and rail casks designed for dry transfers of contents

- licensed transportable storage casks 
- efficient licensed TRU waste containers and shipping casks

- standardized and licensed waste containers.

\subsubsection{Handling and Processing}

The need to achieve a relatively large facility throughput and capacity will require additional development and improvements to some of the present systems and methods. Development and prototype testing should be conducted on:

- grapples to handle canisters and waste packages

- automated cask decontamination station

- remotely operated contamination detection equipment

- container leak testing systems.

\subsubsection{Cask Storage}

Research and development needs for dry cask storage include:

- experiments using prototypical components to demonstrate the satisfactory thermal behavior of the cask storing spent fuel or solidified HLW canisters and to establish large surface storage cask heat transfer parameters for site-specific environments

- models and computer codes to permit accurate calculation of the thermal behavior of the cask and the material stored in it

- optimization of the design of the HLW canister to include consideration of cask storage

- experiments to determine the seismic response of the cask and its contents

- experiments to determine the long-term performance of the casks (e.g., degradation of heat transfer capability or structural integrity)

- simpler, less expensive casks and methods to permit transport of storage casks. 


\subsubsection{Drywell Storage}

Research and development needs for drywell storage include:

- heat transfer models and programs to define the thermal behavior of the waste, the canister, and the surrounding soil for a large array of drywells, and to establish drywell heat transfer parameters for site-specific environments

- methods and/or equipment to prevent animals from burrowing in the vicinity of drywells

- methods or selection of materials to prevent corrosion from affecting storage, monitoring, or retrieval of the waste

- evaluation of requirements for spent fuel canisters

- design development of high-thermal-efficiency drywells.

\subsubsection{TRU Waste}

Although no new requirements for research are identified for TRU waste storage, there does appear to be a need for development in the following areas:

- improved definition of compacted and consolidated TRU wastes in terms of heat output and radiation levels

- development of handling and transfer systems for RHTRU (fuel residue), viz., wet or dry transfer as discussed in Section 6.2.8.2

- selection of corrosion protection methods and materials for subsurface storage. 


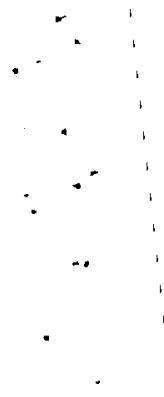


APPENDIX A

DETAILS OF ECONOMIC COMPARISONS

A.1 MRS/IS FACILITY CO-LOCATED WITH A REPROCESSING PLANT Tables A.1 - A.18

A.2 MRS/IS STAND-ALONE FACILITY

Tables A.19 - A.36

A.3 MRS/IS FACILITY CO-LOCATED WITH A REPOSITORY

Tables A.37 - A.45 
APPENDIX A

\section{DETAILS OF ECONOMIC COMPARISONS}

This appendix contains supplemental data on the economic evaluations and comparisons of the three MRS/IS concepts included in this study. The data are provided in support of the economic comparisons given in the body of the report.

In each section of this appendix, cost tables are provided for one of the three concepts. Presented in order in each section are 1) life-cycle cash flows for each of the three scenarios considered, for alternatives of storage in casks and in drywells (or in berm-protected dry wells, in the case of the site co-located with a reprocessing plant); 2) capital costs for each scenario and storage method; and 3) operating costs, presented as annual costs or as unit costs, for each alternative.

Explanations and further details of these costs and the underlying assumptions may be found in the draft reports for the three concepts. 
TABLE A.1. MRS/IS Facility Co-located With a Reprocessing Plant--Reference Scenario, Life-Cycle Cash Flows: Cask Storage (millions mid-1982 dol 1 ars)

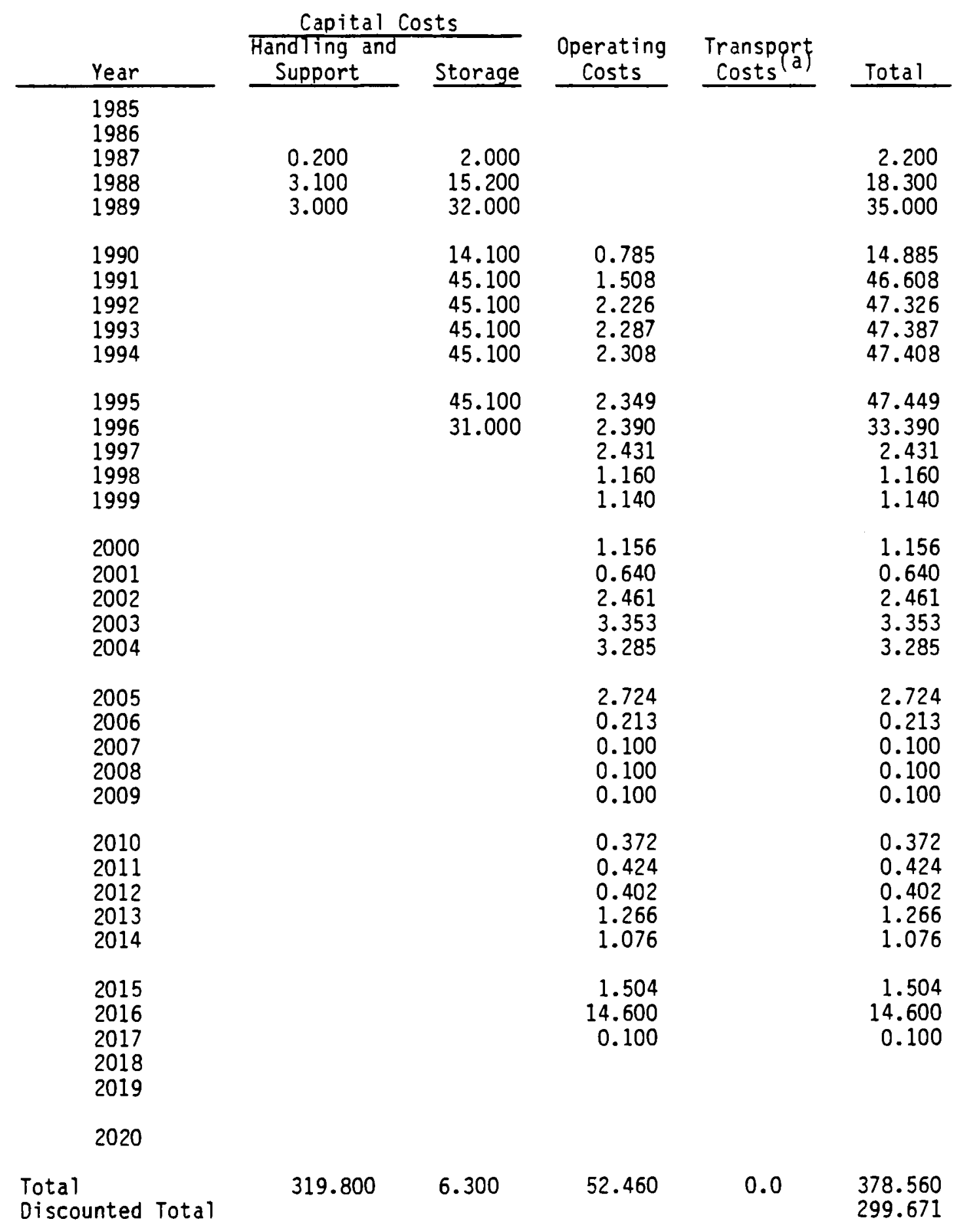

(a) Transportation costs are incremental to those which would be incurred if no MRS existed.

$$
\text { A. } 2
$$


TABLE A.2. MRS/IS Facility Co-located With a Reprocessing Plant--Reference Scenario, Life-Cycle Cash Flows: Drywell Storage (millions mid-1982 dollars)

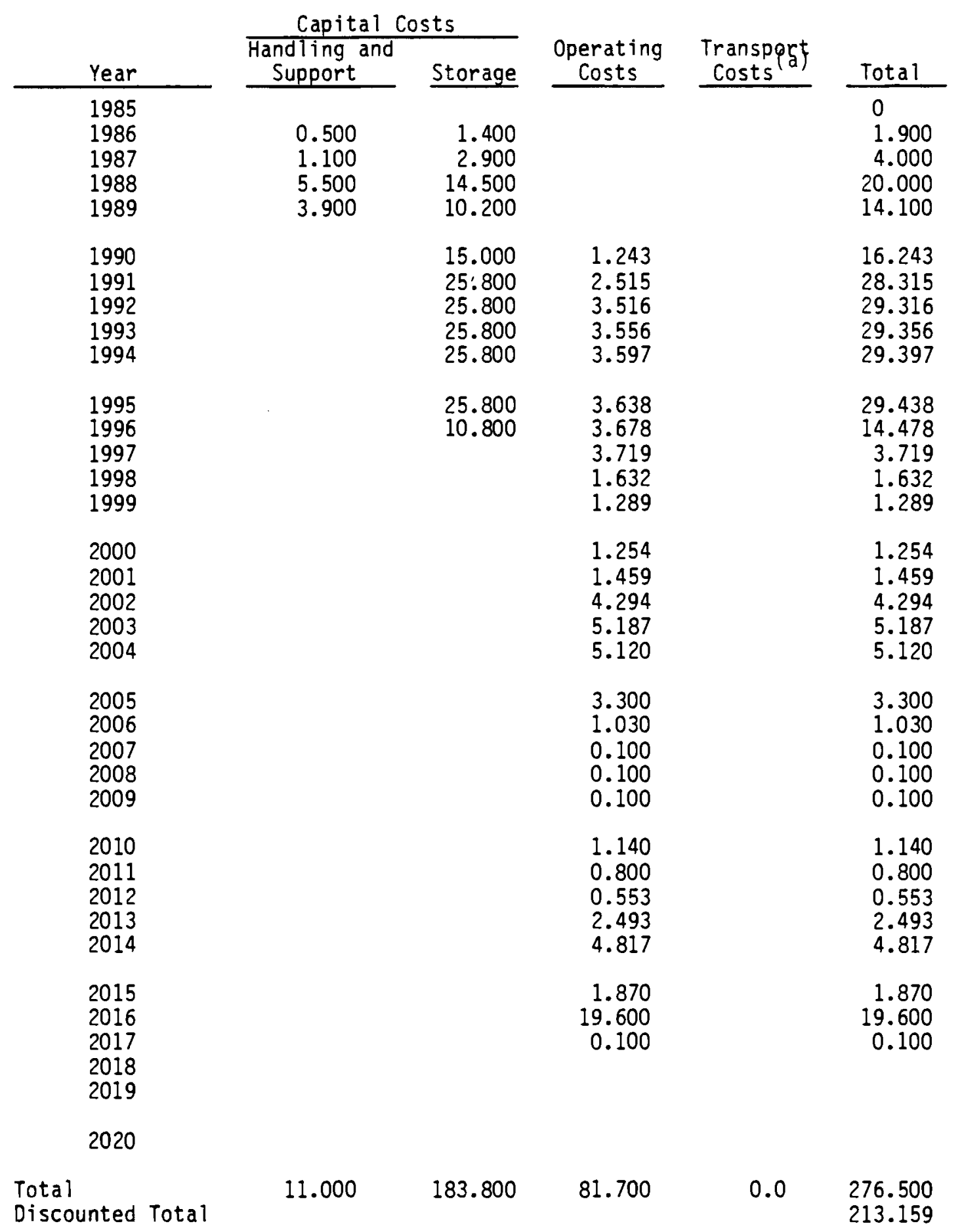

(a) Transportation costs are incremental to those which would be incurred if no MRS existed. 
TABLE A.3. MRS/IS Facility Co-located With a Reprocessing Plant--Delayed Reprocessing Scenario, Life-Cycle Cash Flows: Cask Storage (millions mid-1982 dollars)

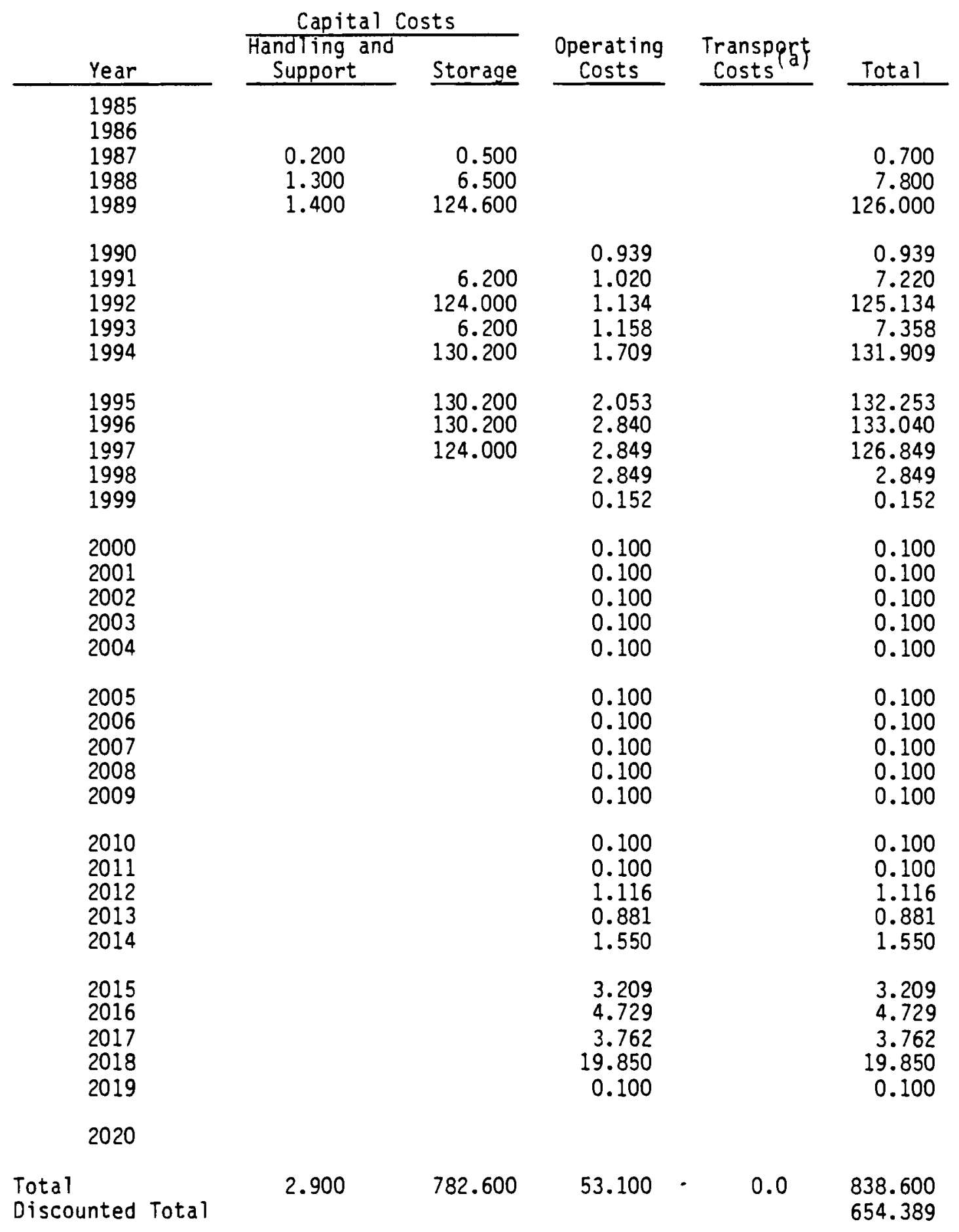

(a) Transportation costs are incremental to those which would be incurred if no MRS existed. 
TABLE A.4. MRS/IS Facility Co-located With a Reprocessing Plant--Delayed Reprocessing Scenario, Life-Cycle Cash Flows: Drywell Storage (millions mid-1982 dollars)

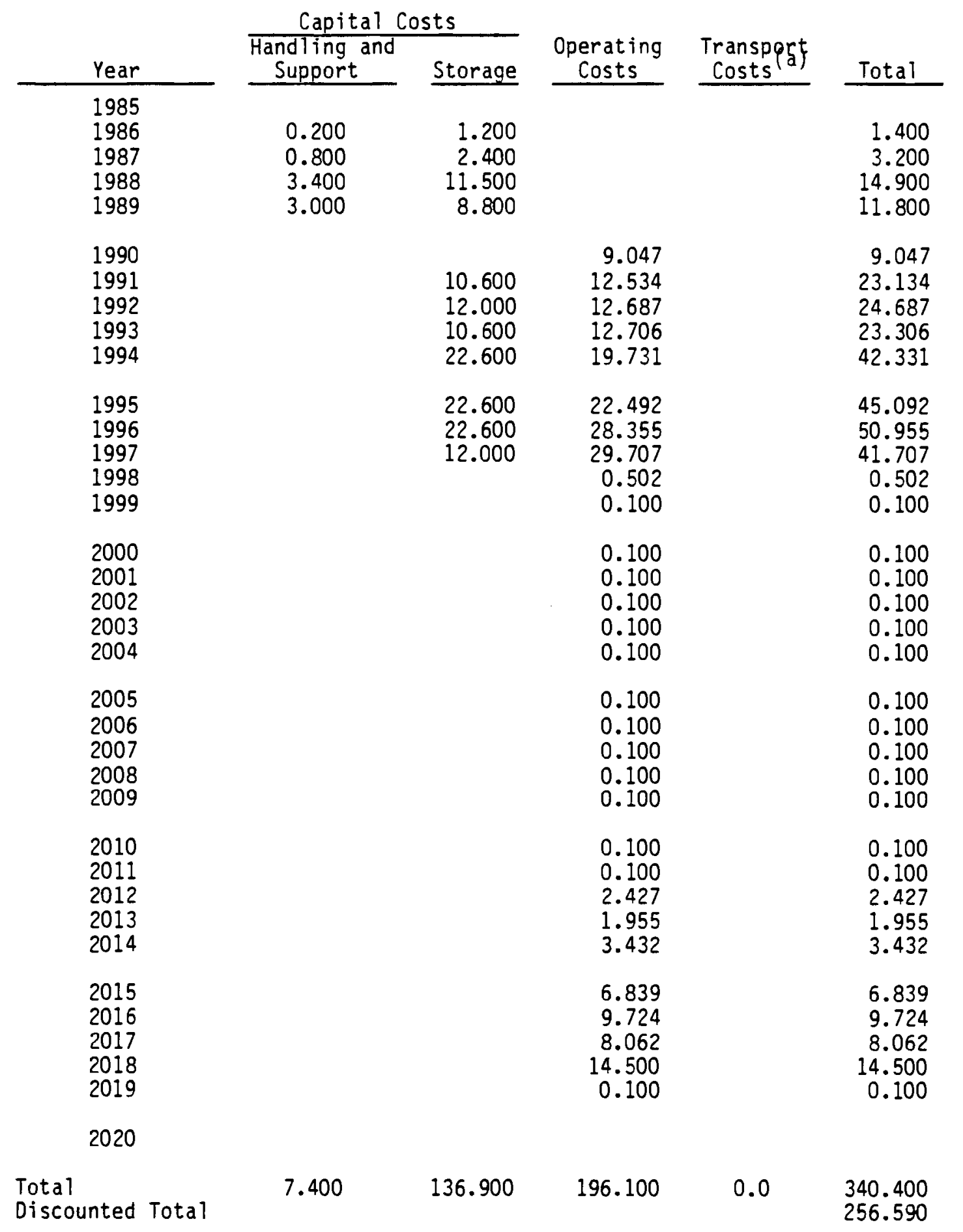

(a) Transportation costs are incremental to those which would be incurred if no MRS existed. 
TABLE A.5. MRS/IS Facility Co-located With a Reprocessing Plant--Delayed Disposal Scenario, Life-Cycle Cash Flows: Cask Storage (millions mid-1982 dollars)

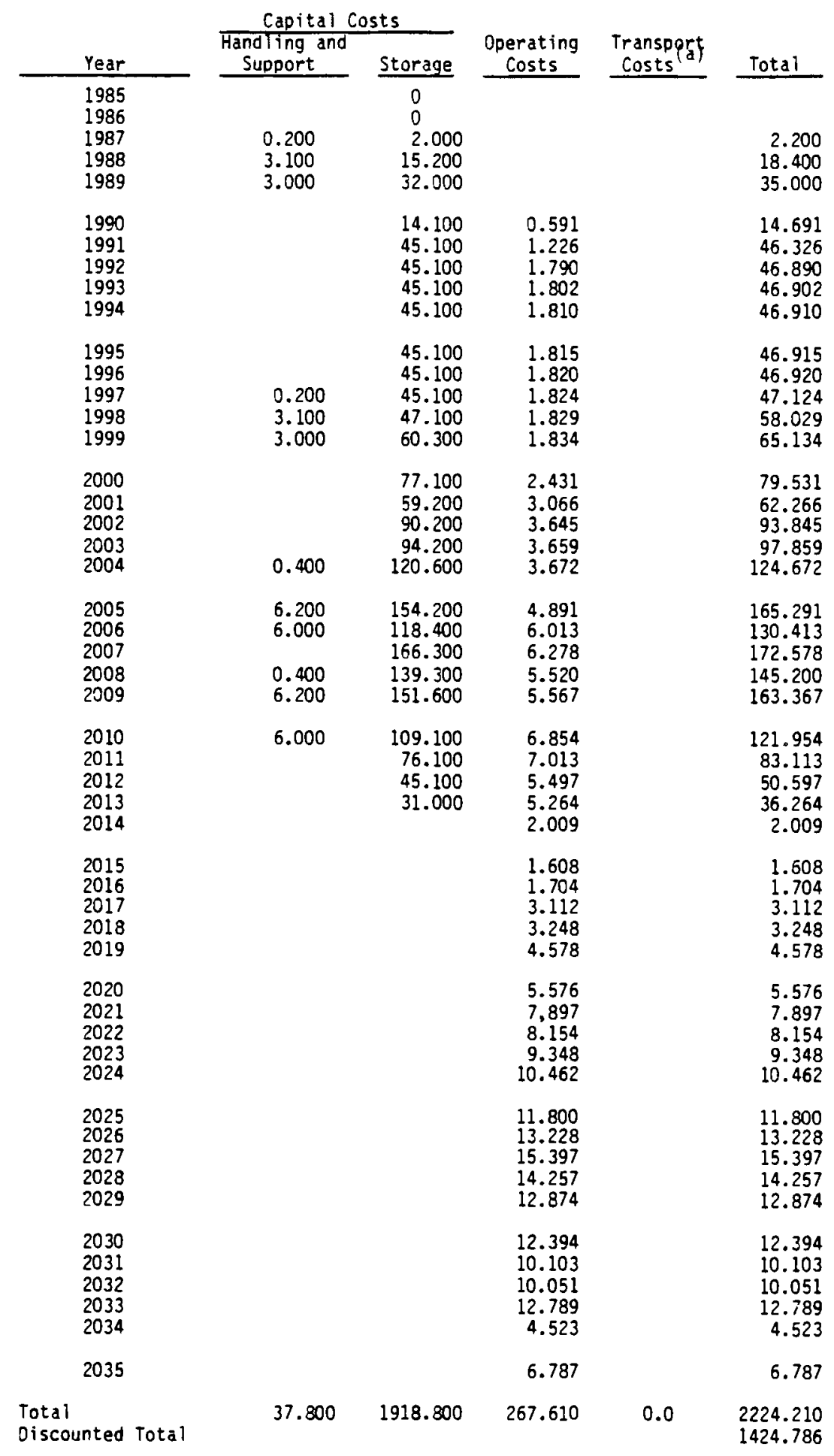

(a) Transportation costs are incremental to those which would be incurred if no MRS existed. 
TABLE A.6. MRS/IS Facility Co-located With a Reprocessing Plant--Delayed Disposal Scenario, Life-Cycle Cash Flows: Drywell Storage (millions mid-1982 dollars)

\begin{tabular}{|c|c|c|c|c|c|}
\hline \multirow[b]{2}{*}{ Year } & \multicolumn{2}{|c|}{ Capital Costs } & \multirow[b]{2}{*}{$\begin{array}{l}\text { Operating } \\
\text { Costs } \\
\end{array}$} & \multirow[b]{2}{*}{$\begin{array}{l}\text { Transport } \\
\text { Costs }\end{array}$} & \multirow[b]{2}{*}{ Total } \\
\hline & $\begin{array}{l}\text { Handling and } \\
\text { Support } \\
\end{array}$ & Storage & & & \\
\hline $\begin{array}{l}1985 \\
1986 \\
1987 \\
1988 \\
1989\end{array}$ & $\begin{array}{l}0.500 \\
1.100 \\
5.500 \\
3.900\end{array}$ & $\begin{array}{r}1.400 \\
2.900 \\
14.500 \\
10.200\end{array}$ & & & $\begin{array}{r}1.900 \\
4.000 \\
20.000 \\
14.100\end{array}$ \\
\hline $\begin{array}{l}1990 \\
1991 \\
1992 \\
1993 \\
1994\end{array}$ & & $\begin{array}{l}15.000 \\
25.800 \\
25.800 \\
25.800 \\
25.800\end{array}$ & $\begin{array}{l}0.916 \\
2.110 \\
3.104 \\
3.022 \\
3.029\end{array}$ & & $\begin{array}{l}15.916 \\
27.910 \\
28.904 \\
28.822 \\
28.829\end{array}$ \\
\hline $\begin{array}{l}1995 \\
1996 \\
1997 \\
1998 \\
1999\end{array}$ & $\begin{array}{l}0.500 \\
1.100 \\
5.500 \\
3.900\end{array}$ & $\begin{array}{l}25.800 \\
25.800 \\
27.200 \\
28.700 \\
40.300\end{array}$ & $\begin{array}{l}3.034 \\
3.038 \\
3.043 \\
3.047 \\
3.051\end{array}$ & & $\begin{array}{l}28.834 \\
29.338 \\
31.343 \\
37.247 \\
47.251\end{array}$ \\
\hline $\begin{array}{l}2000 \\
2001 \\
2002 \\
2003 \\
2004\end{array}$ & $\begin{array}{l}1.000 \\
2.200\end{array}$ & $\begin{array}{l}36.000 \\
40.800 \\
54.400 \\
57.400 \\
80.600\end{array}$ & $\begin{array}{l}3.972 \\
5.144 \\
6.152 \\
6.087 \\
6.101\end{array}$ & & $\begin{array}{l}39.972 \\
45.944 \\
60.552 \\
64.487 \\
88.901\end{array}$ \\
\hline $\begin{array}{l}2005 \\
2006 \\
2007 \\
2008 \\
2009\end{array}$ & $\begin{array}{r}11.000 \\
7.800 \\
1.000 \\
2.200 \\
11.000\end{array}$ & $\begin{array}{l}72.000 \\
66.600 \\
80.200 \\
83.200 \\
91.400\end{array}$ & $\begin{array}{r}7.960 \\
10.104 \\
9.790 \\
9.113 \\
9.188\end{array}$ & & $\begin{array}{r}90.960 \\
84.504 \\
90.990 \\
94.513 \\
111.588\end{array}$ \\
\hline $\begin{array}{l}2010 \\
2011 \\
2012 \\
2013 \\
2014\end{array}$ & 7.800 & $\begin{array}{l}82.800 \\
25.800 \\
25.800 \\
10.800\end{array}$ & $\begin{array}{r}11.154 \\
10.862 \\
11.437 \\
11.043 \\
1.551\end{array}$ & & $\begin{array}{r}101.754 \\
36.662 \\
37.237 \\
21.843 \\
1.551\end{array}$ \\
\hline $\begin{array}{l}2015 \\
2016 \\
2017 \\
2018 \\
2019\end{array}$ & & & $\begin{array}{r}5.034 \\
3.889 \\
6.593 \\
5.748 \\
12.664\end{array}$ & & $\begin{array}{r}5.034 \\
3.889 \\
6.593 \\
5.748 \\
12.664\end{array}$ \\
\hline $\begin{array}{l}2020 \\
2021 \\
2022 \\
2023 \\
2024\end{array}$ & & & $\begin{array}{r}9.704 \\
15.291 \\
15.518 \\
19.993 \\
20.024\end{array}$ & & $\begin{array}{r}9.704 \\
15.291 \\
15.518 \\
19.993 \\
20.024\end{array}$ \\
\hline $\begin{array}{l}2025 \\
2026 \\
2027 \\
2028 \\
2029\end{array}$ & & & $\begin{array}{l}20.747 \\
21.391 \\
24.573 \\
22.793 \\
20.655\end{array}$ & & $\begin{array}{l}20.747 \\
21.391 \\
24.573 \\
22.793 \\
20.655\end{array}$ \\
\hline $\begin{array}{l}2030 \\
2031 \\
2032 \\
2033 \\
2034\end{array}$ & & & $\begin{array}{l}19.207 \\
16.278 \\
16.187 \\
53.807 \\
27.000\end{array}$ & & $\begin{array}{l}19.207 \\
16.278 \\
16.187 \\
53.307 \\
27.000\end{array}$ \\
\hline 2035 & & & 40.500 & & 40.500 \\
\hline $\begin{array}{l}\text { Total } \\
\text { Discounted Total }\end{array}$ & 66.000 & 1102.800 & 544.650 & 0.0 & $\begin{array}{l}1713.450 \\
1032.053\end{array}$ \\
\hline
\end{tabular}

(a) Transportation costs are incremental to those which would be incurred if no MRS existed. 
TABLE A.7. MRS/IS Facility Co-located With a Reprocessing Plant Reference Scenario, Capital Costs: Cask Storage (thousands of mid-1982 dollars)

\begin{tabular}{|c|c|c|c|c|}
\hline Descriptions & $\underline{\text { Units }}$ & $\begin{array}{c}\text { Storage } \\
\text { Costs } \\
\end{array}$ & $\begin{array}{c}\text { Handling } \\
\text { and Support } \\
\text { Costs } \\
\end{array}$ & $\begin{array}{l}\text { Total } \\
\text { Costs } \\
\end{array}$ \\
\hline \multicolumn{5}{|l|}{ First Module } \\
\hline $\begin{array}{l}\text { Site improvements } \\
\text { Cask pads and structures } \\
\text { Casks } \\
\text { Hulls/HLGPT drywells } \\
\text { HLGPT drum drywells } \\
\text { LLGPT drum storage containers } \\
\text { Transporters } \\
\text { Other equipment } \\
\text { Total-Direct Costs }\end{array}$ & $\begin{array}{r}37 \\
549 \\
140 \\
48\end{array}$ & $\begin{array}{c}-- \\
636 \\
25,900 \\
3,598 \\
1,263 \\
665 \\
-- \\
-- \\
32,062\end{array}$ & $\begin{array}{l}755 \\
-- \\
-- \\
-- \\
-- \\
\overline{1,750} \\
1,512 \\
4,017\end{array}$ & $\begin{array}{r}755 \\
636 \\
25,900 \\
3,598 \\
1,263 \\
665 \\
1,750 \\
1,512 \\
36,079\end{array}$ \\
\hline Indirect Cask & & 2,810 & 417 & 3,227 \\
\hline A-E Services & & 2,932 & 368 & 3,300 \\
\hline Owners Costs & & 1,600 & 200 & 1,800 \\
\hline Contingency & & 9,796 & 1,298 & $\underline{11,094}$ \\
\hline Total-First Module & & 49,200 & 6,300 & 55,500 \\
\hline \multicolumn{5}{|l|}{ Additional Modules } \\
\hline $\begin{array}{l}\text { Cask pads and structures } \\
\text { Casks } \\
\text { Hulls/HLGPT drywells } \\
\text { HLGPT drum drywells } \\
\text { LLGPT drum storage containers } \\
\text { Total-Direct Costs }\end{array}$ & & $\begin{array}{r}636 \\
25,900 \\
3,598 \\
1,263 \\
\quad 665 \\
32,062\end{array}$ & $\begin{array}{l}-- \\
-- \\
-- \\
-- \\
--\end{array}$ & $\begin{array}{r}636 \\
25,900 \\
3,598 \\
1,263 \\
655 \\
32,062\end{array}$ \\
\hline Indirect Cask & & 3,153 & -- & 3,153 \\
\hline A-E Services & & 180 & - & 180 \\
\hline Owners Costs & & 700 & -- & 700 \\
\hline Cont ingency & & 9,005 & - & 9,005 \\
\hline Total-Additional Modules & & 45,100 & -- & 45,100 \\
\hline
\end{tabular}


TABLE A.8. MRS/IS Facility Co-located With a Reprocessing Plant--Reference Scenario, Capital Costs: Drywell Storage (thousands of mid-1982 dol 1 ars)

\begin{tabular}{|c|c|c|c|c|}
\hline Descriptions & Units & $\begin{array}{c}\text { Storage } \\
\text { Costs } \\
\end{array}$ & $\begin{array}{c}\text { Handling } \\
\text { and Support } \\
\text { Costs } \\
\end{array}$ & $\begin{array}{l}\text { Total } \\
\text { Costs } \\
\end{array}$ \\
\hline \multicolumn{5}{|l|}{ First Module } \\
\hline $\begin{array}{l}\text { Site improvements } \\
\text { Glass log drywells } \\
\text { Hulls/HLGPT drywells } \\
\text { HLGPT drum drywells } \\
\text { LLGPT drum storage containers } \\
\text { Transporters } \\
\text { Other equipment } \\
\text { Total-Direct Costs }\end{array}$ & & $\begin{array}{c}-\overline{6,843} \\
3,598 \\
1,263 \\
665 \\
-- \\
-- \\
12,369\end{array}$ & $\begin{array}{l}1,014 \\
-- \\
-- \\
-- \\
-- \\
3,420 \\
\frac{1,712}{6.146}\end{array}$ & $\begin{array}{r}1,014 \\
6,843 \\
3,598 \\
1,263 \\
665 \\
3,420 \\
1,712 \\
18,515\end{array}$ \\
\hline Indirect Cask & & 6,552 & 537 & 7,089 \\
\hline A-E Services & & 2,605 & 1,295 & 3,900 \\
\hline Owners Costs & & 1,670 & 830 & 2,500 \\
\hline Contingency & & 5,804 & 2,192 & 7,996 \\
\hline Total-First Module & & 29,000 & 11,000 & 40,000 \\
\hline
\end{tabular}

Additional Modules

Glass log drywells

Hulls/HLGPT drywells

HLGPT drum drywells

LLGPT drum storage containers

Total-Direct Costs

Indirect Cask

6,843

3,598

1,263

665

12,369

6,989

180

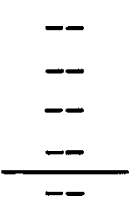

6,843

3,598

1,263

A-E Services

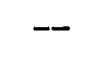

$\longdiv { 1 2 , 3 6 9 }$

Owners Costs

1,100

$-$

6,989

180

Cont ingency

5, 162

$--$

1,100

Total-Additional Modules

25,800

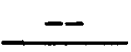

5,162

$-$

25,800 
TABLE A.9. MRS/IS Facility Co-located With a Reprocessing Plant--Delayed Reprocessing Scenario, Capital Costs: Cask Storage (thousands of mid-1982 dollars)

\begin{tabular}{|c|c|c|c|c|}
\hline Descriptions & Units & $\begin{array}{l}\text { Storage } \\
\text { Costs } \\
\end{array}$ & $\begin{array}{c}\text { Handling } \\
\text { and Support } \\
\text { Costs } \\
\end{array}$ & $\begin{array}{l}\text { Total } \\
\text { Costs } \\
\end{array}$ \\
\hline \multicolumn{5}{|l|}{ First Module } \\
\hline $\begin{array}{l}\text { Site improvements } \\
\text { Cask pads and structures } \\
\text { Casks } \\
\text { Hulls/HLGPT drywells } \\
\text { HLGPT drum drywells } \\
\text { LLGPT drum storage containers } \\
\text { Transporters } \\
\text { Other equipment } \\
\text { Total-Direct Costs }\end{array}$ & $\begin{array}{r}140 \\
-- \\
-- \\
--\end{array}$ & $\begin{array}{c}5,002 \\
98,000 \\
-- \\
-- \\
-- \\
-- \\
103,002\end{array}$ & $\begin{array}{r}65 \\
601 \\
4,017\end{array}$ & $\begin{array}{c}801 \\
5,002 \\
98,000 \\
-- \\
-- \\
-- \\
65 \\
601 \\
104,469\end{array}$ \\
\hline Indirect Cask & & 360 & 64 & 424 \\
\hline A-E Services & & 767 & 133 & 900 \\
\hline Owners Costs & & 1,100 & 700 & 1,800 \\
\hline Cont ingency & & 26,371 & 536 & 26,907 \\
\hline Total-First Module & & 131,600 & 2,900 & 134,500 \\
\hline \multicolumn{5}{|l|}{ Additional Modules } \\
\hline $\begin{array}{l}\text { Cask pads and structures } \\
\text { Casks } \\
\text { Hulls/HLGPT drywells } \\
\text { HLGPT drum drywells } \\
\text { LLGPT drum storage containers } \\
\text { Total-Direct Costs }\end{array}$ & $\begin{array}{c}140 \\
-- \\
-- \\
--\end{array}$ & $\begin{array}{c}5,002 \\
98,000 \\
-- \\
-- \\
-- \\
103,002\end{array}$ & $\begin{array}{l}-- \\
-- \\
-- \\
-- \\
--\end{array}$ & $\begin{array}{c}5,002 \\
98,000 \\
-- \\
-- \\
-- \\
103,002\end{array}$ \\
\hline Indirect Cask & & 385 & - & 385 \\
\hline A-E Services & & 120 & -- & 120 \\
\hline Owners Costs & & 700 & - & 700 \\
\hline Contingency & & 25,993 & -- & 25,993 \\
\hline Total-Additional Modules & & 130,200 & - & 130,200 \\
\hline
\end{tabular}


TABLE A.10. MRS/IS Facility Co-located With a Reprocessing Plant--Delayed Reprocessing Scenario, Capital Costs: Drywell Storage (thousands of mid-1982 dollars)

\begin{tabular}{|c|c|c|c|c|}
\hline Descriptions & Units & $\begin{array}{c}\text { Storage } \\
\text { Costs } \\
\end{array}$ & $\begin{array}{c}\text { Handling } \\
\text { and Support } \\
\text { Costs } \\
\end{array}$ & $\begin{array}{l}\text { Total } \\
\text { Costs } \\
\end{array}$ \\
\hline \multicolumn{5}{|l|}{ First Module } \\
\hline $\begin{array}{l}\text { Site improvements } \\
\text { Glass log drywells } \\
\text { Hulls/HLGPT drywells } \\
\text { HLGPT drum drywells } \\
\text { LLGPT drum storage containers } \\
\text { Transporters } \\
\text { Other equipment } \\
\text { Total-Direct Costs }\end{array}$ & 1,100 & $\begin{array}{c}-\overline{10,899} \\
-- \\
-- \\
-- \\
-- \\
-- \\
10,899\end{array}$ & $\begin{array}{l}1,445 \\
-- \\
-- \\
-- \\
-- \\
1,700 \\
842 \\
3,987\end{array}$ & $\begin{array}{c}1,445 \\
10,899 \\
-- \\
-- \\
-- \\
1,700 \\
\frac{842}{14,886}\end{array}$ \\
\hline Indirect Cask & & 5,252 & 828 & 6,080 \\
\hline A-E Services & & 1,142 & 418 & 1,560 \\
\hline Owners Costs & & 1,830 & 670 & 2,500 \\
\hline Contingency & & 4,777 & $\underline{1,497}$ & 6,274 \\
\hline Total-First Module & & 23,900 & 7,400 & 31,300 \\
\hline \multicolumn{5}{|l|}{ Additional Modules } \\
\hline $\begin{array}{l}\text { Glass log drywells } \\
\text { Hulls/HLGPT drywells } \\
\text { HLGPT drum drywells } \\
\text { LLGPT drum storage containers } \\
\text { Total-Direct Costs }\end{array}$ & 1,100 & $\begin{array}{c}10,899 \\
-- \\
-- \\
-- \\
10,899\end{array}$ & $\begin{array}{l}-- \\
-- \\
-- \\
-- \\
--\end{array}$ & $\begin{array}{c}10,899 \\
-- \\
-- \\
\frac{--}{10,899}\end{array}$ \\
\hline Indirect Cask & & 5,988 & - & 5,988 \\
\hline A-E Services & & 120 & -- & 120 \\
\hline Owners Costs & & 1,100 & -- & 1,100 \\
\hline Contingency & & 4,493 & - & 4,493 \\
\hline Total-Additional Modules & & 22,600 & - & 22,600 \\
\hline
\end{tabular}


TABLE A.11. MRS/IS Facility Co-located With a Reprocessing Plant--Delayed Disposal Scenario, Capital Costs: Cask Storage (thousands of mid-1982 dollars)

\begin{tabular}{|c|c|c|c|c|}
\hline Descriptions & Units & $\begin{array}{c}\text { Storage } \\
\text { Costs } \\
\end{array}$ & $\begin{array}{c}\text { Handling } \\
\text { and Support } \\
\text { Costs } \\
\end{array}$ & $\begin{array}{l}\text { Total } \\
\text { Costs } \\
\end{array}$ \\
\hline \multicolumn{5}{|l|}{ First Module } \\
\hline $\begin{array}{l}\text { Site improvements } \\
\text { Cask pads and structures } \\
\text { Casks } \\
\text { Hulls/HLGPT drywells } \\
\text { HLGPT drum drywel1s } \\
\text { LLGPT drum storage containers } \\
\text { Transporters } \\
\text { Other equipment } \\
\text { Total-Direct Costs }\end{array}$ & $\begin{array}{r}37 \\
549 \\
140 \\
48\end{array}$ & $\begin{array}{c}-- \\
636 \\
25,900 \\
3,598 \\
1,263 \\
665 \\
-- \\
-- \\
32,062\end{array}$ & $\begin{array}{l}755 \\
-- \\
-- \\
-- \\
-- \\
1,750 \\
1,512 \\
4,017\end{array}$ & $\begin{array}{r}755 \\
636 \\
25,900 \\
3,598 \\
1,263 \\
665 \\
1,750 \\
1,512 \\
36,079\end{array}$ \\
\hline Indirect Cask & & 2,810 & 417 & 3,227 \\
\hline A-E Services & & 2,932 & 368 & 3,300 \\
\hline Owners Costs & & 1,600 & 200 & 1,800 \\
\hline Contingency & & 9,796 & 1,298 & 11,094 \\
\hline Total-First Module & & 49,200 & 6,300 & 55,500 \\
\hline \multicolumn{5}{|l|}{ Additional Modules } \\
\hline $\begin{array}{l}\text { Cask pads and structures } \\
\text { Casks } \\
\text { Hulls/HLGPT drywells } \\
\text { HLGPT drum drywells } \\
\text { LLGPT drum storage containers } \\
\text { Total-Direct Costs }\end{array}$ & & $\begin{array}{r}636 \\
25,900 \\
3,598 \\
1,263 \\
665 \\
32,062\end{array}$ & $\begin{array}{l}-- \\
-- \\
-- \\
-- \\
-- \\
--\end{array}$ & $\begin{array}{r}636 \\
25,900 \\
3,598 \\
1,263 \\
665 \\
32,062\end{array}$ \\
\hline Indirect Cask & & 3,513 & -- & 3,513 \\
\hline A-E Services & & 180 & - & 180 \\
\hline Owners Costs & & 700 & -- & 700 \\
\hline Contingency & & 9,005 & - & 9,005 \\
\hline Total-First Modules & & 45,100 & -- & 45,100 \\
\hline
\end{tabular}


TABLE A.12. MRS/IS Facility Co-located With a Reprocessing Plant--Delayed Disposal Scenario, Capital Costs: Drywell Storage (thousands of mid-1982 dollars)

\begin{tabular}{|c|c|c|c|c|}
\hline Descriptions & Units & $\begin{array}{l}\text { Storage } \\
\text { Costs } \\
\end{array}$ & $\begin{array}{c}\text { Handling } \\
\text { and Support } \\
\text { Costs } \\
\end{array}$ & $\begin{array}{l}\text { Total } \\
\text { Costs } \\
\end{array}$ \\
\hline \multicolumn{5}{|l|}{ First Module } \\
\hline $\begin{array}{l}\text { Site improvements } \\
\text { Glass log drywells } \\
\text { Hulls/HLGPT drywells } \\
\text { HLGPT drum drywells } \\
\text { LLGPT drum storage containers } \\
\text { Transporters } \\
\text { Other equipment } \\
\text { Total-Direct Costs }\end{array}$ & & $\begin{array}{c}-- \\
6,843 \\
3,598 \\
1,263 \\
665 \\
-- \\
-- \\
12,369\end{array}$ & $\begin{array}{l}1,014 \\
-- \\
-- \\
-- \\
-- \\
3,420 \\
\frac{1,712}{6,146}\end{array}$ & $\begin{array}{r}1,014 \\
6,843 \\
3,598 \\
1,263 \\
665 \\
3,420 \\
1,712 \\
18,515\end{array}$ \\
\hline Indirect Cask & & 6,552 & 537 & 7,089 \\
\hline A-E Services & & 2,605 & 1,295 & 3,900 \\
\hline Owners Costs & & 1,670 & 830 & 2,500 \\
\hline Contingency & & 5,804 & 2,192 & 7,996 \\
\hline Total-F irst Module & & 29,000 & 11,000 & 40,000 \\
\hline \multicolumn{5}{|l|}{ Additional Modules } \\
\hline $\begin{array}{l}\text { Glass log drywells } \\
\text { Hulls/HLGPT drywells } \\
\text { HLGPT drum drywells } \\
\text { LLGPT drum storage containers } \\
\text { Total-Direct Costs }\end{array}$ & & $\begin{array}{r}6,843 \\
3,598 \\
1,263 \\
665 \\
12,369\end{array}$ & $\begin{array}{l}-- \\
-- \\
-- \\
--\end{array}$ & $\begin{array}{r}6,843 \\
3,598 \\
1,263 \\
655 \\
12,369\end{array}$ \\
\hline Indirect Cask & & 6,989 & - & 6,989 \\
\hline A-E Services & & 180 & -- & 180 \\
\hline Owners Costs & & 1,100 & -- & 1,100 \\
\hline Contingency & & 5,162 & - & 5,162 \\
\hline Total-Additional Modules & & 25,800 & - & 25,800 \\
\hline
\end{tabular}


TABLE A.13. MRS/IS Facility Co-located With a Reprocessing Plant--Reference Scenario, Operating Costs: Cask Storage (thousands of mid-1982 dollars)

\begin{tabular}{|c|c|c|c|c|c|}
\hline Year & Manpower & Supplies & Utilities & Decom. & Total \\
\hline $\begin{array}{l}1990 \\
1991 \\
1992 \\
1993 \\
1994\end{array}$ & $\begin{array}{r}579 \\
1,019 \\
1,473 \\
1,473 \\
1,473\end{array}$ & $\begin{array}{l}134 \\
269 \\
403 \\
403 \\
403\end{array}$ & $\begin{array}{r}72 \\
220 \\
350 \\
411 \\
432\end{array}$ & $\begin{array}{l}0 \\
0 \\
0 \\
0 \\
0\end{array}$ & $\begin{array}{r}785 \\
1,508 \\
2,226 \\
2,287 \\
2,308\end{array}$ \\
\hline $\begin{array}{l}1995 \\
1996 \\
1997 \\
1998 \\
1999\end{array}$ & $\begin{array}{r}1,473 \\
1,473 \\
1,473 \\
723 \\
723\end{array}$ & $\begin{array}{r}403 \\
403 \\
403 \\
63 \\
61\end{array}$ & $\begin{array}{l}473 \\
514 \\
555 \\
374 \\
356\end{array}$ & $\begin{array}{l}0 \\
0 \\
0 \\
0 \\
0\end{array}$ & $\begin{array}{l}2,349 \\
2,390 \\
2,431 \\
1,160 \\
1,140\end{array}$ \\
\hline $\begin{array}{l}2000 \\
2001 \\
2002 \\
2003 \\
2004\end{array}$ & $\begin{array}{r}723 \\
364 \\
1,789 \\
2,508 \\
2,508\end{array}$ & $\begin{array}{r}92 \\
15 \\
184 \\
276 \\
276\end{array}$ & $\begin{array}{l}341 \\
261 \\
488 \\
569 \\
501\end{array}$ & $\begin{array}{l}0 \\
0 \\
0 \\
0 \\
0\end{array}$ & $\begin{array}{r}1,156 \\
640 \\
2,461 \\
3,353 \\
3,285\end{array}$ \\
\hline $\begin{array}{l}2005 \\
2006 \\
2007 \\
2008 \\
2009\end{array}$ & $\begin{array}{r}2,149 \\
193 \\
97 \\
97 \\
97\end{array}$ & $\begin{array}{r}128 \\
7 \\
0 \\
0 \\
0\end{array}$ & $\begin{array}{r}357 \\
13 \\
3 \\
3 \\
3\end{array}$ & $\begin{array}{l}0 \\
0 \\
0 \\
0 \\
0\end{array}$ & $\begin{array}{r}2,724 \\
213 \\
100 \\
100 \\
100\end{array}$ \\
\hline $\begin{array}{l}2010 \\
2011 \\
2012 \\
2013 \\
2014\end{array}$ & $\begin{array}{l}192 \\
300 \\
364 \\
817 \\
817\end{array}$ & $\begin{array}{r}165 \\
93 \\
13 \\
309 \\
90\end{array}$ & $\begin{array}{r}15 \\
31 \\
25 \\
140 \\
169\end{array}$ & $\begin{array}{l}0 \\
0 \\
0 \\
0 \\
0\end{array}$ & $\begin{array}{r}372 \\
424 \\
402 \\
1,266 \\
1,076\end{array}$ \\
\hline $\begin{array}{l}2015 \\
2016 \\
2017 \\
2018 \\
2019 \\
2020\end{array}$ & $\begin{array}{r}1,176 \\
99 \\
100 \\
0 \\
0 \\
0\end{array}$ & $\begin{array}{r}125 \\
0 \\
0 \\
0 \\
0 \\
0\end{array}$ & $\begin{array}{r}203 \\
1 \\
0 \\
0 \\
0 \\
0\end{array}$ & $\begin{array}{r}0 \\
14,500 \\
0 \\
0 \\
0 \\
0\end{array}$ & $\begin{array}{r}1,504 \\
14,600 \\
100 \\
0 \\
0 \\
0\end{array}$ \\
\hline Totals & 26,272 & 4,788 & 6,880 & 14,500 & 52,460 \\
\hline
\end{tabular}


TABLE A.14. MRS/IS Facility Co-located With a Reprocessing Plant--Reference Scenario, Operating Costs: Drywell Storage (thousands of mid-1982 dollars)

\begin{tabular}{|c|c|c|c|c|c|}
\hline Year & Manpower & Supplies & Utilities & Decom. & Total \\
\hline $\begin{array}{l}1990 \\
1991 \\
1992 \\
1993 \\
1994\end{array}$ & $\begin{array}{l}1,014 \\
1,991 \\
2,710 \\
2,710 \\
2,710\end{array}$ & $\begin{array}{r}99 \\
198 \\
196 \\
296 \\
296\end{array}$ & $\begin{array}{l}125 \\
326 \\
510 \\
550 \\
591\end{array}$ & $\begin{array}{l}0 \\
0 \\
0 \\
0 \\
0\end{array}$ & $\begin{array}{l}1,243 \\
2,515 \\
3,516 \\
3,556 \\
3,597\end{array}$ \\
\hline $\begin{array}{l}1995 \\
1996 \\
1997 \\
1998 \\
1999\end{array}$ & $\begin{array}{r}2,710 \\
2,710 \\
2,710 \\
1,082 \\
817\end{array}$ & $\begin{array}{r}296 \\
296 \\
296 \\
115 \\
87\end{array}$ & $\begin{array}{l}632 \\
672 \\
713 \\
435 \\
385\end{array}$ & $\begin{array}{l}0 \\
0 \\
0 \\
0 \\
0\end{array}$ & $\begin{array}{l}3,638 \\
3,678 \\
3,719 \\
1,632 \\
1,284\end{array}$ \\
\hline $\begin{array}{l}2000 \\
2001 \\
2002 \\
2003 \\
2004\end{array}$ & $\begin{array}{r}817 \\
973 \\
3,277 \\
3,996 \\
3,996\end{array}$ & $\begin{array}{r}78 \\
110 \\
339 \\
431 \\
431\end{array}$ & $\begin{array}{l}359 \\
376 \\
678 \\
760 \\
693\end{array}$ & $\begin{array}{l}0 \\
0 \\
0 \\
0 \\
0\end{array}$ & $\begin{array}{l}1,254 \\
1,459 \\
4,294 \\
5,187 \\
5,120\end{array}$ \\
\hline $\begin{array}{l}2005 \\
2006 \\
2007 \\
2008 \\
2009\end{array}$ & $\begin{array}{r}2,571 \\
818 \\
97 \\
97 \\
97\end{array}$ & $\begin{array}{r}287 \\
93 \\
0 \\
0 \\
0\end{array}$ & $\begin{array}{r}442 \\
119 \\
3 \\
3 \\
3\end{array}$ & $\begin{array}{l}0 \\
0 \\
0 \\
0 \\
0\end{array}$ & $\begin{array}{r}3,300 \\
1,030 \\
100 \\
100 \\
100\end{array}$ \\
\hline $\begin{array}{l}2010 \\
2011 \\
2012 \\
2013 \\
2014\end{array}$ & $\begin{array}{r}926 \\
660 \\
457 \\
1,991 \\
3,840\end{array}$ & $\begin{array}{r}93 \\
57 \\
39 \\
203 \\
410\end{array}$ & $\begin{array}{r}121 \\
83 \\
57 \\
299 \\
567\end{array}$ & $\begin{array}{l}0 \\
0 \\
0 \\
0 \\
0\end{array}$ & $\begin{array}{r}1,140 \\
800 \\
553 \\
2,493 \\
4,817\end{array}$ \\
\hline $\begin{array}{l}2015 \\
2016 \\
2017 \\
2018 \\
2019 \\
2020\end{array}$ & $\begin{array}{r}1,441 \\
99 \\
100 \\
0 \\
0 \\
0\end{array}$ & $\begin{array}{r}170 \\
0 \\
0 \\
0 \\
0 \\
0\end{array}$ & $\begin{array}{r}259 \\
1 \\
0 \\
0 \\
0 \\
0\end{array}$ & $\begin{array}{r}0 \\
19,500 \\
0 \\
0 \\
0 \\
0\end{array}$ & $\begin{array}{r}1,870 \\
19,600 \\
100 \\
0 \\
0 \\
0\end{array}$ \\
\hline Totals & 47,422 & 5,016 & 9,762 & 19,500 & 81,700 \\
\hline
\end{tabular}


TABLE A.15. MRS/IS Facility Co-located With a Reprocessing Plant--Delayed Reprocessing Scenario, Operating Costs: Cask Storage (thous ands of mid-1982 dollars)

\begin{tabular}{|c|c|c|c|c|c|}
\hline Year & Manpower & Supplies & Utilities & Decom. & Total \\
\hline $\begin{array}{l}1990 \\
1991 \\
1992 \\
1993 \\
1994\end{array}$ & $\begin{array}{l}458 \\
458 \\
458 \\
458 \\
660\end{array}$ & $\begin{array}{l}35 \\
41 \\
50 \\
51 \\
77\end{array}$ & $\begin{array}{l}446 \\
521 \\
626 \\
649 \\
972\end{array}$ & $\begin{array}{l}0 \\
0 \\
0 \\
0 \\
0\end{array}$ & $\begin{array}{r}939 \\
1,020 \\
1,134 \\
1,158 \\
1,709\end{array}$ \\
\hline $\begin{array}{l}1995 \\
1996 \\
1997 \\
1998 \\
1999\end{array}$ & $\begin{array}{r}754 \\
1,273 \\
1,273 \\
1,273 \\
149\end{array}$ & $\begin{array}{r}95 \\
115 \\
115 \\
115 \\
0\end{array}$ & $\begin{array}{r}1,204 \\
1,452 \\
1,461 \\
1,461 \\
3\end{array}$ & $\begin{array}{l}0 \\
0 \\
0 \\
0 \\
0\end{array}$ & $\begin{array}{r}2,053 \\
2,840 \\
2,849 \\
2,849 \\
152\end{array}$ \\
\hline $\begin{array}{l}2000 \\
2001 \\
2002 \\
2003 \\
2004\end{array}$ & $\begin{array}{l}97 \\
97 \\
97 \\
97 \\
97\end{array}$ & $\begin{array}{l}0 \\
0 \\
0 \\
0 \\
0\end{array}$ & $\begin{array}{l}3 \\
3 \\
3 \\
3 \\
3\end{array}$ & $\begin{array}{l}0 \\
0 \\
0 \\
0 \\
0\end{array}$ & $\begin{array}{l}100 \\
100 \\
100 \\
100 \\
100\end{array}$ \\
\hline $\begin{array}{l}2005 \\
2006 \\
2007 \\
2008 \\
2009\end{array}$ & $\begin{array}{l}97 \\
97 \\
97 \\
97 \\
97\end{array}$ & $\begin{array}{l}0 \\
0 \\
0 \\
0 \\
0\end{array}$ & $\begin{array}{l}3 \\
3 \\
3 \\
3 \\
3\end{array}$ & $\begin{array}{l}0 \\
0 \\
0 \\
0 \\
0\end{array}$ & $\begin{array}{l}100 \\
100 \\
100 \\
100 \\
100\end{array}$ \\
\hline $\begin{array}{l}2010 \\
2011 \\
2012 \\
2013 \\
2014\end{array}$ & $\begin{array}{r}97 \\
97 \\
457 \\
364 \\
629\end{array}$ & $\begin{array}{r}0 \\
0 \\
48 \\
37 \\
67\end{array}$ & $\begin{array}{r}3 \\
3 \\
611 \\
480 \\
854\end{array}$ & $\begin{array}{l}0 \\
0 \\
0 \\
0 \\
0\end{array}$ & $\begin{array}{r}100 \\
100 \\
1,116 \\
881 \\
1,550\end{array}$ \\
\hline $\begin{array}{l}2015 \\
2016 \\
2017 \\
2018 \\
2019 \\
2020\end{array}$ & $\begin{array}{r}1,335 \\
2,057 \\
1,539 \\
100 \\
100 \\
0\end{array}$ & $\begin{array}{r}138 \\
197 \\
164 \\
0 \\
0 \\
0\end{array}$ & $\begin{array}{r}1,736 \\
2,475 \\
2,059 \\
0 \\
0 \\
0\end{array}$ & $\begin{array}{r}0 \\
0 \\
0 \\
19,750 \\
0 \\
0\end{array}$ & $\begin{array}{r}3,209 \\
4,729 \\
3,762 \\
19,850 \\
100 \\
0\end{array}$ \\
\hline Totals & 14,959 & 1,345 & 17,046 & 19,750 & 53,100 \\
\hline
\end{tabular}


TABLE A.16. MRS/IS Facility Co-located With a Reprocessing Plant--Delayed Reprocessing Scenario, Operating Costs: Drywell Storage (thousands of mid-1982 dollars)

\begin{tabular}{|c|c|c|c|c|c|}
\hline Year & Manpower & Supplies & Utilities & Decom. & Total \\
\hline $\begin{array}{l}1990 \\
1991 \\
1992 \\
1993 \\
1994\end{array}$ & $\begin{array}{l}1,165 \\
1,196 \\
1,430 \\
1,430 \\
2,231\end{array}$ & $\begin{array}{r}7,431 \\
10,822 \\
10,624 \\
10,619 \\
16,519\end{array}$ & $\begin{array}{l}451 \\
516 \\
633 \\
657 \\
981\end{array}$ & $\begin{array}{l}0 \\
0 \\
0 \\
0 \\
0\end{array}$ & $\begin{array}{r}9,047 \\
12,534 \\
12,687 \\
12,706 \\
19,731\end{array}$ \\
\hline $\begin{array}{l}1995 \\
1996 \\
1997 \\
1998 \\
1999\end{array}$ & $\begin{array}{r}2,844 \\
3,203 \\
3,204 \\
371 \\
97\end{array}$ & $\begin{array}{r}18,423 \\
23,681 \\
25,029 \\
43 \\
0\end{array}$ & $\begin{array}{r}1,225 \\
1,471 \\
1,474 \\
88 \\
3\end{array}$ & $\begin{array}{l}0 \\
0 \\
0 \\
0 \\
0\end{array}$ & $\begin{array}{r}22,492 \\
28,355 \\
29,707 \\
502 \\
100\end{array}$ \\
\hline $\begin{array}{l}2000 \\
2001 \\
2002 \\
2003 \\
2004\end{array}$ & $\begin{array}{l}97 \\
97 \\
97 \\
97 \\
97\end{array}$ & $\begin{array}{l}0 \\
0 \\
0 \\
0 \\
0\end{array}$ & $\begin{array}{l}3 \\
3 \\
3 \\
3 \\
3\end{array}$ & $\begin{array}{l}0 \\
0 \\
0 \\
0 \\
0\end{array}$ & $\begin{array}{l}100 \\
100 \\
100 \\
100 \\
100\end{array}$ \\
\hline $\begin{array}{l}2005 \\
2006 \\
2007 \\
2008 \\
2009\end{array}$ & $\begin{array}{l}97 \\
97 \\
97 \\
97 \\
97\end{array}$ & $\begin{array}{l}0 \\
0 \\
0 \\
0 \\
0\end{array}$ & $\begin{array}{l}3 \\
3 \\
3 \\
3 \\
3\end{array}$ & $\begin{array}{l}0 \\
0 \\
0 \\
0 \\
0\end{array}$ & $\begin{array}{l}100 \\
100 \\
100 \\
100 \\
100\end{array}$ \\
\hline $\begin{array}{l}2010 \\
2011 \\
2012 \\
2013 \\
2014\end{array}$ & $\begin{array}{r}97 \\
97 \\
1,430 \\
1,165 \\
2,044\end{array}$ & $\begin{array}{r}0 \\
0 \\
373 \\
295 \\
523\end{array}$ & $\begin{array}{r}3 \\
3 \\
624 \\
495 \\
865\end{array}$ & $\begin{array}{l}0 \\
0 \\
0 \\
0 \\
0\end{array}$ & $\begin{array}{r}100 \\
100 \\
2,427 \\
1,955 \\
3,432\end{array}$ \\
\hline $\begin{array}{l}2015 \\
2016 \\
2017 \\
2018 \\
2019 \\
2020\end{array}$ & $\begin{array}{r}4,018 \\
5,697 \\
4,725 \\
100 \\
100\end{array}$ & $\begin{array}{r}1,070 \\
1,531 \\
1,270 \\
0 \\
0 \\
0\end{array}$ & $\begin{array}{r}1,751 \\
2,496 \\
2,067 \\
0 \\
0 \\
0\end{array}$ & $\begin{array}{r}0 \\
0 \\
0 \\
14,400 \\
0 \\
0\end{array}$ & $\begin{array}{r}6,839 \\
9,724 \\
8,062 \\
14,500 \\
100 \\
0\end{array}$ \\
\hline Totals & 37,614 & 128,253 & 15,833 & 14,400 & 196,100 \\
\hline
\end{tabular}


TABLE A.17. MRS/IS Facility Co-located With a Reprocessing Plant--Delayed Disposal Scenario, Operating Costs: Cask Storage (thousands of mid-1982 dollars)

\begin{tabular}{|c|c|c|c|c|c|}
\hline Year & Manpower & Supplies & Utilities & Decom. & Total \\
\hline $\begin{array}{l}1990 \\
1991 \\
1992 \\
1993 \\
1994\end{array}$ & $\begin{array}{r}457 \\
817 \\
1,176 \\
1,176 \\
1,176\end{array}$ & $\begin{array}{l}134 \\
269 \\
403 \\
403 \\
403\end{array}$ & $\begin{array}{r}0 \\
140 \\
211 \\
223 \\
231\end{array}$ & $\begin{array}{l}0 \\
0 \\
0 \\
0 \\
0\end{array}$ & $\begin{array}{r}591 \\
1,226 \\
1,790 \\
1,802 \\
1,810\end{array}$ \\
\hline $\begin{array}{l}1995 \\
1996 \\
1997 \\
1998 \\
1999\end{array}$ & $\begin{array}{l}1,176 \\
1,176 \\
1,176 \\
1,176 \\
1,176\end{array}$ & $\begin{array}{l}403 \\
403 \\
403 \\
403 \\
403\end{array}$ & $\begin{array}{l}236 \\
241 \\
245 \\
250 \\
255\end{array}$ & $\begin{array}{l}0 \\
0 \\
0 \\
0 \\
0\end{array}$ & $\begin{array}{l}1,815 \\
1,820 \\
1,824 \\
1,829 \\
1,834\end{array}$ \\
\hline $\begin{array}{l}2000 \\
2001 \\
2002 \\
2003 \\
2004\end{array}$ & $\begin{array}{l}1,633 \\
1,993 \\
2,352 \\
2,352 \\
2,352\end{array}$ & $\begin{array}{l}538 \\
673 \\
807 \\
807 \\
807\end{array}$ & $\begin{array}{l}260 \\
400 \\
486 \\
500 \\
513\end{array}$ & $\begin{array}{l}0 \\
0 \\
0 \\
0 \\
0\end{array}$ & $\begin{array}{l}2,431 \\
3,066 \\
3,645 \\
3,659 \\
3,672\end{array}$ \\
\hline $\begin{array}{l}2005 \\
2006 \\
2007 \\
2008 \\
2009\end{array}$ & $\begin{array}{l}3,286 \\
3,986 \\
3,828 \\
3,628 \\
3,628\end{array}$ & $\begin{array}{l}1,075 \\
1,341 \\
1,468 \\
1,209 \\
1,209\end{array}$ & $\begin{array}{l}530 \\
686 \\
982 \\
683 \\
730\end{array}$ & $\begin{array}{l}0 \\
0 \\
0 \\
0 \\
0\end{array}$ & $\begin{array}{l}4,891 \\
6,013 \\
6,278 \\
5,520 \\
5,567\end{array}$ \\
\hline $\begin{array}{l}2010 \\
2011 \\
2012 \\
2013 \\
2014\end{array}$ & $\begin{array}{l}4,562 \\
4,386 \\
3,728 \\
3,728 \\
1,100\end{array}$ & $\begin{array}{r}1,478 \\
1,599 \\
922 \\
804 \\
259\end{array}$ & $\begin{array}{r}814 \\
1,028 \\
847 \\
732 \\
650\end{array}$ & $\begin{array}{l}0 \\
0 \\
0 \\
0 \\
0\end{array}$ & $\begin{array}{l}6,854 \\
7,013 \\
5,497 \\
5,264 \\
2,009\end{array}$ \\
\hline $\begin{array}{l}2015 \\
2016 \\
2017 \\
2018 \\
2019\end{array}$ & $\begin{array}{r}857 \\
763 \\
1,836 \\
1,836 \\
3,011\end{array}$ & $\begin{array}{r}36 \\
25 \\
155 \\
205 \\
250\end{array}$ & $\begin{array}{r}715 \\
916 \\
1,121 \\
1,207 \\
1,317\end{array}$ & $\begin{array}{l}0 \\
0 \\
0 \\
0 \\
0\end{array}$ & $\begin{array}{r}1608 \\
1704 \\
3,112 \\
3,248 \\
4,578\end{array}$ \\
\hline $\begin{array}{l}2020 \\
2021 \\
2022 \\
2023 \\
2024\end{array}$ & $\begin{array}{l}3,562 \\
5,607 \\
5,607 \\
6,517 \\
7,527\end{array}$ & $\begin{array}{l}488 \\
652 \\
805 \\
960 \\
949\end{array}$ & $\begin{array}{l}1,526 \\
1,638 \\
1,742 \\
1,871 \\
1,986\end{array}$ & $\begin{array}{l}0 \\
0 \\
0 \\
0 \\
0\end{array}$ & $\begin{array}{r}5,576 \\
7,897 \\
8,154 \\
9,348 \\
10,462\end{array}$ \\
\hline $\begin{array}{l}2025 \\
2026 \\
2027 \\
2028 \\
2029 \\
2030 \\
2031 \\
2032 \\
2033 \\
2034 \\
2035\end{array}$ & $\begin{array}{r}8,722 \\
9,766 \\
11,609 \\
10,714 \\
9,589 \\
9,276 \\
7,570 \\
7,570 \\
3,863 \\
0 \\
0\end{array}$ & $\begin{array}{r}1,042 \\
1,288 \\
1,571 \\
1,428 \\
1,382 \\
1,291 \\
1,122 \\
1,074 \\
537 \\
0 \\
0\end{array}$ & $\begin{array}{r}2,036 \\
2,174 \\
2,217 \\
2,115 \\
1,903 \\
1,327 \\
1,411 \\
1,411 \\
699 \\
0 \\
0\end{array}$ & $\begin{array}{r}0 \\
0 \\
0 \\
0 \\
0 \\
0 \\
0 \\
0 \\
7,690 \\
4,523 \\
6,787\end{array}$ & $\begin{array}{r}11,800 \\
13,228 \\
15,397 \\
14,257 \\
12,874 \\
12,394 \\
10,103 \\
10,051 \\
12,789 \\
4,523 \\
6,787\end{array}$ \\
\hline Totals & 173,026 & 33,879 & 41,705 & 19,000 & 267,610 \\
\hline
\end{tabular}


TABLE A.18. MRS/IS Facility Co-located With a Reprocessing Plant--Delayed Disposal Scenario, Operating Costs: Drywell Storage (thousands of mid-1982 dollars)

\begin{tabular}{|c|c|c|c|c|c|}
\hline Year & Manpower & Supplies & Utilities & Decom. & Total \\
\hline $\begin{array}{l}1990 \\
1991 \\
1992 \\
1993 \\
1994\end{array}$ & $\begin{array}{r}817 \\
1,665 \\
2,438 \\
2,344 \\
2,344\end{array}$ & $\begin{array}{r}99 \\
198 \\
296 \\
296 \\
296\end{array}$ & $\begin{array}{r}0 \\
247 \\
370 \\
382 \\
389\end{array}$ & $\begin{array}{l}0 \\
0 \\
0 \\
0 \\
0\end{array}$ & $\begin{array}{r}916 \\
2,110 \\
3,104 \\
3,022 \\
3,029\end{array}$ \\
\hline $\begin{array}{l}1995 \\
1996 \\
1997 \\
1998 \\
1999\end{array}$ & $\begin{array}{l}2,344 \\
2,344 \\
2,344 \\
2,344 \\
2,344\end{array}$ & $\begin{array}{l}296 \\
296 \\
296 \\
296 \\
296\end{array}$ & $\begin{array}{l}394 \\
398 \\
403 \\
407 \\
411\end{array}$ & $\begin{array}{l}0 \\
0 \\
0 \\
0 \\
0\end{array}$ & $\begin{array}{l}3,034 \\
3,038 \\
3,043 \\
3,047 \\
3,051\end{array}$ \\
\hline $\begin{array}{l}2000 \\
2001 \\
2002 \\
2003 \\
2004\end{array}$ & $\begin{array}{l}3,161 \\
4,009 \\
4,782 \\
4,688 \\
4,688\end{array}$ & $\begin{array}{l}395 \\
494 \\
592 \\
592 \\
592\end{array}$ & $\begin{array}{l}416 \\
641 \\
778 \\
807 \\
821\end{array}$ & $\begin{array}{l}0 \\
0 \\
0 \\
0 \\
0\end{array}$ & $\begin{array}{l}3,972 \\
5,144 \\
6,152 \\
6,087 \\
6,101\end{array}$ \\
\hline $\begin{array}{l}2005 \\
2006 \\
2007 \\
2008 \\
2009\end{array}$ & $\begin{array}{l}6,322 \\
8,018 \\
7,320 \\
7,132 \\
7,132\end{array}$ & $\begin{array}{l}790 \\
988 \\
899 \\
888 \\
888\end{array}$ & $\begin{array}{r}848 \\
1,098 \\
1,571 \\
1,093 \\
1,168\end{array}$ & $\begin{array}{l}0 \\
0 \\
0 \\
0 \\
0\end{array}$ & $\begin{array}{r}7,960 \\
10,104 \\
9,790 \\
9,113 \\
9,188\end{array}$ \\
\hline $\begin{array}{l}2010 \\
2011 \\
2012 \\
2013 \\
2014\end{array}$ & $\begin{array}{r}8,766 \\
8,218 \\
9,764 \\
9,576 \\
500\end{array}$ & $\begin{array}{r}1,086 \\
999 \\
318 \\
246 \\
11\end{array}$ & $\begin{array}{l}1,302 \\
1,645 \\
1,355 \\
1,171 \\
1,040\end{array}$ & $\begin{array}{l}0 \\
0 \\
0 \\
0 \\
0\end{array}$ & $\begin{array}{r}11,154 \\
10,862 \\
11,437 \\
11,043 \\
1,551\end{array}$ \\
\hline $\begin{array}{l}2015 \\
2016 \\
2017 \\
2018 \\
2019\end{array}$ & $\begin{array}{l}3,545 \\
2,218 \\
4,618 \\
3,291 \\
9,406\end{array}$ & $\begin{array}{r}345 \\
205 \\
181 \\
526 \\
1,151\end{array}$ & $\begin{array}{l}1,144 \\
1,466 \\
1,794 \\
1,931 \\
2,107\end{array}$ & $\begin{array}{l}0 \\
0 \\
0 \\
0 \\
0\end{array}$ & $\begin{array}{r}5,034 \\
3,889 \\
6,593 \\
5,748 \\
12,664\end{array}$ \\
\hline $\begin{array}{l}2020 \\
2021 \\
2022 \\
2023 \\
2024\end{array}$ & $\begin{array}{r}6,439 \\
11,871 \\
11,676 \\
15,343 \\
15,330\end{array}$ & $\begin{array}{r}823 \\
799 \\
1,055 \\
1,656 \\
1,516\end{array}$ & $\begin{array}{l}2,442 \\
2,621 \\
2,787 \\
2,994 \\
3,178\end{array}$ & $\begin{array}{l}0 \\
0 \\
0 \\
0 \\
0\end{array}$ & $\begin{array}{r}9,704 \\
15,291 \\
15,518 \\
19,993 \\
20,024\end{array}$ \\
\hline $\begin{array}{l}2025 \\
2026 \\
2027 \\
2028 \\
2029 \\
2030 \\
2031 \\
2032 \\
2033 \\
2034 \\
2035\end{array}$ & $\begin{array}{r}14,740 \\
16,037 \\
18,767 \\
17,321 \\
15,527 \\
14,618 \\
12,287 \\
12,287 \\
5,970 \\
0 \\
0\end{array}$ & $\begin{array}{r}1,712 \\
1,876 \\
2,260 \\
2,158 \\
2,079 \\
1,917 \\
1,733 \\
1,642 \\
821 \\
0 \\
0\end{array}$ & $\begin{array}{r}3,295 \\
3,478 \\
3,546 \\
3,314 \\
3,049 \\
2,672 \\
2,258 \\
2,258 \\
1,118 \\
0 \\
0\end{array}$ & $\begin{array}{r}0 \\
0 \\
0 \\
0 \\
0 \\
0 \\
0 \\
0 \\
45,900 \\
27,000 \\
40,500\end{array}$ & $\begin{array}{l}20,747 \\
21,391 \\
24,573 \\
22,793 \\
20,655 \\
19,207 \\
16,278 \\
16,187 \\
53,809 \\
27,000 \\
40,500\end{array}$ \\
\hline Total & 327,695 & 36,948 & 66,607 & 113,400 & 544,650 \\
\hline
\end{tabular}


TABLE A.19. Stand-Alone Facility--Reference Scenario, Life-Cycle Cash Flows: Cask Storage (millions mid-1982 dollars)

\begin{tabular}{|c|c|c|c|c|c|}
\hline \multirow[b]{2}{*}{ Year } & \multicolumn{2}{|c|}{ Capital Costs } & \multirow[b]{2}{*}{$\begin{array}{c}\text { Operating } \\
\text { Costs } \\
\end{array}$} & \multirow[b]{2}{*}{$\begin{array}{l}\text { Transpert } \\
\text { Costs }\end{array}$} & \multirow[b]{2}{*}{ Total } \\
\hline & $\begin{array}{l}\text { Handling and } \\
\text { Support } \\
\end{array}$ & Storage & & & \\
\hline $\begin{array}{l}1984 \\
1985 \\
1986 \\
1987 \\
1988\end{array}$ & $\begin{array}{l}15.649 \\
31.298 \\
46.949 \\
78.248 \\
80.748\end{array}$ & $\begin{array}{r}2.707 \\
5.416 \\
8.124 \\
13.539 \\
13.539\end{array}$ & & & $\begin{array}{l}18.356 \\
36.714 \\
55.073 \\
91.787 \\
94.287\end{array}$ \\
\hline $\begin{array}{l}1989 \\
1990 \\
1991 \\
1992 \\
1993\end{array}$ & 65.097 & $\begin{array}{l}32.263 \\
29.750 \\
43.750 \\
43.750 \\
49.213\end{array}$ & $\begin{array}{l}12.783 \\
14.734 \\
15.313 \\
15.313\end{array}$ & $\begin{array}{r}6.200 \\
11.920 \\
18.040 \\
18.040\end{array}$ & $\begin{array}{l}97.360 \\
48.733 \\
70.404 \\
77.103 \\
82.566\end{array}$ \\
\hline $\begin{array}{l}1994 \\
1995 \\
1996 \\
1997 \\
1998\end{array}$ & & $\begin{array}{l}66.342 \\
43.750 \\
43.750\end{array}$ & $\begin{array}{l}15.313 \\
15.400 \\
15.400 \\
15.400 \\
12.870\end{array}$ & $\begin{array}{l}18.040 \\
18.040 \\
18.040 \\
18.040\end{array}$ & $\begin{array}{l}99.695 \\
77.190 \\
77.190 \\
33.440 \\
12.870\end{array}$ \\
\hline $\begin{array}{l}1999 \\
2000 \\
2001 \\
2002 \\
2003\end{array}$ & & & $\begin{array}{l}12.870 \\
12.870 \\
12.506 \\
15.622 \\
16.413\end{array}$ & & $\begin{array}{l}12.870 \\
12.870 \\
12.506 \\
15.622 \\
16.413\end{array}$ \\
\hline $\begin{array}{l}2004 \\
2005 \\
2006 \\
2007 \\
2008\end{array}$ & & & $\begin{array}{l}16.413 \\
16.096 \\
14.035 \\
14.035 \\
12.506\end{array}$ & & $\begin{array}{l}16.413 \\
16.096 \\
14.035 \\
14.035 \\
12.506\end{array}$ \\
\hline $\begin{array}{l}2009 \\
2010 \\
2011 \\
2012 \\
2013\end{array}$ & & & $\begin{array}{l}12.506 \\
12.506 \\
12.559 \\
12.559 \\
14.662\end{array}$ & $\begin{array}{r}8.970 \\
10.020\end{array}$ & $\begin{array}{l}12.506 \\
12.506 \\
21.529 \\
12.559 \\
24.682\end{array}$ \\
\hline $\begin{array}{l}2014 \\
2015 \\
2016 \\
2017 \\
2018\end{array}$ & & & $\begin{array}{l}14.662 \\
15.243 \\
13.721 \\
13.721 \\
13.721\end{array}$ & 14.780 & $\begin{array}{l}29.442 \\
15.243 \\
13.721 \\
13.721 \\
13.721\end{array}$ \\
\hline $\begin{array}{l}2019 \\
2020 \\
2021\end{array}$ & & & $\begin{array}{l}13.721 \\
20.338 \\
20.338\end{array}$ & & $\begin{array}{l}13.721 \\
20.338 \\
20.338\end{array}$ \\
\hline unted Total & 317.989 & 395.893 & 466.149 & 160.130 & $\begin{array}{l}1340.161 \\
1026.256\end{array}$ \\
\hline
\end{tabular}

(a) Transportation costs are incremental to those which would be incurred if no MRS existed. 
TABLE A.20. Stand-Alone Facility--Reference Scenario, Life-Cycle Cash Flows: Drywell Storage (millions mid-1982 dollars)

\begin{tabular}{|c|c|c|c|c|c|}
\hline \multirow[b]{2}{*}{ Year } & \multicolumn{2}{|c|}{ Capital Costs } & \multirow[b]{2}{*}{$\begin{array}{l}\text { Operating } \\
\text { Costs } \\
\end{array}$} & \multirow[b]{2}{*}{$\begin{array}{l}\text { Transpert } \\
\text { Costs }\end{array}$} & \multirow[b]{2}{*}{ Total } \\
\hline & $\begin{array}{l}\text { Handling and } \\
\text { Support } \\
\end{array}$ & Storage & & & \\
\hline $\begin{array}{l}1984 \\
1985 \\
1986 \\
1987 \\
1988\end{array}$ & $\begin{array}{l}16.083 \\
32.165 \\
48.248 \\
80.414 \\
80.414\end{array}$ & $\begin{array}{r}2.707 \\
5.416 \\
8.124 \\
13.539 \\
15.113\end{array}$ & & & $\begin{array}{l}18.790 \\
37.581 \\
56.372 \\
93.953 \\
95.527\end{array}$ \\
\hline $\begin{array}{l}1989 \\
1990 \\
1991 \\
1992 \\
1993\end{array}$ & 64.330 & $\begin{array}{r}12.405 \\
6.075 \\
9.119 \\
9.119 \\
14.582\end{array}$ & $\begin{array}{l}13.853 \\
15.846 \\
16.425 \\
16.425\end{array}$ & $\begin{array}{r}6.200 \\
11.920 \\
18.040 \\
18.040\end{array}$ & $\begin{array}{l}76.735 \\
26.128 \\
36.885 \\
43.584 \\
49.047\end{array}$ \\
\hline $\begin{array}{l}1994 \\
1995 \\
1996 \\
1997 \\
1998\end{array}$ & & $\begin{array}{r}25.506 \\
9.119 \\
9.119\end{array}$ & $\begin{array}{l}16.425 \\
16.425 \\
16.425 \\
16.425 \\
13.853\end{array}$ & $\begin{array}{l}18.040 \\
18.040 \\
18.040 \\
18.040\end{array}$ & $\begin{array}{l}59.971 \\
43.584 \\
43.584 \\
34.465 \\
13.853\end{array}$ \\
\hline $\begin{array}{l}1999 \\
2000 \\
2001 \\
2002 \\
2003\end{array}$ & & & $\begin{array}{l}13.853 \\
13.853 \\
13.512 \\
16.646 \\
17.438\end{array}$ & & $\begin{array}{l}13.853 \\
13.853 \\
13.512 \\
16.646 \\
17.438\end{array}$ \\
\hline $\begin{array}{l}2004 \\
2005 \\
2006 \\
2007 \\
2008\end{array}$ & & & $\begin{array}{l}17.438 \\
17.121 \\
15.060 \\
15.060 \\
13.489\end{array}$ & & $\begin{array}{l}17.438 \\
17.121 \\
15.060 \\
15.060 \\
13.489\end{array}$ \\
\hline $\begin{array}{l}2009 \\
2010 \\
2011 \\
2012 \\
2013\end{array}$ & & & $\begin{array}{l}13.489 \\
13.489 \\
13.542 \\
13.542 \\
15.687\end{array}$ & $\begin{array}{r}8.970 \\
10.020 \\
14.780\end{array}$ & $\begin{array}{l}13.489 \\
22.459 \\
13.542 \\
23.562 \\
30.467\end{array}$ \\
\hline $\begin{array}{l}2014 \\
2015 \\
2016 \\
2017 \\
2018\end{array}$ & & & $\begin{array}{l}15.687 \\
16.267 \\
14.745 \\
14.745 \\
14.745\end{array}$ & & $\begin{array}{l}15.687 \\
16.267 \\
14.745 \\
14.745 \\
14.745\end{array}$ \\
\hline $\begin{array}{l}2019 \\
2020 \\
2021\end{array}$ & & & $\begin{array}{l}14.745 \\
23.080 \\
23.080\end{array}$ & & $\begin{array}{l}14.745 \\
23.080 \\
23.080\end{array}$ \\
\hline nted Total & 321.654 & 139.943 & 502.415 & 160.130 & $\begin{array}{r}1124.142 \\
846.394\end{array}$ \\
\hline
\end{tabular}

(a) Transportation costs are incremental to those which would be incurred if no MRS existed. 
TABLE A.21. Stand-Alone Facility--Delayed Reprocessing Scenario, LifeCycle Cash Flows: Cask Storage (millions mid-1982 dollars)

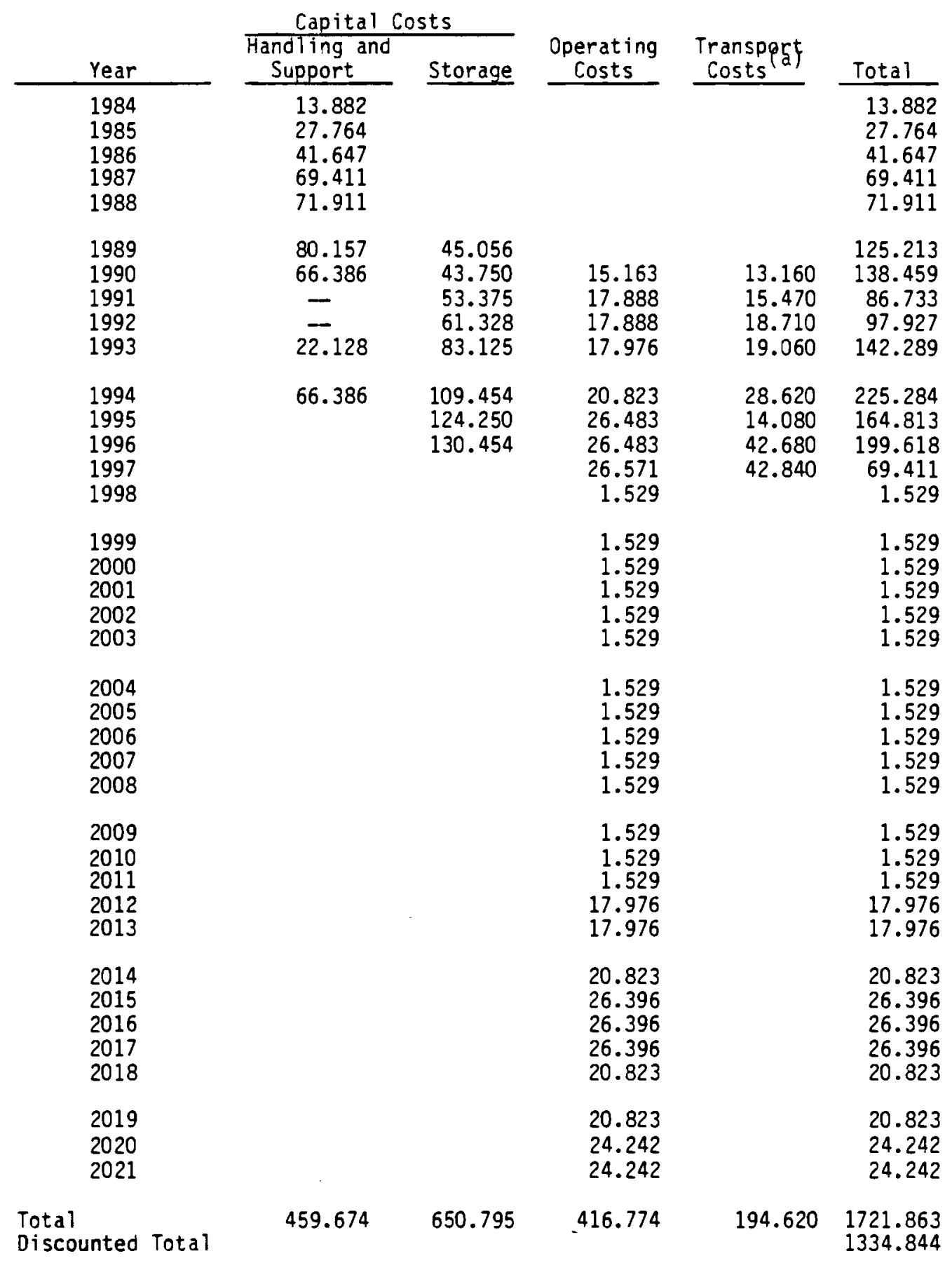

(a) Transportation costs are incremental to those which would be incurred if no MRS existed. 
TABLE A.22. Stand-Alone Facility--Delayed Reprocessing Scenario, Life-Cycle Cash Flows: Drywell Storage (millions mid-1982 dollars)

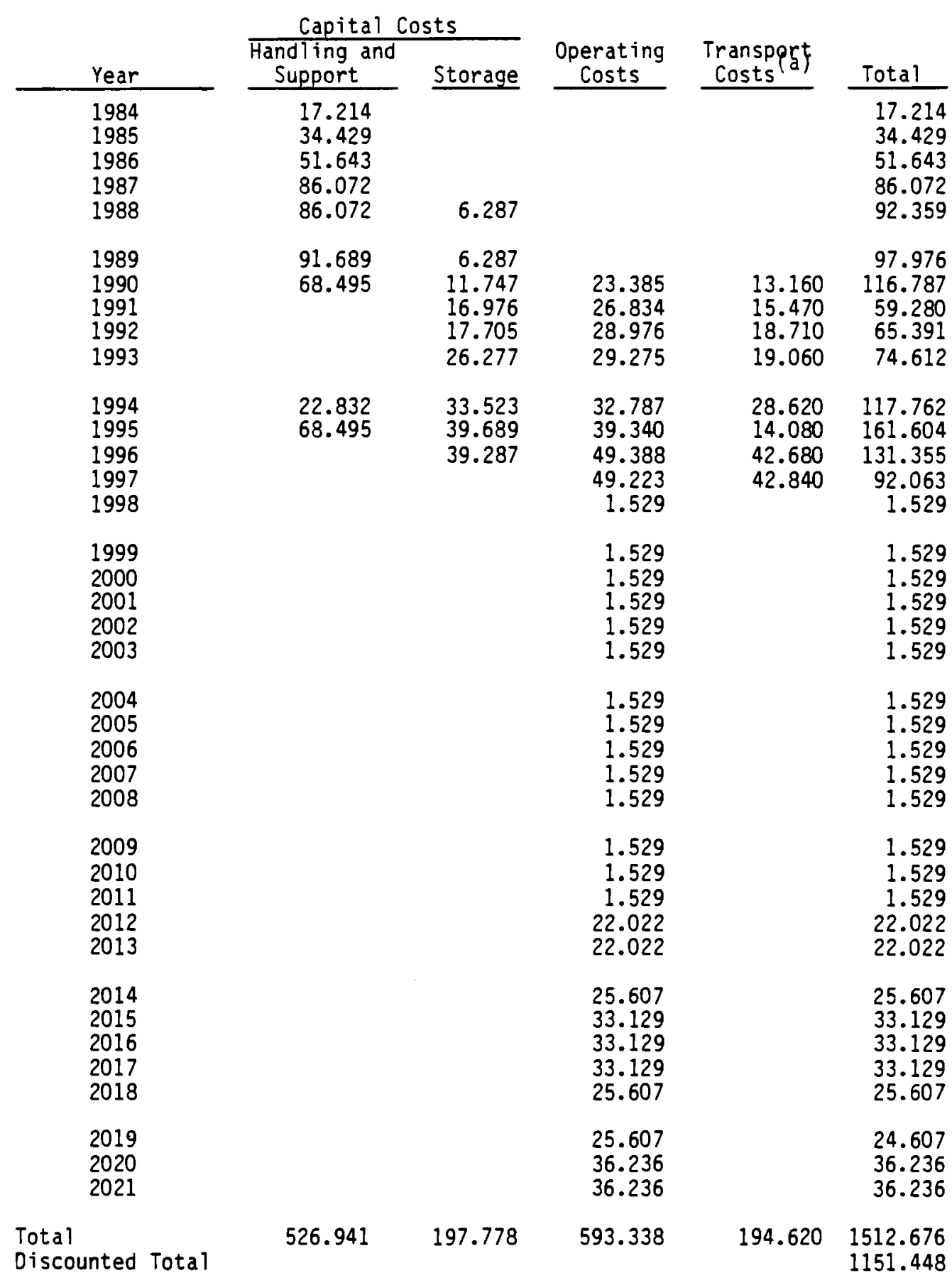

(a) Transportation costs are incremental to those which would be incurred if no MRS existed. 
TABLE A.23. Stand-Alone Facility--Delayed Disposal Scenario, Life-Cycle Cash Flows: Cask Storage (millions mid-1982 dollars)

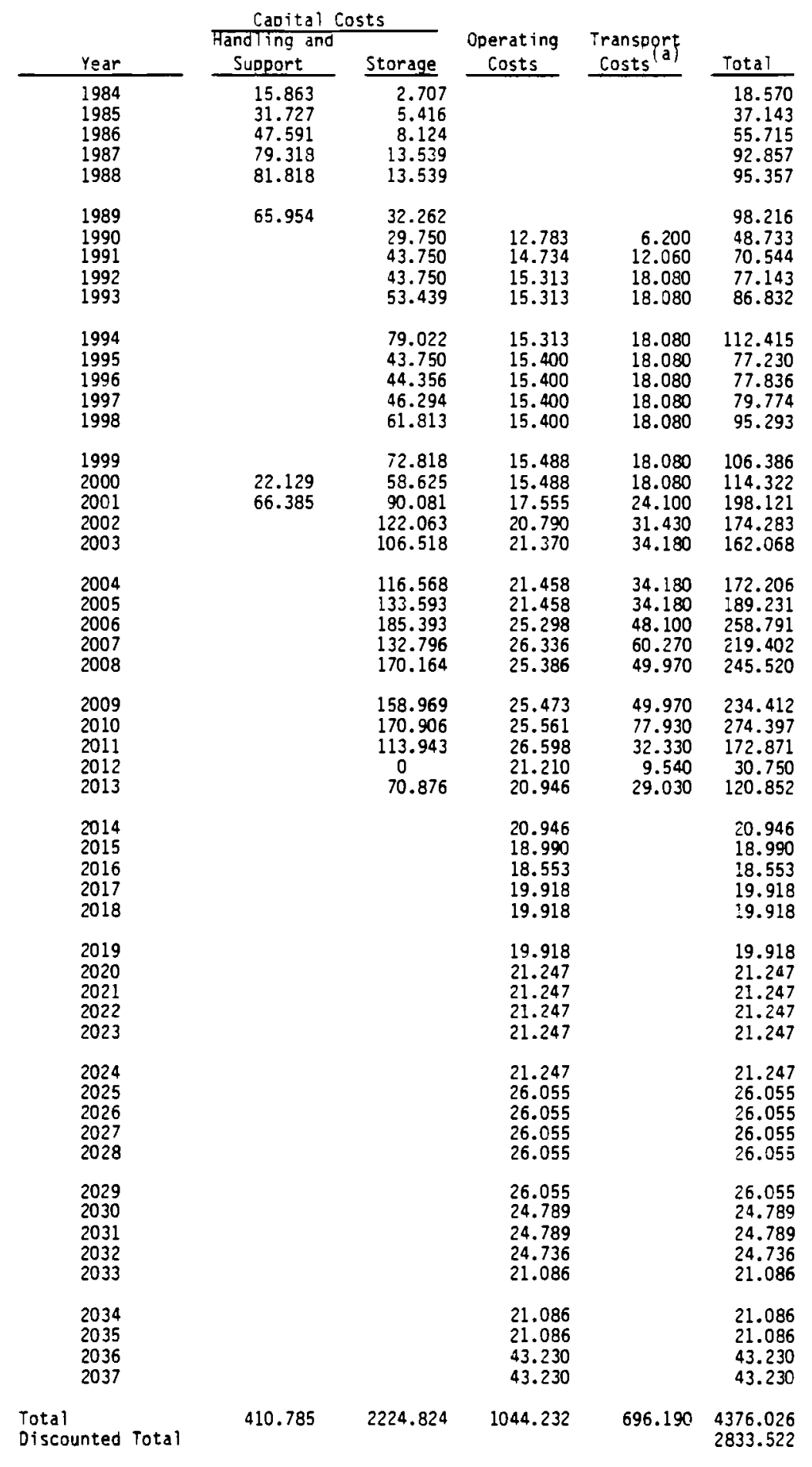

(a) Transportation costs are incremental to those which would be incurred if no MRS existed. 
TABLE A.24. Stand-Alone Facility--Delayed Disposal Case Life-Cycle Cash Flows: Drywell Storage (millions mid-1982 dollars)

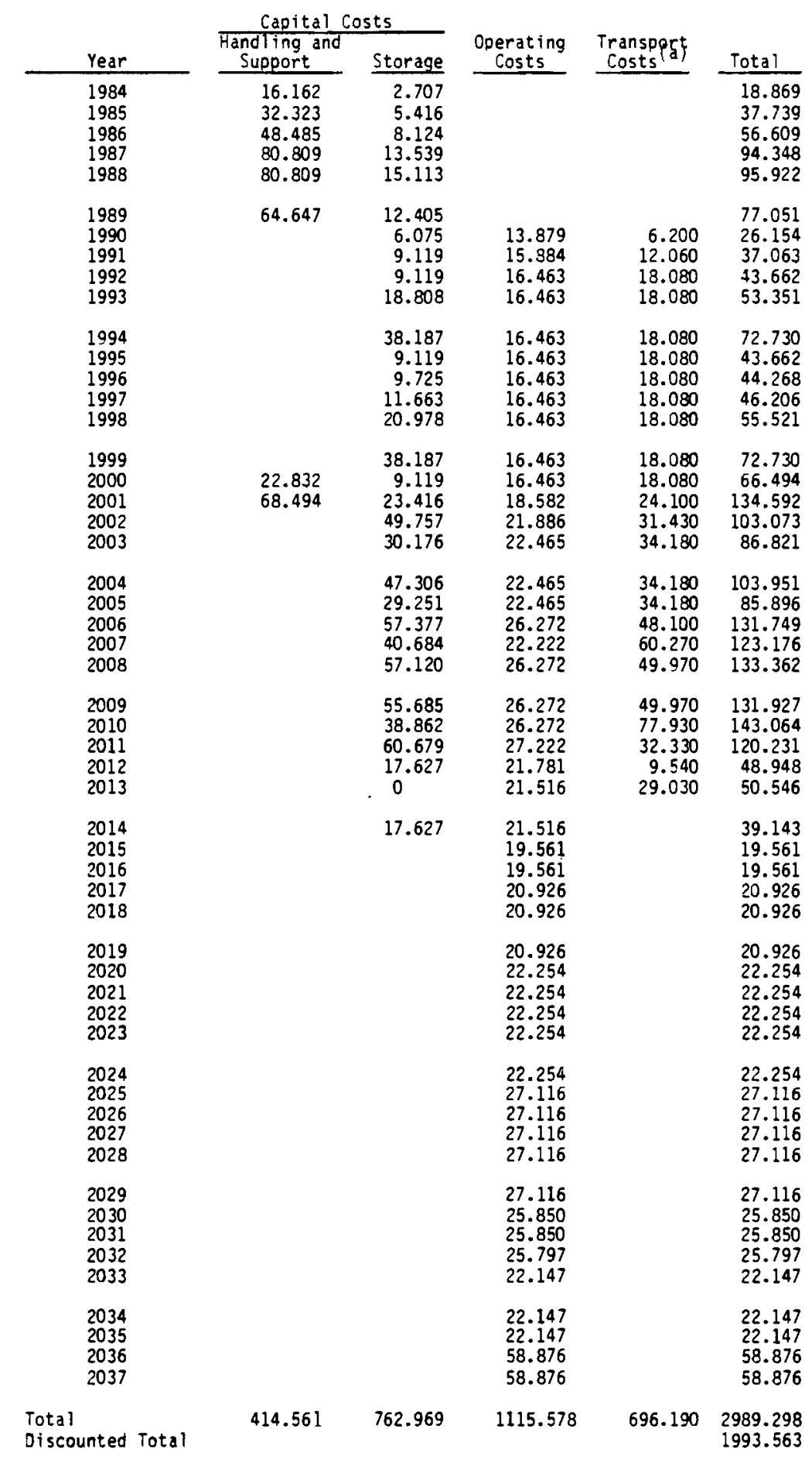

(a) Transportation costs are incremental to those which would be incurred if no MRS existed. 
TABLE A.25. Stand-Alone Facility--Reference Scenario, Capital Cost: Cask Storage (thousands of mid-1982 dollars)

\begin{tabular}{|c|c|c|c|c|}
\hline & $\begin{array}{c}\text { 1st } \\
\text { Module }\end{array}$ & $\begin{array}{c}\text { 2nd } \\
\text { Module }\end{array}$ & $\begin{array}{c}3 r d \\
\text { Module } \\
\end{array}$ & Total \\
\hline Site Improvements & 7,408 & & & 7,408 \\
\hline Support Facilities & 59,208 & & & 59,208 \\
\hline \multicolumn{5}{|l|}{ Spent Fuel/HLW Handling } \\
\hline Facility & 99,311 & & & 99,311 \\
\hline Transfer System & 2,967 & & & 2,967 \\
\hline TRU Receiving Transfer Facility & 19,796 & & & 19,796 \\
\hline Subtotal - Direct Costs & 188,690 & & & 188,690 \\
\hline Engineering Services & 49,059 & & & 49,059 \\
\hline Contingency & 59,437 & & & 59,437 \\
\hline Owner's Cost & 20,803 & & & 20,803 \\
\hline $\begin{array}{l}\text { Total Cost - Handling Support } \\
\text { Structures }\end{array}$ & 317,989 & & & 317,989 \\
\hline (Cask/Drywe11) Cost & 11,900 & 233,800 & & 245,700 \\
\hline Other SF/HLW Storage Costs & 3,890 & 3,890 & & 7,780 \\
\hline CH-TRU Storage & 1,910 & - & & 1,910 \\
\hline RH-TRU Storage & 3,525 & - & & 3,525 \\
\hline Fuel Residue Storage & 26,700 & 13,700 & & 40,400 \\
\hline Subtotal - Direct Cost & 47,925 & 251,390 & & 299,315 \\
\hline Engineering Services & 9,367 & 3,386 & & 12,753 \\
\hline Contingency & 14,323 & 63,694 & & 78,017 \\
\hline Owner's Cost & 3,972 & 1,836 & & 5,808 \\
\hline Total Cost - Storage Systems & 75,587 & 320,306 & & 395,893 \\
\hline Total Capital Cost & 393,576 & 320,306 & & 713,882 \\
\hline
\end{tabular}


TABLE A.26. Stand-Alone Facility--Reference Scenario, Capital Cost:

Drywell Storage (thousands of mid-1982 dollars)

\begin{tabular}{|c|c|c|c|c|}
\hline & $\begin{array}{c}\text { 1st } \\
\text { Module }\end{array}$ & $\begin{array}{l}\text { 2nd } \\
\text { Module }\end{array}$ & $\begin{array}{c}3 r d \\
\text { Module } \\
\end{array}$ & Total \\
\hline Site Improvements & 6,488 & & & 6,488 \\
\hline Support Facilities & 59,208 & & & 59,208 \\
\hline \multicolumn{5}{|l|}{ Spent Fuel/HLW Handling } \\
\hline Facility & 101,502 & & & 101,502 \\
\hline Transfer System & 3,870 & & & 3,870 \\
\hline TRU Receiving \& Transfer Facility & 19,796 & & & 19,796 \\
\hline Subtotal - Direct Costs & 190,864 & & & 190,864 \\
\hline Engineering Services & 49,625 & & & 49,625 \\
\hline Contingency & 60,122 & & & 60,122 \\
\hline Owner's Cost & 21,043 & & & 21,043 \\
\hline $\begin{array}{l}\text { Total Cost - Handling \& Support } \\
\text { Structures }\end{array}$ & 321,654 & & & 321,654 \\
\hline (Cask/Drywe11) Cost & 2,353 & 46,987 & & 49,340 \\
\hline Other SF/HLW Storage Costs & - & - & & - \\
\hline CH-TRU Storage & 1,910 & - & & 1,910 \\
\hline RH-TRU Storage & 3,525 & - & & 3,525 \\
\hline Fuel Residue Storage & 26,700 & 13,700 & & 40,400 \\
\hline Subtotal - Direct Cost & 34,488 & 60,687 & & 95,175 \\
\hline Engineering Services & 8,355 & 2,637 & & 10,992 \\
\hline Contingency & 10,711 & 15,831 & & 26,542 \\
\hline Owner's Cost & 3,749 & 3,485 & & 7,234 \\
\hline Total Cost - Storage Systems & 57,303 & 82,640 & & 139,943 \\
\hline Total Capital Cost & 378,957 & 82,640 & & 461,597 \\
\hline
\end{tabular}


TABLE A.27. Stand-Alone Facility--Delayed Reprocessing Scenario, Capital Cost: Cask Storage (thousands of mid-1982 dollars)

\begin{tabular}{|c|c|c|c|c|}
\hline & $\begin{array}{c}1 s t \\
\text { Module }\end{array}$ & $\begin{array}{c}\text { 2nd } \\
\text { Module }\end{array}$ & $\begin{array}{c}3 r d \\
\text { Module } \\
\end{array}$ & Total \\
\hline Site Improvements & 6,230 & - & - & 6,230 \\
\hline Support Facilities & 59,208 & - & - & 59,208 \\
\hline \multicolumn{5}{|l|}{ Spent Fuel/HLW Handling } \\
\hline Facility & 99,311 & 55,496 & 55,496 & 210,303 \\
\hline Transfer System & 2,967 & - & - & 2,967 \\
\hline TRU Receiving \& Transfer Facility & - & - & - & \\
\hline Subtotal - Direct Costs & 167,716 & 55,496 & 55,496 & 278,708 \\
\hline Engineering Services & 43,606 & 10,683 & 10,683 & 64,972 \\
\hline Cont ingency & 52,831 & 16,545 & 16,545 & 85,921 \\
\hline Owner's Cost & 18,491 & 5,791 & 5,791 & 30,073 \\
\hline $\begin{array}{l}\text { Total Cost - Handling \& Support } \\
\text { Structures }\end{array}$ & 282,644 & 88,515 & 88,515 & 459,674 \\
\hline (Cask/Drywe11) Cost & 30,800 & 469,700 & - & 500,500 \\
\hline Other SF/HLW Storage Costs & 3,890 & 3,890 & 7,780 & 15,560 \\
\hline CH-TRU Storage & - & - & - & - \\
\hline RH-TRU Storage & - & - & - & - \\
\hline Fuel Residue Storage & - & - & - & - \\
\hline Subtotal - Direct Cost & 34,690 & 473,590 & 7,780 & 516,060 \\
\hline Engineering Services & 1,011 & 749 & 1,498 & 3,258 \\
\hline Contingency & 8,925 & 118,585 & 2,320 & 129,830 \\
\hline Owner's Cost & 429 & 406 & 812 & 1,647 \\
\hline Total Cost - Storage Systems & 45,055 & 593,330 & $\underline{12,410}$ & 650,795 \\
\hline
\end{tabular}

Total Capital Cost 
TABLE A.28. Stand-Alone Facility--Delayed Reprocessing Scenario, Capital Cost: Drywell Storage (thousands of mid-1982 dollars)

\begin{tabular}{|c|c|c|c|c|}
\hline & $\begin{array}{c}\text { lst } \\
\text { Module } \\
\end{array}$ & $\begin{array}{c}\text { 2nd } \\
\text { Module } \\
\end{array}$ & $\begin{array}{c}3 r d \\
\text { Module } \\
\end{array}$ & Total \\
\hline Site Improvements & 6,630 & - & - & 6,630 \\
\hline Support Facilities & 59,208 & - & - & 59,208 \\
\hline \multicolumn{5}{|l|}{ Spent Fuel/HLW Handling } \\
\hline Facility & 136,531 & 57,259 & 57,259 & 251,049 \\
\hline Transfer System & 1,926 & - & - & 1,926 \\
\hline TRU Receiving \& Transfer Facility & - & - & - & - \\
\hline Subtotal - Direct Costs & 204,295 & 57,259 & 57,259 & 318,813 \\
\hline Engineering Services & 53,117 & 11,022 & 11,022 & 75,161 \\
\hline Contingency & 64,353 & 17,070 & 17,070 & 98,493 \\
\hline Owner's Cost & 22,524 & 5,975 & 5,975 & 34,474 \\
\hline $\begin{array}{l}\text { Total Cost - Handling \& Support } \\
\text { Structures }\end{array}$ & 344,289 & 91,326 & 91,326 & 526,941 \\
\hline (Cask/Drywe11) Cost & 9,401 & 143,153 & -0 & 152,554 \\
\hline Other SF/HLW Storage Costs & - & - & - & - \\
\hline CH-TRU Storage & - & - & - & - \\
\hline RH-TRU Storage & - & - & - & - \\
\hline Fuel Residue Storage & - & - & - & - \\
\hline Subtotal - Direct Cost & 9,401 & 143,153 & - & 152,554 \\
\hline Engineering Services & - & - & - & - \\
\hline Contingency & 2,350 & 35,788 & - & 38,138 \\
\hline Owner's Cost & 823 & 6,263 & - & 7,086 \\
\hline Total Cost - Storage Systems & 12,574 & 185,204 & -0 & 197,778 \\
\hline Total Capital Cost & 356,863 & 276,350 & 91,326 & 724,719 \\
\hline
\end{tabular}


TABLE A.29. Stand-Alone Facility--Delayed Disposal Scenario, Capital Cost: Cask Storage (thousands of mid-1982 dollars)

\begin{tabular}{|c|c|c|c|c|}
\hline & $\begin{array}{c}\text { lst } \\
\text { Module }\end{array}$ & $\begin{array}{l}\text { 2nd } \\
\text { Module } \\
\end{array}$ & $\begin{array}{c}3 r d \\
\text { Module } \\
\end{array}$ & Total \\
\hline Site Improvements & 9,948 & - & & 9,948 \\
\hline Support Facilities & 59,208 & - & & 59,208 \\
\hline \multicolumn{5}{|l|}{ Spent Fuel/HLW Handling } \\
\hline Facility & 99,311 & 55,496 & & 154,807 \\
\hline Transfer System & 2,967 & - & & 2,967 \\
\hline TRU Receiving \& Transfer Facility & 19,796 & - & & 19,796 \\
\hline Subtotal - Direct Costs & 191,230 & 55,496 & & 246,726 \\
\hline Engineering Services & 49,720 & 10,683 & & 60,403 \\
\hline Contingency & 60,237 & 16,545 & & 76,782 \\
\hline Owner's Cost & 21,083 & 5,791 & & 26,874 \\
\hline $\begin{array}{l}\text { Total Cost - Handling \& Support } \\
\text { Structures }\end{array}$ & 322,270 & 88,515 & & 410,785 \\
\hline (Cask/Drywel1) Cost & 11,900 & $1,404,900$ & & $1,416,800$ \\
\hline Other SF/HLW Storage Costs & 3,890 & 35,010 & & 38,900 \\
\hline CH-TRU Storage & 1,910 & 7,340 & & 9,250 \\
\hline RH-TRU Storage & 3,525 & 7,320 & & 10,845 \\
\hline Fuel Residue Storage & 26,700 & 196,800 & & 223,500 \\
\hline Subtotal - Direct Cost & 47,925 & $1,651,370$ & & $1,699,295$ \\
\hline Engineering Services & 9,367 & 47,445 & & 56,812 \\
\hline Contingency & 14,323 & 424,704 & & 439,027 \\
\hline Owner's Cost & 3,972 & 25,718 & & 29,690 \\
\hline Total Cost - Storage Systems & 75,587 & $2,149,237$ & & $2,224,824$ \\
\hline Total Capital Cost & 397,857 & $2,237,752$ & & $2,635,609$ \\
\hline
\end{tabular}


TABLE A.30. Stand-Alone Facility--Delayed Disposal Scenario, Capital Cost: Drywell Storage (thousands of mid-1982 dollars)

\begin{tabular}{|c|c|c|c|c|}
\hline & $\begin{array}{c}1 \text { st } \\
\text { Module } \\
\end{array}$ & $\begin{array}{l}\text { 2nd } \\
\text { Module }\end{array}$ & $\begin{array}{c}3 r d \\
\text { Module } \\
\end{array}$ & Total \\
\hline Site Improvements & 6,775 & - & & 6,775 \\
\hline Support Facilities & 59,208 & - & & 59,208 \\
\hline \multicolumn{5}{|l|}{ Spent Fue $1 /$ HLW Handling } \\
\hline Facility & 101,502 & 57,259 & & 158,761 \\
\hline Transfer System & 4,521 & - & & 3,870 \\
\hline TRU Receiving \& Transfer Facility & 19,796 & - & & 19,796 \\
\hline Subtotal - Direct Costs & 191,802 & 57,259 & & 249,061 \\
\hline Engineering Services & 49,869 & 11,022 & & 60,891 \\
\hline Contingency & 60,418 & 17,070 & & 77,488 \\
\hline Owner's Cost & 21,146 & 5,975 & & 27,121 \\
\hline $\begin{array}{l}\text { Total Cost - Handling \& Support } \\
\text { Structures }\end{array}$ & 323,235 & 91,326 & & 414,561 \\
\hline (Cask/Drywe11) Cost & 2,353 & 284,748 & & 287,101 \\
\hline Other SF/HLW Storage Costs & - & - & & - \\
\hline CH-TRU Storage & 1,910 & 7,340 & & 9,250 \\
\hline RH-TRU Storage & 3,525 & 7,320 & & 10,845 \\
\hline Fuel Residue Storage & 26,700 & 196,800 & & 223,500 \\
\hline Subtotal - Direct Cost & 34,488 & 496,208 & & 530,696 \\
\hline Engineering Services & 8,355 & 40,706 & & 49,061 \\
\hline Contingency & 10,711 & 134,229 & & 144,940 \\
\hline Owner's Cost & 3,749 & 34,523 & & 38,272 \\
\hline Total Cost - Storage Systems & 57,303 & 705,666 & & 762,969 \\
\hline Total Capital Cost & 380,538 & 796,992 & & $, 177,530$ \\
\hline
\end{tabular}


TABLE A.31. Stand-Alone Facility--Reference Scenario, Operating Costs: Cask Storage (thousands of mid-1982 dollars)

\begin{tabular}{|c|c|c|c|c|c|c|}
\hline Year & Labor & Consumables & $\begin{array}{c}\text { Maint.l } \\
\text { Contract } \\
\text { Labor } \\
\end{array}$ & $\begin{array}{c}\text { G\&A } \\
\text { Utilities } \\
\end{array}$ & Other & Total \\
\hline $\begin{array}{l}1990 \\
1991 \\
1992 \\
1993 \\
1994\end{array}$ & $\begin{array}{l}7,190 \\
8,774 \\
9,244 \\
9,244 \\
9,244\end{array}$ & $\begin{array}{l}719 \\
877 \\
924 \\
924 \\
924\end{array}$ & $\begin{array}{l}3,925 \\
3,925 \\
3,925 \\
3,925 \\
3,925\end{array}$ & $\begin{array}{r}949 \\
1,158 \\
1,220 \\
1,220 \\
1,220\end{array}$ & & $\begin{array}{l}12,783 \\
14,734 \\
15,313 \\
15,313 \\
15,313\end{array}$ \\
\hline $\begin{array}{l}1995 \\
1996 \\
1997 \\
1998 \\
1999\end{array}$ & $\begin{array}{l}9,244 \\
9,244 \\
9,244 \\
7,190 \\
7,190\end{array}$ & $\begin{array}{l}924 \\
924 \\
924 \\
719 \\
719\end{array}$ & $\begin{array}{l}4,012 \\
4,012 \\
4,012 \\
4,012 \\
4,012\end{array}$ & $\begin{array}{r}1,220 \\
1,220 \\
1,220 \\
949 \\
949\end{array}$ & & $\begin{array}{l}15,400 \\
15,400 \\
15,400 \\
12,870 \\
12,870\end{array}$ \\
\hline $\begin{array}{l}2000 \\
2001 \\
2002 \\
2003 \\
2004\end{array}$ & $\begin{array}{l}7,190 \\
7,019 \\
9,287 \\
9,929 \\
9,929\end{array}$ & $\begin{array}{l}719 \\
702 \\
929 \\
993 \\
993\end{array}$ & $\begin{array}{l}4,012 \\
3,859 \\
4,180 \\
4,180 \\
4,180\end{array}$ & $\begin{array}{r}949 \\
926 \\
1,226 \\
1,311 \\
1,311\end{array}$ & & $\begin{array}{l}12,870 \\
12,506 \\
15,622 \\
16,413 \\
16,413\end{array}$ \\
\hline $\begin{array}{l}2005 \\
2006 \\
2007 \\
2008 \\
2009\end{array}$ & $\begin{array}{l}9,672 \\
8,260 \\
8,260 \\
7,019 \\
7,019\end{array}$ & $\begin{array}{l}967 \\
826 \\
826 \\
702 \\
702\end{array}$ & $\begin{array}{l}4,180 \\
3,859 \\
3,859 \\
3,859 \\
3,859\end{array}$ & $\begin{array}{r}1,277 \\
1,090 \\
1,090 \\
926 \\
926\end{array}$ & & $\begin{array}{l}16,096 \\
14,035 \\
14,035 \\
12,506 \\
12,506\end{array}$ \\
\hline $\begin{array}{l}2010 \\
2011 \\
2012 \\
2013 \\
2014\end{array}$ & $\begin{array}{l}7,019 \\
7,062 \\
7,062 \\
8,645 \\
8,645\end{array}$ & $\begin{array}{l}702 \\
706 \\
706 \\
864 \\
864\end{array}$ & $\begin{array}{l}3,859 \\
3,859 \\
3,859 \\
4,012 \\
4,012\end{array}$ & $\begin{array}{c}926 \\
932 \\
932 \\
1,141 \\
1,141\end{array}$ & & $\begin{array}{l}12,506 \\
12,559 \\
12,559 \\
14,662 \\
14,662\end{array}$ \\
\hline $\begin{array}{l}2015 \\
2016 \\
2017 \\
2018 \\
2019\end{array}$ & $\begin{array}{l}9,116 \\
8,046 \\
8,046 \\
8,046 \\
8,046\end{array}$ & $\begin{array}{l}912 \\
805 \\
805 \\
805 \\
805\end{array}$ & $\begin{array}{l}4,012 \\
3,808 \\
3,808 \\
3,808 \\
3,808\end{array}$ & $\begin{array}{l}1,203 \\
1,062 \\
1,062 \\
1,062 \\
1,062\end{array}$ & 13,721 & $\begin{array}{l}15,243 \\
13,721 \\
13,721 \\
13,721\end{array}$ \\
\hline $\begin{array}{l}2020 \\
2021\end{array}$ & & & & & $\begin{array}{l}20,338 \\
20,338\end{array}$ & $\begin{array}{l}20,338 \\
20,338\end{array}$ \\
\hline TALS & 249,125 & 24,911 & 118,557 & 32,880 & 40,676 & 466,149 \\
\hline
\end{tabular}


TABLE A.32. Stand-Alone Facility--Reference Scenario, Operating Costs: Drywell Storage (thousands of mid-1982 dollars)

\begin{tabular}{|c|c|c|c|c|c|c|}
\hline Year & Labor & Consumables & $\begin{array}{c}\text { Maint./ } \\
\text { Contract } \\
\text { Labor } \\
\end{array}$ & $\begin{array}{c}\text { G\&A } \\
\text { Utilities } \\
\end{array}$ & Other & Total \\
\hline $\begin{array}{l}1990 \\
1991 \\
1992 \\
1993 \\
1994\end{array}$ & $\begin{array}{l}6,933 \\
8,560 \\
9,030 \\
9,030 \\
9,030\end{array}$ & $\begin{array}{l}693 \\
856 \\
903 \\
903 \\
903\end{array}$ & $\begin{array}{l}5,306 \\
5,306 \\
5,306 \\
5,306 \\
5,306\end{array}$ & $\begin{array}{r}921 \\
1,124 \\
1,186 \\
1,186 \\
1,186\end{array}$ & & $\begin{array}{l}13,853 \\
15,846 \\
16,425 \\
16,425 \\
16,425\end{array}$ \\
\hline $\begin{array}{l}1995 \\
1996 \\
1997 \\
1998 \\
1999\end{array}$ & $\begin{array}{l}9,030 \\
9,030 \\
9,030 \\
6,933 \\
6,933\end{array}$ & $\begin{array}{l}903 \\
903 \\
903 \\
693 \\
693\end{array}$ & $\begin{array}{l}5,306 \\
5,306 \\
5,306 \\
5,306 \\
5,306\end{array}$ & $\begin{array}{r}1,186 \\
1,186 \\
1,186 \\
921 \\
921\end{array}$ & & $\begin{array}{l}16,425 \\
16,425 \\
16,425 \\
13,853 \\
13,853\end{array}$ \\
\hline $\begin{array}{l}2000 \\
2001 \\
2002 \\
2003 \\
2004\end{array}$ & $\begin{array}{l}6,933 \\
6,762 \\
9,073 \\
9,715 \\
9,715\end{array}$ & $\begin{array}{l}693 \\
676 \\
907 \\
972 \\
972\end{array}$ & $\begin{array}{l}5,306 \\
5,153 \\
5,474 \\
5,474 \\
5,474\end{array}$ & $\begin{array}{r}921 \\
921 \\
1,192 \\
1,277 \\
1,277\end{array}$ & & $\begin{array}{l}13,853 \\
13,512 \\
16,646 \\
17,438 \\
17,448\end{array}$ \\
\hline $\begin{array}{l}2005 \\
2006 \\
2007 \\
2008 \\
2009\end{array}$ & $\begin{array}{l}9,458 \\
8,046 \\
8,046 \\
6,762 \\
6,762\end{array}$ & $\begin{array}{l}946 \\
805 \\
805 \\
676 \\
676\end{array}$ & $\begin{array}{l}5,474 \\
5,153 \\
5,153 \\
5,153 \\
5,153\end{array}$ & $\begin{array}{r}1,243 \\
1,056 \\
1,056 \\
898 \\
898\end{array}$ & & $\begin{array}{l}17,121 \\
15,060 \\
15,060 \\
13,489 \\
13,489\end{array}$ \\
\hline $\begin{array}{l}2010 \\
2011 \\
2012 \\
2013 \\
2014\end{array}$ & $\begin{array}{l}6,762 \\
6,805 \\
6,805 \\
8,431 \\
8,431\end{array}$ & $\begin{array}{l}676 \\
680 \\
680 \\
843 \\
843\end{array}$ & $\begin{array}{l}5,153 \\
5,153 \\
5,153 \\
5,306 \\
5,306\end{array}$ & $\begin{array}{r}898 \\
904 \\
904 \\
1,107 \\
1,107\end{array}$ & & $\begin{array}{l}13,489 \\
13,542 \\
13,542 \\
15,687 \\
15,687\end{array}$ \\
\hline $\begin{array}{l}2015 \\
2016 \\
2017 \\
2018 \\
2019\end{array}$ & $\begin{array}{l}8,902 \\
7,832 \\
7,832 \\
7,832 \\
7,832\end{array}$ & $\begin{array}{l}890 \\
783 \\
783 \\
783 \\
783\end{array}$ & $\begin{array}{l}5,306 \\
5,102 \\
5,102 \\
5,102 \\
5,102\end{array}$ & $\begin{array}{l}1,169 \\
1,028 \\
1,028 \\
1,028 \\
1,028\end{array}$ & & $\begin{array}{l}16,267 \\
14,745 \\
14,745 \\
14,745 \\
14,745\end{array}$ \\
\hline $\begin{array}{l}2020 \\
2021\end{array}$ & & & & & $\begin{array}{l}23,080 \\
23,080\end{array}$ & $\begin{array}{l}23,080 \\
23,080\end{array}$ \\
\hline$n$ & 242,275 & 24,225 & 157,812 & 31,943 & 46,160 & 502,415 \\
\hline
\end{tabular}


TABLE A.33. Stand-Alone Facility--Delayed Reprocessing Scenario, Operating Costs: Cask Storage (thousands of mid-1982 dollars)

\begin{tabular}{|c|c|c|c|c|c|c|}
\hline Year & Labor & Consumables & $\begin{array}{c}\text { Maint.l } \\
\text { Contract } \\
\text { Labor } \\
\end{array}$ & $\begin{array}{c}\text { G\&A } \\
\text { Utilities } \\
\end{array}$ & Other & Total \\
\hline $\begin{array}{l}1990 \\
1991 \\
1992 \\
1993 \\
1994\end{array}$ & $\begin{array}{r}9,287 \\
10,486 \\
10,486 \\
10,486 \\
12,797\end{array}$ & $\begin{array}{r}929 \\
1,049 \\
1,049 \\
1,049 \\
1,280\end{array}$ & $\begin{array}{l}3,721 \\
4,969 \\
4,969 \\
5,057 \\
5,057\end{array}$ & $\begin{array}{l}1,226 \\
1,384 \\
1,384 \\
1,384 \\
1,689\end{array}$ & & $\begin{array}{l}15,163 \\
17,888 \\
17,888 \\
17,976 \\
20,823\end{array}$ \\
\hline $\begin{array}{l}1995 \\
1996 \\
1997 \\
1998 \\
1999\end{array}$ & $\begin{array}{r}16,306 \\
16,306 \\
16,306 \\
1,241 \\
1,241\end{array}$ & $\begin{array}{r}1,631 \\
1,631 \\
1,631 \\
124 \\
124\end{array}$ & $\begin{array}{l}6,393 \\
6,393 \\
6,481\end{array}$ & $\begin{array}{r}2,153 \\
2,153 \\
2,153 \\
164 \\
164\end{array}$ & & $\begin{array}{r}26,483 \\
26,483 \\
26,571 \\
1,529 \\
1,529\end{array}$ \\
\hline $\begin{array}{l}2000 \\
2001 \\
2002 \\
2003 \\
2004\end{array}$ & $\begin{array}{l}1,241 \\
1,241 \\
1,241 \\
1,241 \\
1,241\end{array}$ & $\begin{array}{l}124 \\
124 \\
124 \\
124 \\
124\end{array}$ & & $\begin{array}{l}164 \\
164 \\
164 \\
164 \\
164\end{array}$ & & $\begin{array}{l}1,529 \\
1,529 \\
1,529 \\
1,529 \\
1,529\end{array}$ \\
\hline $\begin{array}{l}2005 \\
2006 \\
2007 \\
2008 \\
2009\end{array}$ & $\begin{array}{l}1,241 \\
1,241 \\
1,241 \\
1,241 \\
1,241\end{array}$ & $\begin{array}{l}124 \\
124 \\
124 \\
124 \\
124\end{array}$ & & $\begin{array}{l}164 \\
164 \\
164 \\
164 \\
164\end{array}$ & & $\begin{array}{l}1,529 \\
1,529 \\
1,529 \\
1,529 \\
1,529\end{array}$ \\
\hline $\begin{array}{l}2010 \\
2011 \\
2012 \\
2013 \\
2014\end{array}$ & $\begin{array}{r}1,241 \\
1,241 \\
10,486 \\
10,486 \\
12,797\end{array}$ & $\begin{array}{r}124 \\
124 \\
1,049 \\
1,049 \\
1,280\end{array}$ & 5,057 & $\begin{array}{c}164 \\
164 \\
1,384 \\
1,384 \\
1,689\end{array}$ & & $\begin{array}{r}1,529 \\
1,529 \\
17,976 \\
17,976 \\
20,823\end{array}$ \\
\hline $\begin{array}{l}2015 \\
2016 \\
2017 \\
2018 \\
2019\end{array}$ & $\begin{array}{l}16,306 \\
16,306 \\
16,306 \\
12,797 \\
12,797\end{array}$ & $\begin{array}{l}1,631 \\
1,631 \\
1,631 \\
1,280 \\
1,280\end{array}$ & $\begin{array}{l}6,306 \\
5,057\end{array}$ & $\begin{array}{l}2,153 \\
2,153 \\
2,153 \\
1,689 \\
1,689\end{array}$ & & $\begin{array}{l}26,396 \\
26,396 \\
26,396 \\
20,823 \\
20,823\end{array}$ \\
\hline $\begin{array}{l}2020 \\
2021\end{array}$ & & & & & $\begin{array}{l}24,242 \\
24,242\end{array}$ & $\begin{array}{l}24,242 \\
24,242\end{array}$ \\
\hline TALS & 228,115 & 22,816 & 87,243 & 30,116 & 48,484 & 416,774 \\
\hline
\end{tabular}


TABLE A.34. Stand-Alone Facility--Delayed Reprocessing Scenario, Operating Costs: Drywell Storage (thousands of mid-1982 dollars)

\begin{tabular}{|c|c|c|c|c|c|c|}
\hline Year & Labor & Consumables & $\begin{array}{c}\text { Maint./ } \\
\text { Contract } \\
\text { Labor } \\
\end{array}$ & $\begin{array}{c}\text { G\&A } \\
\text { Utilities } \\
\end{array}$ & Other & Total \\
\hline $\begin{array}{l}1990 \\
1991 \\
1992 \\
1993 \\
1994\end{array}$ & $\begin{array}{r}9,886 \\
11,342 \\
11,342 \\
11,342 \\
11,342\end{array}$ & $\begin{array}{r}989 \\
1,134 \\
1,134 \\
1,134 \\
1,134\end{array}$ & $\begin{array}{l}6,222 \\
8,049 \\
8,049 \\
8,049 \\
8,049\end{array}$ & $\begin{array}{l}1,305 \\
1,497 \\
1,497 \\
1,497 \\
1,497\end{array}$ & $\begin{array}{r}4,983 \\
4,812 \\
6,954 \\
7,253 \\
10,765\end{array}$ & $\begin{array}{l}23,385 \\
26,834 \\
28,976 \\
29,275 \\
32,787\end{array}$ \\
\hline $\begin{array}{l}1995 \\
1996 \\
1997 \\
1998 \\
1999\end{array}$ & $\begin{array}{c}14,252 \\
18,874 \\
18,874 \\
1,241 \\
1,241\end{array}$ & $\begin{array}{r}1,425 \\
1,887 \\
1,887 \\
124 \\
124\end{array}$ & $\begin{array}{l}8,049 \\
9,876 \\
9,876\end{array}$ & $\begin{array}{r}1,881 \\
2,492 \\
2,492 \\
164 \\
164\end{array}$ & $\begin{array}{l}13,733 \\
16,259 \\
16,094\end{array}$ & $\begin{array}{r}39,340 \\
49,388 \\
49,223 \\
1,529 \\
1,529\end{array}$ \\
\hline $\begin{array}{l}2000 \\
2001 \\
2002 \\
2003 \\
2004\end{array}$ & $\begin{array}{l}1,241 \\
1,241 \\
1,241 \\
1,241 \\
1,241\end{array}$ & $\begin{array}{l}124 \\
124 \\
124 \\
124 \\
124\end{array}$ & & $\begin{array}{l}164 \\
164 \\
164 \\
164 \\
164\end{array}$ & & $\begin{array}{l}1,529 \\
1,529 \\
1,529 \\
1,529 \\
1,529\end{array}$ \\
\hline $\begin{array}{l}2005 \\
2006 \\
2007 \\
2008 \\
2009\end{array}$ & $\begin{array}{l}1,241 \\
1,241 \\
1,241 \\
1,241 \\
1,241\end{array}$ & $\begin{array}{l}124 \\
124 \\
124 \\
124 \\
124\end{array}$ & & $\begin{array}{l}164 \\
164 \\
164 \\
164 \\
164\end{array}$ & & $\begin{array}{l}1,529 \\
1,529 \\
1,529 \\
1,529 \\
1,529\end{array}$ \\
\hline $\begin{array}{l}2010 \\
2011 \\
2012 \\
2013 \\
2014\end{array}$ & $\begin{array}{r}1,241 \\
1,241 \\
11,342 \\
11,342 \\
14,252\end{array}$ & $\begin{array}{r}124 \\
124 \\
1,134 \\
1,134 \\
1,425\end{array}$ & $\begin{array}{l}8,049 \\
8,049 \\
8,049\end{array}$ & $\begin{array}{c}164 \\
164 \\
1,497 \\
1,497 \\
1,881\end{array}$ & & $\begin{array}{r}1,529 \\
1,529 \\
22,022 \\
22,022 \\
25,607\end{array}$ \\
\hline $\begin{array}{l}2015 \\
2016 \\
2017 \\
2018 \\
2019\end{array}$ & $\begin{array}{l}18,874 \\
18,874 \\
18,874 \\
14,252 \\
14,252\end{array}$ & $\begin{array}{l}1,887 \\
1,887 \\
1,887 \\
1,425 \\
1,425\end{array}$ & $\begin{array}{l}9,876 \\
9,876 \\
9,876 \\
8,049 \\
8,049\end{array}$ & $\begin{array}{l}2,492 \\
2,492 \\
2,492 \\
1,881 \\
1,881\end{array}$ & & $\begin{array}{l}33,129 \\
33,129 \\
33,129 \\
25,607 \\
25,607\end{array}$ \\
\hline $\begin{array}{l}2020 \\
2021\end{array}$ & & & & & $\begin{array}{l}36,236 \\
36,236\end{array}$ & $\begin{array}{l}36,236 \\
36,236\end{array}$ \\
\hline TALS & 246,690 & 24,664 & 136,092 & 32,567 & 153,325 & 593,338 \\
\hline
\end{tabular}


TABLE A.35. Stand-Alone Facility--Delayed Disposal Scenario, Operating Costs: Cask Storage (thousands of mid-1982 dollars)

\begin{tabular}{|c|c|c|c|c|c|c|}
\hline Year & Labor & Consumables & $\begin{array}{c}\text { Maint.l } \\
\text { Contract } \\
\text { Labor } \\
\end{array}$ & $\begin{array}{c}\text { G8A } \\
\text { Utilities } \\
\end{array}$ & Other & Total \\
\hline $\begin{array}{l}1990 \\
1991 \\
1992 \\
1993 \\
1994\end{array}$ & $\begin{array}{l}7,190 \\
8,774 \\
9,244 \\
9,244 \\
9,244\end{array}$ & $\begin{array}{l}719 \\
877 \\
924 \\
924 \\
924\end{array}$ & $\begin{array}{l}3,925 \\
3,925 \\
3,925 \\
3,925 \\
3,925\end{array}$ & $\begin{array}{c}949 \\
1,158 \\
1,220 \\
1,220 \\
1,220\end{array}$ & & $\begin{array}{l}12,783 \\
14,734 \\
15,313 \\
15,313 \\
15,313\end{array}$ \\
\hline $\begin{array}{l}1995 \\
1996 \\
1997 \\
1998 \\
1999\end{array}$ & $\begin{array}{l}9,244 \\
9,244 \\
9,244 \\
9,244 \\
9,244\end{array}$ & $\begin{array}{l}924 \\
924 \\
924 \\
924 \\
924\end{array}$ & $\begin{array}{l}4,012 \\
4,012 \\
4,012 \\
4,012 \\
4,100\end{array}$ & $\begin{array}{l}1,220 \\
1,220 \\
1,220 \\
1,220 \\
1,220\end{array}$ & & $\begin{array}{l}15,400 \\
15,400 \\
15,400 \\
15,400 \\
15,488\end{array}$ \\
\hline $\begin{array}{l}2000 \\
2001 \\
2002 \\
2003 \\
2004\end{array}$ & $\begin{array}{r}9,244 \\
10,785 \\
12,326 \\
12,797 \\
12,797\end{array}$ & $\begin{array}{r}924 \\
1,078 \\
1,233 \\
1,280 \\
1,280\end{array}$ & $\begin{array}{l}4,100 \\
4,268 \\
5,604 \\
5,604 \\
5,692\end{array}$ & $\begin{array}{l}1,220 \\
1,424 \\
1,627 \\
1,689 \\
1,689\end{array}$ & & $\begin{array}{l}15,488 \\
17,555 \\
20,790 \\
21,370 \\
21,458\end{array}$ \\
\hline $\begin{array}{l}2005 \\
2006 \\
2007 \\
2008 \\
2009\end{array}$ & $\begin{array}{l}12,797 \\
15,707 \\
16,478 \\
15,707 \\
15,707\end{array}$ & $\begin{array}{l}1,280 \\
1,571 \\
1,648 \\
1,571 \\
1,571\end{array}$ & $\begin{array}{l}5,692 \\
5,947 \\
6,035 \\
6,035 \\
6,122\end{array}$ & $\begin{array}{l}1,689 \\
2,073 \\
2,175 \\
2,073 \\
2,073\end{array}$ & & $\begin{array}{l}21,458 \\
25,298 \\
26,336 \\
25,386 \\
25,473\end{array}$ \\
\hline $\begin{array}{l}2010 \\
2011 \\
2012 \\
2013 \\
2014\end{array}$ & $\begin{array}{l}15,707 \\
16,478 \\
12,241 \\
12,027 \\
12,027\end{array}$ & $\begin{array}{l}1,571 \\
1,648 \\
1,224 \\
1,203 \\
1,203\end{array}$ & $\begin{array}{l}6,210 \\
6,297 \\
6,129 \\
6,129 \\
6,129\end{array}$ & $\begin{array}{l}2,073 \\
2,175 \\
1,616 \\
1,587 \\
1,587\end{array}$ & & $\begin{array}{l}25,561 \\
26,598 \\
21,210 \\
20,946 \\
20,946\end{array}$ \\
\hline $\begin{array}{l}2015 \\
2016 \\
2017 \\
2018 \\
2019\end{array}$ & $\begin{array}{l}10,700 \\
10,700 \\
11,684 \\
11,684 \\
11,684\end{array}$ & $\begin{array}{l}1,070 \\
1,070 \\
1,168 \\
1,168 \\
1,168\end{array}$ & $\begin{array}{l}5,808 \\
5,371 \\
5,524 \\
5,524 \\
5,524\end{array}$ & $\begin{array}{l}1,412 \\
1,412 \\
1,542 \\
1,542 \\
1,542\end{array}$ & & $\begin{array}{l}18,990 \\
18,553 \\
19,918 \\
19,918 \\
19,918\end{array}$ \\
\hline $\begin{array}{l}2020 \\
2021 \\
2022 \\
2023 \\
2024\end{array}$ & $\begin{array}{l}12,626 \\
12,626 \\
12,626 \\
12,626 \\
12,626\end{array}$ & $\begin{array}{l}1,263 \\
1,263 \\
1,263 \\
1,263 \\
1,263\end{array}$ & $\begin{array}{l}5,692 \\
5,692 \\
5,692 \\
5,692 \\
5,692\end{array}$ & $\begin{array}{l}1,666 \\
1,666 \\
1,666 \\
1,666 \\
1,666\end{array}$ & & $\begin{array}{l}21,247 \\
21,247 \\
21,247 \\
21,247 \\
21,247\end{array}$ \\
\hline $\begin{array}{l}2025 \\
2026 \\
2027 \\
2028 \\
2029\end{array}$ & $\begin{array}{l}16,392 \\
16,392 \\
16,392 \\
16,392 \\
16,392\end{array}$ & $\begin{array}{l}1,639 \\
1,639 \\
1,639 \\
1,639 \\
1,639\end{array}$ & $\begin{array}{l}5,860 \\
5,860 \\
5,860 \\
5,860 \\
5,860\end{array}$ & $\begin{array}{l}2,164 \\
2,164 \\
2,164 \\
2,164 \\
2,164\end{array}$ & & $\begin{array}{l}26,055 \\
26,055 \\
26,055 \\
26,055 \\
26,055\end{array}$ \\
\hline $\begin{array}{l}2030 \\
2031 \\
2032 \\
2033 \\
2034 \\
2035\end{array}$ & $\begin{array}{l}15,365 \\
15,365 \\
15,322 \\
12,797 \\
12,797 \\
12,797\end{array}$ & $\begin{array}{l}1,536 \\
1,536 \\
1,532 \\
1,280 \\
1,280 \\
1,280\end{array}$ & $\begin{array}{l}5,860 \\
5,860 \\
5,860 \\
5,320 \\
5,320 \\
5,320\end{array}$ & $\begin{array}{l}2,028 \\
2,028 \\
2,022 \\
1,689 \\
1,689 \\
1,689\end{array}$ & & $\begin{array}{l}24,789 \\
24,789 \\
24,736 \\
21,086 \\
21,086 \\
21,086\end{array}$ \\
\hline $\begin{array}{l}2036 \\
2037\end{array}$ & & & & & $\begin{array}{l}43,230 \\
43,230\end{array}$ & $\begin{array}{l}43,230 \\
43,230\end{array}$ \\
\hline & 578,726 & 57,871 & 244,817 & 76,382 & 86,460 & $1,044,256$ \\
\hline
\end{tabular}


TABLE A.36. Stand-Alone Facility--Delayed Disposal Scenario, Operating Costs: Drywell Storage (thousands of mid-1982 dollars)

\begin{tabular}{|c|c|c|c|c|c|c|}
\hline Year & Labor & Consumabies & $\begin{array}{l}\text { Maint./ } \\
\text { Contract } \\
\text { Labor } \\
\end{array}$ & $\begin{array}{c}\text { G\&A } \\
\text { Utilities } \\
\end{array}$ & Other & Total \\
\hline $\begin{array}{l}1990 \\
1991 \\
1992 \\
1993 \\
1994\end{array}$ & $\begin{array}{l}6,933 \\
8,560 \\
9,030 \\
9,030 \\
9,030\end{array}$ & $\begin{array}{l}693 \\
856 \\
903 \\
903 \\
903\end{array}$ & $\begin{array}{l}5,338 \\
5,338 \\
5,338 \\
5,338 \\
5,338\end{array}$ & $\begin{array}{c}915 \\
1,130 \\
1,192 \\
1,192 \\
1,192\end{array}$ & & $\begin{array}{l}13,879 \\
15,884 \\
16,463 \\
16,463 \\
16,463\end{array}$ \\
\hline $\begin{array}{l}1995 \\
1996 \\
1997 \\
1998 \\
1999\end{array}$ & $\begin{array}{l}9,030 \\
9,030 \\
9,030 \\
9,030 \\
9,030\end{array}$ & $\begin{array}{l}903 \\
903 \\
903 \\
903 \\
903\end{array}$ & $\begin{array}{l}5,338 \\
5,338 \\
5,338 \\
5,338 \\
5,338\end{array}$ & $\begin{array}{l}1,192 \\
1,192 \\
1,192 \\
1,192 \\
1,192\end{array}$ & & $\begin{array}{l}16,463 \\
16,463 \\
16,463 \\
16,463 \\
16,463\end{array}$ \\
\hline $\begin{array}{l}2000 \\
2001 \\
2002 \\
2003 \\
2004\end{array}$ & $\begin{array}{r}9,030 \\
10,614 \\
11,813 \\
12,283 \\
12,283\end{array}$ & $\begin{array}{r}903 \\
1,061 \\
1,181 \\
1,228 \\
1,228\end{array}$ & $\begin{array}{l}5,338 \\
5,506 \\
7,333 \\
7,333 \\
7,333\end{array}$ & $\begin{array}{l}1,192 \\
1,401 \\
1,559 \\
1,621 \\
1,621\end{array}$ & & $\begin{array}{l}16,463 \\
18,582 \\
21,886 \\
22,465 \\
22,465\end{array}$ \\
\hline $\begin{array}{l}2005 \\
2006 \\
2007 \\
2008 \\
2009\end{array}$ & $\begin{array}{l}12,283 \\
15,236 \\
16,007 \\
15,236 \\
15,236\end{array}$ & $\begin{array}{l}1,228 \\
1,524 \\
1,601 \\
1,524 \\
1,524\end{array}$ & $\begin{array}{l}7,333 \\
7,501 \\
7,501 \\
7,501 \\
7,501\end{array}$ & $\begin{array}{l}1,621 \\
2,011 \\
2,113 \\
2,011 \\
2,011\end{array}$ & & $\begin{array}{l}22,465 \\
26,272 \\
27,222 \\
26,272 \\
26,272\end{array}$ \\
\hline $\begin{array}{l}2010 \\
2011 \\
2012 \\
2013 \\
2014\end{array}$ & $\begin{array}{l}15,236 \\
16,007 \\
11,727 \\
11,513 \\
11,513\end{array}$ & $\begin{array}{l}1,524 \\
1,601 \\
1,173 \\
1,151 \\
1,151\end{array}$ & $\begin{array}{l}7,501 \\
7,501 \\
7,333 \\
7,333 \\
7,333\end{array}$ & $\begin{array}{l}2,011 \\
2,113 \\
1,548 \\
1,519 \\
1,519\end{array}$ & & $\begin{array}{l}26,272 \\
27,222 \\
21,781 \\
21,516 \\
21,516\end{array}$ \\
\hline $\begin{array}{l}2015 \\
2016 \\
2017 \\
2018 \\
2019\end{array}$ & $\begin{array}{l}10,186 \\
10,186 \\
11,170 \\
11,170 \\
11,170\end{array}$ & $\begin{array}{l}1,019 \\
1,019 \\
1,117 \\
1,117 \\
1,117\end{array}$ & $\begin{array}{l}7,012 \\
7,012 \\
7,165 \\
7,165 \\
7,165\end{array}$ & $\begin{array}{l}1,344 \\
1,344 \\
1,474 \\
1,474 \\
1,474\end{array}$ & & $\begin{array}{l}19,561 \\
19,561 \\
20,926 \\
20,926 \\
20,926\end{array}$ \\
\hline $\begin{array}{l}2020 \\
2021 \\
2022 \\
2023 \\
2024\end{array}$ & $\begin{array}{l}12,112 \\
12,112 \\
12,112 \\
12,112 \\
12,112\end{array}$ & $\begin{array}{l}1,211 \\
1,211 \\
1,211 \\
1,211 \\
1,211\end{array}$ & $\begin{array}{l}7,333 \\
7,333 \\
7,333 \\
7,333 \\
7,333\end{array}$ & $\begin{array}{l}1,598 \\
1,598 \\
1,598 \\
1,598 \\
1,598\end{array}$ & & $\begin{array}{l}22,254 \\
22,254 \\
22,254 \\
22,254 \\
22,254\end{array}$ \\
\hline $\begin{array}{l}2025 \\
2026 \\
2027 \\
2028 \\
2029\end{array}$ & $\begin{array}{l}15,921 \\
15,921 \\
15,921 \\
15,921 \\
15,921\end{array}$ & $\begin{array}{l}1,592 \\
1,592 \\
1,592 \\
1,592 \\
1,592\end{array}$ & $\begin{array}{l}7,501 \\
7,501 \\
7,501 \\
7,501 \\
7,501\end{array}$ & $\begin{array}{l}2,102 \\
2,102 \\
2,102 \\
2,102 \\
2,102\end{array}$ & & $\begin{array}{l}27,116 \\
27,116 \\
27,116 \\
27,116 \\
27,116\end{array}$ \\
\hline $\begin{array}{l}2030 \\
2031 \\
2032 \\
2033 \\
2034 \\
2035\end{array}$ & $\begin{array}{l}14,894 \\
14,894 \\
14,851 \\
12,326 \\
12,326 \\
12,326\end{array}$ & $\begin{array}{l}1,489 \\
1,489 \\
1,485 \\
1,233 \\
1,233 \\
1,233\end{array}$ & $\begin{array}{l}7,501 \\
7,501 \\
7,501 \\
6,961 \\
6,961 \\
6,961\end{array}$ & $\begin{array}{l}1,966 \\
1,966 \\
1,960 \\
1,627 \\
1,627 \\
1,627\end{array}$ & & $\begin{array}{l}25,850 \\
25,850 \\
25,797 \\
22,147 \\
22,147 \\
22,147\end{array}$ \\
\hline $\begin{array}{l}2036 \\
2037\end{array}$ & & & & & $\begin{array}{l}58,876 \\
58,876\end{array}$ & $\begin{array}{l}58,876 \\
58,876\end{array}$ \\
\hline ALS & 559,414 & 55,941 & 313,636 & 73,835 & 117,752 & $1,115,578$ \\
\hline
\end{tabular}


TABLE A.37. MRS/IS Facility Co-located With a Repository--Reference Scenario, Life-Cycle Cash Flows: Cask Storage (millions mid-1982 dollars) (a)

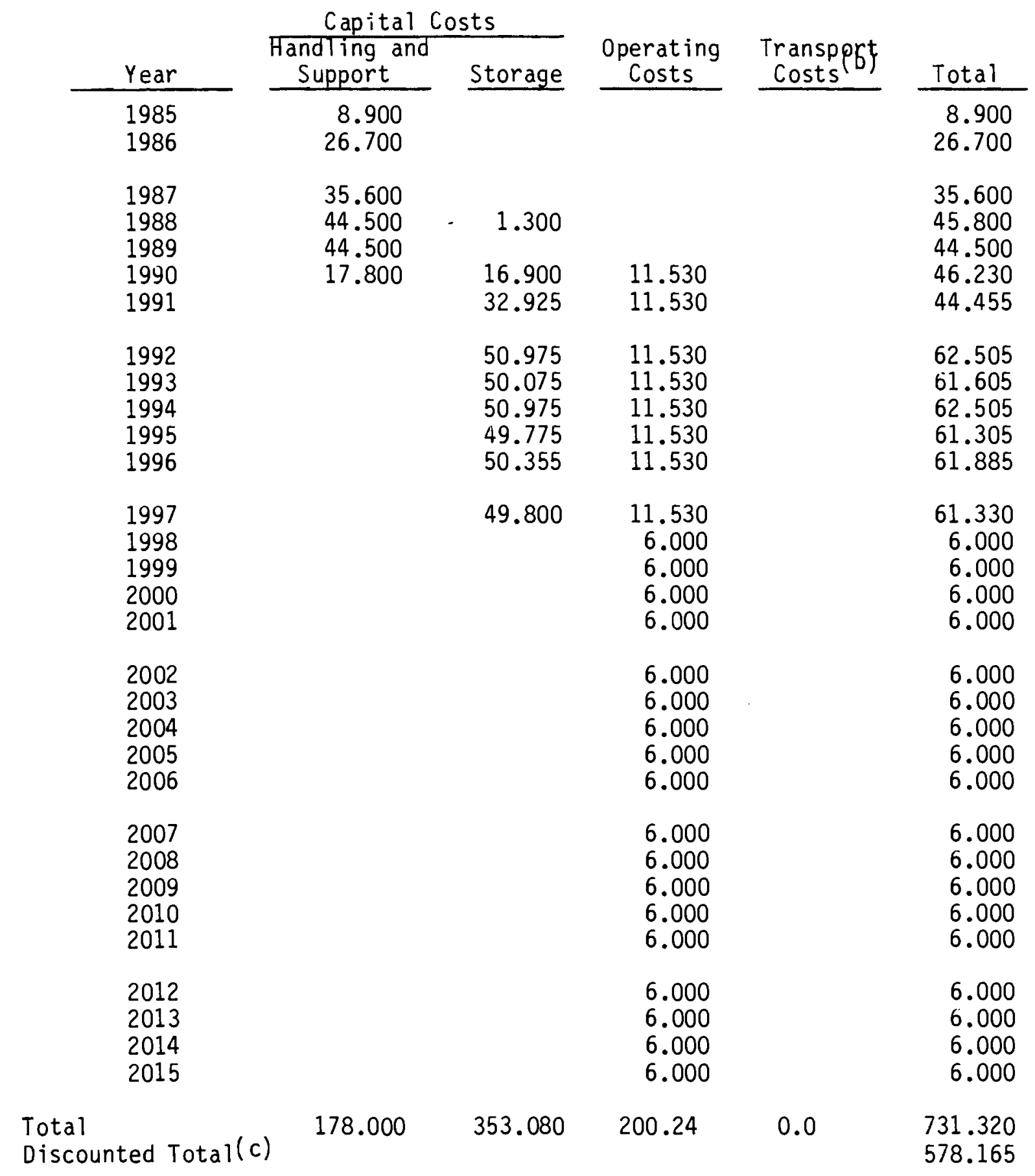

(a) The number of significant figures is for computational accuracy and does not imply precision to the nearest $\$ 1000$.

(b) Transportation costs are incremental to those which would be incurred if no MRS existed.

(c) Discount rate of 2 percent per year. 
TABLE A.38. MRS/IS Facility Co-located With a Repository--Reference Scenario, Life-Cycle Cash Flpws: Drywell Storage (millions mid-1982 dollars) (a)

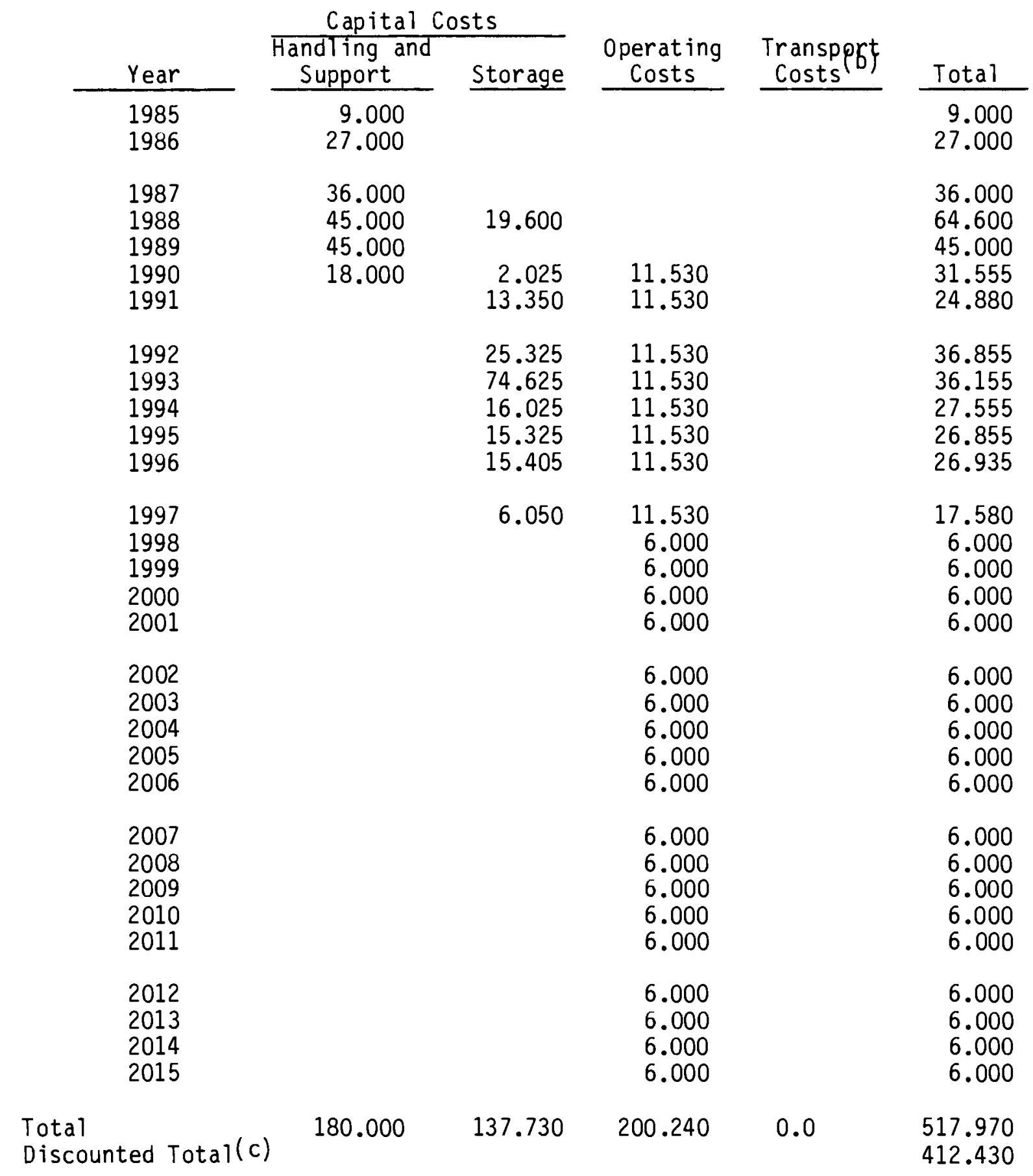

(a) The number of significant figures is for computational accuracy and does not imply precision to the nearest $\$ 1000$.

(b) Transportation costs are incremental to those which would be incurred if no MRS existed.

(c) Discount rate of 2 percent per year. 
TABLE A.39. MRS/IS Facility Co-located With a Repository--Delayed Reprocessing Scenario, Life-Cycle Cash Flows: Cask Storage (millions mid-1982 dollars)(a)

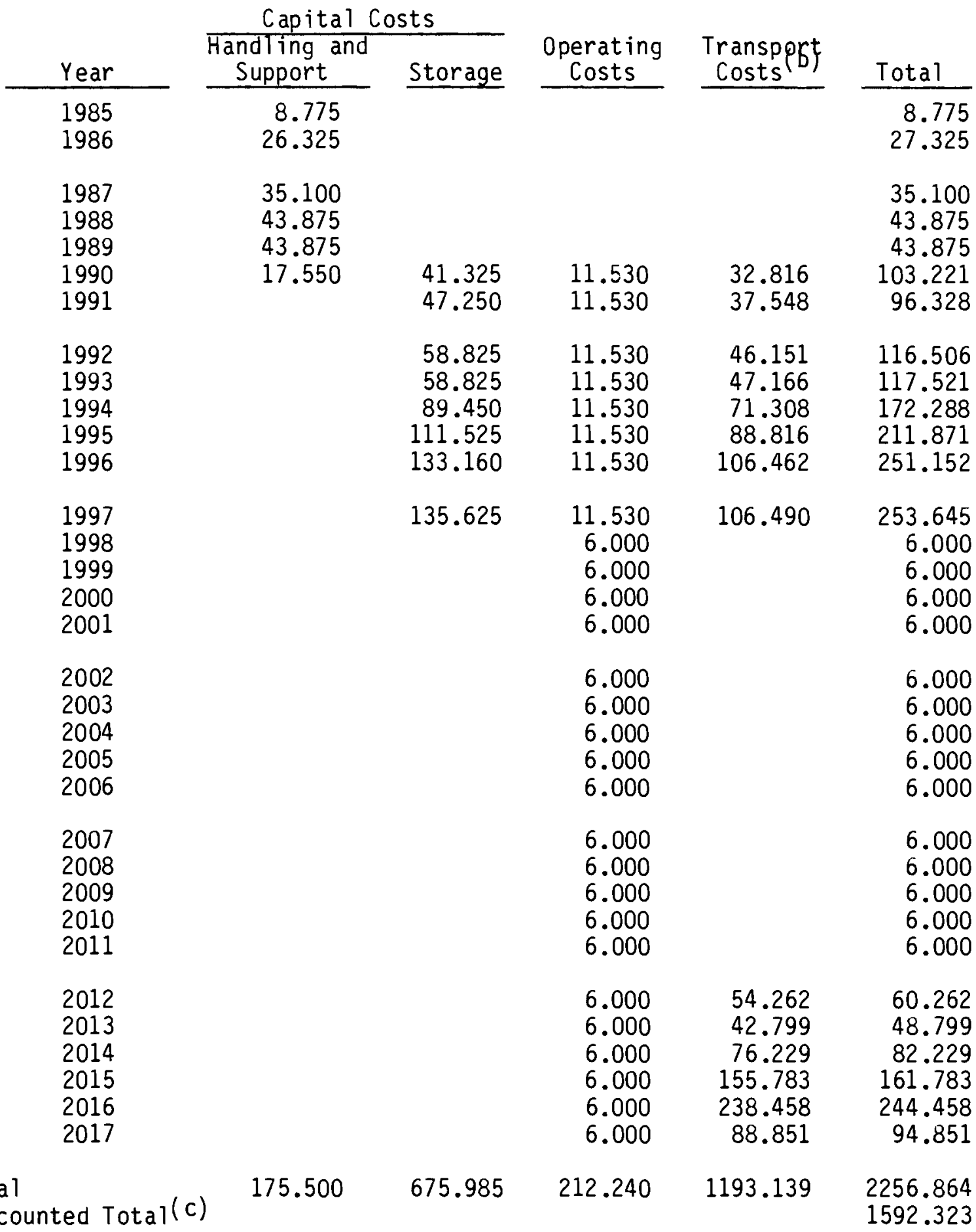

$\begin{array}{llllll}\text { Total } & 175.500 & 675.985 & 212.240 & 1193.139 & 2256.864 \\ \text { Discounted Total }(c) & & & & & 1592.323\end{array}$

(a) The number of significant figures is for computational accuracy and does not imply precision to the nearest $\$ 1000$.

(b) Transportation costs are incremental to those which would be incurred if no MRS existed.

(c) Discount rate of 2 percent per year. 
TABLE A.40. MRS/IS Facility Co-located With a Repository--Delayed Reprocessing Scenario, Life-Cycle Cash Flows: Drywell Storage (millions mid-1982 dollars) (a)

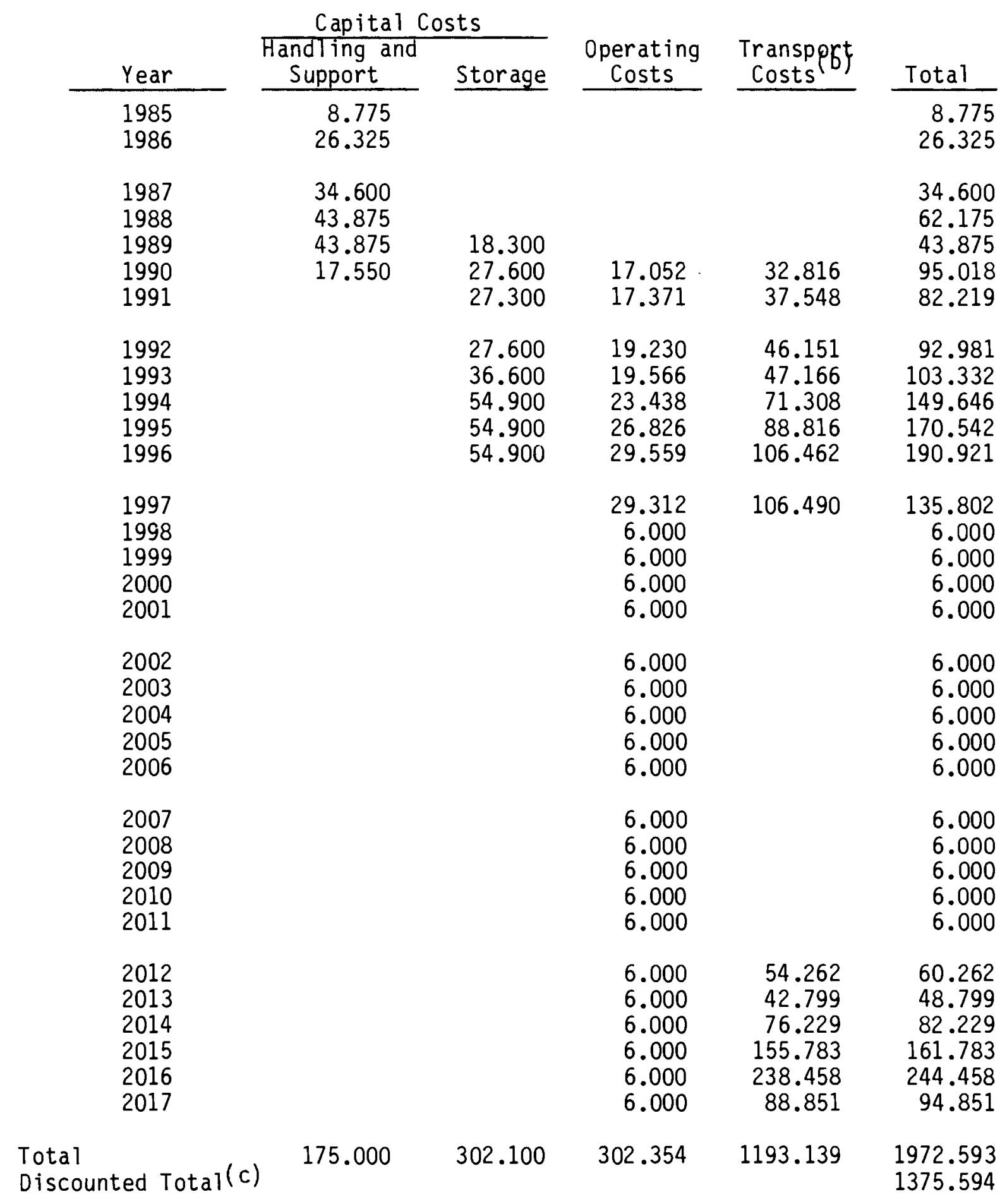

(a) The number of significant figures is for computational accuracy and does not imply precision to the nearest $\$ 1000$.

(b) Transportation costs are incremental to those which would be incurred if no MRS existed.

(c) Discount rate of 2 percent per year. 
TABLE A.41. MRS/IS Facility Co-located With a Repository--Delayed Reprocessing Scenario, Life-Cycle Cash Flows: Cask Storage (militions mid-1982 dollars) (a)

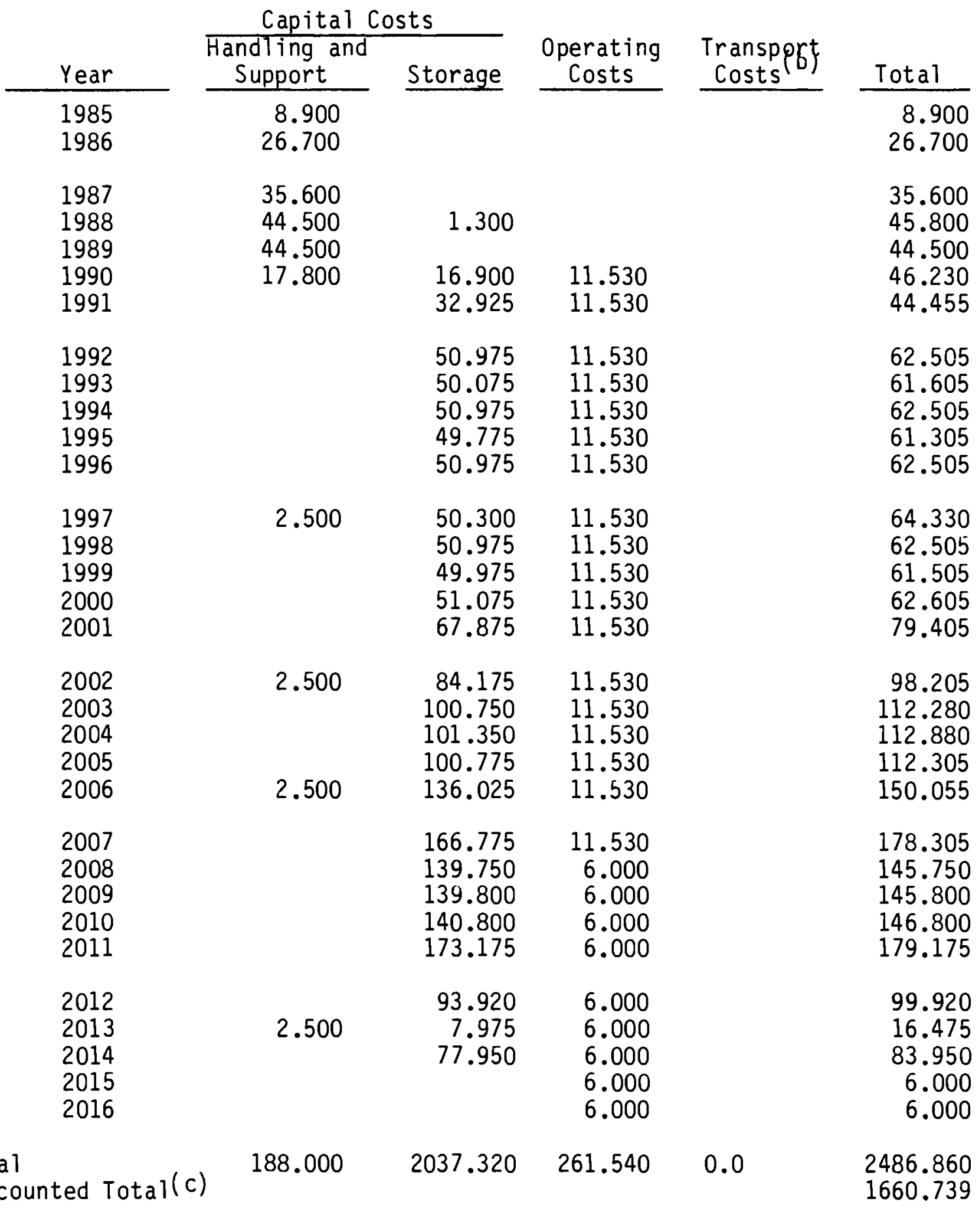

(a) The number of significant figures is for computational accuracy and does not imply precision to the nearest $\$ 1000$.

(b) Transportation costs are incremental to those which would be incurred if no MRS existed.

(c) Discount rate of 2 percent per year. 
TABLE A.42. MRS/IS Facility Co-located With a Repository-- Delayed Disposal Scenario, Life-Cycle Cash Flows: Drywell Storage (millions mid-1982 dollars)(a)

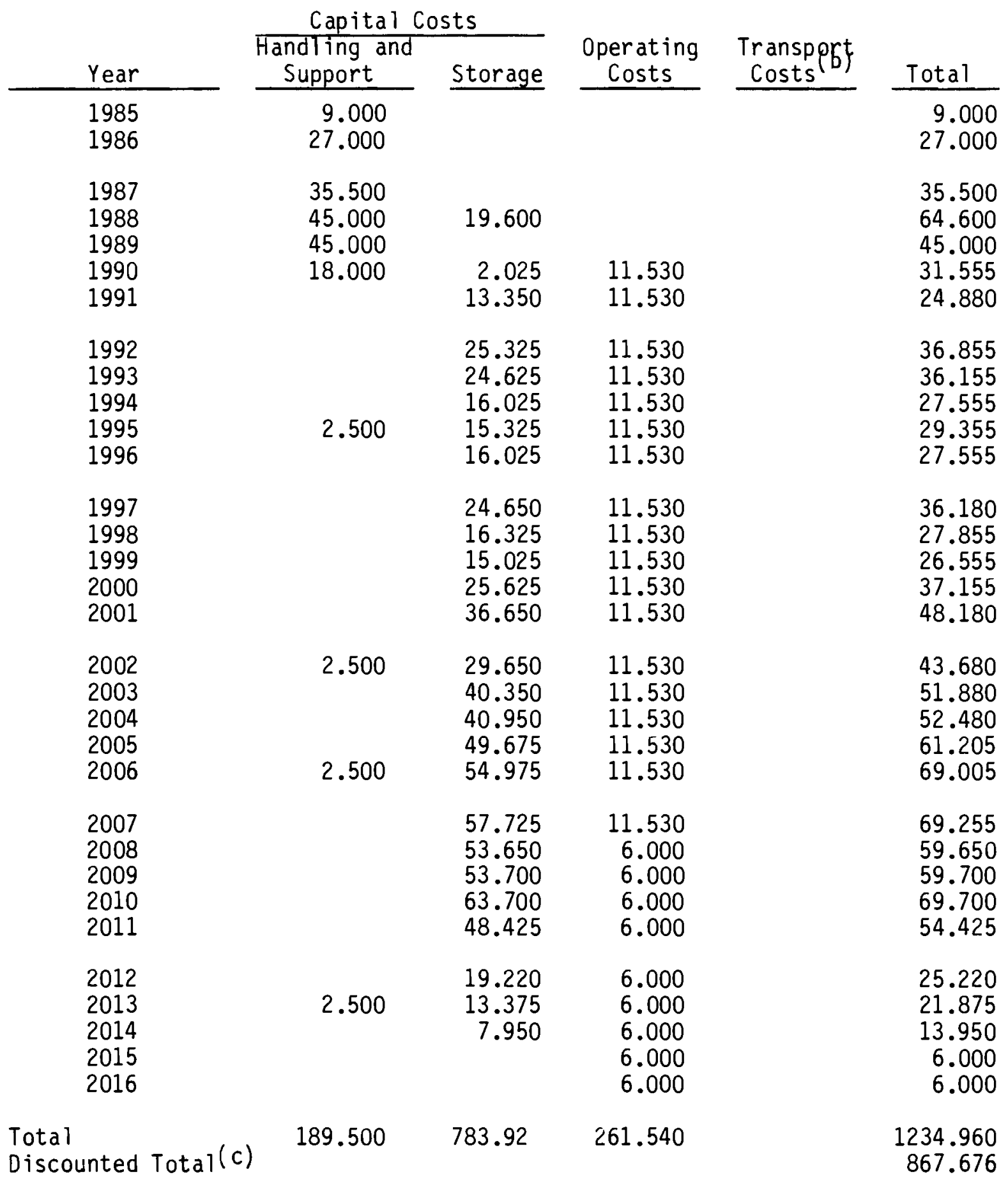

(a) The number of significant figures is for computational accuracy and does not imply precision to the nearest $\$ 1000$.

(b) Transportation costs are incremental to those which would be incurred if no MRS existed.

(c) Discount rate of 2 percent per year. 
TABLE A.43. MRS/IS Facility Co-located With a Repository--Capital Costs of Handling and Support Systems (thousands of mid-1982 dollars)

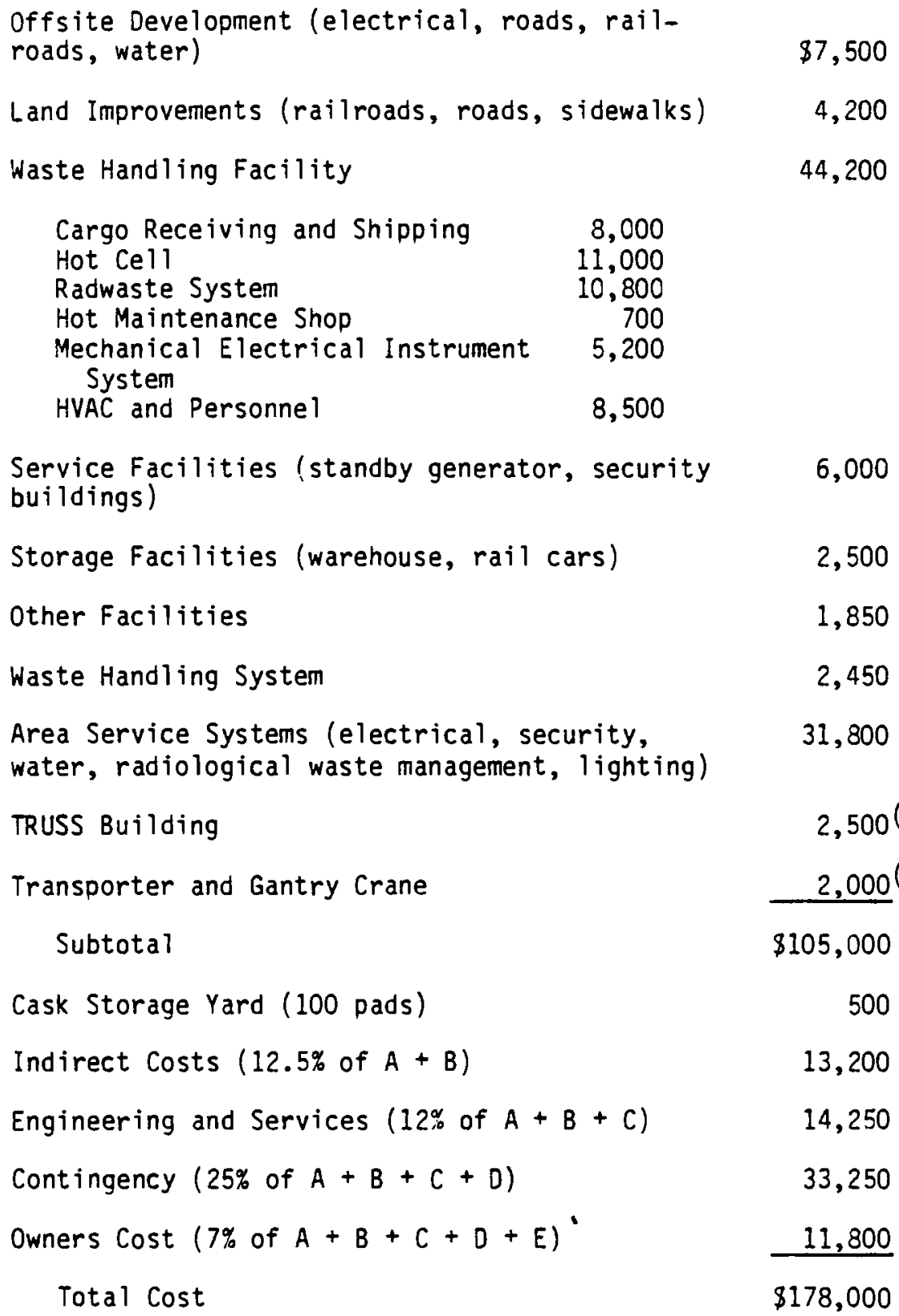

(a) TRUSS building is used for storage of contact handled transuranic wastes (CHTRU). Not required for storage of spent fuel.

(b) Required for loading/unloading metal storage cask and concrete TRU storage casks. If drywell storage is used a second transporter (also $\$ 2 \mathrm{million}$ ) is required to service the drywells. 
TABLE A.44. MRS/IS Facility Co-located With a Repository--Capital Costs of Storage Systems (mid-1982 dollars)

Metal Cask Systems (a)

Metal Casks, each

Cask Pads, each

Cask Fields, each

Concrete Cask Systems (a)

Concrete Casks, each

Cask Pads, each

Cask Fields, each

Drywe11 Systems (a)

Drywells, each

Drywell Fields, each
(HLW or Spent Fuel Storage)

$\$ 700,000(b)$

2,000

$300,000(c)$

(Remote-Handled TRU Storage)

$\$ 25,000$

2,000

$300,000(c)$

(HLW or Spent Fuel Storage)

$\$ 18,00$

$300,000(d)$

(a) Storage systems are added as needed

(b) A $25 \%$ contingency is applied to metal cask costs

(c) A cask field accommodates 1000 metal or concrete casks (separate fields). Cask pads required.

(d) A drywell field accommodates 1000 drywells 
TABLE A.45. MRS/IS Facility Co-located With a Repository--0perating Costs (thousands of mid-1982 dollars)

Fixed Annual Costs

$\begin{array}{lc}\text { Labor } & 7,440 \\ \text { Consumables } & 740 \\ \text { Maintenance } & 2,370 \\ \text { Utilities, G\&A, etc } & \frac{980}{11,530(a)}\end{array}$

Variable Operating Cost (dollars)

Spent fuel canisters $\$ 5,500$ each

(used for dry storage only)

(a) Following repository startup, fixed costs are shared with the repository. The MRS share is $\$ 6$ million annually 


\section{APPENDIX B}

STUDY DATA BASE AND EVALUATION GUIDELINES

B.1 MRS/IS FUEL CYCLE AND WASTE SCENARIOS

Tables B.1 - B.18

B.2 CONSIDERATIONS FOR MRS/IS COST EVALUATION

Tables B.19-B.25

B.3 TRANSPORTATION UNIT COSTS

Tables B.26 - B.34 
APPENDIX B

\section{STUDY DATA BASE AND EVALUATION GUIDELINES}

\section{B.1 MRS/IS FUEL CYCLE AND WASTE SCENARIOS}

Five MRS/IS scenarios are to be used by all MRS/IS projects. Each MRS/IS facility should be designed to satisfy the reference scenario, the delayed reprocessing scenario, and the delayed disposal scenario. The early disposal scenario and the delayed disposal-no reprocessing scenario are included for information only.

Basis for Projections

The bases and assumptions used in developing the projections are as follows:

- Maximum pool expansion at reactors is assumed based on utility estimates.

- Each pool maintains a full core reserve.

- Historic spent fuel inventory data are used as reported by utilities.

- Discharge projections used are as given by utilities.

- Generic reactors added beginning in 1996 have lifetime storage capability.

- TRU wastes are sent to disposal or storage the year after reprocessing.

- The maximum receiving rate for each repository for spent fuel or equivalent HLW is $1800 \mathrm{MTHM} / \mathrm{yr}$ the first five years and $3000 \mathrm{MTHM} / \mathrm{yr}$ for the next 21 years.

- The maximum TRU receiving rates are designed to be compatible with the $H L W$ receiving rates and are about 15 percent greater than those rates in terms of equivalent MTHM. 
- Solidified HLW is sent to disposal or storage one year after reprocessing or 10 years after reactor discharge, whichever is 1 ater.

- Time from discharge is determined by youngest fuel in the mixture.

- 01dest fuel is shipped first to MRS/IS or reprocessing.

- Shipping the oldest fuel first is assumed to relieve the at-reactor storage problems.

- Spent fuel can be sent to disposal if the overflow from reactor basins is 10 years old and reprocessing is limited.

- The first two reprocessing plants have capacities of $1500 \mathrm{MTHM} / \mathrm{yr}$ and the next two have capacities of $3000 \mathrm{MTHM} / \mathrm{yr}$.

- The fourth reprocessing plant is a replacement for the first plant, which is assumed to be retired after about 20 years service.

- Each reprocessing $\mathrm{plant}$ operates at $1 / 3$ and $2 / 3$ capacity in its first two years.

- Spent fuel requiring storage prior to 1990 is stored in casks at reactor sites or at government-owned emergency storage.

The startup dates for reprocessing $\mathrm{plants}$ and repositories which def ine the scenarios are summarized in Table B.1. MRS/IS activity concludes before 2025 for all except the delayed disposal scenario; a fourth repository is needed in the delayed disposal scenario to permit retiring the MRS/IS at a reasonable date.

Reprocessing Plant Waste Quantities

Reprocessing plant waste quantities are based on information provided by AGNS in a draft report. (a) The projection is based on:

- Compaction of the hulls (after separation of hardware) and other compactible and noncombustible wastes

(a) W. H. Carr, Estimation of Nuclear Waste from the Barnwell Nuclear Fuel Plant, Allied-Generai Nuclear Services, April 26, 1982 (Draft). 
TABLE B.1. Startup Dates for the Scenarios

\begin{tabular}{|c|c|c|}
\hline Scenario & Reprocessing & Disposal \\
\hline Reference & $1989,2000,2005,2010$ & $1998,2002,2015$ \\
\hline $\begin{array}{l}\text { Delayed } \\
\text { Reprocessing }\end{array}$ & $1999,2010,2015,2020$ & $1998,2002,2015$ \\
\hline Delayed Disposal & $1989,2000,2005,2010$ & $2008,2012,2015,2025$ \\
\hline Early Disposal(a) & $1989,2000,2005,2010$ & 1993, 1998, 2010 \\
\hline $\begin{array}{l}\text { Delayed Disposal( }(a) \\
\text { no Reprocessing }\end{array}$ & & $2008,2012,2015$ \\
\hline
\end{tabular}

(a) Information only

- Incineration of combustible wastes with cement immobilization of the ash and incinerator scrubber solution

- Immobilization of $\mathrm{UF}_{6} \mathrm{plant}$ particulates with cement

- Volume reduction factors based on data developed for the GEIS on commercial radioactive waste (DOE/ET-0028)

- Use of a 2-ft diameter $\times 10-f t$ long canister for hulls and other canistered wastes (excluding HLW). This size is assumed to be more compatible with storage and shipping casks than the 4-ft diameter $x$ 8-ft long canister.

The annual quantities of waste from the 1500 MT/yr AGNS plant are summarized in Table B.2 for the volume-reduced and immobilized wastes. Table B.2 also shows the number of HLW canisters, if a standard 1-ft diameter $x$ 10-ft long canister is used. The TRU wastes are divided into five surface dose rate categories: $0.2,0.2-5,5-50,50-500$, and $>500 \mathrm{R} / \mathrm{hr}$. Waste containers with surface dose rates greater than $0.2 \mathrm{R} / \mathrm{hr}$ are identified here as remote handled TRU (RHTRU). Those less than $0.2 \mathrm{R} / \mathrm{hr}$ are identified as 
TABLE B.2. Annual AGNS Plant HLW and TRU Wastes with Volume Reduction and Immobilization (Per 1500 MTU) (a)

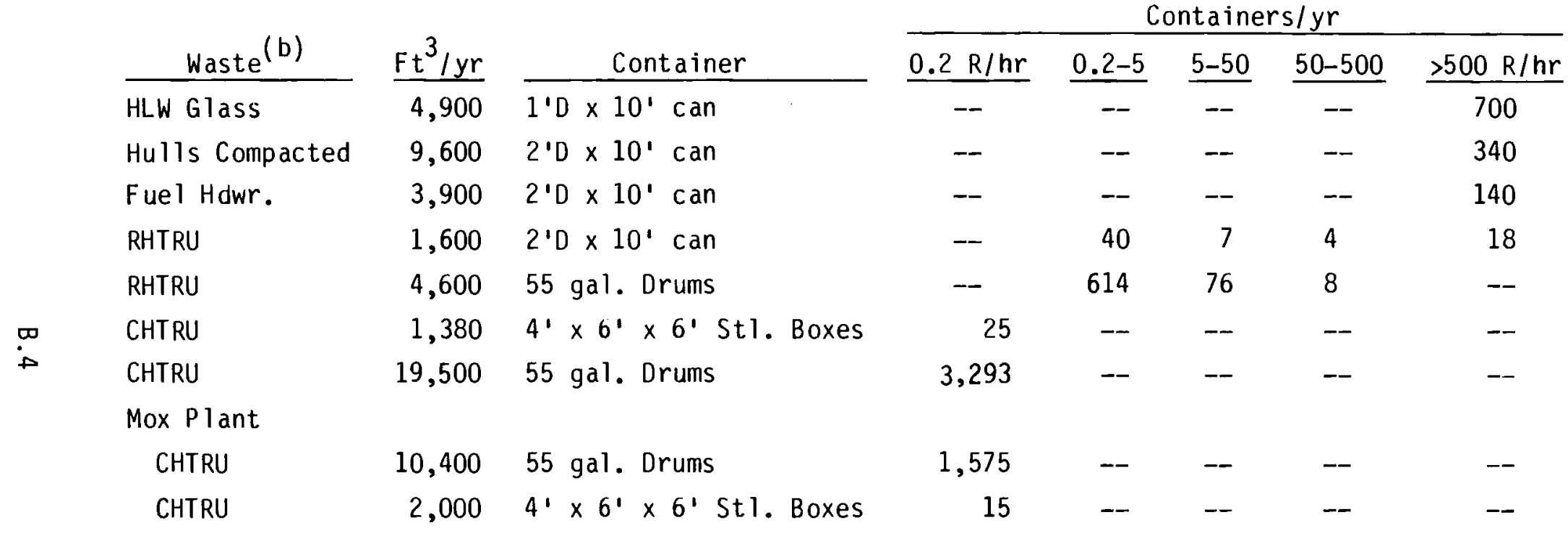

(a) Based on information available at the time the RFP was prepared.

(b) Waste quantities are based on data from W. H. Carr, "Estimation of Nuclear Waste Types, Characteristics and Quantities from the Barnwell Nuclear Fuel Plant," document E-512-09600R dated May 1982, Allied-General Nuclear Services for "as generated" quantities and volume reduction ratio obtained from DOE/ET0028, Technology for Commercial Radioactive Waste Management, U.S. Department of Energy, May 1979. (Estimates are based on a 10 nanocuries/gram for TRU waste.) 
contact handled (CHTRU). The AGNS data included a category 0.05 to $0.5 \mathrm{R} / \mathrm{hr}$. For this analysis one-half the waste in that category is assumed to have a surface dose rate of less than $0.2 \mathrm{R} / \mathrm{hr}$ and, therefore, to be CHTRU. The remainder is assumed to be greater than $0.2 \mathrm{R} / \mathrm{hr}$ and, therefore, to be RHTRU. Scenario Projection

The reference scenario is summarized in Table B.3. All numbers on this table are expressed as metric tons of spent fuel or metric tons equivalent of HLW (i.e., metric tons of spent fuel reprocessed to produce the HLW). To convert from MTHM to fuel assemblies or HLW canisters, divide the listed MTHM values by 0.18 MTHM/BWR, 0.42 MTHM/PWR, 2.143 MTHM/Canister. Column headings can be defined as follows:

\begin{tabular}{|c|c|c|}
\hline Column & Label & Definition \\
\hline 2 & Discharge & MT spent fuel discharged per year \\
\hline 3 & AR Inv. & $\begin{array}{l}\text { At-reactor spent fuel storage } \\
\text { inventories, MT }\end{array}$ \\
\hline 4 & MRS Inv. & $\begin{array}{l}\text { Spent fuel inventory at the } \\
\text { MRS/IS, MT }\end{array}$ \\
\hline 4 & MRS Inv. & $\begin{array}{l}\text { Spent fuel inventory at the } \\
\text { MRS/IS, MT }\end{array}$ \\
\hline 5 & Reprocess & Reprocessing rate, MT/yr \\
\hline 6 & Disposal & $\begin{array}{l}\text { Spent fuel shipped to disposal, } \\
\text { MT/yr }\end{array}$ \\
\hline 7 & Disposal Inv. & $\begin{array}{l}\text { Spent fuel inventory in reposi- } \\
\text { tories, MT }\end{array}$ \\
\hline 8 & HLW AR & $\begin{array}{l}\text { HLW stored at reprocessing plant, } \\
\text { MT equivalent }\end{array}$ \\
\hline 9 & HLW MRS & HLW stored at MRS/IS, MT equivalent \\
\hline 10 & Disposal & HLW sent to disposal, MT/yr \\
\hline 11 & Disposal Inv. & $\begin{array}{l}\text { HLW inventories in repositories, } \\
\text { MT equivalent }\end{array}$ \\
\hline
\end{tabular}


TABLE B.3. Reference Scenario Summary

NEDERENCE CASE JUNE AS, TYOC

\begin{tabular}{|c|c|c|c|c|c|c|c|c|c|c|}
\hline A & DI ICEMARGE & AN INV & MRS IOU & MERMULESS & LASHIJOAL & UIJH INR & $M L A D$ & MLA MKS & DLXRUSAL & ulat you \\
\hline $\begin{array}{l}1901 \\
1902 \\
1903 \\
1900 \\
1905\end{array}$ & $\begin{array}{l}1000 . \\
12370 \\
1607 \% \\
17440 \\
2167 \%\end{array}$ & $\begin{array}{l}7671 . \\
41040 \\
107195 \\
12447 . \\
100240\end{array}$ & $\begin{array}{l}0 . \\
0 . \\
190 \\
190 \\
130\end{array}$ & $\begin{array}{l}0 . \\
0 . \\
0 . \\
0 . \\
0 .\end{array}$ & $\begin{array}{l}0 . \\
0 . \\
0 . \\
0 . \\
v .\end{array}$ & $\begin{array}{l}0 . \\
u: \\
u: \\
u .\end{array}$ & $\begin{array}{l}0: \\
0 \vdots \\
0 \\
0 \\
0\end{array}$ & $\begin{array}{l}0 . \\
0 . \\
0 . \\
0 . \\
0 .\end{array}$ & $\begin{array}{l}0 . \\
u: \\
0: \\
i .\end{array}$ & $\begin{array}{l}0 . \\
0 . \\
0.0 \\
0 . \\
0 .\end{array}$ \\
\hline $\begin{array}{l}1006 \\
1406 \\
1906 \\
1409 \\
1040\end{array}$ & $\begin{array}{l}2010 . \\
20220 \\
20660 \\
32250 \\
3015 .\end{array}$ & $\begin{array}{l}171710 \\
295070 \\
221460 \\
20449 \\
27507 .\end{array}$ & $\begin{array}{l}116.0 \\
2820 \\
350 . \\
\text { sus. } \\
120\end{array}$ & $\begin{array}{l}0 . \\
0 . \\
000 \\
10000\end{array}$ & $\begin{array}{l}0 . \\
0 . \\
0 . \\
0 . \\
0 .\end{array}$ & $\begin{array}{l}u_{0} \\
u_{0} \\
u_{0} \\
u_{1}\end{array}$ & $\begin{array}{r}0: \\
0: \\
0: \\
900: 5 \\
1100 !\end{array}$ & $\begin{array}{l}u . \\
u . \\
u . \\
u . \\
\text { soü }\end{array}$ & $\begin{array}{l}0 . \\
0: \\
0:\end{array}$ & $\begin{array}{l}0 . \\
0 . \\
0 . \\
0 . \\
0 .\end{array}$ \\
\hline $\begin{array}{l}1991 \\
1998 \\
1993 \\
6994 \\
1998\end{array}$ & $\begin{array}{l}3010,0 \\
3490 . \\
34850 \\
33890 \\
32740\end{array}$ & 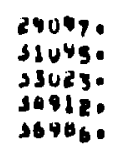 & $\begin{array}{l}u . \\
0 . \\
j 0 \\
u . \\
u .\end{array}$ & $\begin{array}{l}\text { isou. } \\
\text { iscou. } \\
\text { isvo. } \\
\text { isou. } \\
\text { isoo. }\end{array}$ & $\begin{array}{l}u . \\
u: \\
11 . \\
0 . \\
0 .\end{array}$ & $\begin{array}{l}u . \\
u . \\
u . \\
u . \\
u .\end{array}$ & $\begin{array}{l}1900: \\
1500: \\
1500 \\
1500 \\
1500 ?\end{array}$ & 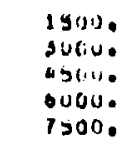 & $\begin{array}{l}\text { a. } \\
\text { c: } \\
\text { i. } \\
0 .\end{array}$ & $\begin{array}{l}u \\
1 \% \\
0.0 \\
0 .\end{array}$ \\
\hline $\begin{array}{l}1996 \\
1997 \\
1990 \\
1999 \\
2000\end{array}$ & $\begin{array}{l}3470 . \\
3496 . \\
30940 \\
30600 \\
3964 .\end{array}$ & $\begin{array}{l}544560 \\
409540 \\
433280 \\
45600 \\
47652 .\end{array}$ & $\begin{array}{l}\cdots \\
0 \\
0 . \\
0 . \\
i .\end{array}$ & $\begin{array}{l}1900 . \\
15000 \\
19000 \\
15000 \\
2000 .\end{array}$ & $\begin{array}{l}0 . \\
0: \\
u: \\
0:\end{array}$ & $\begin{array}{l}u: \\
u: \\
i: \\
u: \\
u .\end{array}$ & $\begin{array}{l}1500: \\
1500: \\
1500: \\
1500: \\
2000:\end{array}$ & 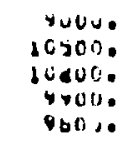 & 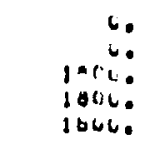 & 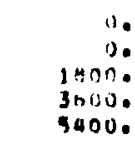 \\
\hline $\begin{array}{l}2001 \\
2002 \\
2003 \\
2000 \\
2005\end{array}$ & $\begin{array}{l}43860 \\
44070 \\
45690 \\
49190 \\
40480\end{array}$ & $\begin{array}{l}495330 \\
209450 \\
32350 \\
544340 \\
352740\end{array}$ & $\begin{array}{l}0 . \\
u \\
u \\
0 . \\
0 .\end{array}$ & 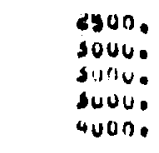 & $\begin{array}{l}0 . \\
0 . \\
0 . \\
0 . \\
0 .\end{array}$ & $\begin{array}{l}u . \\
u \\
u: \\
\because:\end{array}$ & $\begin{array}{l}\text { asou: } \\
\text { suov: } \\
\text { Jouo: } \\
\text { soov: } \\
\text { 4rou: }\end{array}$ & $\begin{array}{l}9000 . \\
01000 \\
6 \times 060 \\
5100 . \\
3500 .\end{array}$ & 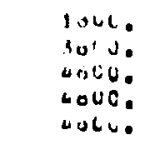 & $\begin{array}{l}\text { raou. } \\
\text { lcouts. } \\
\text { innol. } \\
\text { enur.. } \\
\text { enzno. }\end{array}$ \\
\hline $\begin{array}{l}2006 \\
2007 \\
2008 \\
2009 \\
2020\end{array}$ & $\begin{array}{l}\text { g256. } \\
60010 \\
64930 \\
65370 \\
02910\end{array}$ & $\begin{array}{l}25500, \\
555010 \\
356250 \\
361610 \\
354120\end{array}$ & $\begin{array}{l}0 . \\
0 . \\
30 \\
0 .\end{array}$ & $\begin{array}{l}20000 \\
00000 \\
00000 \\
00000 \\
1000 .\end{array}$ & $\begin{array}{l}u . \\
u \\
i: \\
u: \\
u .\end{array}$ & $\begin{array}{l}u . \\
u: \\
u ̈ \\
u \\
u\end{array}$ & $\begin{array}{l}5000: \\
6000: \\
6000: \\
6000: \\
1009 !\end{array}$ & $\begin{array}{l}\text { isco. } \\
\text { isone. } \\
\text { isoue } \\
\text { isno. } \\
\text { i soue }\end{array}$ & 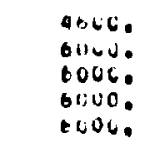 & 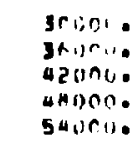 \\
\hline $\begin{array}{l}2012 \\
2012 \\
2013 \\
2014 \\
0012\end{array}$ & $\begin{array}{l}6226 . \\
6391 . \\
6485 . \\
67270 \\
7033 .\end{array}$ & $\begin{array}{l}3424 n . \\
50022 . \\
33006: \\
322330 \\
31767 .\end{array}$ & $\begin{array}{l}u: \\
0: \\
0: \\
0: \\
\text { s. }\end{array}$ & $\begin{array}{l}\text { isco. } \\
\text { isoo. } \\
\text { is } 150 . \\
1500 . \\
1500 .\end{array}$ & $\begin{array}{l}i . \\
0: \\
i . \\
i . \\
u .\end{array}$ & $\begin{array}{l}u . \\
u: \\
u: \\
u: \\
0 .\end{array}$ & $\begin{array}{l}6900 \% \\
1500 \% \\
60500 \% \\
10500: \\
19000:\end{array}$ & $\begin{array}{l}2500 . \\
\text { 3000. } \\
2700 . \\
+5000 \\
+800\end{array}$ & 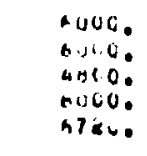 & $\begin{array}{l}60000 . \\
60000, \\
70000 \\
10000 \\
435200\end{array}$ \\
\hline $\begin{array}{l}2016 \\
2019 \\
2019 \\
2019 \\
2020\end{array}$ & $\begin{array}{l}6090 . \\
6469 . \\
7290 . \\
60920 \\
7006 .\end{array}$ & $\begin{array}{l}3045,9 \\
303260 \\
50084 . \\
492760 \\
48022 .\end{array}$ & $\begin{array}{l}n . \\
u: \\
0 . \\
\text { u. } \\
\text { j. }\end{array}$ & $\begin{array}{l}7501) . \\
1300 . \\
1300 . \\
1500 . \\
1500 .\end{array}$ & $\begin{array}{l}0 . \\
0 . \\
0 . \\
0 . \\
0 .\end{array}$ & $\begin{array}{l}u . \\
u \\
0 . \\
u \\
0 .\end{array}$ & $\begin{array}{l}11000: \\
18000: \\
10000: \\
22300 \\
225011\end{array}$ & $\begin{array}{l}0 . \\
0: \\
0 . \\
0 . \\
\text { u. }\end{array}$ & $\begin{array}{l}3400 . \\
1320 . \\
1500 . \\
3000 . \\
1500 .\end{array}$ & $\begin{array}{l}\text { GAS00. } \\
96000 . \\
1035100 . \\
106500 . \\
114000 .\end{array}$ \\
\hline
\end{tabular}


The 13 tons in MRS/IS before 1986 come from Surry-2. It is possible the ulitity will find another solution to its storage problem. Columns six and seven are provided for spent fuel disposal in other scenarios. Column eight represents the HLW inventory at the reprocessing plant, based on a minimum of one year hold up or until 10 years after reactor discharge.

Table B.4 contains the details of shipments of fuel and HLW to and from the MRS/IS. The left half of the table has BWR data and the right half PWR data. Positive numbers represent additions or shipment to the facility while negative values represent shipments or removals from the facility. In Table B.4, the amount of each shipment is given as the tonnes of heavy metal in the original fuel. Thus the HLW shipments must be converted to canisters to obtain storage requirements (see Table B.5). The exposure is the average exposure in MWd/kg. The discharge year is the year the youngest fuel in the mixture was discharged.

Table B. 6 contains similar data for TRU. On this table, the left-hand column of each pair represents TRU generated while reprocessing BWR fuel and the right-hand column of each pair represents TRU generated while reprocessing PWR fuel. Number of packages of treated wastes handled each year is also given in Table B.6. In addition to the data given in Table B.6, the Mox plant is assumed to produce one $4 \mathrm{ft} \times 6 \mathrm{ft} \times 6 \mathrm{ft}$ box for each 100 drums.

Tables B.7 and B.8 are similar to Tables B.3 and B.4 and present data for the delayed reprocessing scenario. Table B.8, however, does not include TRU since the MRS/IS will not receive any TRU in this scenario. Tables B.9-11 are similar to Tables B.4-6 and present data for the delayed disposal scenario. Tables B.12 through B.16 present data for the early disposal and delayed disposal-no reprocessing scenarios and are for information only.

The spent fuel and HLW requirements at MRS/IS were summarized in Table B.5. The peak rates given in Tables B.4, B.8, and B.10 were averaged over 2 or 3 years since the peaks are the result of setting the age of $a$ year's reprocessing plant production of HLW equal to the age of the youngest fuel in the mixture. This causes large and unrealistic variations in 
$8^{\circ} \mathrm{g}$

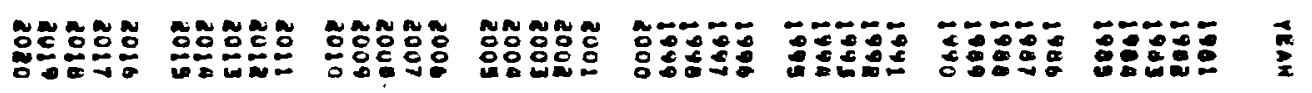

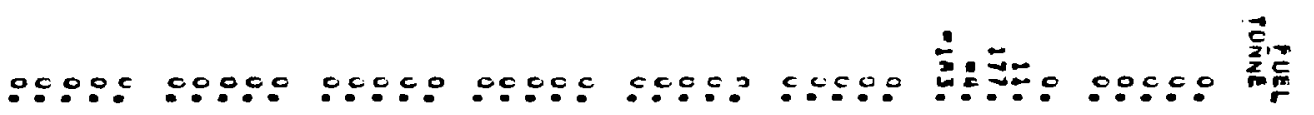

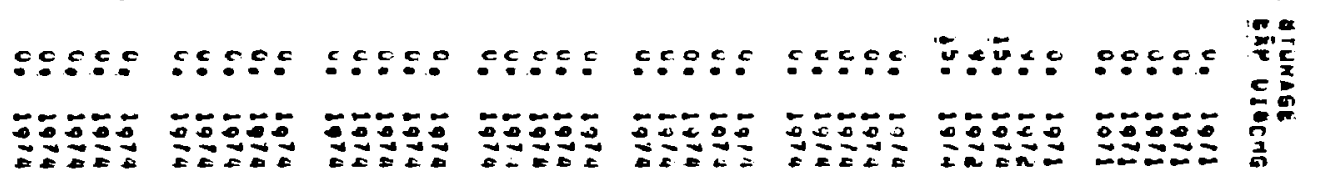

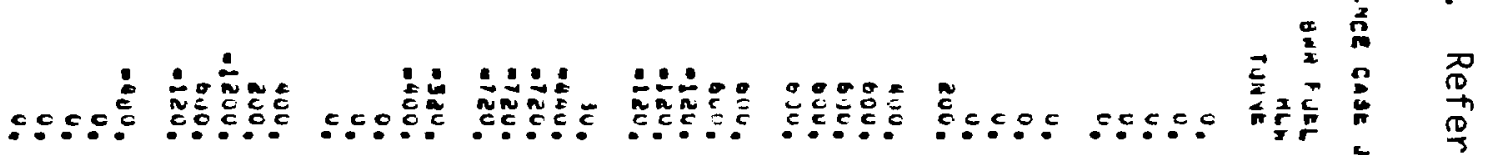

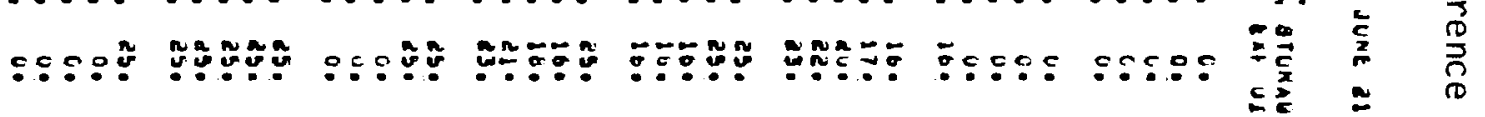

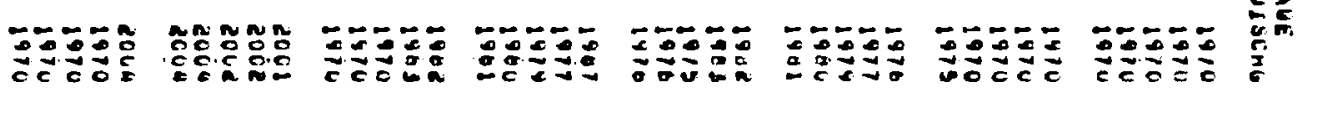

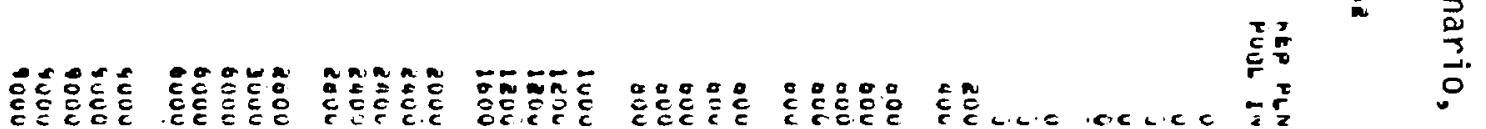

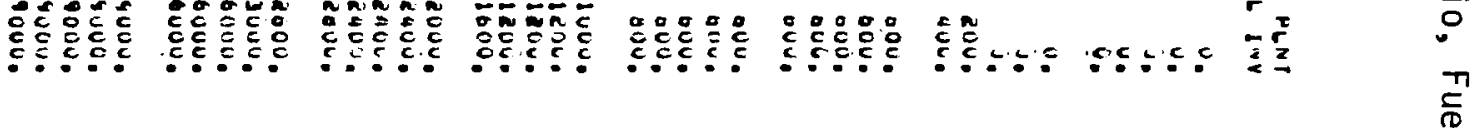

О:S:

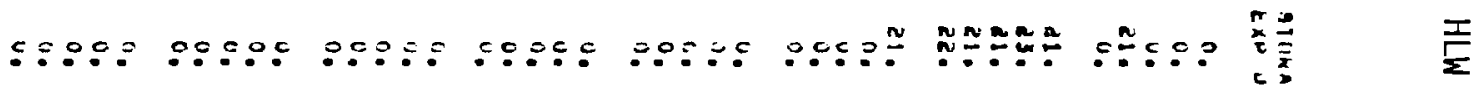

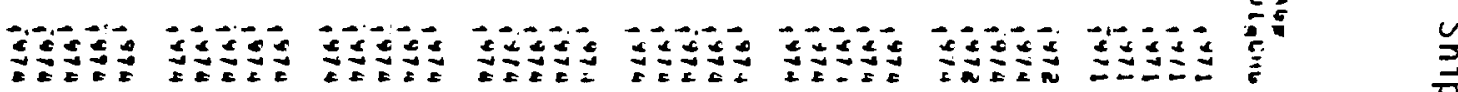

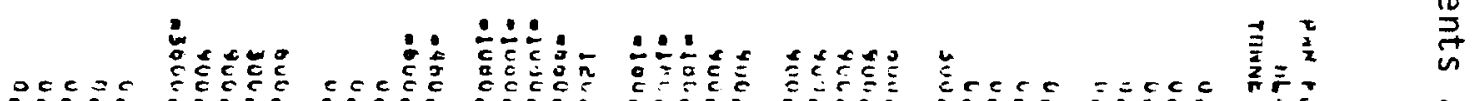

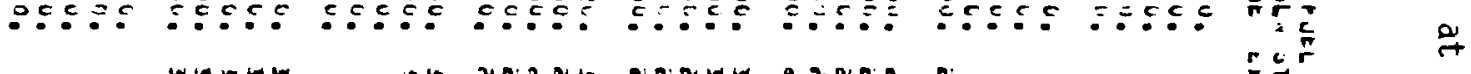

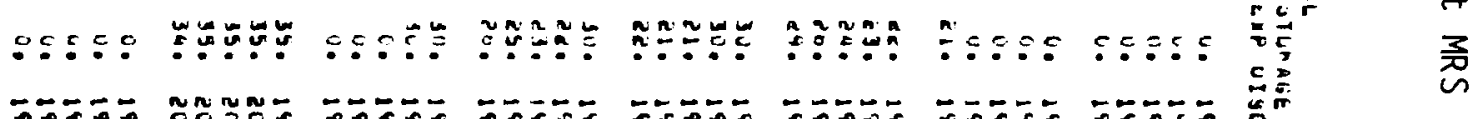

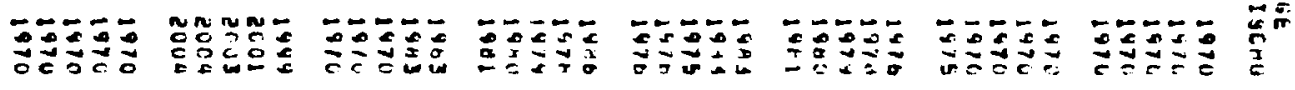

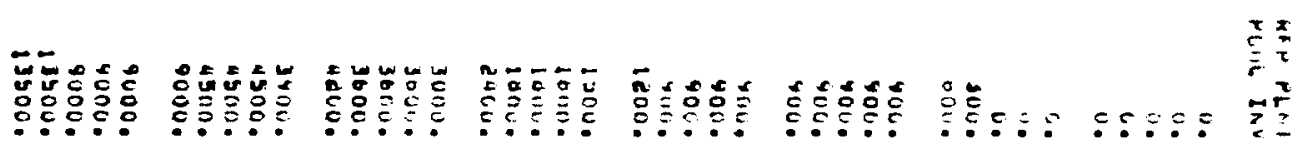


TABLE B.5. Spent Fuel and HLW (MTHM) Storage Capacity Requirements at MRS/IS Facility

Reference $\begin{array}{cl}\begin{array}{c}\text { Delayed } \\ \text { Reprocessing }\end{array} & \begin{array}{l}\text { Delayed } \\ \text { Disposal }\end{array}\end{array}$

\begin{tabular}{|c|c|c|c|}
\hline Fuel capacity & $\ldots(a)$ & 7,547 & $\ldots(a)$ \\
\hline HLW capacity & 10,500 & - & 60,600 \\
\hline Annual receiving rate ${ }^{(b)}$ & 1,500 & 1,500 & 4,500 \\
\hline Annual removal rate ${ }^{(c)}$ & 1,800 & 2,200 & 4,800 \\
\hline
\end{tabular}

(a) No spent fuel is stored at MRS/IS facility prior to startup in 1990 .

(b) Peak rates averaged over 2 years.

(b) Peak rates averaged over 3 years. 
TABLE B.6. Reference Scenario, Number of TRU Packages Handled at MRS

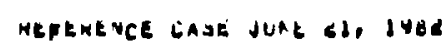

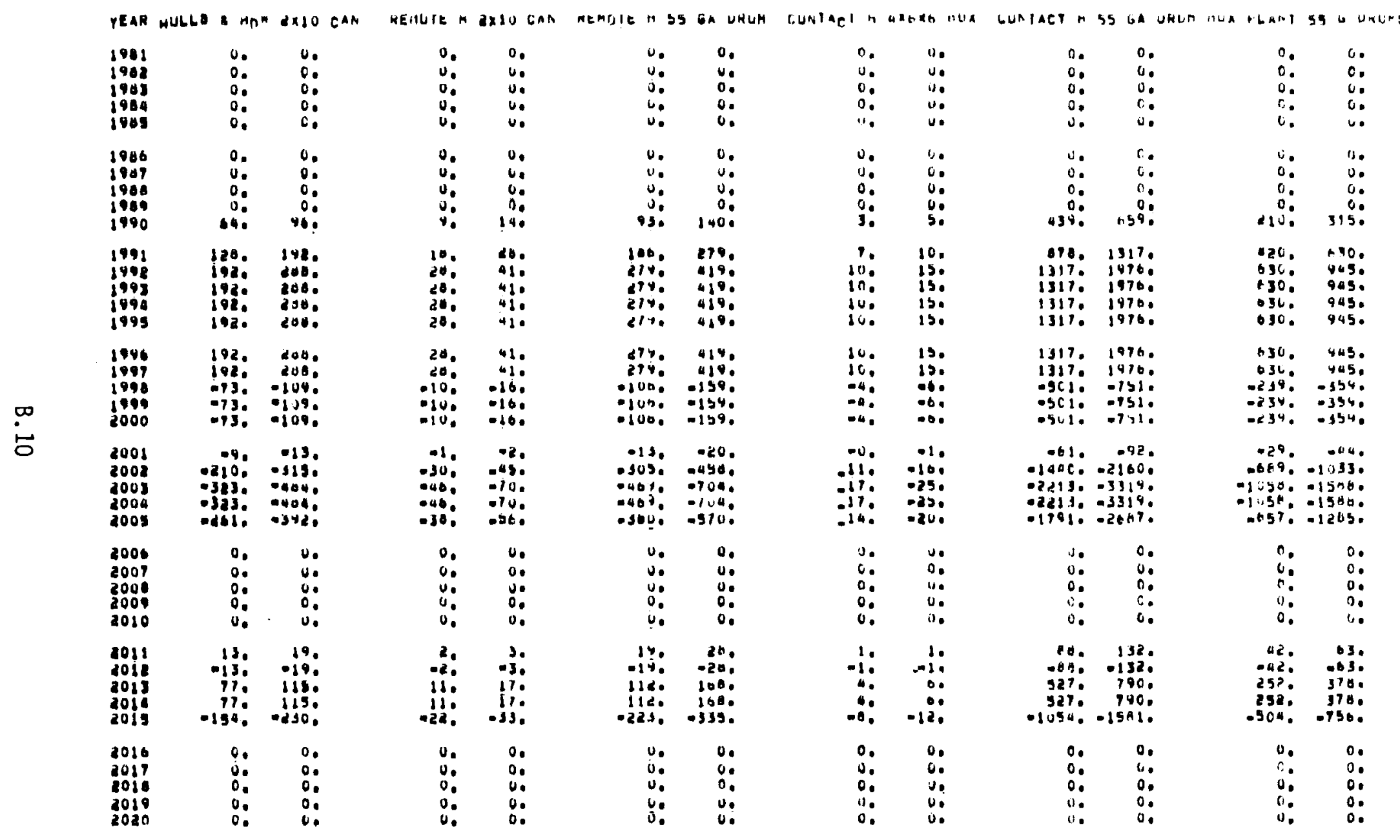


TABLE B.7. Delayed Reprocessing Scenario Summary

\begin{tabular}{|c|c|c|c|c|c|c|c|c|c|c|}
\hline YEAK & DLOÇMARGE & $A R I_{N V}$ & MAS INV & HEPFUCESA & DLJPJBAL & LISP INV & $M L \neq A D$ & HLW MNS & LISPUBAL & $\| I S P I N V$ \\
\hline $\begin{array}{l}1981 \\
1988 \\
1983 \\
1986 \\
1985\end{array}$ & $\begin{array}{l}1040 . \\
1237 . \\
1007 . \\
1944: \\
2167 .\end{array}$ & 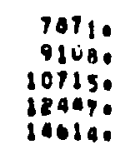 & $\begin{array}{l}0 . \\
0: \\
0: \\
130 \\
130\end{array}$ & $\begin{array}{l}0 . \\
0 . \\
0: \\
0 . \\
i .\end{array}$ & $\begin{array}{l}u . \\
0 . \\
0 . \\
0 . \\
0 .\end{array}$ & $\begin{array}{l}u . \\
v: \\
u: \\
u:\end{array}$ & $\begin{array}{l}u \\
u \\
n \\
n ! \\
u\end{array}$ & $\begin{array}{l}u . \\
u: \\
0 . \\
0: \\
v .\end{array}$ & $\begin{array}{l}c . \\
i . \\
i: \\
i .\end{array}$ & $\begin{array}{l}0 . \\
0: \\
0 . \\
0 .\end{array}$ \\
\hline $\begin{array}{l}1980 \\
1987 \\
1980 \\
1990 \\
1990\end{array}$ & 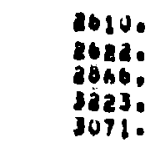 & $\begin{array}{l}171210 \\
193670 \\
221960 \\
29945 \\
215350\end{array}$ & $\begin{array}{r}1100 \\
2920 \\
530 \\
10030 \\
14630\end{array}$ & $\begin{array}{l}u . \\
0: \\
u: \\
0 . \\
0 .\end{array}$ & $\begin{array}{l}0 . \\
0 . \\
u \\
u: \\
0 .\end{array}$ & $\begin{array}{l}u . \\
0 . \\
i j \\
i_{0} \\
0 .\end{array}$ & $\begin{array}{l}0: \\
0: \\
u \\
u ! \\
0 !\end{array}$ & $\begin{array}{l}u . \\
i . \\
0 . \\
u . \\
u .\end{array}$ & $\begin{array}{l}\text { i. } \\
\text { c. } \\
u: \\
0 . \\
0 .\end{array}$ & $\begin{array}{l}0 . \\
0 . \\
u . \\
0 . \\
0 .\end{array}$ \\
\hline $\begin{array}{l}1991 \\
1998 \\
1993 \\
1989 \\
1495\end{array}$ & $\begin{array}{l}3070, \\
3496, \\
3428, \\
3394 . \\
3374 .\end{array}$ & 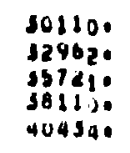 & $\begin{array}{l}19070 \\
26350 \\
33020 \\
43020 \\
35520\end{array}$ & $\begin{array}{l}0 . \\
0 . \\
0 . \\
0 . \\
0 .\end{array}$ & $\begin{array}{l}u . \\
0 . \\
0 . \\
0 . \\
0 .\end{array}$ & $\begin{array}{l}u . \\
u \\
u \\
u \\
u \\
u\end{array}$ & $\begin{array}{l}0: \\
u: \\
u ! \\
4 ! \\
0 !\end{array}$ & $\begin{array}{l}u . \\
i: \\
i: \\
u . \\
u .\end{array}$ & $\begin{array}{l}u . \\
c . \\
i . \\
u . \\
0 .\end{array}$ & $\begin{array}{l}0 . \\
0 . \\
0 . \\
0 . \\
0 .\end{array}$ \\
\hline $\begin{array}{l}1996 \\
1997 \\
1998 \\
1996 \\
8000\end{array}$ & $\begin{array}{l}3470 . \\
3498 . \\
3674 . \\
3060 \% \\
3469 .\end{array}$ & 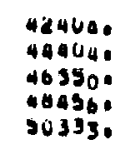 & $\begin{array}{l}\text { l052. } \\
8550 . \\
0470 . \\
9479 . \\
0470 .\end{array}$ & $\begin{array}{r}0 . \\
0 . \\
00 \\
5000 \\
1000\end{array}$ & $\begin{array}{r}0 . \\
u . \\
\text { loce. } \\
\text { lasu. } \\
\text { loug. }\end{array}$ & $\begin{array}{r}u . \\
u . \\
180 u \\
3454 . \\
4345 .\end{array}$ & $\begin{array}{r}n ! \\
\text { buu! } \\
\text { bou! }\end{array}$ & $\begin{array}{l}u . \\
u: \\
u \\
u . \\
u .\end{array}$ & $\begin{array}{c}0 . \\
\vdots: \\
0.0\end{array}$ & $\begin{array}{r}0 . \\
0 . \\
0 . \\
\text { sno: }\end{array}$ \\
\hline $\begin{array}{l}2001 \\
6002 \\
2003 \\
2004 \\
2005\end{array}$ & 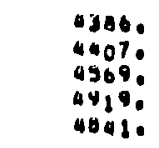 & 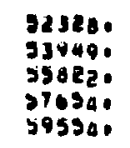 & 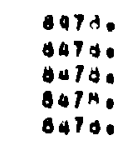 & $\begin{array}{l}15000 \\
\text { iso0. } \\
15000 \\
\text { j500. } \\
\text { iscoo. }\end{array}$ & $\begin{array}{l}8910 \\
1200 \% \\
1191 \% \\
15000 \\
19410\end{array}$ & $\begin{array}{l}\text { s232, } \\
\text { osis: } \\
\text { i7is: } \\
\text { 9sue. } \\
\text { ivi4s. }\end{array}$ & $\begin{array}{l}1500: \\
15000 \\
1500 ? \\
1500 ? \\
1500 ?\end{array}$ & $\begin{array}{l}41 . \\
0.0 \\
0 . \\
0 . \\
0.0\end{array}$ & $\begin{array}{l}500 . \\
\text { isyl. } \\
\text { isou. } \\
\text { isuo. } \\
\text { isco. }\end{array}$ & $\begin{array}{l}1400 . \\
3000 . \\
4500 . \\
60000 \\
1500 .\end{array}$ \\
\hline $\begin{array}{l}2006 \\
2007 \\
2008 \\
2000 \\
2010\end{array}$ & $\begin{array}{l}2226, \\
6045: \\
6043 . \\
6537: \\
0251 .\end{array}$ & 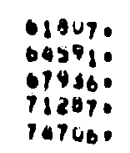 & $\begin{array}{l}0470, \\
0478, \\
8478, \\
0478, \\
04760\end{array}$ & $\begin{array}{l}1500 . \\
15000 \\
15000 \\
1560 . \\
2000 .\end{array}$ & $\begin{array}{l}14720 \\
1790 . \\
1800 \\
1600 . \\
\text { 032. }\end{array}$ & $\begin{array}{l}12213, \\
140230 \\
152120 \\
16046 . \\
17720 .\end{array}$ & $\begin{array}{l}1200 \% \\
1500 ! \\
1500 ! \\
1900 ? \\
2000 ?\end{array}$ & $\begin{array}{l}0 . \\
u: \\
0 . \\
0 . \\
0 .\end{array}$ & $\begin{array}{l}1500 . \\
150.0 \\
1000 . \\
1500 . \\
1500 .\end{array}$ & $\begin{array}{l}0000 . \\
10301 . \\
12000 . \\
13900 . \\
15000 .\end{array}$ \\
\hline $\begin{array}{l}2018 \\
2018 \\
0013 \\
2018 \\
2015\end{array}$ & 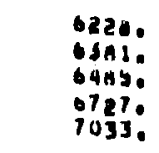 & $\begin{array}{l}103100 \\
023170 \\
063580 \\
909620 \\
95709 .\end{array}$ & $\begin{array}{l}04760 \\
10520 \\
71560 \\
64790 \\
4689 .\end{array}$ & $\begin{array}{l}2500, \\
\text { s000. } \\
20000 \\
\text { so00. } \\
\text { 40013. }\end{array}$ & $\begin{array}{l}0 \% \text {. } \\
u: \\
i . \\
u .\end{array}$ & $\begin{array}{l}17795 . \\
\text { i7795. } \\
67709 . \\
17793 . \\
17743 .\end{array}$ & $\begin{array}{l}25000: \\
310010 \\
3600: \\
3000: \\
4000:\end{array}$ & $\begin{array}{l}u . \\
1 \% \\
30 \\
13 . \\
1 .\end{array}$ & $\begin{array}{l}2060 . \\
2500 . \\
\text { suov. } \\
3060 . \\
3060 .\end{array}$ & $\begin{array}{l}17000 . \\
19500 \\
22500 \\
25300 \\
28900\end{array}$ \\
\hline $\begin{array}{l}2016 \\
2017 \\
2018 \\
2019 \\
2020\end{array}$ & $\begin{array}{l}1640 . \\
6869 . \\
7250 . \\
6692 . \\
1000 .\end{array}$ & 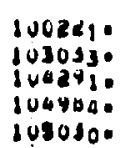 & $\begin{array}{r}1443 . \\
0: \\
0: \\
0 .\end{array}$ & 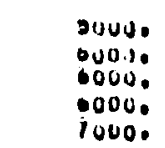 & $\begin{array}{l}0 . \\
u: \\
0 . \\
0 . \\
i .\end{array}$ & $\begin{array}{l}17795, \\
17745: \\
17743, \\
17795: \\
17793:\end{array}$ & 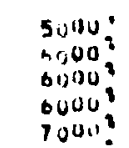 & $\begin{array}{l}u . \\
u . \\
u: \\
u: \\
0 .\end{array}$ & 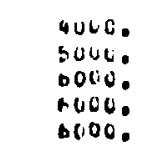 & $\begin{array}{l}92500 . \\
57500 . \\
435100 . \\
49500 . \\
59900 .\end{array}$ \\
\hline
\end{tabular}


TABLE B.8. Delayed Reprocessing Scenario, Fuel and HLW Shipment at MRS

JUNE al, IYUA UELATEU MENGLLEBOIMG

\begin{tabular}{|c|c|c|c|c|c|c|c|c|c|c|c|c|c|c|}
\hline YGAH & $\begin{array}{l}\text { PUEL } \\
\text { TONNEL }\end{array}$ & funt & $\begin{array}{l}\text { OE } \\
\text { IOCNG }\end{array}$ & $\begin{array}{l}\text { HN FUEL } \\
\text { TUNEL" }\end{array}$ & 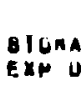 & CnG & $\begin{array}{l}\text { MEP HINI } \\
\text { POOL INV }\end{array}$ & TOULEL & $\begin{array}{l}\text { Slilna } \\
\text { Expe }\end{array}$ & $I_{0} \operatorname{lin}_{6}$ & $\begin{array}{l}\text { PUA PUE } \\
\text { PUNAK }\end{array}$ & Expo & $8 C H G$ & $\begin{array}{l}\text { REP PLWI } \\
\text { POOL INV }\end{array}$ \\
\hline $\begin{array}{l}1981 \\
1982 \\
1923 \\
1984 \\
1009\end{array}$ & $\begin{array}{l}0 . \\
0 . \\
0 . \\
0 . \\
0 .\end{array}$ & $\begin{array}{l}u_{1} \\
0: \\
0: \\
00 \\
0 .\end{array}$ & $\begin{array}{l}1911 \\
1911 \\
1971 \\
1971 \\
1911\end{array}$ & $\begin{array}{l}0 . \\
0: \\
0: \\
0 . \\
0 .\end{array}$ & $\begin{array}{l}0 . \\
0: \\
0: \\
0: \\
0:\end{array}$ & $\begin{array}{l}1970 \\
1970 \\
1970 \\
1970 \\
1070\end{array}$ & $\begin{array}{l}u_{0} \\
0.0 \\
0.0 \\
0 . \\
0 .\end{array}$ & $\begin{array}{r}0 . \\
0: \\
0 . \\
0 .\end{array}$ & $\begin{array}{l}0 . \\
0.0 \\
0.0\end{array}$ & $\begin{array}{l}1971 \\
1071 \\
1971 \\
1011 \\
1011\end{array}$ & $\begin{array}{l}u . \\
u: \\
u \\
i . \\
0 .\end{array}$ & $\begin{array}{l}0 . \\
0 . \\
0.0 \\
0 . \\
0 .\end{array}$ & $\begin{array}{l}1970 \\
1470 \\
1910 \\
1970 \\
1410\end{array}$ & $\begin{array}{l}1 . \\
0 . \\
0 . \\
0 . \\
n .\end{array}$ \\
\hline $\begin{array}{l}1986 \\
1097 \\
1908 \\
1980 \\
1990\end{array}$ & $\begin{array}{l}0.0 \\
1970 \\
1900 \\
190 .\end{array}$ & $\begin{array}{l}4: \\
9 ! \\
19: \\
17:\end{array}$ & $\begin{array}{l}1071 \\
1912 \\
1914 \\
1019 \\
1016\end{array}$ & $\begin{array}{l}u_{0} \\
u: \\
u \\
u: \\
0 .\end{array}$ & $\begin{array}{l}0: \\
0: \\
0: \\
0: \\
0 .\end{array}$ & $\begin{array}{l}1970 \\
1970 \\
1970 \\
1970 \\
1970\end{array}$ & $\begin{array}{l}. \\
j: \\
0.0 \\
0 . \\
0 .\end{array}$ & $\begin{array}{r}103 . \\
105: \\
61: \\
871 . \\
203 .\end{array}$ & $\begin{array}{l}21 . \\
23: \\
21: \\
21: \\
21 .\end{array}$ & $\begin{array}{l}1172 \\
1974 \\
1974 \\
1975 \\
1916\end{array}$ & $\begin{array}{l}0 . \\
\therefore: \\
0 . \\
0 . \\
0 .\end{array}$ & $\begin{array}{l}0 . \\
0 . \\
0: \\
0 . \\
0 .\end{array}$ & $\begin{array}{l}1911 \\
1914 \\
147 \\
1411 \\
1470\end{array}$ & $\begin{array}{l}0 . \\
10 \\
u: \\
\text { u. } \\
n:\end{array}$ \\
\hline $\begin{array}{l}1991 \\
1998 \\
1993 \\
1948 \\
1945\end{array}$ & 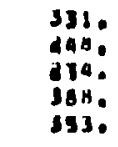 & $\begin{array}{l}170 \\
11: \\
19: \\
42: \\
42 !\end{array}$ & $\begin{array}{l}1977 \\
1977 \\
1978 \\
1976 \\
1919\end{array}$ & $\begin{array}{l}0 . \\
0: \\
0: \\
0 .\end{array}$ & $\begin{array}{l}0 . \\
0: \\
c: \\
0: \\
0 .\end{array}$ & $\begin{array}{l}1970 \\
1970 \\
1970 \\
1470 \\
1970\end{array}$ & $\begin{array}{l}u_{0} \\
u_{0} \\
u_{0} \\
u_{0} \\
u_{0}\end{array}$ & $\begin{array}{l}143 . \\
390 . \\
435 . \\
012 . \\
090 .\end{array}$ & $\begin{array}{l}22, \\
23: \\
23: \\
23 . \\
26 .\end{array}$ & $\begin{array}{l}1970 \\
647 \\
i 470 \\
i 410 \\
1400\end{array}$ & $\begin{array}{l}u: \\
0: \\
0: \\
i:\end{array}$ & $\begin{array}{l}0 . \\
3: \\
0 . \\
0 . \\
11 .\end{array}$ & $\begin{array}{l}1916 \\
1510 \\
1571 \\
1410 \\
1910\end{array}$ & $\begin{array}{l}0 . \\
0 . \\
0 . \\
0 . \\
i .\end{array}$ \\
\hline $\begin{array}{l}1996 \\
1947 \\
1996 \\
1999 \\
2000\end{array}$ & $\begin{array}{r}210 . \\
290 . \\
1710 \\
0 . \\
0 .\end{array}$ & $\begin{array}{l}48 . \\
140 \\
140 \\
0 .\end{array}$ & $\begin{array}{l}1900 \\
1941 \\
1974 \\
1010 \\
1010\end{array}$ & $\begin{array}{l}u_{0} \\
u_{0} \\
u_{0} \\
u_{0} \\
u_{0}\end{array}$ & $\begin{array}{l}0: \\
0: \\
u ! \\
0: \\
0:\end{array}$ & $\begin{array}{l}1970 \\
1810 \\
1470 \\
1970 \\
1970\end{array}$ & $\begin{array}{r}u_{0} \\
u . \\
u_{0} \\
\text { cou. } \\
\text { asu. }\end{array}$ & $\begin{array}{r}901 . \\
\text { You. } \\
-1 . \\
0 . \\
0 .\end{array}$ & $\begin{array}{l}89 . \\
30 . \\
61 \\
0 . \\
0 .\end{array}$ & 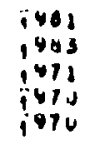 & $\begin{array}{l}0 . \\
0: \\
0: \\
0 .\end{array}$ & $\begin{array}{l}c . \\
\because . \\
u: \\
u \\
b .\end{array}$ & $\begin{array}{l}19111 \\
1410 \\
1471 \\
1970 \\
1970\end{array}$ & $\begin{array}{r}0 . \\
u . \\
\text { un } \\
\text { sou. }\end{array}$ \\
\hline $\begin{array}{l}2001 \\
2002 \\
2003 \\
2004 \\
2005\end{array}$ & $\begin{array}{l}u . \\
u: \\
0 . \\
\text { u. }\end{array}$ & $\begin{array}{l}u: \\
u: \\
0 . \\
u: \\
u:\end{array}$ & $\begin{array}{l}1910 \\
1970 \\
1910 \\
1970 \\
1910\end{array}$ & $\begin{array}{r}1 . \\
0: \\
0 ; \\
0 ;\end{array}$ & $\begin{array}{l}25 ! \\
2 s ! \\
0 . \\
u: \\
u !\end{array}$ & $\begin{array}{l}1908 \\
1905 \\
1970 \\
1890 \\
1870\end{array}$ & $\begin{array}{l}550 . \\
000 . \\
000 . \\
000 . \\
000.0\end{array}$ & $\begin{array}{l}0 . \\
0: \\
8: \\
0:\end{array}$ & $\begin{array}{l}3: \\
0 . \\
0: \\
0 .\end{array}$ & $\begin{array}{l}i 910 \\
1910 \\
i v 10 \\
i 470 \\
i v 10\end{array}$ & $\begin{array}{c}0.0 \\
0.0 \\
0.0 \\
0 . \\
0.0\end{array}$ & $\begin{array}{l}3 w . \\
3 n: \\
u: \\
0 . \\
0 .\end{array}$ & $\begin{array}{l}1905 \\
1005 \\
1516 \\
1910 \\
1470\end{array}$ & $\begin{array}{l}450 . \\
900 . \\
\text { Y00. } \\
9100 . \\
00 .\end{array}$ \\
\hline $\begin{array}{l}2006 \\
2007 \\
2000 \\
2009 \\
2010\end{array}$ & $\begin{array}{l}0 . \\
0 . \\
0 . \\
0 . \\
0 .\end{array}$ & $\begin{array}{l}u: \\
0: \\
0: \\
0: \\
0 !\end{array}$ & $\begin{array}{l}1910 \\
1970 \\
1910 \\
1970 \\
1970\end{array}$ & $\begin{array}{l}u_{0} \\
u_{0} \\
u_{0} \\
u_{0} \\
u_{0}\end{array}$ & $\begin{array}{l}0.0 \\
0: \\
0: \\
0: \\
0 .\end{array}$ & $\begin{array}{l}1970 \\
1970 \\
1970 \\
1970 \\
1410\end{array}$ & $\begin{array}{l}600 . \\
000 . \\
600 . \\
000 . \\
000 .\end{array}$ & $\begin{array}{l}u: \\
0: \\
0 . \\
0 . \\
j .\end{array}$ & $\begin{array}{l}0 . \\
0 . \\
0 . \\
0 . \\
0 .\end{array}$ & $\begin{array}{l}1+10 \\
1+10 \\
1+10 \\
i \neq 10 \\
i \$ 10\end{array}$ & $\begin{array}{l}u: \\
u: \\
u: \\
u: \\
u .\end{array}$ & $\begin{array}{l}0 . \\
0 . \\
0 . \\
10 \\
10\end{array}$ & $\begin{array}{l}1910 \\
19713 \\
1510 \\
1470 \\
1010\end{array}$ & $\begin{array}{l}400, \\
900 . \\
401 \% \\
900 . \\
1000 .\end{array}$ \\
\hline $\begin{array}{l}2011 \\
2012 \\
2013 \\
2014 \\
2019\end{array}$ & $\begin{array}{r}0 . \\
-1040 \\
-94, \\
-3130 \\
-698 .\end{array}$ & $\begin{array}{l}0 . \\
10: \\
10: \\
i 1 \\
i 1\end{array}$ & $\begin{array}{l}1910 \\
1919 \\
1915 \\
1918 \\
1918\end{array}$ & $\begin{array}{l}u_{0} \\
u_{0} \\
u_{0} \\
u_{0} \\
u_{0}\end{array}$ & $\begin{array}{l}10 . \\
00 \\
0: \\
00 \\
0.0\end{array}$ & $\begin{array}{l}1910 \\
1810 \\
1870 \\
1910 \\
1970\end{array}$ & $\begin{array}{l}1000 . \\
12000 \\
1200 . \\
1200 . \\
1000 .\end{array}$ & $\begin{array}{r}0, \\
-442, \\
-418, \\
-3640 \\
-11030\end{array}$ & $\begin{array}{l}0 . \\
22: \\
21: \\
22: \\
23:\end{array}$ & $\begin{array}{l}i \times 10 \\
i 915 \\
i 410 \\
i y 11 \\
i+19\end{array}$ & $\begin{array}{l}1.0 \\
u \cdot \\
0 . \\
u . \\
i .\end{array}$ & $\begin{array}{l}0 . \\
j .0 \\
j 0 \\
0 . \\
10 .\end{array}$ & $\begin{array}{l}1970 \\
1970 \\
1970 \\
1911 \\
1510\end{array}$ & $\begin{array}{l}1500, \\
100100 \\
10000 \\
10000 \\
240300\end{array}$ \\
\hline $\begin{array}{l}2016 \\
2017 \\
2016 \\
2010 \\
2020\end{array}$ & $\begin{array}{r}-963, \\
0.23, \\
0 . \\
0 . \\
0 .\end{array}$ & $\begin{array}{c}d z: \\
410 ! \\
0 ! \\
0 ! \\
0 !\end{array}$ & $\begin{array}{l}1980 \\
1902 \\
1902 \\
1901 \\
1941\end{array}$ & $\begin{array}{l}u_{0} \\
u_{0} \\
u_{0} \\
u_{0} \\
0_{0}\end{array}$ & $\begin{array}{l}0 . \\
0: \\
0: \\
0: \\
0:\end{array}$ & $\begin{array}{l}1970 \\
1970 \\
1970 \\
1970 \\
1990\end{array}$ & $\begin{array}{l}2000 . \\
2400 . \\
2400 . \\
2400 . \\
2000 .\end{array}$ & $\begin{array}{r}-1181 . \\
-1019 \\
0 . \\
0 \\
60\end{array}$ & $\begin{array}{l}21 . \\
30: \\
0: \\
0 .\end{array}$ & 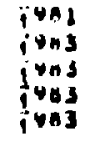 & $\begin{array}{l}0 . \\
0 . \\
0 . \\
0 . \\
u .\end{array}$ & $\begin{array}{l}\text { ve } \\
\text { je } \\
v_{0} \\
v_{0} \\
0 .\end{array}$ & $\begin{array}{l}1970 \\
1971 \\
1470 \\
1511 \\
1410\end{array}$ & $\begin{array}{l}3000 . \\
3000 . \\
3000 . \\
3000 . \\
40000\end{array}$ \\
\hline
\end{tabular}


$\varepsilon \tau \cdot g$

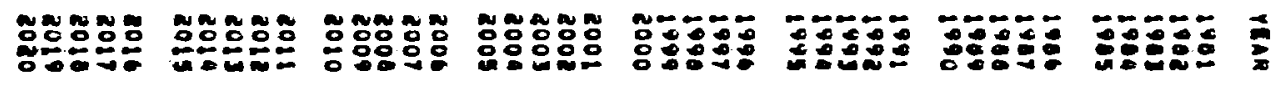

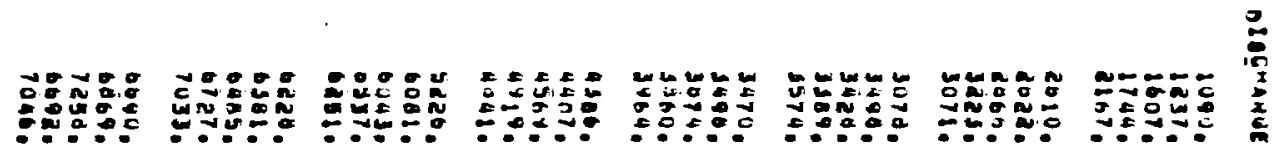

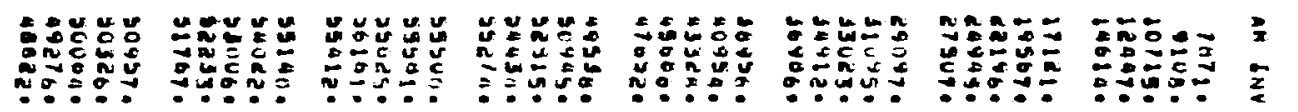

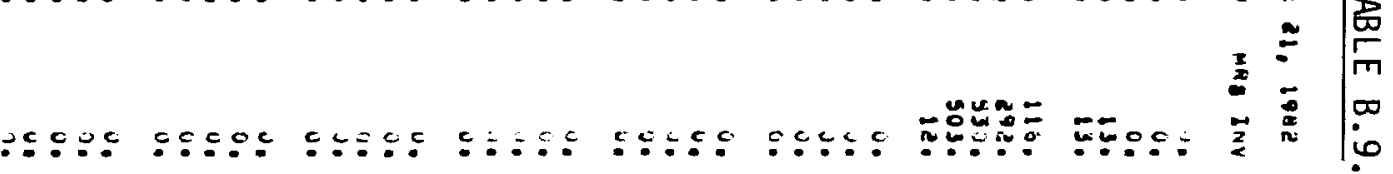

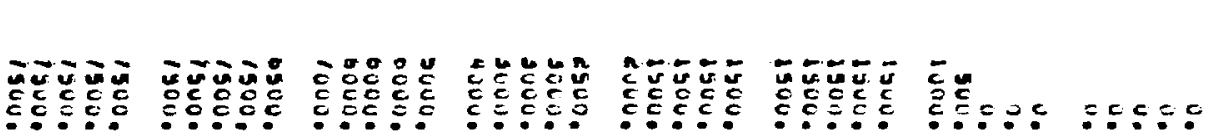

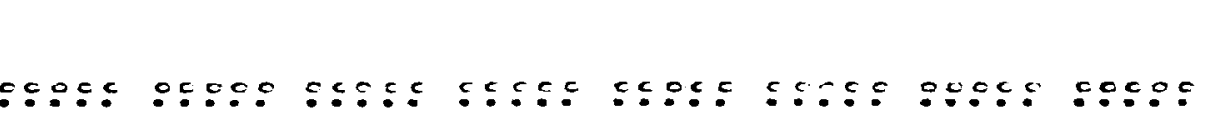

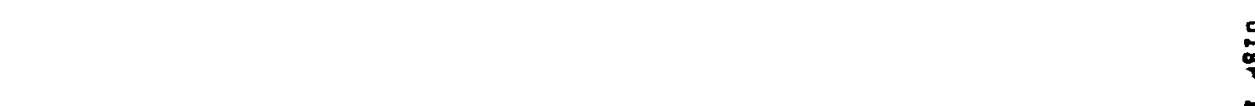

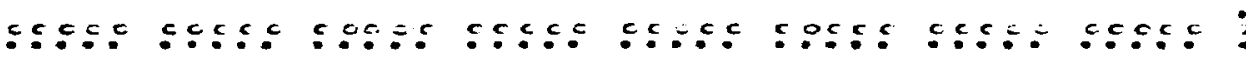

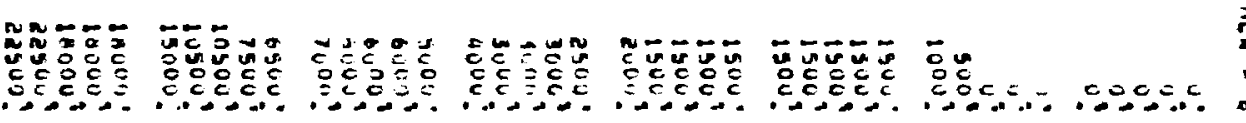

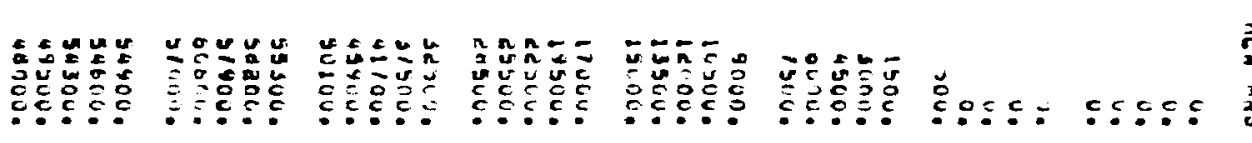

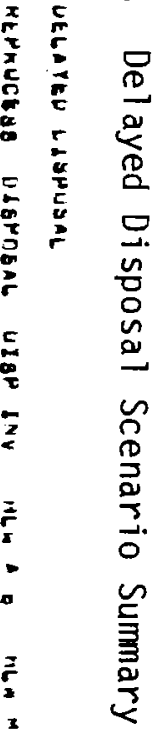

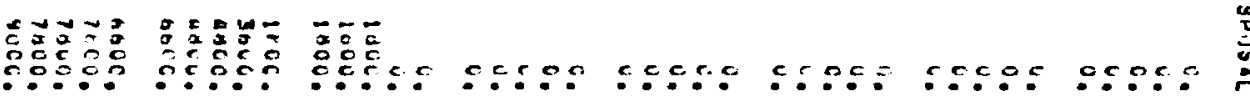

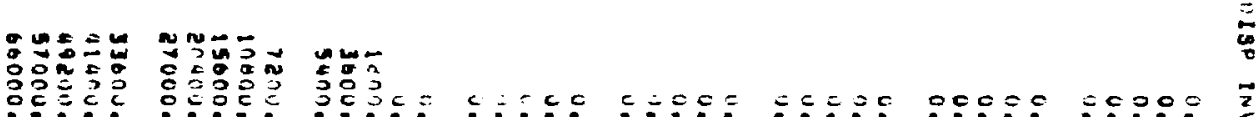


TABLE B.9 (contd)

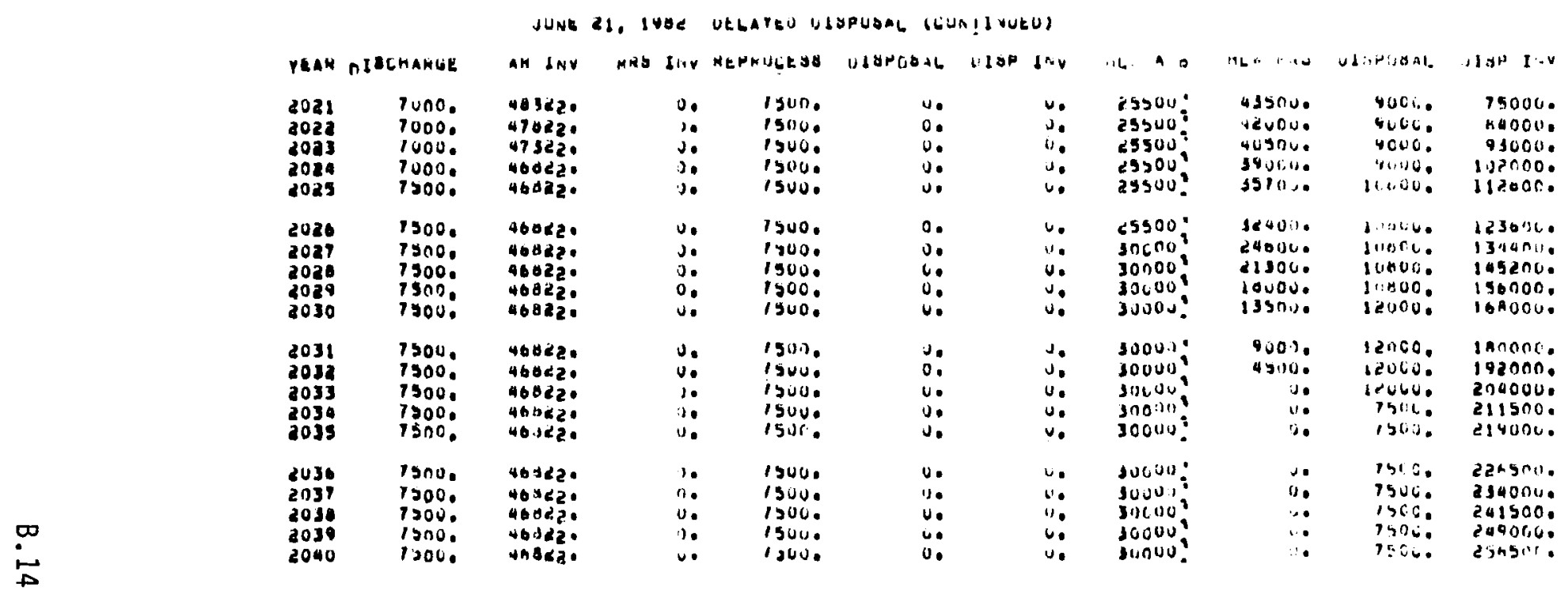


TABLE B.10. Delayed Disposal Scenario, Fuel and HLW Shipments at MRS

JUNE 21, IYOZ UELAYEU GISPUBAL

reAN rUEL DIUTAG GHE PHEL

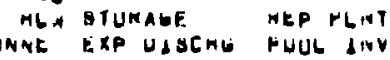

1908
1408
1408
1984
1908
1986
1407
1980
1989
1940

in

\begin{tabular}{|c|c|c|c|c|c|c|c|c|c|}
\hline $\begin{array}{l}0 . \\
0 . \\
0: \\
0: \\
0 .\end{array}$ & $\begin{array}{l}0, \\
0: \\
0: \\
u: \\
0 !\end{array}$ & $\begin{array}{l}1971 \\
1911 \\
1971 \\
1971 \\
1911\end{array}$ & $\begin{array}{l}0 . \\
u: \\
u: \\
u:\end{array}$ & $\begin{array}{l}0.0 \\
0 . \\
0 . \\
0 . \\
0 .\end{array}$ & $\begin{array}{l}1970 \\
1870 \\
1870 \\
1410 \\
1810\end{array}$ & $\begin{array}{l}u_{0} \\
u_{0} \\
u \\
u \\
u\end{array}$ & $\begin{array}{c}0: \\
0: \\
0: 0 \\
0:\end{array}$ & $\begin{array}{r}0 . \\
0: \\
21: \\
0 .\end{array}$ & $\begin{array}{l}1411 \\
1971 \\
1971 \\
1471 \\
1471\end{array}$ \\
\hline $\begin{array}{l}0 . \\
11: \\
31:\end{array}$ & $\begin{array}{r}0 . \\
90 \\
130 \\
90 \\
190\end{array}$ & $\begin{array}{l}1911 \\
1912 \\
1914 \\
1912 \\
1914\end{array}$ & $\begin{array}{l}u_{0} \\
u: \\
u u_{0}\end{array}$ & $\begin{array}{l}0 . \\
0 . \\
0 . \\
0 .\end{array}$ & $\begin{array}{l}1810 \\
1810 \\
1910 \\
1970 \\
1975\end{array}$ & 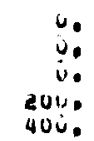 & $\begin{array}{r}103 . \\
105 \\
01 . \\
-22 \\
-307 .\end{array}$ & $\begin{array}{l}21 . \\
230 \\
210 \\
210 \\
22 .\end{array}$ & $\begin{array}{l}1410 \\
i 474 \\
1474 \\
1412 \\
9714\end{array}$ \\
\hline $\begin{array}{l}0 . \\
0 . \\
0 . \\
0 . \\
0 .\end{array}$ & $\begin{array}{l}u \cdot \\
u \\
u \\
u \\
0 \\
0 \\
0\end{array}$ & $\begin{array}{l}1914 \\
1974 \\
1914 \\
1914 \\
1914\end{array}$ & $\begin{array}{l}\text { ano. } \\
\text { bou. } \\
\text { bou. } \\
\text { ous. } \\
\text { bou. }\end{array}$ & $\begin{array}{l}160 \\
170 \\
200 \\
220 \\
130\end{array}$ & $\begin{array}{l}1470 \\
1111 \\
1974 \\
1900 \\
1901\end{array}$ & 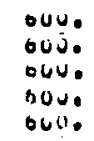 & $\begin{array}{r}-12 . \\
u \\
u \\
0 . \\
u \\
u\end{array}$ & $\begin{array}{l}31 . \\
110 \\
0: \\
0 .\end{array}$ & $\begin{array}{l}974 \\
1914 \\
1410 \\
141 . \\
1014\end{array}$ \\
\hline $\begin{array}{l}0 . \\
0: \\
0: \\
0 . \\
0 .\end{array}$ & $\begin{array}{l}0 . \\
u: \\
0 . \\
0 . \\
u:\end{array}$ & $\begin{array}{l}1974 \\
1914 \\
1914 \\
1914 \\
1974\end{array}$ & $\begin{array}{l}000 . \\
6000 \\
6000: \\
6000 \\
600 .\end{array}$ & $\begin{array}{l}250 \\
250 \\
250 \\
250 \\
250\end{array}$ & $\begin{array}{l}1942 \\
1909 \\
1904 \\
1905 \\
1906\end{array}$ & $\begin{array}{l}600 . \\
60 j . \\
200 . \\
000 . \\
00 \% .\end{array}$ & $\begin{array}{l}0 . \\
0 . \\
0 . \\
0 .\end{array}$ & $\begin{array}{l}0 . \\
\because: \\
\because: \\
0 .\end{array}$ & $\begin{array}{l}9414 \\
1474 \\
1414 \\
1470 \\
1 \times 14\end{array}$ \\
\hline $\begin{array}{l}0 . \\
0: \\
0: \\
0: \\
0 .\end{array}$ & $\begin{array}{l}u: \\
u \\
u: \\
u: \\
u:\end{array}$ & $\begin{array}{l}1914 \\
1974 \\
1914 \\
1979 \\
1974\end{array}$ & 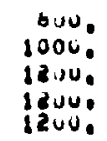 & $\begin{array}{l}25 . \\
250 \\
250 \\
250 \\
250\end{array}$ & $\begin{array}{l}1001 \\
1900 \\
1908 \\
1990 \\
1091\end{array}$ & 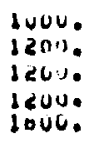 & $\begin{array}{l}0 . \\
0: \\
u: \\
u: \\
0 .\end{array}$ & $\begin{array}{l}u . \\
a . \\
a . \\
0 . \\
0 .\end{array}$ & 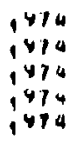 \\
\hline $\begin{array}{l}0 . \\
u_{0} \\
0 . \\
0 . \\
u_{0}\end{array}$ & $\begin{array}{l}u . \\
u: \\
0 . \\
0 . \\
u .\end{array}$ & $\begin{array}{l}1974 \\
1414 \\
1974 \\
1174 \\
1914\end{array}$ & $\begin{array}{l}16110 . \\
20100 . \\
1640 . \\
10.100 \\
16000\end{array}$ & $\begin{array}{l}d s, \\
d b_{0} \\
d b_{0} \\
d 5 \\
d S_{0}\end{array}$ & $\begin{array}{l}1948 \\
1984 \\
1945 \\
1947 \\
1944\end{array}$ & $\begin{array}{l}2000 . \\
2400 . \\
2400 . \\
2400 . \\
2000 .\end{array}$ & $\begin{array}{l}0 . \\
0 . \\
0: \\
0: \\
0 .\end{array}$ & $\begin{array}{l}n: \\
0: \\
0 . \\
0:\end{array}$ & $\begin{array}{l}1914 \\
1+14 \\
1914 \\
1974 \\
1914\end{array}$ \\
\hline $\begin{array}{l}0 . \\
0: \\
0 . \\
0 . \\
0 .\end{array}$ & $\begin{array}{l}u . \\
v . \\
u: \\
v . \\
v .\end{array}$ & $\begin{array}{l}1914 \\
1914 \\
1974 \\
1974 \\
1974\end{array}$ & $\begin{array}{l}2000, \\
1100 . \\
11020 . \\
1000 . \\
360 .\end{array}$ & $\begin{array}{l}25 . \\
250 \\
100 \\
250 \\
250\end{array}$ & $\begin{array}{l}2001 \\
2002 \\
1900 \\
2604 \\
2608\end{array}$ & 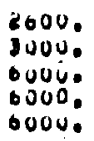 & $\begin{array}{l}0 . \\
0: \\
0: \\
0:\end{array}$ & $\begin{array}{l}0 . \\
0: \\
0: \\
0:\end{array}$ & $\begin{array}{l}1714 \\
1974 \\
1474 \\
1474 \\
1474\end{array}$ \\
\hline $\begin{array}{l}0 . \\
0 . \\
0 . \\
0 . \\
0 .\end{array}$ & $\begin{array}{l}0 . \\
i: \\
0: \\
0:\end{array}$ & $\begin{array}{l}1914 \\
1914 \\
1974 \\
1974 \\
1970\end{array}$ & $\begin{array}{l}-2040 . \\
-120 . \\
-120 . \\
-120 . \\
-600 .\end{array}$ & $\begin{array}{l}24 . \\
250 \\
\text { as. } \\
250 \\
250\end{array}$ & $\begin{array}{l}1904 \\
1804 \\
1804 \\
1963 \\
1900\end{array}$ & 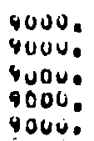 & $\begin{array}{l}0 . \\
u: \\
0: \\
0 .\end{array}$ & $\begin{array}{l}0 . \\
i: \\
0: \\
n:\end{array}$ & 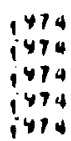 \\
\hline
\end{tabular}

Pank rutel

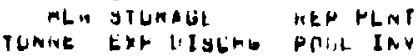

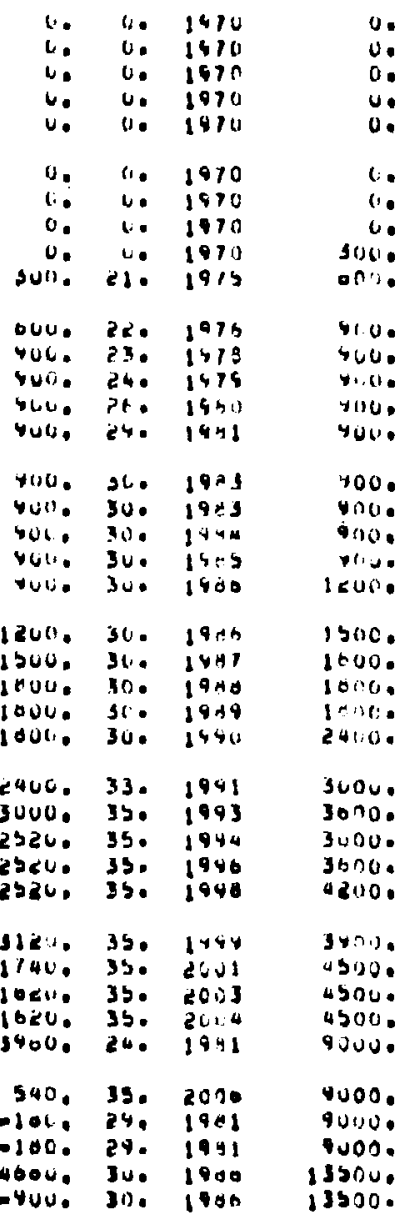


TABLE B. 10 (contd)

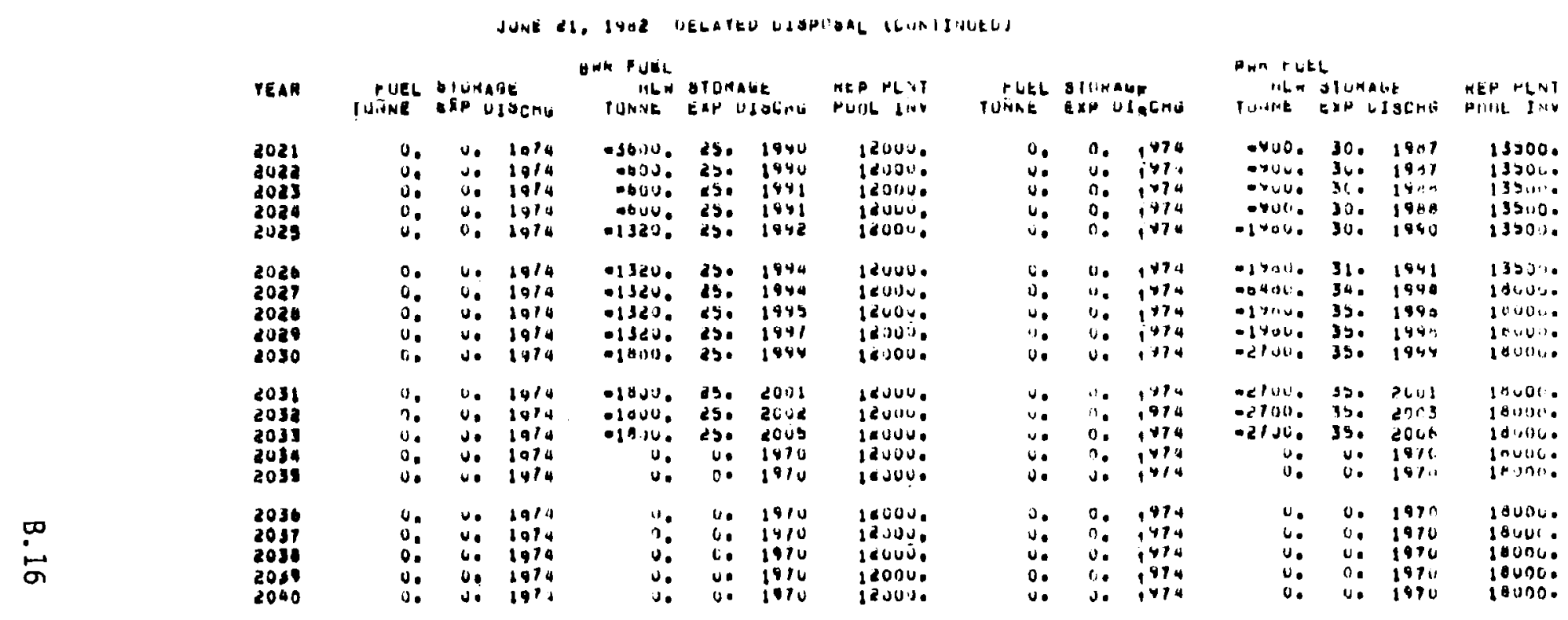


TABLE B.11. Delayed Disposal Scenario, Number of TRU Packages Handled at MRS

JURE 21, 19O\% VELATEV UAOPUSAL

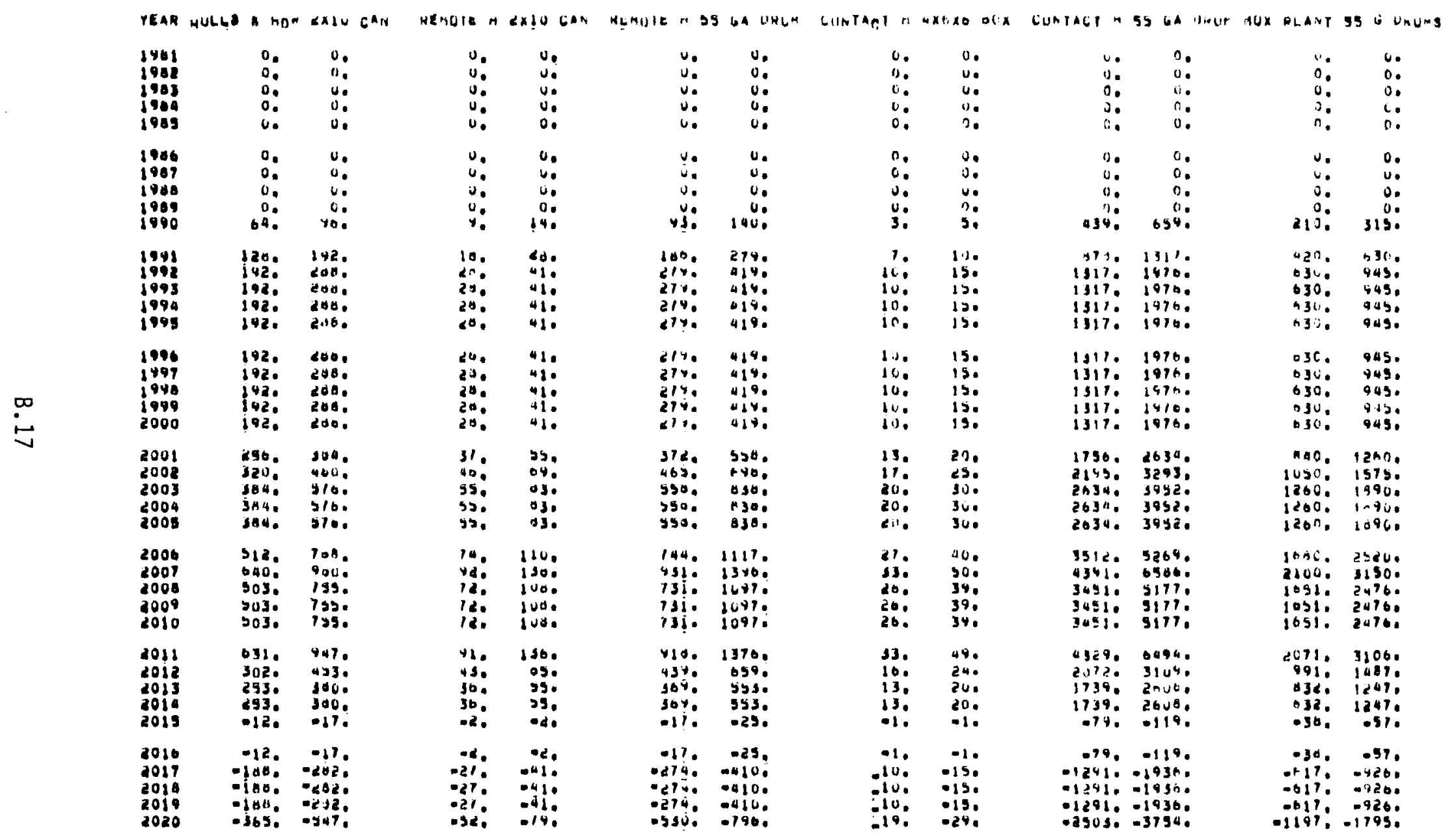


TABLE B.11 (contd)

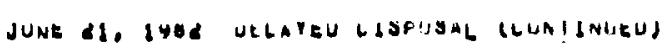

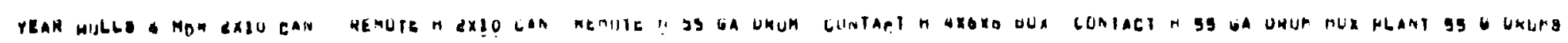

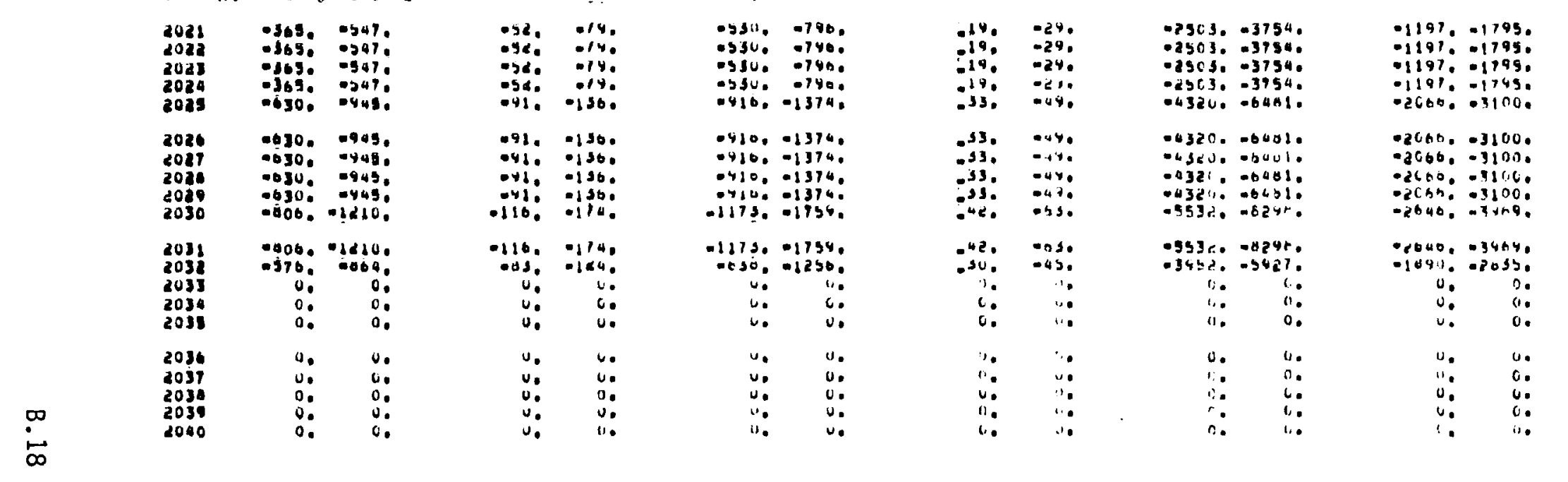


TABLE B.12. Early Disposal Scenario Summary

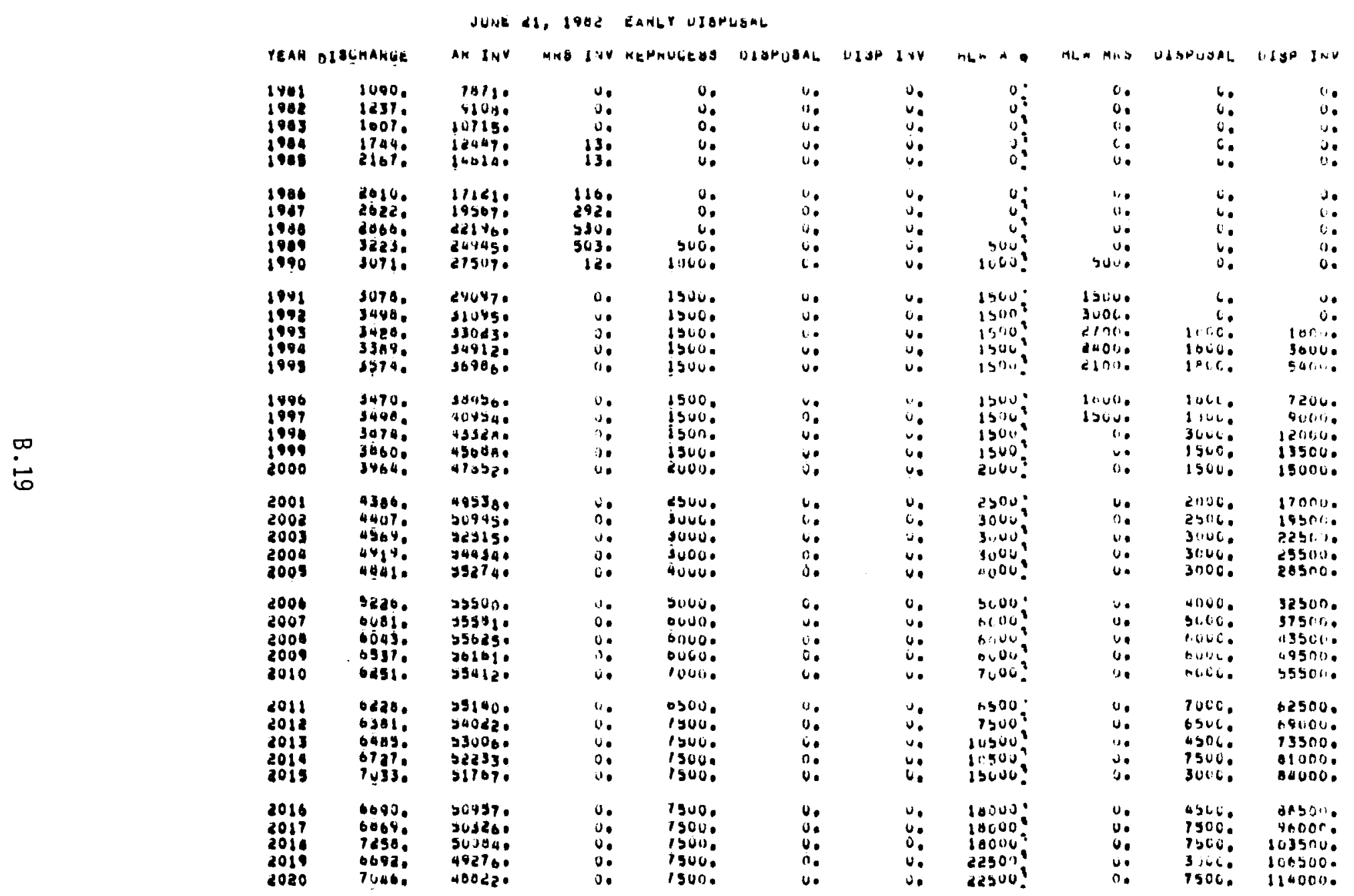


TABLE B.13. Early Disposal Scenario, Fuel and HLW Shipment at MRS

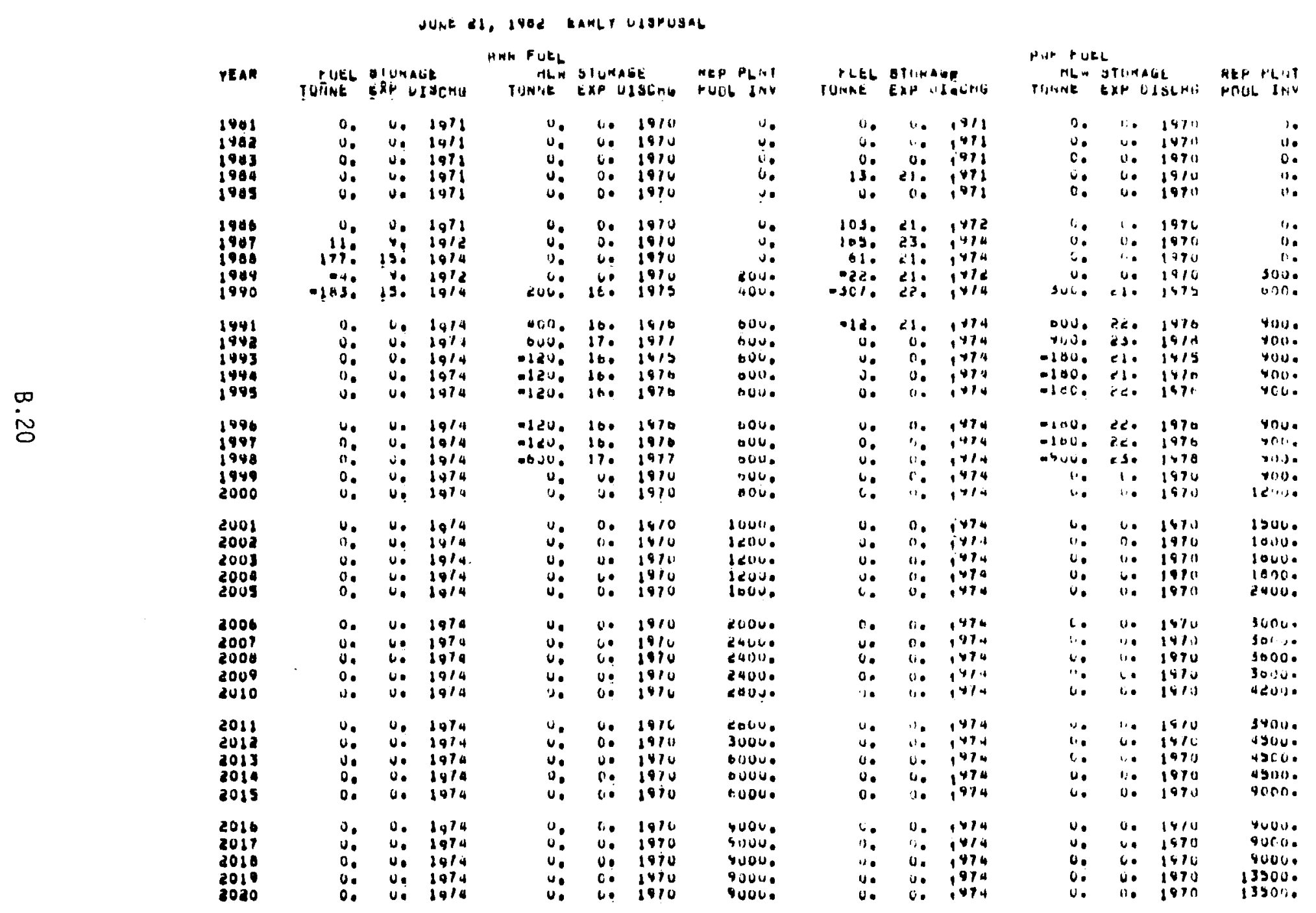


IABLE B.14. Early Disposal Scenario, Number of TRU Packages Handled at MRS

JUNE L1, 2902 BANLY VIOHUSAL

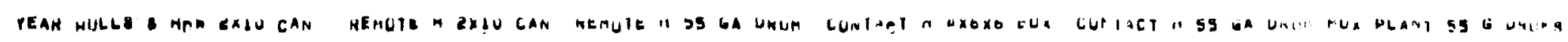

ש

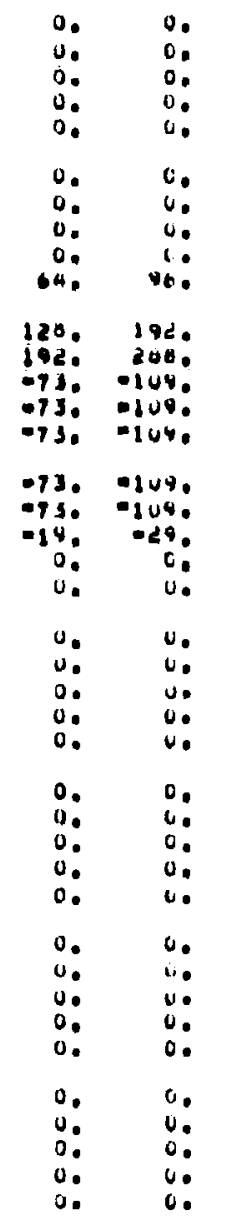

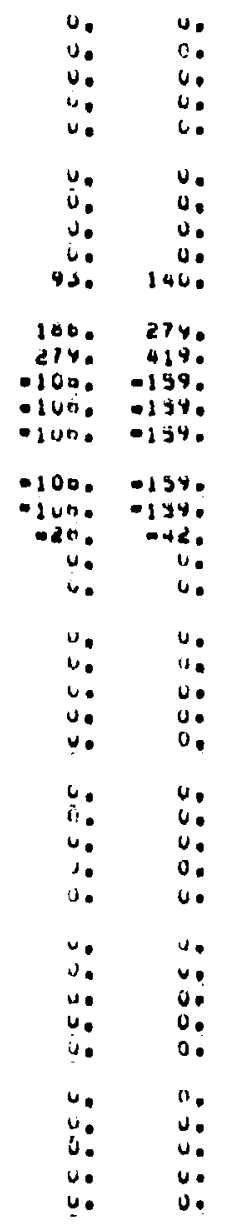

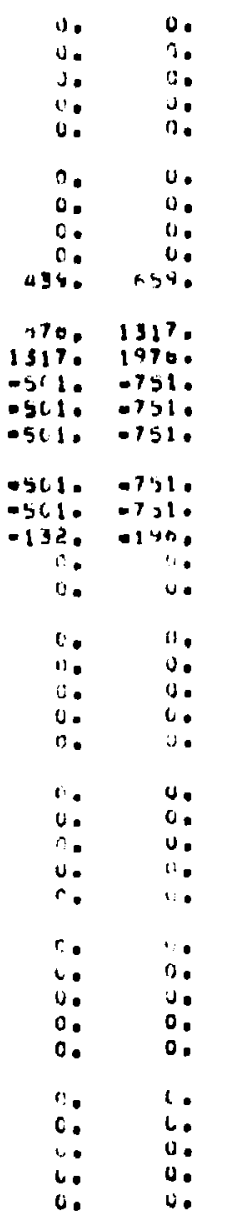

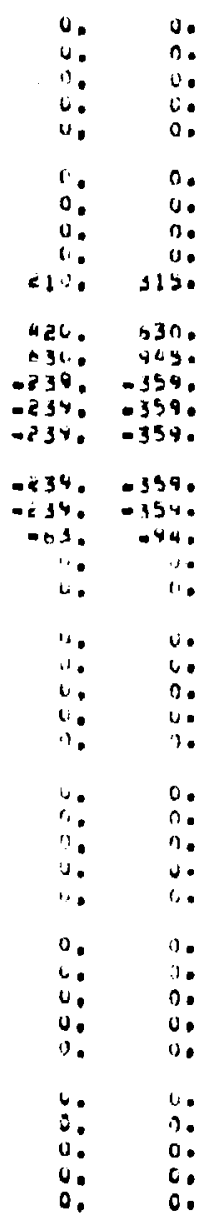


TABLE B.15. Delayed Disposal No Reprocessing Scenario Summary

$\stackrel{\infty}{\sim}$

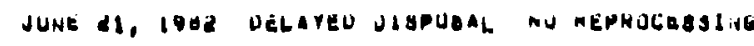

\begin{tabular}{|c|c|c|c|c|c|c|c|c|c|c|c|}
\hline rEAN & DIOCGMAKGE & AA INV & MAS INV & HEHRULESE & DA APUBAL & DIAH LN & HLWA & ILL $x$ & MHS & WLSHOSAL & DISH \\
\hline $\begin{array}{l}1981 \\
1802 \\
1883 \\
1984 \\
1809\end{array}$ & $\begin{array}{l}1090 . \\
1237 . \\
1607 . \\
1144 . \\
2167 .\end{array}$ & $\begin{array}{r}70710 \\
91080 \\
207290 \\
124970 \\
240240\end{array}$ & $\begin{array}{l}0 . \\
0 . \\
\text { u. } \\
\text { is: } \\
19 .\end{array}$ & $\begin{array}{l}u . \\
u: \\
u \\
j: \\
u .\end{array}$ & $\begin{array}{l}0 . \\
0 . \\
0 . \\
0 . \\
0 .\end{array}$ & $\begin{array}{l}u . \\
u: \\
u . \\
u . \\
u .\end{array}$ & $\begin{array}{c}0 \\
0 \\
j \\
0 \\
0 ?\end{array}$ & & $\begin{array}{l}u . \\
u: \\
u: \\
u: \\
u .\end{array}$ & $\begin{array}{l}0 . \\
0 . \\
0 . \\
i . \\
i .\end{array}$ & \\
\hline $\begin{array}{l}1906 \\
1907 \\
1908 \\
1944 \\
1940\end{array}$ & $\begin{array}{l}2610, \\
2022: \\
2066: \\
32230 \\
3071:\end{array}$ & $\begin{array}{l}27121 . \\
195670 \\
22140 . \\
249450 \\
27595 .\end{array}$ & $\begin{array}{l}1170 \\
2920 \\
5800 \\
10090 \\
14050\end{array}$ & $\begin{array}{l}3 . \\
0: \\
0: \\
0: \\
0 .\end{array}$ & $\begin{array}{l}j . \\
u: \\
0 . \\
u: \\
0 .\end{array}$ & $\begin{array}{l}u: \\
u: \\
u: \\
u \\
u\end{array}$ & $\begin{array}{l}u: \\
j \\
u \\
n \\
\vdots ! \\
u\end{array}$ & & $\begin{array}{l}u: \\
0: \\
0 . \\
0 . \\
i:\end{array}$ & $\begin{array}{l}0: \\
0: \\
0: \\
0:\end{array}$ & \\
\hline $\begin{array}{l}1441 \\
1992 \\
1993 \\
1944 \\
1995\end{array}$ & $\begin{array}{l}3070, \\
3490 . \\
3429 . \\
3364 . \\
3574 .\end{array}$ & $\begin{array}{l}501200 \\
529620 \\
581210 \\
562100 \\
404340\end{array}$ & $\begin{array}{l}1907 . \\
20330 \\
33020 \\
43020 \\
5532 .\end{array}$ & $\begin{array}{l}u . \\
0 . \\
u . \\
u . \\
u .\end{array}$ & $\begin{array}{l}0 . \\
u: \\
u: \\
u: \\
u .\end{array}$ & $\begin{array}{l}u . \\
u \\
u \\
u \\
u\end{array}$ & $\begin{array}{l}n: \\
u \\
u \\
u \\
u ! \\
0\end{array}$ & & $\begin{array}{l}u . \\
u . \\
u: \\
u . \\
u .\end{array}$ & $\begin{array}{l}\dot{u} . \\
\dot{0}: \\
u: \\
\dot{0}: \\
0 .\end{array}$ & \\
\hline $\begin{array}{l}1946 \\
1997 \\
1944 \\
1999 \\
2000\end{array}$ & $\begin{array}{l}3470 . \\
3494: \\
3094: \\
3560 . \\
3464 .\end{array}$ & $\begin{array}{l}424090 \\
444090 \\
469500 \\
164560 \\
603330\end{array}$ & $\begin{array}{l}7052 . \\
\text { 6590. } \\
20270 . \\
23232 . \\
10919 .\end{array}$ & $\begin{array}{l}u: \\
u: \\
0: \\
0: \\
u .\end{array}$ & $\begin{array}{l}u . \\
i: \\
0: \\
0: \\
0 .\end{array}$ & 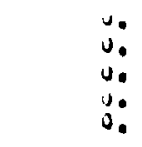 & $\begin{array}{l}10: \\
0: \\
0: \\
0 ! \\
4 !\end{array}$ & & $\begin{array}{l}u . \\
u_{0} \\
u_{0} \\
u . \\
u .\end{array}$ & $\begin{array}{l}0 . \\
0: \\
c: \\
0: \\
0:\end{array}$ & \\
\hline $\begin{array}{l}2001 \\
2002 \\
2003 \\
2004 \\
2005\end{array}$ & $\begin{array}{l}4346 . \\
4409 . \\
4568, \\
4419 . \\
4041 .\end{array}$ & $\begin{array}{l}323210 \\
33906 . \\
956220 \\
37650 . \\
345540\end{array}$ & $\begin{array}{l}167100 \\
194800 \\
22189 . \\
29280 . \\
282210\end{array}$ & $\begin{array}{l}u . \\
0 . \\
u: \\
0 . \\
0 .\end{array}$ & $\begin{array}{l}u . \\
0: \\
0 . \\
u \\
i 0\end{array}$ & $\begin{array}{l}u_{0} \\
u: \\
u: \\
u \\
u\end{array}$ & 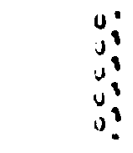 & & $\begin{array}{l}u: \\
0 . \\
u \\
u: \\
0 .\end{array}$ & $\begin{array}{l}u . \\
i: \\
c: \\
c: \\
c .\end{array}$ & \\
\hline $\begin{array}{l}8006 \\
2007 \\
2000 \\
2004 \\
2010\end{array}$ & $\begin{array}{l}8226, \\
0001: \\
60435 \\
6537 . \\
051 .\end{array}$ & $\begin{array}{l}020070 \\
645910 \\
67986: \\
11297: \\
14706 .\end{array}$ & $\begin{array}{l}31243 . \\
344910 \\
33309 \\
36774 \\
\text { 17006. }\end{array}$ & $\begin{array}{l}4 . \\
0 . \\
0 . \\
1 . \\
1 .\end{array}$ & $\begin{array}{l}0 . \\
00 \\
18000 \\
24000 \\
2060 .\end{array}$ & $\begin{array}{l}u . \\
u . \\
1000 . \\
9000 . \\
3400 .\end{array}$ & $\begin{array}{l}u: \\
0: \\
0: \\
10 \\
4:\end{array}$ & & $\begin{array}{l}0 . \\
u: \\
u: \\
u: \\
i, 0\end{array}$ & $\begin{array}{l}0 . \\
0 . \\
0: \\
0:\end{array}$ & \\
\hline $\begin{array}{l}2012 \\
2012 \\
2013 \\
2014 \\
2013\end{array}$ & $\begin{array}{l}6220, \\
0381: \\
6495, \\
6727 . \\
15330\end{array}$ & 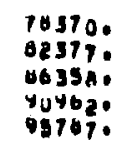 & $\begin{array}{l}38510 . \\
373440 \\
390440 \\
313710 \\
27900 .\end{array}$ & $\begin{array}{l}0 . \\
i: \\
0: \\
u: \\
0 .\end{array}$ & $\begin{array}{l}1300 . \\
3600 . \\
48000 \\
40000 \\
66000\end{array}$ & 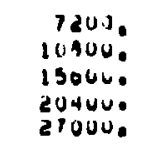 & $\begin{array}{c}u \\
\vdots \\
\vdots \\
\vdots \\
\vdots \\
\vdots\end{array}$ & & $\begin{array}{l}u: \\
u: \\
u: \\
u: \\
u\end{array}$ & $\begin{array}{l}0 . \\
0 . \\
i: \\
i . \\
0 .\end{array}$ & \\
\hline $\begin{array}{l}2016 \\
2017 \\
2016 \\
2019 \\
2021\end{array}$ & $\begin{array}{l}6090 . \\
6064: \\
1250 . \\
6692, \\
7040 .\end{array}$ & 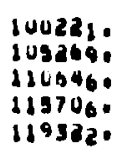 & $\begin{array}{r}23035 . \\
176500 \\
11730 . \\
53710 \\
0 .\end{array}$ & $\begin{array}{l}3 . \\
0: \\
0 . \\
11 . \\
0 .\end{array}$ & $\begin{array}{l}00000 \\
10000 \\
70000 \\
10000 \\
\text { Y000. }\end{array}$ & $\begin{array}{l}35000 . \\
41400 . \\
442000 \\
57000: \\
06000 .\end{array}$ & $\begin{array}{l}0: \\
4 \\
0 \\
0 ! \\
0\end{array}$ & & $\begin{array}{l}0 . \\
u: \\
0 . \\
u: \\
\text { jo }\end{array}$ & $\begin{array}{l}u: \\
0 . \\
0:\end{array}$ & \\
\hline
\end{tabular}


TABLE B.16. Delayed Disposal No Reprocessing Scenario, Fuel and HLW Shipments at MRS

\begin{tabular}{|c|c|c|c|c|c|c|c|c|c|c|c|c|c|c|c|}
\hline \multirow{2}{*}{$\begin{array}{l}\text { YEAA } \\
1901 \\
1908 \\
1903 \\
1904 \\
1905\end{array}$} & \multirow{2}{*}{ 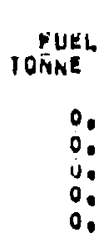 } & \multicolumn{2}{|c|}{$\begin{array}{l}\text { MUKAGE } \\
\text { LAP DIVERU }\end{array}$} & $\begin{array}{c}\text { OHA FlLEL } \\
\text { HLW TONE }\end{array}$ & \multicolumn{2}{|c|}{$\begin{array}{l}\text { orlmage } \\
\text { Extudolno }\end{array}$} & \multirow[t]{2}{*}{$\begin{array}{l}\text { rete } \\
\text { ruOL }\end{array}$} & \multirow{2}{*}{ 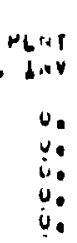 } & \multirow{2}{*}{$\begin{array}{c}\text { PUEL } \\
\text { TUNAE } \\
0 . \\
u \\
u \\
13: \\
0 .\end{array}$} & \multicolumn{2}{|c|}{ 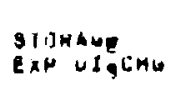 } & \multicolumn{3}{|c|}{ 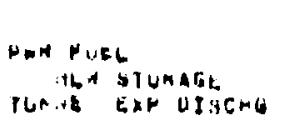 } & \multirow{2}{*}{ 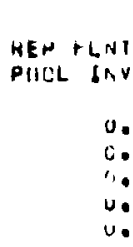 } \\
\hline & & $\begin{array}{l}0 . \\
0 ! \\
0: \\
0 ! \\
0 !\end{array}$ & $\begin{array}{l}1011 \\
1971 \\
1071 \\
1971 \\
1471\end{array}$ & $\begin{array}{l}u_{0} \\
u_{0} \\
u_{0} \\
u_{0}\end{array}$ & $\begin{array}{l}0 . \\
i: \\
0: \\
i 0 \\
i .\end{array}$ & $\begin{array}{l}1910 \\
1910 \\
1910 \\
1910 \\
1910\end{array}$ & & & & $\begin{array}{l}0 . \\
n: \\
0: \\
n:\end{array}$ & $\begin{array}{l}1911 \\
1+11 \\
1471 \\
1 \times 11 \\
1491\end{array}$ & $\begin{array}{l}0 . \\
0: \\
0: \\
0: \\
0 .\end{array}$ & $\begin{array}{l}\because . \\
\because \because \\
i: \\
i .\end{array}$ & $\begin{array}{l}1870 \\
1970 \\
1470 \\
1971 \\
1470\end{array}$ & \\
\hline $\begin{array}{l}1486 \\
1989 \\
1980 \\
1989 \\
1890\end{array}$ & $\begin{array}{l}0 . \\
11 \%: \\
1760 . \\
100 .\end{array}$ & $\begin{array}{l}0 . \\
9: \\
130 \\
10 \\
110\end{array}$ & $\begin{array}{l}1971 \\
1912 \\
1974 \\
1975 \\
1976\end{array}$ & $\begin{array}{l}u_{0} \\
0 . \\
u_{0} \\
u_{0} \\
u_{0}\end{array}$ & $\begin{array}{l}u \cdot \\
0: \\
i: \\
i:\end{array}$ & $\begin{array}{l}1910 \\
1910 \\
1910 \\
1910 \\
1910\end{array}$ & & $\begin{array}{l}u_{0} \\
j: \\
u: \\
u: \\
j .\end{array}$ & $\begin{array}{r}1030 \\
1090 \\
610 \\
2710 \\
6930\end{array}$ & $\begin{array}{l}21 . \\
23: \\
610 \\
210 \\
21 .\end{array}$ & $\begin{array}{l}1412 \\
1414 \\
1474 \\
1415 \\
1470\end{array}$ & $\begin{array}{l}0 . \\
u: \\
0: \\
u:\end{array}$ & $\begin{array}{l}0 . \\
\text { u. } \\
6 . \\
u: \\
j .\end{array}$ & $\begin{array}{l}1470 \\
1470 \\
1970 \\
1470 \\
1410\end{array}$ & $\begin{array}{l}u . \\
u . \\
\text { u. } \\
\text { u. }\end{array}$ \\
\hline $\begin{array}{l}1991 \\
1992 \\
1993 \\
1994 \\
1995\end{array}$ & $\begin{array}{l}331 . \\
209: \\
234: \\
300 . \\
393 .\end{array}$ & $\begin{array}{l}17 . \\
17: \\
10: \\
510 \\
220\end{array}$ & $\begin{array}{l}1917 \\
1917 \\
1978 \\
1978 \\
1974\end{array}$ & $\begin{array}{l}u_{0} \\
u: \\
u: \\
u: \\
u_{0}\end{array}$ & $\begin{array}{l}0 . \\
u: \\
0: \\
i: \\
i .\end{array}$ & $\begin{array}{l}1410 \\
1970 \\
1970 \\
1470 \\
1410\end{array}$ & & $\begin{array}{l}0 . \\
u: \\
u: \\
u:\end{array}$ & $\begin{array}{l}193 . \\
390 . \\
499 . \\
0120 \\
990 .\end{array}$ & $\begin{array}{l}22 . \\
23 . \\
23 . \\
250 \\
26 .\end{array}$ & $\begin{array}{l}1476 \\
1917 \\
1470 \\
1 \times 74 \\
1090\end{array}$ & $\begin{array}{l}u: \\
u: \\
u: \\
\therefore .\end{array}$ & $\begin{array}{l}0 . \\
\because \\
30 \\
4:\end{array}$ & $\begin{array}{l}14711 \\
1970 \\
1470 \\
1470 \\
1410\end{array}$ & $\begin{array}{l}u . \\
u . \\
u . \\
u .\end{array}$ \\
\hline $\begin{array}{l}1996 \\
1997 \\
1998 \\
1999 \\
2000\end{array}$ & $\begin{array}{l}318, \\
398, \\
328, \\
199, \\
654 .\end{array}$ & $\begin{array}{l}63 . \\
29: \\
25: \\
29 . \\
45:\end{array}$ & $\begin{array}{l}1000 \\
1901 \\
1902 \\
1404 \\
1905\end{array}$ & $\begin{array}{l}0 . \\
0 . \\
0 . \\
0 . \\
0 .\end{array}$ & $\begin{array}{l}u: \\
0: \\
u: \\
u: \\
0\end{array}$ & $\begin{array}{l}1490 \\
1910 \\
1910 \\
1910 \\
1910\end{array}$ & & $\begin{array}{l}u_{0} \\
u_{0} \\
u_{0} \\
u_{0}\end{array}$ & $\begin{array}{l}941 . \\
\text { Y00. } \\
1194 . \\
1195 . \\
1033 .\end{array}$ & $\begin{array}{l}29 . \\
30 . \\
30 . \\
30 . \\
30 .\end{array}$ & 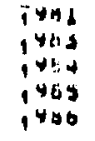 & $\begin{array}{l}0 . \\
\because \vdots \\
u \\
i:\end{array}$ & $\begin{array}{l}\because 0 \\
\because \vdots \\
0\end{array}$ & $\begin{array}{l}1970 \\
1970 \\
1970 \\
1410 \\
1510\end{array}$ & $\begin{array}{l}1 . \\
u . \\
0 . \\
1 .\end{array}$ \\
\hline $\begin{array}{l}2002 \\
2002 \\
2003 \\
2004 \\
2005\end{array}$ & $\begin{array}{r}622 . \\
489 . \\
11410 \\
11900 \\
1190 .\end{array}$ & $\begin{array}{l}\text { 65, } \\
25: \\
250 \\
25 . \\
25 .\end{array}$ & $\begin{array}{l}1986 \\
1947 \\
1908 \\
1999 \\
1990\end{array}$ & $\begin{array}{l}u: \\
u: \\
u: \\
u:\end{array}$ & $\begin{array}{l}c: \\
0: \\
u: \\
c\end{array}$ & $\begin{array}{l}1410 \\
1570 \\
1910 \\
1970 \\
1910\end{array}$ & & $\begin{array}{l}u . \\
u: \\
0 . \\
0 . \\
j .\end{array}$ & $\begin{array}{l}1560 . \\
1145 . \\
1351 . \\
1098 . \\
1191 .\end{array}$ & $\begin{array}{l}310 . \\
3110 \\
3110 \\
300 \\
30 .\end{array}$ & $\begin{array}{l}1901 \\
1 \times 10 \\
1 \times 80 \\
1+94 \\
1 \times 4 i\end{array}$ & $\begin{array}{l}u: \\
u: \\
u: \\
u:\end{array}$ & $\begin{array}{l}0: \\
0: \\
u: \\
i .\end{array}$ & $\begin{array}{l}1410 \\
1470 \\
1470 \\
1476 \\
1470\end{array}$ & $\begin{array}{l}0 . \\
10 \\
0 .\end{array}$ \\
\hline $\begin{array}{l}2006 \\
2007 \\
2004 \\
2004 \\
2010\end{array}$ & $\begin{array}{r}1250^{\circ} \\
1230 . \\
324 . \\
194 \\
340^{\circ}\end{array}$ & $\begin{array}{l}2 y, \\
25: \\
230 \\
25, \\
25 .\end{array}$ & $\begin{array}{l}1991 \\
1942 \\
1993 \\
1944 \\
1905\end{array}$ & $\begin{array}{l}u_{0} \\
u_{0} \\
u_{0} \\
u_{0}\end{array}$ & $\begin{array}{l}1 . \\
0 \\
0: \\
0 \\
\text { ve }\end{array}$ & $\begin{array}{l}1910 \\
1970 \\
1970 \\
1910 \\
1970\end{array}$ & & $\begin{array}{l}1 . \\
u: \\
u: \\
j: \\
u:\end{array}$ & $\begin{array}{l}1118 . \\
240.0 \\
313 . \\
031 . \\
643 .\end{array}$ & $\begin{array}{l}33 . \\
35: \\
35 . \\
35 . \\
35 .\end{array}$ & $\begin{array}{l}i 441 \\
1492 \\
1993 \\
1494 \\
i 445\end{array}$ & $\begin{array}{l}3: \\
0: \\
0: \\
0 .\end{array}$ & $\begin{array}{l}a: \\
0: \\
i: \\
i:\end{array}$ & $\begin{array}{l}1470 \\
1970 \\
1970 \\
1470 \\
1470\end{array}$ & $\begin{array}{l}0 . \\
1 . \\
6 . \\
0 . \\
0 .\end{array}$ \\
\hline $\begin{array}{l}2011 \\
2012 \\
2011 \\
2019 \\
2019\end{array}$ & $\begin{array}{r}330, \\
-424: \\
-198: \\
-1013 . \\
-1128 .\end{array}$ & $\begin{array}{l}\text { as. } \\
\text { io: } \\
17 \% \\
21: \\
440\end{array}$ & $\begin{array}{l}1940 \\
1916 \\
1970 \\
1950 \\
1904\end{array}$ & $\begin{array}{l}u: \\
u: \\
u: \\
u: \\
u .\end{array}$ & $\begin{array}{l}u: \\
i: \\
u: \\
i: \\
u:\end{array}$ & $\begin{array}{l}1915 \\
1970 \\
1870 \\
1810 \\
1910\end{array}$ & & $\begin{array}{l}u . \\
0 . \\
u: \\
u: \\
i:\end{array}$ & $\begin{array}{r}434 . \\
-002 . \\
-1498 . \\
-1044 . \\
-2003 .\end{array}$ & $\begin{array}{l}55 . \\
210 \\
230 \\
26 . \\
\text { sil. }\end{array}$ & $\begin{array}{l}1 \times 45 \\
1770 \\
1474 \\
1 \times 41 \\
1405\end{array}$ & $\begin{array}{l}u . \\
u: \\
u: \\
u: \\
u\end{array}$ & $\begin{array}{l}u: \\
b: \\
u \\
u: \\
a .\end{array}$ & $\begin{array}{l}1410 \\
1470 \\
1470 \\
1470 \\
1970\end{array}$ & $\begin{array}{l}0 . \\
0: \\
0 . \\
0 .\end{array}$ \\
\hline $\begin{array}{l}2016 \\
2019 \\
2014 \\
3019 \\
2020\end{array}$ & $\begin{array}{l}-1603, \\
-2460: \\
-21070 \\
-2443, \\
-2264:\end{array}$ & $\begin{array}{l}\text { as: } \\
45: \\
25: \\
65: \\
25:\end{array}$ & $\begin{array}{l}2906 \\
1908 \\
8990 \\
1992 \\
1996\end{array}$ & $\begin{array}{l}u_{0} \\
u: \\
u_{0} \\
u_{0}\end{array}$ & $\begin{array}{l}0 . \\
0: \\
0: \\
0: \\
0 .\end{array}$ & $\begin{array}{l}1970 \\
1910 \\
1970 \\
1910 \\
1910\end{array}$ & & $\begin{array}{l}u . \\
1 . \\
u: \\
i: \\
j .\end{array}$ & $\begin{array}{l}-2141 . \\
-3314 . \\
-3131 . \\
-3125 . \\
-3307 .\end{array}$ & $\begin{array}{l}\text { sn. } \\
\text { 3n: } \\
\text { su: } \\
39: \\
\text { s5: }\end{array}$ & $\begin{array}{l}i 401 \\
1+40 \\
1490 \\
1442 \\
1995\end{array}$ & $\begin{array}{l}0 . \\
\tilde{n}: \\
u: \\
0 .\end{array}$ & $\begin{array}{l}u: \\
u: \\
u: \\
11 \\
1 .\end{array}$ & $\begin{array}{l}1970 \\
1570 \\
1470 \\
1970 \\
1970\end{array}$ & $\begin{array}{l}0 . \\
0 . \\
0 . \\
0 .\end{array}$ \\
\hline
\end{tabular}


repository delivery rates when a full year's production of HLW is held at the reprocessing $p l a n t$ and a portion of it is not yet 10 years old. The TRU capacity requirements are summarized in Table $\underline{B .17}$ and the annual handling requirements in Table $\underline{B .18}$. The peak rates for the Delayed Disposal case are based on the average removal rates in 2030, 2031, and 2032; however, if a design is modular, it may be desirable to design for a lower rate and add capacity as needed.

TABLE B.17. Required Capacity for TRU Packages at MRS/IS Facility

\begin{tabular}{|c|c|c|}
\hline Reference & $\begin{array}{c}\text { Delayed } \\
\text { Reprocessina }\end{array}$ & $\begin{array}{l}\text { Delayed } \\
\text { Disposal }\end{array}$ \\
\hline
\end{tabular}

Hulls and hardware cans

RHTRU $2 \times 10 \mathrm{ft}$ cans

3,400

0

19,400

RHTRU 55 gal drums

500

0

2,800

CHTRU $4 \times 6 \times 6 \mathrm{ft}$ boxes

5,000

0

28,200

175

0

1,010

CHTRU 55 gal drums

24,000

0

133,000

MOX Plant 55 gal drums

12,000

0

64,000

MOX Plant $4 \times 6 \times 6 \mathrm{ft}$

boxes

120

0

640

TABLE B.18. Annual Receiving or Removal Rate for TRU Packages at MRS/IS Facility

Reference $\quad \begin{array}{cl}\begin{array}{c}\text { Delayed } \\ \text { Reprocessing }\end{array} & \begin{array}{l}\text { Delayed } \\ \text { Disposal }\end{array}\end{array}$

Hulls and hardware cans

760

0

1,850

RHTRU $2 \times 10 \mathrm{ft}$ cans

110

0

270

RHTRU 55-gal drums

1,100

0

2,700

CHTRU $4 \times 6 \times 6 \mathrm{ft}$ boxes

40

0

95

CHTRU 55 gal drums

5,200

0

12,500

MOX Plant 55-gal drums

2,500

0

6,000

MoX Plant $4 \times 6 \times 6 \mathrm{ft}$ boxes

25

0

60 


\section{B.2 CONSIDERATIONS FOR MRS/IS COST EVALUATION}

The MRS/IS facility is conceived as a government-owned facility for providing temporary storage capability for spent fuel and/or reprocessing wastes while reprocessing capability and repositories for geologic disposal are introduced.

To provide compatibility with other studies performed in evaluation of spent fuel and waste disposal, all costs should be presented in terms of constant-value, mid-1982 dollars (without cost escalation or inflation). All costs from the present to the final year of decommissioning are to be entered into a cash flow table (Table B.1) and presented both as undiscounted costs and as discounted at 2 percent per year. The annual costs should be summed over all years included, to provide undiscounted program costs and the present worth costs at 2 percent discount. The discounted (present worth) costs will be used in comparing alternatives.

To ensure that all alternatives are equitably treated during comparisons, the details of component costs, background, and cost bases must be presented in support of the costs given in Table B.19. Tables B.20 through B.25 are provided for this purpose. These tables in turn should be supported by the cost schedules indicating the cost bases or components for each category in the tables. Typical cost categories are outlined in Attachment 1, following these tables. Insofar as possible, cost breakdowns by these categories should be provided. If other cost bases are used, these should be detailed.

Table B.20 summarizes the capital construction costs for the first module of the MRS/IS; costs for additional modules should be entered on Table B.24 (in multiple copies if needed). Costs for each module should be prorated into the appropriate years, using Table B.21, and the prorated annual costs should then be included in the cash flow summary of Table B.19.

Owner's costs are defined separately for three periods: those costs incurred during the construction period (Table B.23), annual operating costs for the facility (Table B.24), and decommissioning costs (Table B.25). The costs summarized on Tables B.23 and B.25 should, as before, be prorated into the appropriate years using Table B.21. 
TABLE B.19. Cash Flow and Present Worth for

\begin{tabular}{|c|c|c|c|c|c|}
\hline \multirow[b]{2}{*}{ Year } & \multirow[b]{2}{*}{$\begin{array}{l}\text { Discount } \\
\text { Factor } \\
\end{array}$} & \multicolumn{4}{|c|}{ Costs, $\$ 1000^{\prime} \mathrm{s}$} \\
\hline & & Capital & Operating & Total & $\begin{array}{c}\text { Discountec } \\
\text { Total } \\
\end{array}$ \\
\hline 1982 & 1.0000 & & & & \\
\hline 1983 & 0.9804 & & & & \\
\hline 1984 & 0.9612 & & & & \\
\hline 1985 & 0.9423 & & & & \\
\hline 1986 & 0.9238 & & & & \\
\hline 1987 & 0.9057 & & & & \\
\hline 1988 & 0.8880 & & & & \\
\hline 1989 & 0.8706 & & & & \\
\hline 1990 & 0.8535 & & & & \\
\hline 1991 & 0.8368 & & & & \\
\hline 1992 & 0.8203 & & & & \\
\hline 1993 & 0.8043 & & & & \\
\hline 1994 & 0.7885 & & & & \\
\hline 1995 & 0.7730 & & & & \\
\hline 1996 & 0.7579 & & & & \\
\hline 1997 & 0.7430 & & & & \\
\hline 1998 & 0.7284 & & & & \\
\hline 1999 & 0.7142 & & & & \\
\hline 2000 & 0.7002 & & & & \\
\hline 2001 & 0.6864 & & & & \\
\hline 2002 & 0.6730 & & & & \\
\hline 2003 & 0.6598 & & & & \\
\hline 2004 & 0.6468 & & & & \\
\hline 2005 & 0.6342 & & & & \\
\hline
\end{tabular}


TABLE B.19. (contd)

\begin{tabular}{|c|c|c|c|c|c|}
\hline \multirow[b]{2}{*}{ Year } & \multirow[b]{2}{*}{$\begin{array}{l}\text { Discount } \\
\text { Factor } \\
\end{array}$} & \multicolumn{4}{|c|}{ Costs, $\$ 1000^{\prime} \mathrm{s}$} \\
\hline & & Capital & Operating & Total & $\begin{array}{c}\text { Discounted } \\
\text { Total } \\
\end{array}$ \\
\hline 2006 & 0.6217 & & & & \\
\hline 2007 & 0.6095 & & & & \\
\hline 2008 & 0.5976 & & & & \\
\hline 2009 & 0.5859 & & & & \\
\hline 2010 & 0.5744 & & & & \\
\hline 2011 & 0.5631 & & & & \\
\hline 2012 & 0.5521 & & & & \\
\hline 2013 & 0.5412 & & & & \\
\hline 2014 & 0.5306 & & & & \\
\hline 2015 & 0.5202 & & & & \\
\hline 2016 & 0.5100 & & & & \\
\hline 2017 & 0.5000 & & & & \\
\hline 2018 & 0.4912 & & & & \\
\hline 2019 & 0.4806 & & & & \\
\hline 2020 & 0.4712 & & & & \\
\hline 2021 & 0.4619 & & & & \\
\hline 2022 & 0.4529 & & & & \\
\hline 2023 & 0.4440 & & & & \\
\hline 2024 & 0.4353 & & & & \\
\hline 2025 & 0.4268 & & & & \\
\hline 2026 & 0.4184 & & & & \\
\hline 2027 & 0.4102 & & & & \\
\hline 2028 & 0.4022 & & & & \\
\hline 2029 & 0.3943 & & & & \\
\hline 2030 & 0.3865 & & & & \\
\hline
\end{tabular}

SUM 
TABLE B.20. First Module Capital Cost Estimate for

Cost Element

Manhours, 1000 's $\quad$ Costs, $\$ 1000$ 's

Non-Manual Manual Labor Material Total

Site and improvments

Receiving facility

Canning facility

Drywells or casks

Balance of storage facility

Other buildings

Canning equipment

Transporter

Other engineered equipment

Total directs

Indirects

A-E services

Cont ingency

TOTAL 
B.21. Cost Distribution for

(from Tables B.20, B.22 and B.25

Year Distribution Fraction Annual Cost 
TABLE B.22. Estimate of Additional Module Capital Cost for

Cost Element $\quad \frac{\text { Manhours, } 1000^{\prime} s}{\text { Non-Manual Manual }} \quad \frac{\text { Costs, } \$ 1000^{\prime} s}{\text { Labor Material Total }}$

Site preparation

Drywells or casks

Balance of storage facility

Total directs

Indirects

A-E services

Cont ingency

TOTAL 
TABLE B.23. Estimate of Owner's Costs During Construction for

Manhours

Cost Element or Other Basis Cost

Hearing preparation and testimony

Contract management

Inspection and $Q A$

Training program

Security

General and administrative

TOTAL 
TABLE B.24. Estimate of Owner's Annual Operating Costs During for

Manhours

Cost Element or Other Basis Cost

Supplies

Capital replacement allowance

Cans and lids

Security

Maintenance

Receiving and shipping

Hot cell (canning, etc.)

Placement or removal

Surveillance

Outside support services

Subtotal

General and administrative

Utility costs

Other

TOTAL ANNUAL COST 
TABLE B.25. Estimate of Owner's Costs During Decommissioning for

Casks or drywells

Engineered equipment

Buildings

Site restoration

Supplies (decontamination, cutting, packaging)

Security

Shipping and burial fees

Subtotal

General and administrative

Utilities

Other

TOTAL 
Table B.24 should be used for estimates of annual operating costs. Normally one table will be required for each year of operation. However, if operating costs are identical for successive years, a single table may be used with the notation in the heading as to the years the table applies to. Again, the total cost for each year should be included in the cash flow summary of Table B.19. Transportation-related expenses inside the facility fence (except transportation equipment lease or use fees) are to be estimated and included in annual operating expenses.

\section{Cost Bases}

Bases for estimates should be given in all instances. Design and construction costs are generally influenced by physical conditions at a site. Attachment 2 lists the pertinent conditions that should be described as part of this cost basis. Attachment 3 provides guidelines for social and economic factors that need to be considered and described in the bases. These procedures, should be followed, are based upon work initially done for PNL by Bechtel Corporation during preparation of DOE/ET-0028 (Technology for Commercial Waste Management).

A contingency of 25 percent should be used in defining construction costs.

If the design does not require a facility or an operation given in a table, a cost of zero may be entered. The detail in the tables is not intended to dictate design, only to permit normalization. 


\section{ATTACHMENT 1: OUTLINE OF COST CATEGORIES}

A. Possible capital expenses at MRS/IS

1. Reports and testimony for site approval, cost of permits and licenses

2. Design engineering

3. Site preparation, access control, abatement of impacts on air and water quality

4. Buildings
a) Receiving facility including holding areas for incoming and outgoing casks
b) Canning facility, transfer facility
c) Storage facility including drywells or casks
d) Administration auxiliary, etc.

5. Engineered equipment
a) Cranes
b) Canning equipment
c) Decontamination and waste treatment equipment
d) Ventilation and contamination control
e) Spare parts inventory
f) Transporter for 100 ton cask or shielded transporter for cans

6. Contractor indirects (percent of 4,5 and 6)

7. Construction management and inspection

8. Licensing and safety reports

9. Contingency 
B. Owner's costs for MRS/IS

1. Payroll for personnel at hearings and for preparation of presentation and testimony

2. Contract management
a) Engineering
b) Licensing consultants
c) Construction contractor

3. Inspection and quality assurance

4. Operating supplies
a) Decontamination chemicals, wipes, protective clothing, dosimeters, etc.
b) Filter aids, demineralizers, regeneration chemicals
c) Annual capital replacement as used from spare parts inventory
d) Cans and lids

5. Payroll for personnel to:
a) Operate training program
b) Guard plant and storage yard
c) Maintain cranes, decontamination equipment, waste treatment equipment, heating and ventilating equipment, and transporter
d) Receive, prepare, inspect, survey, cool, flush, and decontaminate shipping casks, storage casks, and/or shielded transporter
e) Move shipping cask and storage cask into hot cell and open them
f) Bring fuel, fuel can, hardware can and lids to work station 
g) Disassemble fuel and place fuel pins in fuel cans and hardware in hardware cans

h) When cans are full, seal, test seal, decontaminate exterior and survey

i) Place completed cans in a cask, shielded transporter or lag storage

j) Mark each can and record the contents and location

k) Move fuel assemblies from shipping cask to storage cask or transporter or cans from storage to the storage cask or transporter

1) Close, inspect, survey and decontaminate a cask or shielded transporter

m) Reassemble and ship the shipping cask

n) Remove the storage cask from the hot cell and place in the storage yard

o) Remove the shielded transporter from the hot cel1, place the fuel or can in a drywe11, seal the drywell, test the seal, survey, and decontaminate.

6. Maintenance and operating supplies for the storage period.

7. Payroll during storage period

a) Guards

b) Maintenance to keep plant in standby and counteract weathering of casks or drywells

c) Leak test casks or drywells and repair as necessary

8. Maintenance and operating supplies for removal

a) Decontamination chemicals, wipes, etc.

b) Filter aids, demineralizer regeneration chemicals

c) Capital replacements as used from spare parts inventory. 
9. Payroll during removal for personnel to:

a) Guard plant and storage yard

b) Maintain cranes, decontamination equipment, waste treatment equipment, heating ventilating equipment and transporter

c) Receive, prepare, inspect, survey, cool, flush and decontaminate storage casks, shipping casks, and/or shielded transporter

d) Move storage cask or fuel from shielded transporter and shipping cask into hot cell and open casks

e) Move fuel assembly or can into shipping cask

f) Record location of all fuel moved

g) Close, inspect, survey and decontaminate casks and/or transporter

h) Prepare and ship the shipping cask to reprocessing or disposal (if storage cask becomes licensed for shipping, this step may replace many of the above steps)

10. Pay premium or receive credit for condition of fuel relative to normal uncanned assemblies based upon impact on reprocessing or disposal.

11. Decommission facility

a) Survey, decontaminate and sell for scrap, send to shallowland burial or disposal the storage casks or drywells

b) Decontaminate, disassemble, and sell for scrap or package and ship for shallow burial or disposal all engineered equipment

c) Convert to other use or demolish and sell for scrap or send to shallow burial or disposal all buildings and storage structures

d) Prepare land for conversion to other uses. 
12. Shipping and burial fees for decontamination wastes generated during fuel placement, storage, and removal, and during decommissioning.

13. General and overhead expenses (as a percentage of 4 through 12)

14. Contracted services.

15. Fuel and utilities. 


\section{ATTACHMENT 2: DESIGN AND CONSTRUCTION BASES}

Please describe the following items in your basis.

1. Site Location

2. Meterological Conditions

2.1 Wind conditions as indicated below:

- Maximum velocity

- Average velocity

- Design velocity (basic wind speed)

- Design pressure.

2.2 Tornado

2.3 Tornado Missiles

2.4 Rainfall (Precipitation)

- Annual average precipitation

- Maximum precipitation

- Design maximum rate (peak $1 \mathrm{hr}$ rate 50 yr recurrence)

- Design maximum duration.

2.5 Snow

2.6 Temperature design basis temperature conditions

- Summer maximum (July)

- Winter minimum (January)

- Design maximum, summer

dry bulb

wet bulb

- Design minimum, winter.

3. Surface Conditions

3.1 Obstructions

3.2 Topography

3.3 Vegetation

3.4 Drainage 


\subsection{Flooding}

3.6 Roads

Approximate new road construction required to provide access to the site from an existing highway suitable for heavy transport.

\subsection{Railroads}

Approximate new railroad required to provide a rail spur service to the site.

3.8 Utilities

Will temporary facilities be required during construction, or are permanent facilities part of site preparation.

\section{Subsurface Conditions}

\subsection{Obstructions}

Are there any major underground obstructions to facility construction.

\subsection{Soils - Thickness}

4.3 Rock - Depth type and load bearing ability

4.4 Groundwater - Depth and need for dewatering

4.5 Frost - Design ground penetration

4.6 Cavities and Small Voids

Do they exist in the soils or rock underlying the site

5. Geologic and Seismic Conditions

5.1 Faults - The nearest known or inferred fault

\subsection{Seismic Design}




\section{ATTACHMENT 3: COST ESTIMATE BASES AND METHOOS}

\section{Construction Conditions}

As a basis for cost estimating, the construction conditions described below are assumed to prevail at all sites.

1.1 Construction Labor will follow a 40-hour, single-shift work week schedule except for casual overtime (e.g., to complete a concrete pour), and in instances where twoor three-shift concrete work operations are planned to meet the construction schedule.

1.2 Severe Work Stoppages such as extensive jurisdictional disputes between labor crafts will not occur during construction.

1.3 Labor Availability in each craft will be adequate so that importing labor, except for general foremen, will not be required.

1.4 Craft Labor Wage Rates, including fringe benefits are those prevailing in the geographic region of the construction site in mid-1982.

\section{Pricing: Field Costs}

The various elements comprising the field costs will be priced by the methods described below:

2.1 Major Equipment Costs will be determined using estimated prices of similar or nearly similar equipment from other cost estimates of fuel reprocessing plants, radioactive wastes disposal processes and other plants dealing with the nuclear fuel cycle.

2.2 Bulk Materials. Except for instances where enough information exists to warrant quantity assessments and unit pricing of certain specifically identified material, bulk materials costs will be determined either as a function of major equipment costs or as a cost allowance.

2.3 Direct Labor Costs will be evaluated from estimated manhours for erection and installation sequences and operations and craft wage rates and fringe benefits in effect at mid-1982. Labor manhours are representative of the craft production rates in the area of reference jobsites. 
2.4 Indirect Site Construction Costs such as contractor's fee, supervision, construction equipment, tools and consumable supplies, temporary facilities and utilities, material handling, cleanup and the like will be combined and evaluated as a factor of the total direct labor.

3. Architect-Engineer (A-E) Services

The costs of A-E services will be estimated as a percentage of the total field costs and will include burden and fee.

4. Owner's Cost

Owner's costs during construction will be estimated in conjunction with the operating and maintenance costs.

5. Costs Not Included

Exclusions from the estimate are generally limited to the following particular cost classifications:

- Site acquisition costs

- Escalation of costs beyond mid-1982

- Process and patent royalties

- General research and development costs

- Costs incurred beyond those that reflect the current degree of involvement in securing approvals from regulatory agencies monitoring environmental and safety considerations

- Costs generated directly by any governing or regulatory agency for administration, engineering, procurement and construction

- Sales/use tax

- Local property tax or payments in lieu thereof

- Impact payments to local government

- Insurance or prorate cost of self insurance

- Nuclear hazards insurance that may be required if nuclear hazards exist on site before completion of project

- Housing for construction workers. 


\section{B.3 TRANSPORTATION UNIT COSTS}

Summary

This section provides unit transportation costs to the contractors performing pre-conceptual design studies for the Monitored Retrievable Storage/Interim Storage (MRS/IS) program in FY-82. The bases and assumptions pertaining to transportation for use by the preconceptual design contractors in their FY-82 studies are also documented in this section. Unit transportation costs are calculated for four fuel-cycle materials; spent fuel, high-level wastes (HLW), remote-handled transuranic (RHTRU) wastes, and contact-handled (CH) TRU wastes. RHTRU wastes are further subdivided into three categories; wastes that are packaged in special cylindrical canisters (including compacted cladding hulls), wastes that are packaged in "standard" 210-liter (55 gal) drums with surface dose rates less than $5 \mathrm{R} / \mathrm{hr}$, and drummed wastes with surface dose rates greater than $5 \mathrm{R} / \mathrm{hr}$. Transportation costs are calculated for shipments by truck and by rail.

Three waste management scenarios are currently under study by the MRS/IS program. They include interim storage facilities located either at a fuel reprocessing plant, a geologic waste disposal repository, or a stand-alone facility. The transportation links and the assumed mileages between each facility are defined. Transportation in this study stops at the fences of the terminal facilities; i.e., onsite transportation is considered as facility handling operations. The reference shipping systems for transporting the spent fuel and HL and TRU wastes between the facilities are selected. Several criteria were used for selecting these systems, in particular the use of existing or near-existing technology, licensability, and compatibility with reference canister sizes. The reference shipping systems selected for use in this study are shown in Table B.26. The reference canister dimensions are also defined. 
TABLE B.26. Reference Shipping Systems Selected for Study

\begin{tabular}{|c|c|c|c|c|}
\hline Material & $\begin{array}{l}\text { Shipping } \\
\text { Mode } \\
\end{array}$ & $\begin{array}{r}\text { Shipping } \\
\text { Container } \\
\end{array}$ & $\begin{array}{c}\text { Canisters } \\
\text { per } \\
\text { Shipment }\end{array}$ & $\begin{array}{l}\text { Leasing } \\
\text { Fee, } \\
\$ / 0 \text { ay }\end{array}$ \\
\hline \multirow[t]{2}{*}{ Spent fuel } & Truck & NAC-1 & $\begin{array}{l}1 \text { PWR or } \\
2 \text { BWR }\end{array}$ & $2000(a)$ \\
\hline & Rail & IF -300 & $\begin{array}{l}7 \text { PWR or } \\
18 \text { BWR }\end{array}$ & 5750 \\
\hline
\end{tabular}

\begin{tabular}{|c|c|c|c|c|}
\hline High-level & Truck & NAC-1 & 1 canister & 2000 \\
\hline & $\mathrm{Raj} 1$ & IF-300 & 5 canisters & 5750 \\
\hline RHTRU special & Truck & HLW-T & 1 canister & 1750 \\
\hline & Rail & $H L W-R$ & 5 canisters & 4375 \\
\hline RHTRU drums & Truck & CNS 14-170 & 14 drums & 175 \\
\hline & $\operatorname{Rail}(b)$ & CNS $14-170$ & 42 drums & 525 \\
\hline RHTRU drums & Truck & CNS $7-100$ & 7 drums & 175 \\
\hline & $\operatorname{Rail}(b)$ & CNS $7-100$ & 21 drums & 525 \\
\hline CHTRU wastes & Truck & TRUPACT & $\begin{array}{l}36 \text { drums or } \\
3 \text { boxes }\end{array}$ & 700 \\
\hline & $\operatorname{Rail}(c)$ & TRUPACT & $\begin{array}{l}72 \text { drums or } \\
6 \text { boxes }\end{array}$ & 1400 \\
\hline
\end{tabular}

(a) Leasing fee for the NAC-1 is calculated from a schedule.

(b) It is assumed that three of these shipping containers can be transported per railcar.

(c) Assumes two truck TRUPACT versions are transported per railcar. 
Transportation costs for the FY-82 MRS/IS program studies are based on the assumption that private industry will provide the transportation services as a commercial venture, although the services could be owned and provided by the government. Therefore, total transportation costs are the sum of the shipping charges, special equipment and security costs (where applicable) and shipping container rental fees. The unit transportation costs for truck and rail shipments of the six different cargoes are summarized in Table B.27. The MRS/IS program design contractors will multiply the values shown in Table B.26 by the appropriate number of shipments their facilities will deal with to calculate total transportation costs over the assumed lifetimes of their facilities. Use of the unit costs shown in Table B.27 provides a common baseline for comparing the total life-cycle transportation costs for the three siting alternatives for MRS/IS facilities.

Special equipment charges and security costs are currently required for shipments of spent fuel and may be required for shipments of high-level wastes in the future. The costs for HLW shipments shown in Table B.27 include these additional costs.

\section{INTRODUCTION}

The objectives of the Monitored Retrievable Storage/Interim Storage Program are to provide Federal contingency capability for storing spent nuclear fuel until a reprocessing facility can eliminate the need for such storage and to provide Federal capability for storing solidified high-level wastes (HLW) and transuranic (TRU) wastes until a waste disposal repository becomes available. Currently, two dry storage concepts are being evaluated to determine their effectiveness for reducing near-term spent fuel and waste storage space shortages. The two concepts consist of storage in large metal casks and drywells. Both concepts offer passive, low cost, easily maintained systems that can be expanded in increments which can be constructed according to demand. The degree of flexibility of these storage concepts is being assessed by comparing the results of using casks and drywells to provide interim storage at three potential sites: co-located at a repository, 
TABLE B.27. Round-Trip Transportation Costs for Truck and Rail Shipments of Spent Fuel and High-Level and Transuranic Wastes $(a)$

\begin{tabular}{|c|c|c|c|c|}
\hline \multirow{2}{*}{$\frac{\text { Material }}{\text { Spent fuel(d) }}$} & \multirow{2}{*}{$\frac{\begin{array}{c}\text { Shipping } \\
\text { Mode }\end{array}}{\text { Truck }}$} & \multicolumn{3}{|c|}{$\begin{array}{c}\text { Round-Trip Unit Transportation Costs } \\
\text { One Way Miles, } \$ / \text { Shipment }(b, c)\end{array}$} \\
\hline & & 12,190 & 29,010 & 34,710 \\
\hline \multirow{3}{*}{$\begin{array}{l}\text { High-level }(d) \\
\text { wastes }\end{array}$} & Rail & 91,140 & 216,920 & 26,240 \\
\hline & Truck & 12,200 & & 31,510 \\
\hline & Rail & 91,210 & & 262,410 \\
\hline \multirow{2}{*}{$\begin{array}{l}\text { RHTRU wastes; } \\
\text { special canisters }\end{array}$} & Truck & 9,280 & & 23,030 \\
\hline & Rail & 69,670 & & 193,770 \\
\hline \multirow{2}{*}{$\begin{array}{l}\text { RHTRU wastes; } \\
\text { drums }<5 \mathrm{R} / \mathrm{hr}\end{array}$} & Truck & 3,450 & & 10,825 \\
\hline & Rail & 21,090 & & 57,530 \\
\hline \multirow{2}{*}{$\begin{array}{l}\text { RHTRU wastes; } \\
\text { drums }>5 \mathrm{R} / \mathrm{hr}\end{array}$} & Truck & 3,380 & & 10,645 \\
\hline & Rail & 20,770 & & 55,680 \\
\hline \multirow[t]{2}{*}{ CHTRU wastes } & Truck & 5,310 & & 14,380 \\
\hline & Rail & 25,600 & & 70,600 \\
\hline
\end{tabular}

(a) Transportation costs include shipping charges, special equipment and security costs (where applicable) and shipping system rental fees.

(b) Rounded to the nearest ten dollars.

(c) These costs do not include demurrage fees for truck shipments. These are, on the average, $\$ 29.30$ for each hour of turnaround time at the terminal facilities. Rail demurrage fees are calculated using shipping system rental fees.

(d) Costs include charges for special equipment and escort services. 
co-located at a fuel reprocessing plant (FRP), and a strategically located stand-alone facility. The two storage concepts are being evaluated for each siting alternative as to their technical status, life cycle costs, safety and licensing issues, environmental issues, transportation considerations, and research and development requirements.

The purpose of this document is to transmit standardized assumptions and unit costs for transportation to the contractors preparing pre-conceptual and reference designs of interim storage facilities for the three siting alternatives. This standard set of numbers is to be used in all three studies to set a baseline for common comparison of lifetime transportation costs. Unit costs are developed for transporting four types of radioactive materials: spent fuel, solidified high-level wastes, remote-handled transuranic (RH-TRU) wastes, and contact-handled TRU (CH-TRU) wastes. RH-TRU wastes are further divided into special canisters and two types of drummed wastes so a total of six fuel cycle materials are considered in this study. In addition to transmitting standardized assumptions and transportation unit costs, this report defines the reference transportation systems for the MRS/IS Program. Also included is an estimate of the costs of requiring security provisions for high-level waste shipments similar to those required for spent fuel in transit.

\section{Bases and Assumptions}

The bases for calculating unit transportation costs and key assumptions that were made to facilitate these calculations are discussed in this section. The section includes definition of the transport links connecting the fuel cycle facilities considered in this study. Transportation in this study refers only to offsite shipments, in the general public domain (i.e., between fences of the terminal facilities). Onsite transportation is considered as handling at the facility and is not included here. However, onsite handling of the cross-country vehicles and packagings can affect facility turnaround times and thus the cost of cross-country transport. Shipping parameters and transportation costs for six fuel cycle materials are considered: spent fuel, solidified high-level wastes, RHTRU cladding hulls, other RHTRU wastes, and CHTRU wastes. 
At this time in the U.S., no commercial reprocessing of spent nuclear fuel to reclaim valuable uranium and plutonium is occurring. As a result, the spent fuel is being stored in reactor fuel storage basins. The maximum capacity of many of these basins is being reached. The strategy used in the MRS/IS studies assumes that: 1) the government will accept and store excess spent fuel in a federally owned facility until a fuel reprocessing plant (FRP) becomes available; 2) in the reference case, a $1500 \mathrm{MgHM} /$ year FRP will open in 1989 and the MRS/IS will accept and store HL and TRU waste from that operation until a repository is available; 3 ) the $H L$ and TRU waste generated by the FRP will ultimately be shipped to a repository for final isolation; and 4) a generic mixed-oxide fuel fabrication plant will begin operation in 1989. A gap exists between the 1998 planned opening date for the repository and the FRP opening date of 1989. The HLW and TRU wastes generated during this period will be shipped to an MRS/interim storage facility until they can be shipped to the repository for final isolation.

Three general waste management scenarios are currently envisioned by the MRS/Interim Storage program. The basic scenarios are defined by the site selected for construction of the MRS/IS facility, either co-located with an FRP (assumed in this study to be Barnwell Nuclear Fuel Plant), co-located with the repository, or a strategically located stand-alone facility. Transport links connecting these facilities and power reactors are shown in Figures $B .1$, B.2, and B.3 for each scenario. From these figures it can be seen that co-locating the MRS/IS facility with either the FRP or the repository eliminates some transport steps. If the MRS/IS facility is co-located with the FRP, transport of spent fuel from interim storage to the FRP and of solidified HLW and TRU wastes from the FRP to interim storage are both eliminated. Co-locating the MRS/IS facility at the repository eliminates transportation of $\mathrm{HLW}$ and TRU wastes from interim storage to the repository. All transport steps between these facilities are required if the MRS/IS facility is a stand-alone facility.

One purpose of this report is to define the reference transportation systems for use in the facility evaluations. There is no intent to endorse or reject any particular shipping system. Reference systems, however, were selected to provide consistency within this study using state-of-the-art 


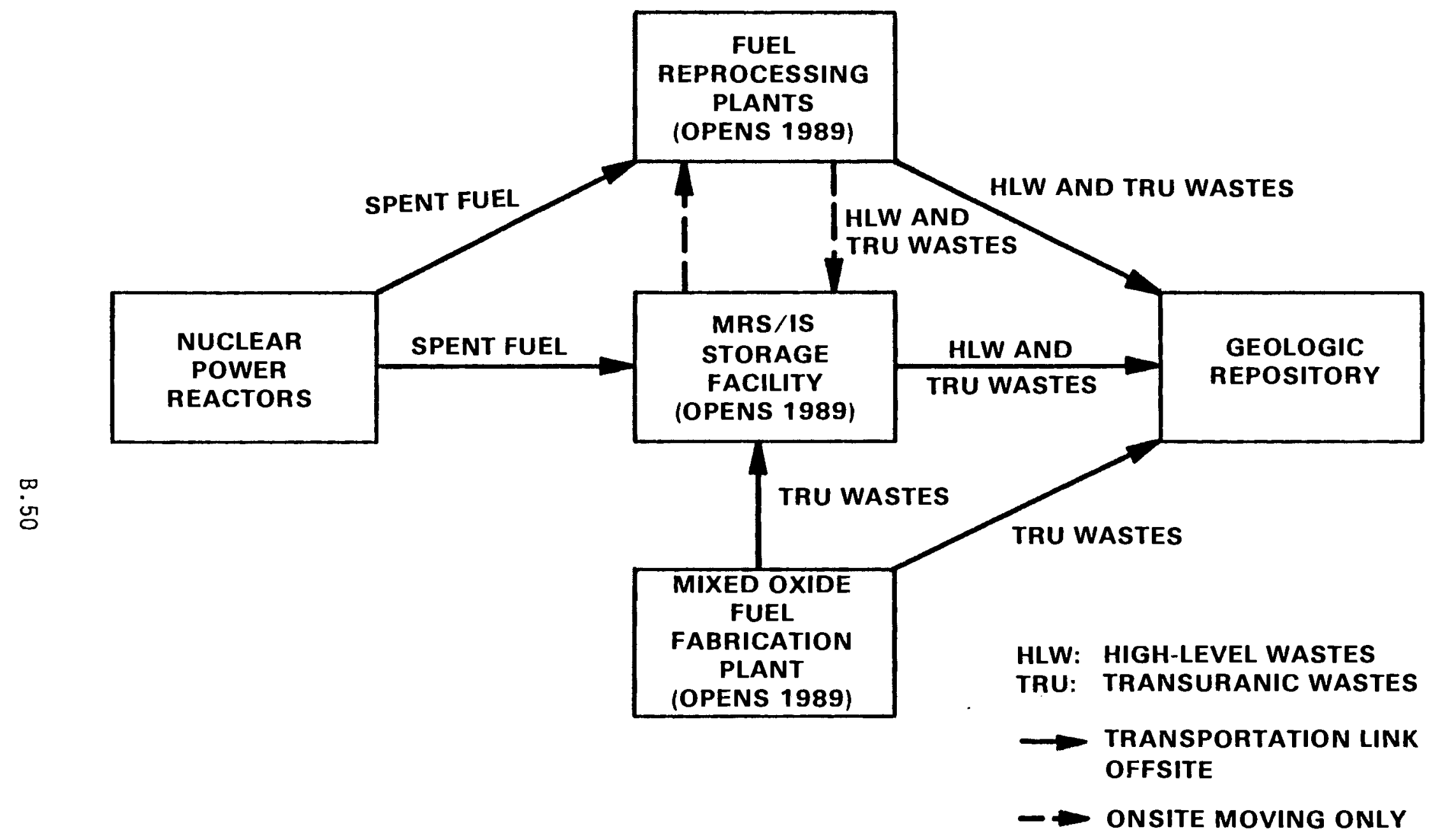

FIGURE B.1. Transportation Links for Co-locating the Interim Waste Storage Facility with the Reprocessing Plant 


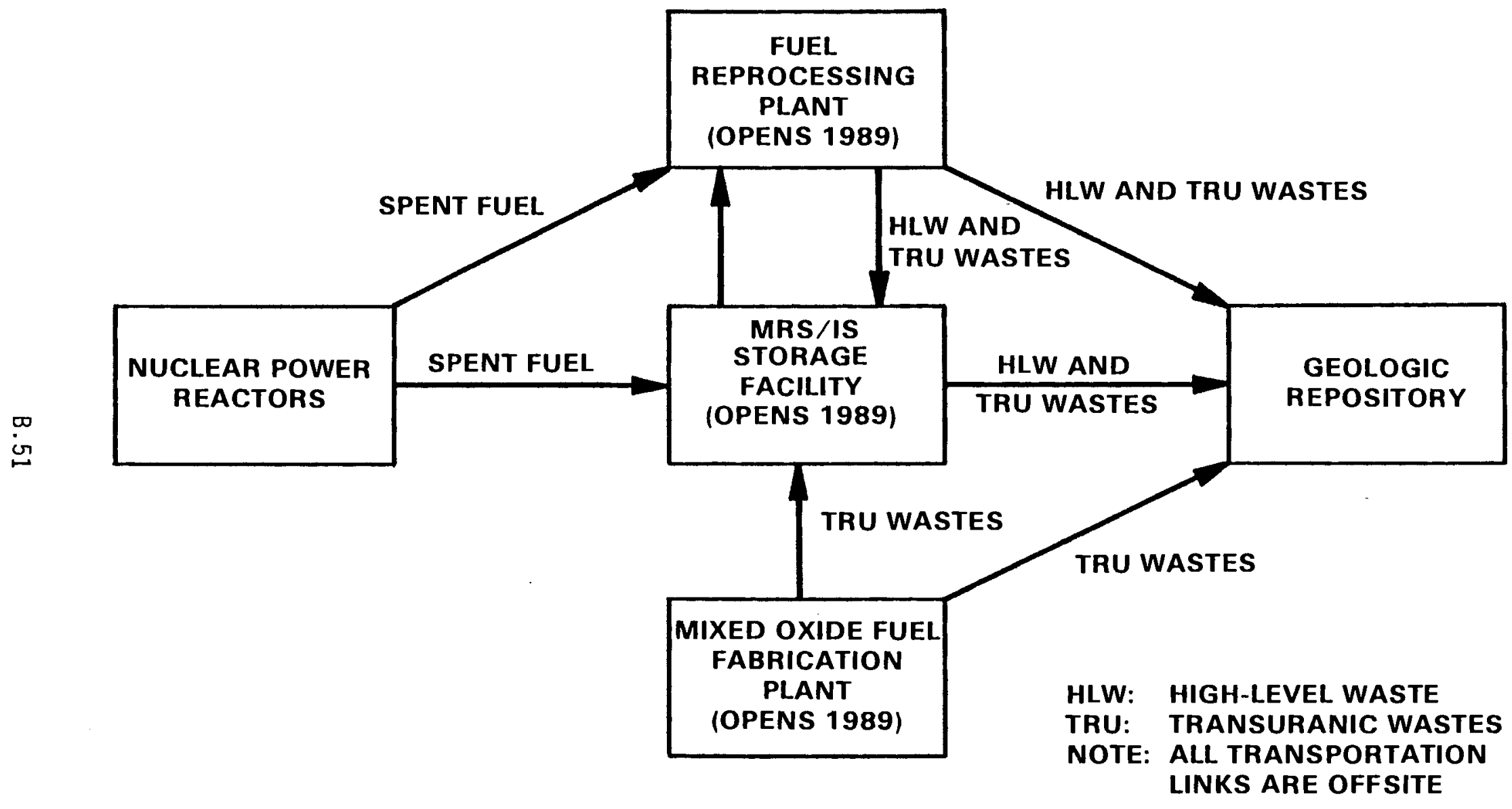

FIGURE B.2. Transportation Links for a Strategically Located, Stand-Alone Interim Storage Facility 


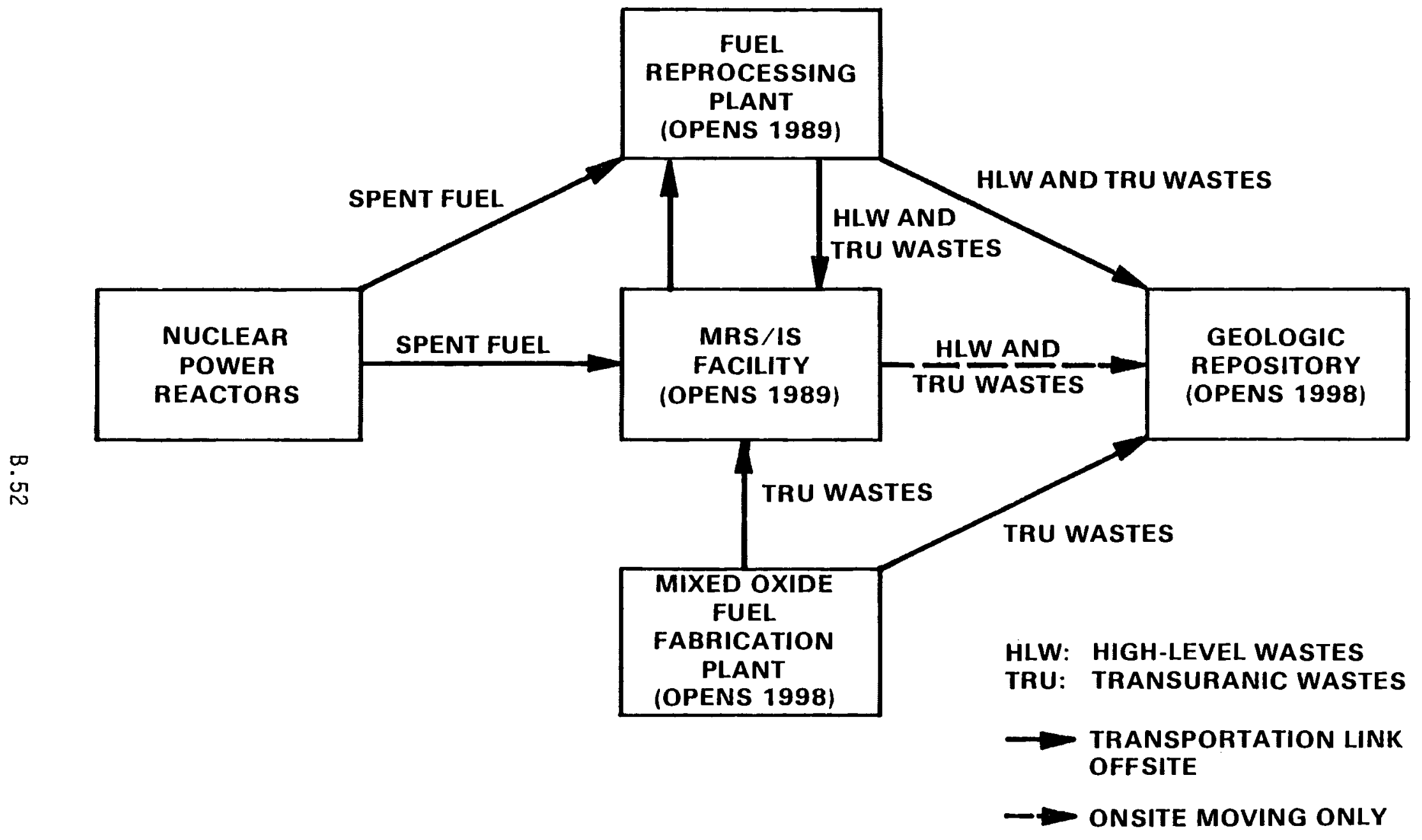

FIGURE B.3. Transportation Links for Co-locating the Interim Waste Storage Facility with the Repository 
hardware. Primarily, the systems selected were existing and licensed where available. If no such systems exist, those that are well along in the design stage were selected. Another criterion that must be met by the shipping system is that of licensability. Application of this criterion requires judgment as to whether or not a conceptual shipping system is expected to eventually meet the packaging regulations in 10 CFR 71 .

A third criterion concerning the selection of the shipping systems is the sizes of the reference canisters assumed as the primary container for the high-level and transuranic wastes. The reference canister sizes for this study are shown in Table B.28.

The reference shipping systems in this study were selected to accommodate these sizes of canisters. Some inconsistencies may exist between these canisters and the canisters that the FRP is planning to use. For example, the cladding hulls canister the FRP is planning to use is $1.1 \mathrm{~m}(3.7 \mathrm{ft})$ in diameter and $2.3 \mathrm{~m}(7.5 \mathrm{ft})$ long. This canister, due to its large diameter,

TABLE B.28. Reference Canister Sizes and Weights for Definition of Shipping Systems and Shipment Parameters

\begin{tabular}{|c|c|c|c|}
\hline Fuel Cycle Material & Dimensions, $m$ & $\begin{array}{c}\operatorname{Net}^{(\mathrm{a})} \\
\text { Capacity, } \mathrm{m}^{3}\left(\mathrm{ft}^{3}\right) \\
\end{array}$ & $\begin{array}{c}\text { Average } \\
\text { Weight } \\
\text { Loaded, kg (1b) } \\
\end{array}$ \\
\hline $\begin{array}{l}\text { Spent fuel } \\
\text { PWR assembly } \\
\text { BWR assembly }\end{array}$ & $\begin{array}{l}N A \\
N A\end{array}$ & $\begin{array}{l}\text { NA } \\
\text { NA }\end{array}$ & $\begin{array}{ll}658 & (1448) \\
284 & (625)\end{array}$ \\
\hline $\begin{array}{l}\text { Solidified high-level } \\
\text { waste canister }\end{array}$ & $0.310 \times 3.1$ & $0.17(6.0)$ & $1050(2310)$ \\
\hline $\begin{array}{l}\text { RHTRU wastes } \\
\text { Hulls canister } \\
210 \text { L (55 gal) drum }\end{array}$ & $\begin{array}{l}0.62 D \times 3.1 \\
0.62 D \times 0.92\end{array}$ & $\begin{array}{l}0.75(2.6) \\
0.17(6.0)\end{array}$ & $3500(7700)$ \\
\hline $\begin{array}{l}\text { CH-TRU Wastes } \\
210 \text { L (55-gal) drum } \\
\text { Metal box }\end{array}$ & $\begin{array}{l}0.620 \times 0.92 \\
1.2 \times 1.9 \times 1.9\end{array}$ & $\begin{array}{l}0.19(6.7) \\
3.5(123.6)\end{array}$ & $\begin{aligned} 300 & (660) \\
4000 & (8800)\end{aligned}$ \\
\hline
\end{tabular}

NA = Not applicable.

(a) Based on maximum of 80 percent full. 
was not transportable in any of the spent fuel or high-level waste truck shipping casks. Therefore, to be more compatible with storage and shipping casks, the equivalent volume of waste is assumed to be transported in a larger number of $0.62 \mathrm{~m}(2 \mathrm{ft})$ diameter canisters for this study.

A key assumption that simplifies the selection of the shipping systems is that the canister provides the second level of containment for plutonium bearing wastes, as required in federal regulations (10 CFR 71). The casks or shipping packagings provide only one level of containment. A final assumption concerning selection of the truck shipping systems is that they will all be legal-weight systems, i.e., gross-vehicle weight (tractor plus trailer plus loaded cask weights) do not exceed $36,400 \mathrm{~kg}(80,000 \mathrm{lb})$. It is recognized that over-weight truck shipments may be more economical than legal-weight shipments, but for this study, there was insufficient time to adequately calculate the charges for over-weight shipments. This would include defining specific routes and finding what each state on each route charges as an over-weight penalty. In addition, the use of overweight trucks routinely for numerous shipments would require considerable administrative efforts to obtain repeatedly the special permits from the states involved.

Shipping distances must be defined to calculate transportation costs. For the purposes of this study, two distances that represent somewhat bounding cases are defined. The first distance is $4000 \mathrm{~km}$ (2500 miles), which represents a cross-country shipment. The second distance is $800 \mathrm{~km}$ (500 miles), which was chosen because it approximates a typical distance between eastern power reactors and BNFP. The cost for each transport link in the evaluation studies of three sites for MRS/IS facilities is calculated using both of these distances.

The assumed distances must be assigned to the various transportation links in Figures B.1 through B.3. Since most of the commercial reactors are in the east and the FRP will be in the east, the transportation link connecting these facilities is assumed to be $800 \mathrm{~km}$ (500 miles). The disposal repository is assumed to be in the west, which results in the $4000 \mathrm{~km}$ (2500 mile) transport distance between the FRP and repository and the MOX-FFP and repository. Depending upon where the MRS/IS facility is co-located, it is 
assumed to be either $800 \mathrm{~km}$ or $4000 \mathrm{~km}$ from the reactors (i.e., if the storage facility is co-located with the repository, the transportation link between the reactors and the MRS/IS facility is $4000 \mathrm{~km}$; it is $800 \mathrm{~km}$ if the MRS/IS facility is co-located at the FRP). The stand-alone MRS/IS facility is assumed to be $800 \mathrm{~km}$ from reactors and from the FRP and $4000 \mathrm{~km}$ from the final isolation repository. In all cases, the MOX-FFP is assumed to be the same distance from the other sites as the FRP.

It is assumed in this study that 50 percent of the spent fuel and waste transported to the IS facility is to be shipped by truck and 50 percent by rail. This shipping mode split was chosen because it is not clear what mode of transport will be most extensively used in the future. Each has its own advantages and disadvantages. The reference truck/rail shipping split reflects no bias toward either mode. If such a split significantly affects the operating costs for any preconceptual MRS/IS facility, the respective contractor may, if desired, select other splits as sensitivity cases to this reference case.

Mid-year 1982 dollars were used when calculating transportation unit costs. Transportation costs are calculated as though private industry was shipping on a commercial basis even though that may eventually not be the case. Costs include operating costs plus amortization costs of hardware plus profits, at commercial rates. Therefore, transportation costs include the shipping charges assessed by carriers and the rental fees assessed by transportation hardware suppliers. A third factor in transportation costs is a fee for demurrage or detention of a carrier's equipment (railcars or truck-trailer rigs) and for drivers while unloading at terminal facilities. These three transportation factors are assumed to be supplied by the private sector as a commercial venture. Thus the total transportation costs are calculated as follows:

$$
\begin{aligned}
& \text { Special Shipping } \\
& \text { Total Round-trip Equipment/ Container Demurrage } \\
& \text { Transportation }=\text { Shipping }+ \text { Security }+ \text { Leasing }+ \text { Fees } \\
& \text { Costs Charges Costs Fees }
\end{aligned}
$$

Transportation System Descriptions

This section describes transportation systems selected for this study for the five fuel cycle materials under consideration in this study: spent fuel, 
solidified HLW, TRU-contaminated fuel cladding hulls, other RHTRU wastes, and CHTRU wastes. Two shipping systems, one truck version and one rail version, are described for each material. It is believed that the future nuclear waste management system will integrate their waste container designs with transportation system designs to provide compatible and optimum shipping configurations. Therefore, if a minor modification to the shipping containers results in significantly increased capacities, it is assumed this will be done. These modifications are noted where they occur.

Table B.29 lists the important shipping parameters and characteristics of the truck and rail shipping systems used in this study. Supplementary descriptive information is contained in the following sections.

\section{Spent Fuel Shipping System}

The representative truck and rail shipping systems used in this study are the NAC-1 owned by the Nuclear Assurance Corporation and the IF-300 owned by the General Electric Company, respectively. The NAC-1 and IF-300 shipping casks are depicted in Figures B.4 and B.5, respectively. The NAC-1 legal weight truck system uses a water-filled cask designed to transport one PWR or two BWR spent fuel assemblies. Decay heat from the spent fuel is removed by conduction and convection through the cask body and is released to the atmosphere by natural convection and radiation. The NAC-1 is currently shipped at a reduced heat loading.

The IF-300 cask of General Electric Company is a water-filled cask (although it is currently shippped dry), designed for rail transport of 7 PWR or 18 BWR spent fuel assemblies. Decay heat is removed from the fuel by natural circulation of the coolant (water, when used), by natural convection and conduction to the external surface, and by forced convection from the external surface to the environment. The forced convection (air impingement) system consists of two diesel-driven blowers and appropriate air ducts. In addition, the cask outer surface is corrugated to facilitate external cooling. The maximum heat-rejection capacity is $76 \mathrm{~kW}$ with blowers operating and $62 \mathrm{~kW}$ without blowers. 
TABLE B.29. Characteristics of Transportation Systems for the MRS/IS Program

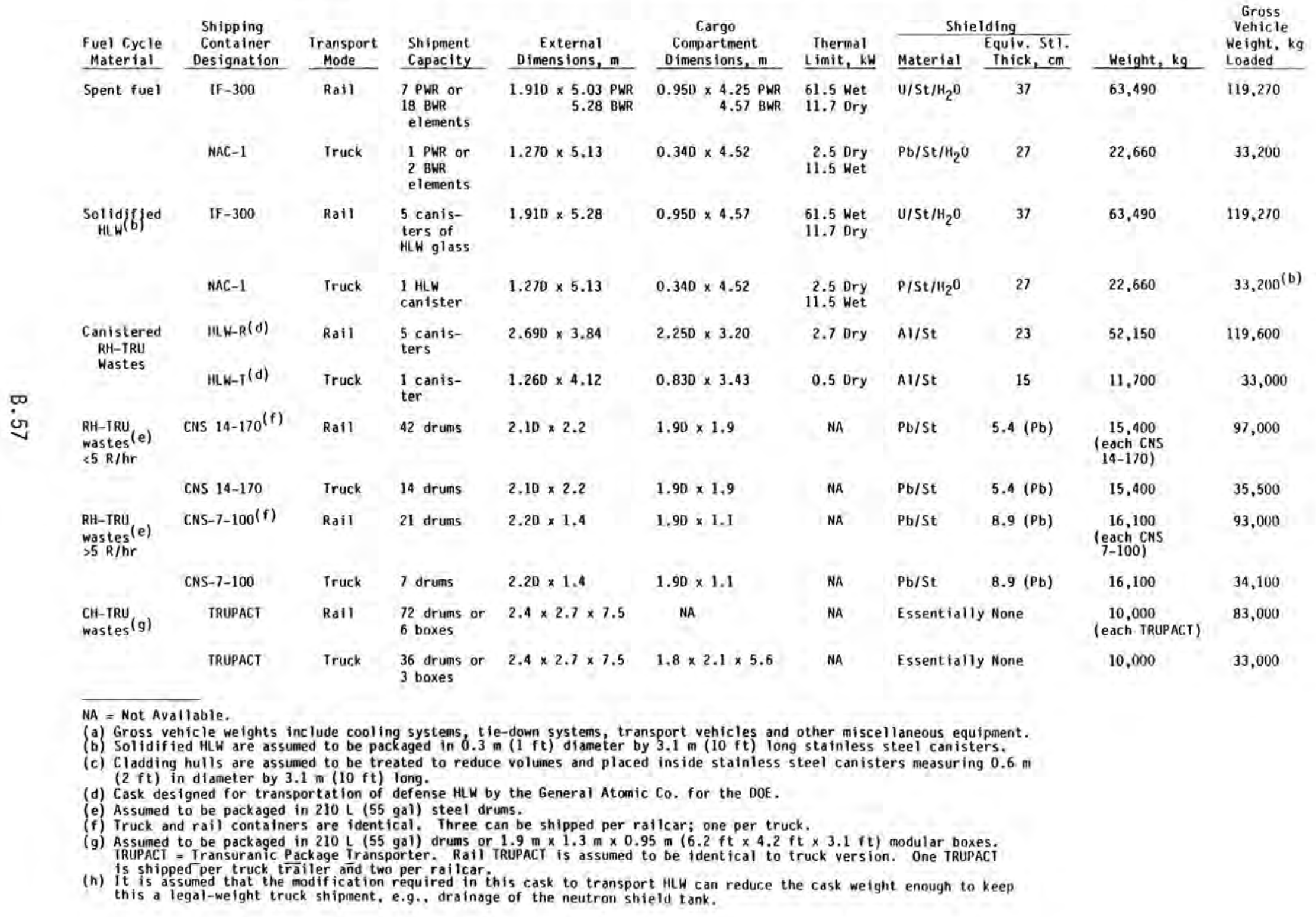




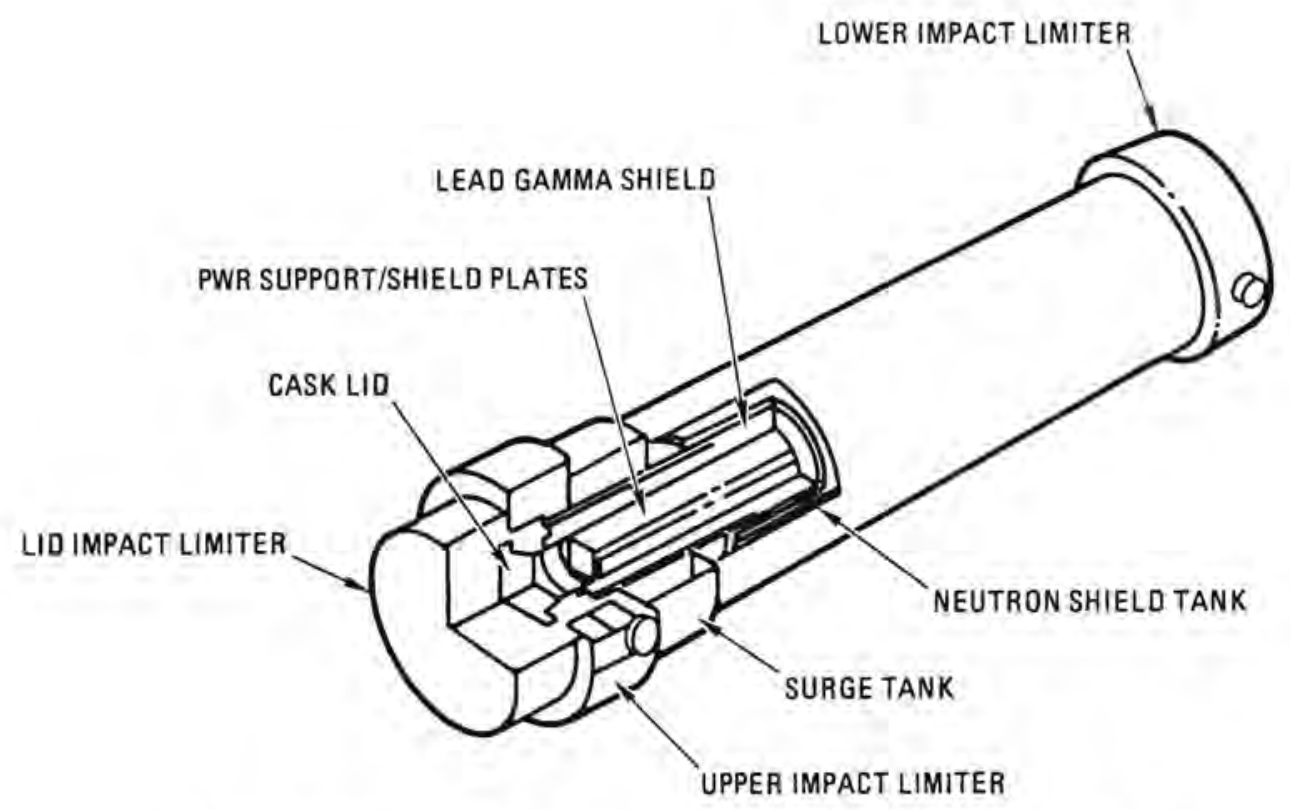

FIGURE B.4. NAC-1 Truck Spent Fuel Shipping Cask

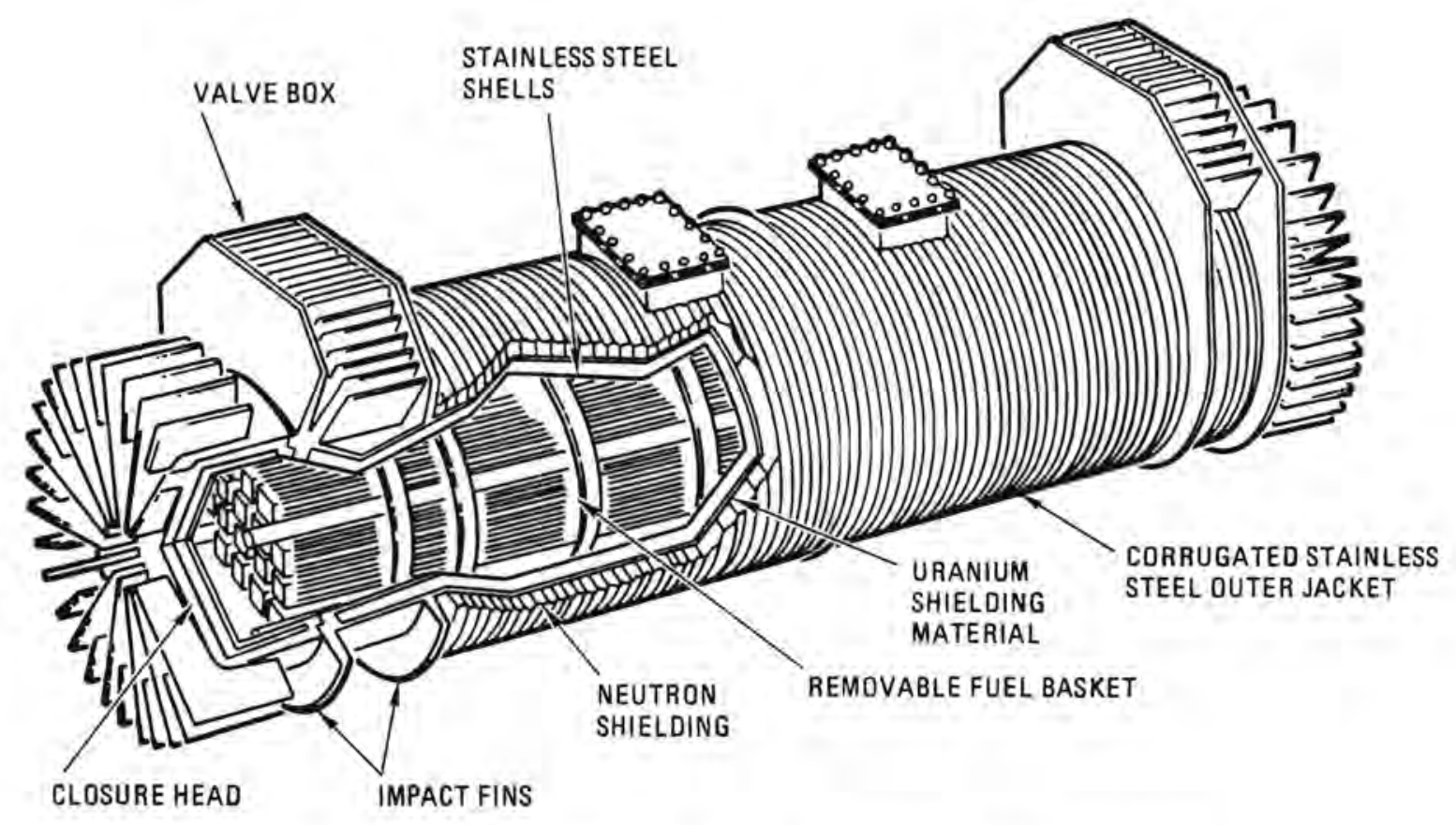

FIGURE B.5. IF-300 Rail Spent Fuel Shipping Cask 


\section{High-Level Waste Shipping Systems}

Transportation systems for solidified high-level wastes have been conceptually designed but not built. These systems are expected to resemble the current generation of spent fuel shipping casks. Therefore, the shipping systems previously described for transport of spent fuel are also assumed to be used to transport high-level wastes in this study. Some minor modifications to the spent fuel casks are required, e.g., designing a new internal basket for the IF-300 with a capacity for five HLW canisters, but it is assumed that these casks would be licensable for HLW shipments by using appropriate baskets and spacer inserts. The only change to the "cask characteristics" is the cargo weights. It is recognized that the NAC-1 and IF-300 are not optimized for transporting high-level wastes and that future transportation systems may have higher cargo capacities for a given gross weight.

\section{RHTRU Waste Shipping Systems}

Different shipping systems are required to transport "standard" $55 \mathrm{gal}$ drums and other special canisters for RHTRU wastes. Special canisters $(0.62 \mathrm{~m}$ in diameter and $3.1 \mathrm{~m}$ long) are assumed to be transported in casks currently designated HLW-T and HLW-R for truck and rail versions, respectively. These casks are being designed by the General Atomic Company to transport defense high-level wastes for the DOE. They are assumed in this study to be licensable for transporting commercial RH-TRU wastes. The HLW-T cask is a thick-walled steel cylinder similar to the current generation of spent fuel truck casks. This cask can accommodate one special canister. The HLW-R cask is a cylindrical, solid steel cask capable of transporting five canisters. Conceptual drawings of these casks are shown in Figures B.6 and B.7 respectively.

RHTRU wastes are also packaged in standard 55-gal drums, having various dose rates from $200 \mathrm{mR} / \mathrm{hr}$ to several hundred $\mathrm{R} / \mathrm{hr}$. To make the economics of transport more realistic for the additional shielding needs, two shipping containers with different features are assumed to be used. For RHTRU waste drums with surface dose rates less than $5 \mathrm{R} / \mathrm{hr}$, the shipping container 


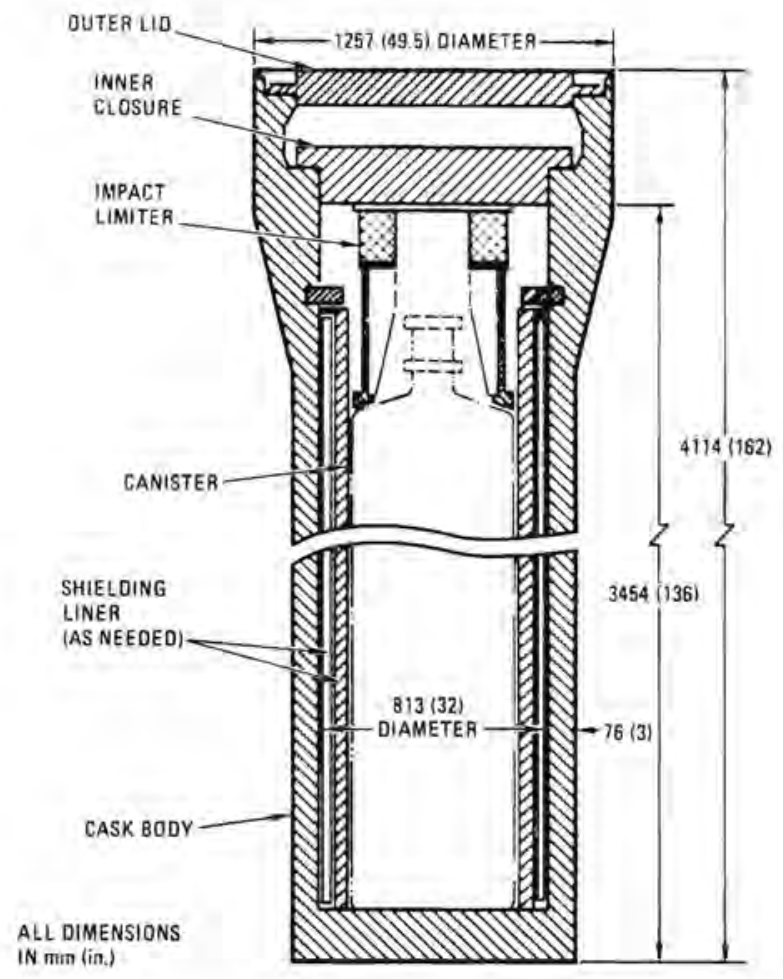

FIGURE B.6. Reference Truck Cask for Transportation of Hulls Canisters (HLW-T cask)

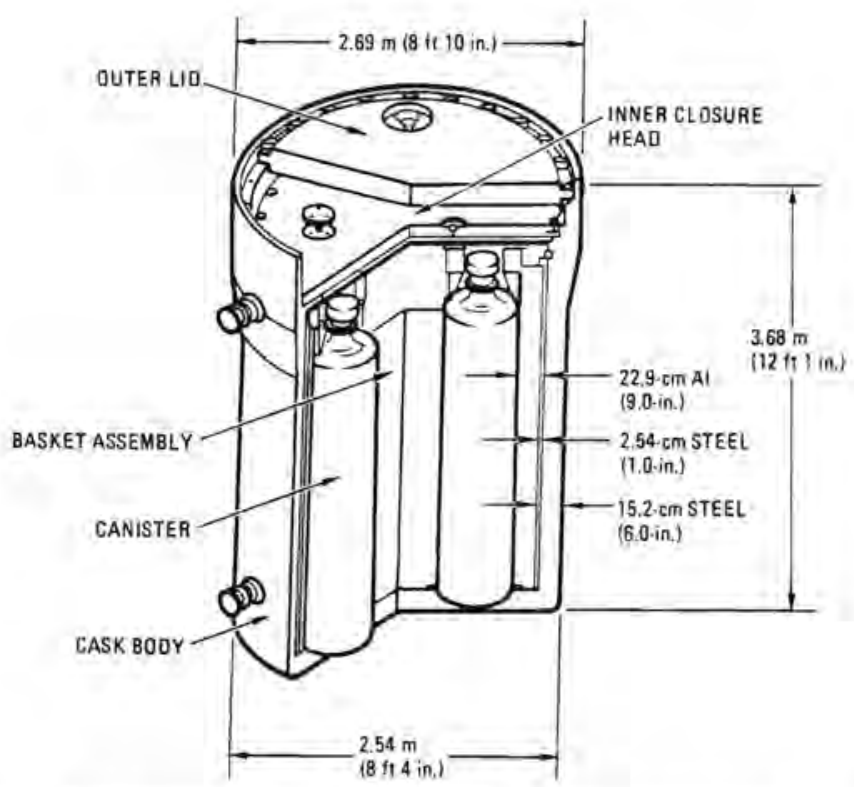

FIGURE B.7. Reference Rail Cask for Transportation of Hulls Canister (HLW-R cask) 
selected is the Chem-Nuclear Systems, Inc. Cask designated CNS 14-170

(Figure B.8 shows a drawing of the CNS 14-170). This is a top-loading, lead and steel shipping cask for dewatered or solidified waste material. It is assumed to be licensable for transportation of TRU wastes.

RHTRU waste drums with surface dose rates exceeding $5 \mathrm{R} / \mathrm{hr}$ are assumed to be shipped in the CNS 7-100 cask. The maximum dose rate for drums in the CNS $7-100$ is $100 \mathrm{R} / \mathrm{hr}$. Any exceeding this value are assumed to be shipped in the HLW-T and HLW-R casks. The CNS $7-100$ is a lead and steel shipping cask (Figure B.9) currentTy used to transport dewatered or solidified waste material. It is also assumed to be licensable for transporting transuranic wastes.

\section{CHTRU Waste Shipping Systems}

The TRansUranic PACkage Iransporter is the reference CHTRU waste shipping system selected for use in this study. The TRUPACT is being developed by the Sandia National Laboratories/Transportation Technology Center and the General Atomic Company for the DOE specifically to provide the containment required to haul large quantities of defense CHTRU wastes. Both truck and rail versions of the TRUPACT are being developed. However, because there are more uncertainties about the availability of a rail version, the TRUPACT system used for rail transport in this study consists of two truck versions shipped on a railroad flatcar. The truck system consists of a single TRUPACT shipped on a flatbed truck trailer.

As presently conceived, the TRUPACT (Figure B.10) will have inner and outer stee 1 frameworks made of rectangular tubing. Steel sheets covering the inner and outer surfaces of the inner and outer frameworks are separated by about $0.3 \mathrm{~m}$ (12 in.) of high-temperature insulation and rigid polyurethane foam.

The inner liner is built of stainless steel sheets; the outer shell may be carbon steel or stainless steel. A steel puncture-resistant plate is located between the two frameworks to prevent puncture damage to the inner liner. Access to the cargo cavity is through two hinged, sealed closures in series at one end that are bolted in place during transport. 


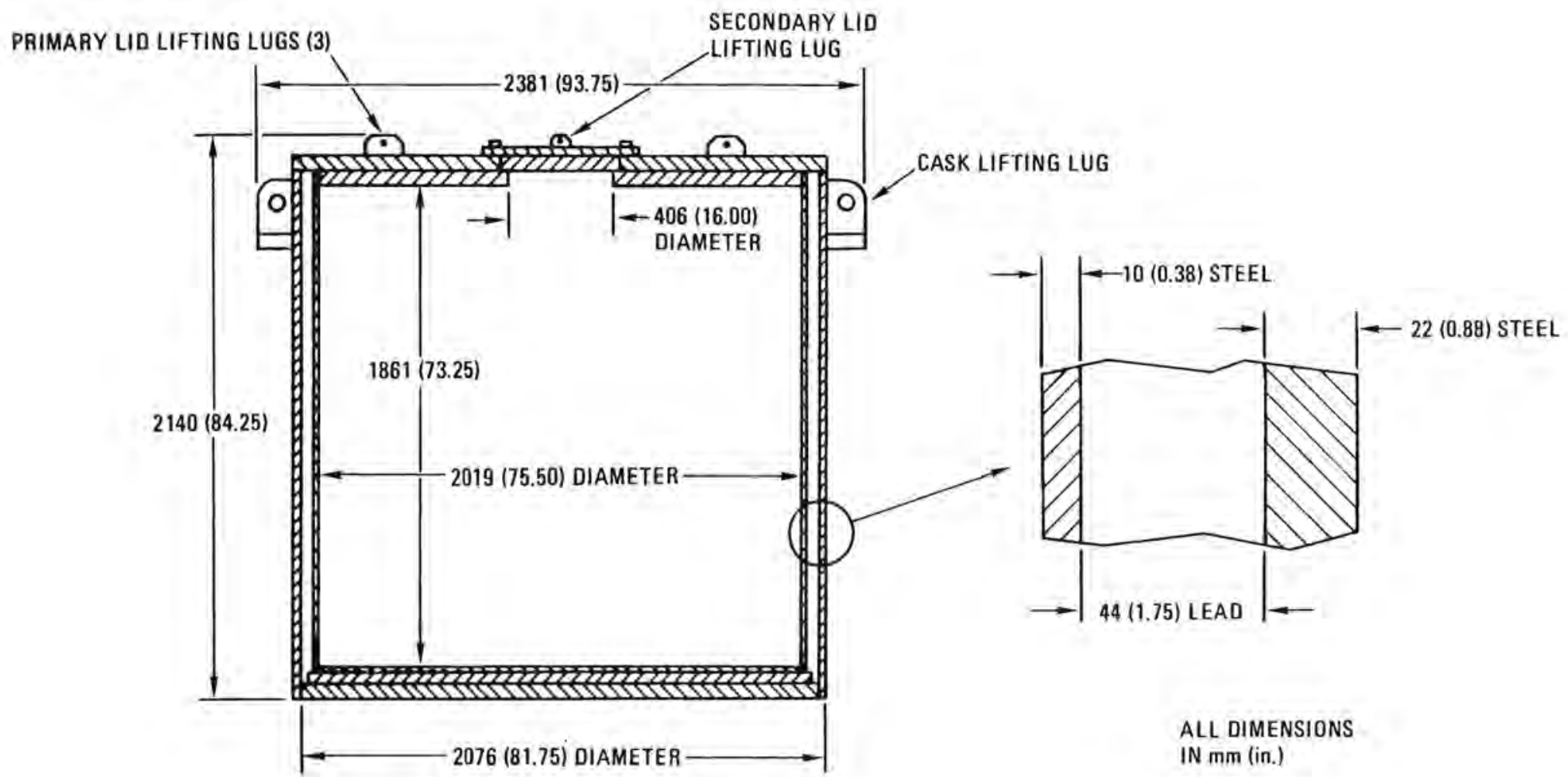

FIGURE B.8. CNS 14-170 Shipping Container 
$\dot{\omega}$

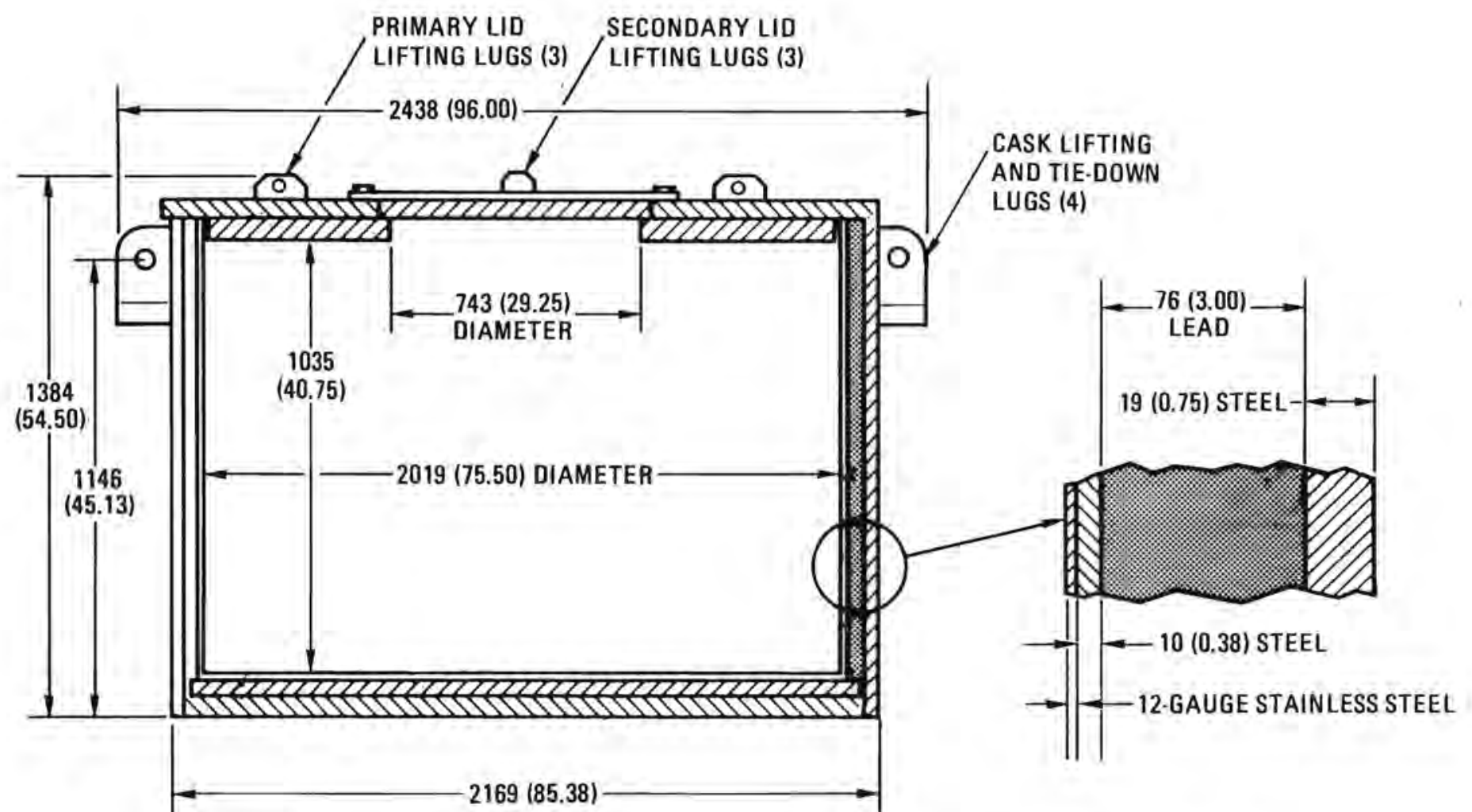

ALL DIMENSIONS

IN mm (in.)

FIGURE B.9. CNS 7-100 Shipping Cask 


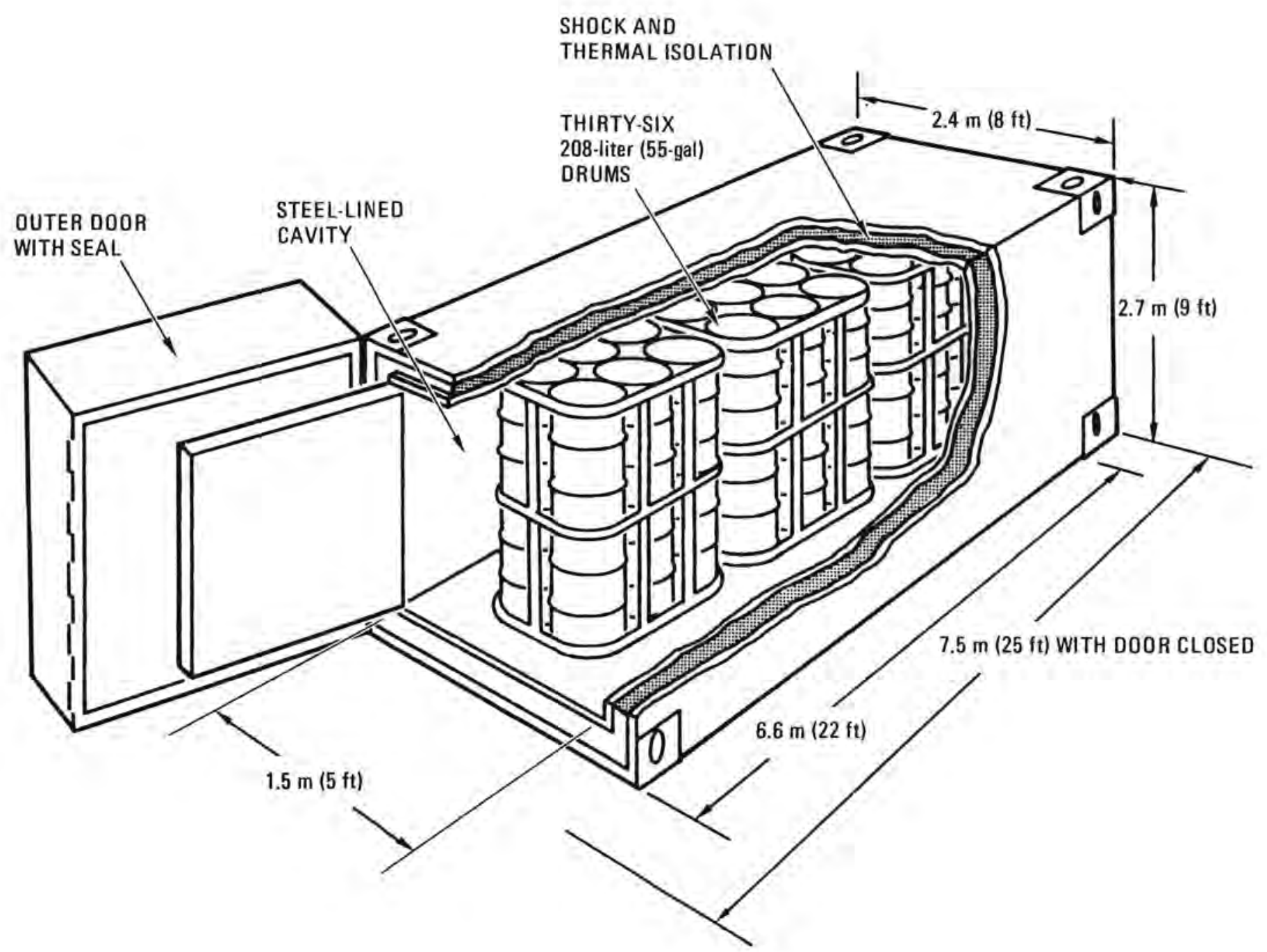

FIGURE B.10. TRUPACT Truck Version. One TRUPACT is shipped per rail truck and two are shipped per rail car. 


\section{Unit Transportation Costs for MRS/IS}

The bases for the various elements of transportation costs are given in this section. The cost elements include shipping charges, special equipment and security charges, shipping container leasing fees, and demurrage fees. Total transport costs are provided at the end of this section.

The actual fee charged by a truck or rail carrier to transport spent fuel, high-level wastes, or transuranic wastes cannot be determined until a contract is negotiated. These charges are based on several conditions, including shipment origins and destinations, shipment weight, shipment size, the route, volume shipped, frequency of shipments, and the existing competition. Fortunately, basic shipping charge structures for these materials do exist in various forms in the U.S. Shipping container rental fees are based on personal contacts with cask suppliers. The purpose of this report is to provide transportation unit costs for the aforementioned materials to be utilized in the preconceptual designs of MRS/IS facilities.

Charges for Shipments by Truck

The truck shipping charges included in this report are from a single carrier (Tri-State Motor Transit Co. 1981). This carrier services the 48 contiguous states and has the capability to comply with NRC requirements for shipping spent fuel. Since transportation requirements for spent fuel are the most stringent, it is expected that this carrier can also comply with the regulations for shipping $H L$ and TRU waste. In addition, the use of a single carrier provides a uniform basis for calculating truck shipping charges.

Basic charges for shipping spent fuel and wastes with legal-weight and legal-dimension vehicles do not vary across the country. Basic weight and dimension charges for spent fuel, high-level wastes and transuranic wastes are shown in Table B.30.

In addition to the charges listed in Table B.30, other charges are imposed on shipments of spent fuel and potentially will be imposed on HLW shipments. If a shipment requires specially equipped vehicles and specially trained personnel, as specified in NRC regulations (10 CFR 73), an additional charge per loaded mile will be imposed on shipments. The regulations require 
TABLE B.30. Truck Shipping Charges for Spent Fuel and High-Level Wastes (Tri-State Motor Trans it Co. 1981(a)

Rates in Dollars per 100 Pounds (b)

\begin{tabular}{|c|c|c|c|c|c|}
\hline $\begin{array}{l}\text { Miles- } \\
\text { Not Over }\end{array}$ & Ful1 & Empty & $\begin{array}{l}\text { Miles- } \\
\text { Not Over }\end{array}$ & Fu11 & Empty \\
\hline $\begin{array}{l}100 \\
110 \\
120 \\
130 \\
140\end{array}$ & $\begin{array}{l}1.52 \\
1.60 \\
1.61 \\
1.65 \\
1.71\end{array}$ & $\begin{array}{r}.98 \\
.99 \\
1.03 \\
1.06 \\
1.08\end{array}$ & $\begin{array}{r}950 \\
975 \\
1000 \\
1025 \\
1050\end{array}$ & $\begin{array}{l}4.68 \\
4.76 \\
4.84 \\
4.93 \\
5.10\end{array}$ & $\begin{array}{l}3.71 \\
3.81 \\
3.89 \\
4.01 \\
4.10\end{array}$ \\
\hline $\begin{array}{l}150 \\
160 \\
170 \\
180 \\
190\end{array}$ & $\begin{array}{l}1.77 \\
1.84 \\
1.90 \\
2.02 \\
2.07\end{array}$ & $\begin{array}{l}1.10 \\
1.11 \\
1.14 \\
1.17 \\
1.21\end{array}$ & $\begin{array}{l}1075 \\
1100 \\
1125 \\
1150 \\
1175\end{array}$ & $\begin{array}{l}5.20 \\
5.35 \\
5.45 \\
5.56 \\
5.72\end{array}$ & $\begin{array}{l}4.17 \\
4.27 \\
4.42 \\
4.48 \\
4.56\end{array}$ \\
\hline $\begin{array}{l}200 \\
225 \\
250 \\
275 \\
300\end{array}$ & $\begin{array}{l}2.16 \\
2.23 \\
2.35 \\
2.42 \\
2.49\end{array}$ & $\begin{array}{l}1.24 \\
1.31 \\
1.39 \\
1.40 \\
1.45\end{array}$ & $\begin{array}{l}1200 \\
1225 \\
1250 \\
1275 \\
1300\end{array}$ & $\begin{array}{l}5.80 \\
5.94 \\
6.07 \\
6.19 \\
6.31\end{array}$ & $\begin{array}{l}4.68 \\
4.76 \\
4.87 \\
4.96 \\
5.08\end{array}$ \\
\hline $\begin{array}{l}325 \\
350 \\
375 \\
400 \\
425\end{array}$ & $\begin{array}{l}2.59 \\
2.68 \\
2.73 \\
2.83 \\
2.94\end{array}$ & $\begin{array}{l}1.56 \\
1.60 \\
1.61 \\
1.65 \\
1.77\end{array}$ & $\begin{array}{l}1325 \\
1350 \\
1375 \\
1400 \\
1425\end{array}$ & $\begin{array}{l}6.41 \\
6.57 \\
6.66 \\
6.79 \\
6.91\end{array}$ & $\begin{array}{l}5.15 \\
5.25 \\
5.36 \\
5.45 \\
5.54\end{array}$ \\
\hline $\begin{array}{l}450 \\
475 \\
500 \\
525 \\
550\end{array}$ & $\begin{array}{l}3.02 \\
3.09 \\
3.19 \\
3.24 \\
3.32\end{array}$ & $\begin{array}{l}1.82 \\
1.90 \\
1.97 \\
2.12 \\
2.20\end{array}$ & $\begin{array}{l}1450 \\
1475 \\
1500 \\
1525 \\
1550\end{array}$ & $\begin{array}{l}7.01 \\
7.17 \\
7.27 \\
7.38 \\
7.53\end{array}$ & $\begin{array}{l}5.63 \\
5.75 \\
5.82 \\
5.95 \\
6.05\end{array}$ \\
\hline $\begin{array}{l}575 \\
600 \\
625 \\
650 \\
675\end{array}$ & $\begin{array}{l}3.44 \\
3.51 \\
3.60 \\
3.67 \\
3.76\end{array}$ & $\begin{array}{l}2.29 \\
2.39 \\
2.50 \\
2.62 \\
2.66\end{array}$ & $\begin{array}{l}1575 \\
1600 \\
1625 \\
1650 \\
1675\end{array}$ & $\begin{array}{l}7.63 \\
7.77 \\
7.90 \\
7.98 \\
8.13\end{array}$ & $\begin{array}{l}6.12 \\
6.21 \\
6.33 \\
6.41 \\
6.52\end{array}$ \\
\hline $\begin{array}{l}700 \\
725 \\
750 \\
775 \\
800\end{array}$ & $\begin{array}{l}3.84 \\
3.93 \\
4.01 \\
4.08 \\
4.16\end{array}$ & $\begin{array}{l}2.72 \\
2.89 \\
2.98 \\
3.03 \\
3.11\end{array}$ & $\begin{array}{l}1700 \\
1725 \\
1750 \\
1775 \\
1800\end{array}$ & $\begin{array}{l}8.24 \\
8.35 \\
8.49 \\
8.59 \\
8.73\end{array}$ & $\begin{array}{l}6.61 \\
6.79 \\
6.87 \\
6.98 \\
7.11\end{array}$ \\
\hline
\end{tabular}


TABLE B.30 (contd)

Rates in Dollars per 100 Pounds (b)

\begin{tabular}{|c|c|c|c|c|c|}
\hline $\begin{array}{l}\text { Miles- } \\
\text { Not Over } \\
\end{array}$ & Ful1 & Empty & $\begin{array}{l}\text { Miles- } \\
\text { Not Over } \\
\end{array}$ & Fu11 & Empty \\
\hline $\begin{array}{l}825 \\
850 \\
875 \\
900 \\
925\end{array}$ & $\begin{array}{l}4.26 \\
4.31 \\
4.44 \\
4.49 \\
4.57\end{array}$ & $\begin{array}{l}3.22 \\
3.30 \\
3.39 \\
3.50 \\
3.63\end{array}$ & $\begin{array}{l}1825 \\
1850 \\
1875 \\
1900 \\
1925\end{array}$ & $\begin{array}{l}8.84 \\
8.96 \\
9.08 \\
9.23 \\
9.34\end{array}$ & $\begin{array}{l}7.17 \\
7.25 \\
7.37 \\
7.50 \\
7.57\end{array}$ \\
\hline $\begin{array}{l}1950 \\
1975 \\
2000 \\
2025 \\
2050\end{array}$ & $\begin{array}{l}9.43 \\
9.60 \\
9.68 \\
9.83 \\
9.94\end{array}$ & $\begin{array}{l}7.64 \\
7.76 \\
7.84 \\
7.93 \\
8.65\end{array}$ & $\begin{array}{l}3200 \\
3250 \\
3300 \\
3350 \\
3400\end{array}$ & $\begin{array}{l}15.53 \\
15.77 \\
16.02 \\
16.22 \\
16.49\end{array}$ & $\begin{array}{l}12.55 \\
12.78 \\
12.92 \\
13.14 \\
13.35\end{array}$ \\
\hline $\begin{array}{l}2075 \\
2100 \\
2125 \\
2150 \\
2175\end{array}$ & $\begin{array}{l}10.07 \\
10.19 \\
10.30 \\
10.40 \\
10.56\end{array}$ & $\begin{array}{l}8.16 \\
8.24 \\
8.32 \\
8.44 \\
8.53\end{array}$ & $\begin{array}{l}3450 \\
3500 \\
3550 \\
3600 \\
3650\end{array}$ & $\begin{array}{l}16.74 \\
16.98 \\
17.20 \\
17.45 \\
17.69\end{array}$ & $\begin{array}{l}13.53 \\
13.72 \\
13.91 \\
14.12 \\
14.33\end{array}$ \\
\hline $\begin{array}{l}2200 \\
2250 \\
2300 \\
2350 \\
2400\end{array}$ & $\begin{array}{l}10.67 \\
10.92 \\
11.16 \\
11.40 \\
11.65\end{array}$ & $\begin{array}{l}8.65 \\
8.82 \\
9.04 \\
9.23 \\
9.42\end{array}$ & $\begin{array}{l}3700 \\
3750 \\
3800 \\
3850 \\
3900\end{array}$ & $\begin{array}{l}17.95 \\
18.18 \\
18.42 \\
18.64 \\
18.92\end{array}$ & $\begin{array}{l}14.48 \\
14.74 \\
14.92 \\
15.11 \\
15.29\end{array}$ \\
\hline $\begin{array}{l}2450 \\
2500 \\
2550 \\
2600 \\
2650\end{array}$ & $\begin{array}{l}11.91 \\
12.10 \\
12.35 \\
12.60 \\
12.85\end{array}$ & $\begin{array}{r}9.62 \\
9.83 \\
10.00 \\
10.21 \\
10.39\end{array}$ & $\begin{array}{l}3050 \\
4000 \\
4050 \\
4100 \\
4150\end{array}$ & $\begin{array}{l}19.16 \\
19.41 \\
19.63 \\
19.87 \\
20.10\end{array}$ & $\begin{array}{l}15.50 \\
15.69 \\
15.92 \\
16.09 \\
16.29\end{array}$ \\
\hline $\begin{array}{l}2700 \\
2750 \\
2800 \\
2850 \\
2900\end{array}$ & $\begin{array}{l}13.09 \\
13.34 \\
13.57 \\
13.83 \\
14.05\end{array}$ & $\begin{array}{l}10.61 \\
10.77 \\
11.00 \\
11.18 \\
11.39\end{array}$ & $\begin{array}{l}4200 \\
4250 \\
4300\end{array}$ & $\begin{array}{l}20.38 \\
20.61 \\
20.84\end{array}$ & $\begin{array}{l}16.48 \\
16.65 \\
16.87\end{array}$ \\
\hline $\begin{array}{l}2950 \\
3000 \\
3050 \\
3100 \\
3150\end{array}$ & $\begin{array}{l}14.32 \\
14.52 \\
14.79 \\
15.03 \\
15.27\end{array}$ & $\begin{array}{l}11.53 \\
11.78 \\
11.96 \\
12.12 \\
12.32\end{array}$ & & & \\
\hline
\end{tabular}

(a) Updated April 22, 1982.

(b) Source: Tri-State Motor Transit Co., Docket MC-109397. Item No. 200, First Revision. 
that these shipments must be scheduled, in writing, at least seven days in advance. If a shipment is cancelled or rescheduled during that seven-day period, a $\$ 1000$ fee is charged. When the carrier is required to furnish armed driver(s) or escort(s), an additional charge is assessed. If a separate escort vehicle is required or necessary, another fee is added to the shipping charge.

NRC regulations (10 CFR 73) state that a spent fuel transport vehicle within a heavily populated area must be occupied by at least two individuals, one of whom serves as an escort. It must be escorted by an armed member of the local law enforcement agency or by a vehicle ahead and one behind, each of which contains at least one armed guard. A spent fuel transport vehicle not within heavily populated areas must be occupied by at least one driver and one escort, or occupied by one driver and escorted by a separate vehicle occupied by at least two escorts, or escorted as required for transport vehicles in heavily populated areas. It is not known at this time whether high-level waste shipments will require these security considerations, but such is assumed here. For this study, security costs are assumed to include one driver and one escort.

The Code of Federal Regulations does not reference security clearance requirements for drivers or escorts. However, if clearances are required, an additional charge will be assessed. These charges are not included in the transportation costs.

A fuel use surcharge was assessed in the past on top of all other charges and surcharges per shipment. This charge was adopted in 1979 when fuel costs became unstable. However, this surcharge has recently been incorporated into the basic shipping charges shown in Table B.30. Many other charges can apply if any deviations occur in the original route, schedule, delivery acceptance, or in-transit stops, but these are ignored in this study.

Summarized in Table B.31 are the additional fees or surcharges that are imposed on spent fuel shipments and assumed here to be imposed on HLW shipments. 
TABLE B.31. Truck Surcharges for Spent Fuel and High-Leve1 Waste Shipments

Type of Charge
Special equipment
Armed driver/escort
Separate escort vehicle
"L" cleared driver
"Q" cleared driver $(c)$

\begin{tabular}{|c|c|}
\hline Cost & NRC Requirement \\
\hline$\$ 0.92$ per loaded mile & $x$ \\
\hline$\$ 0.20$ per mile & \\
\hline$\$ 1.28$ per mile $e^{(a)}$ & $x^{(b)}$ \\
\hline \multicolumn{2}{|l|}{$\$ 0.12$ per mile } \\
\hline$\$ 0.15$ per mile & \\
\hline
\end{tabular}

(a) Total miles are normally based on special equipment and personnel domiciled at Joplin, Missouri. Mileages are computed to point of origin of shipment, then through to the destination, then back to domicile point of shipment. Mileages to Joplin, Missouri, are not included for simplification purposes.

(b) Required in heavily populated areas.

(c) Each additional "Q" cleared driver is a fixed charge of $\$ 200$ per shipment.

A final fee charged by truck carriers is a charge for the ir equipment being idle at the terminal facilities while the shipping container is being loaded, unloaded, or held up by the facility operator. Drivers are assumed to deliver their shipment, wait for it to be unloaded, and then depart with the same shipping system they arrived with. Typically, this demurrage fee is negotiated prior to the shipment and the actual fee varies between contracts. This fee is assessed to compensate for idle equipment and the driver's wages and living expenses while the truck is not with a load. To keep additional calculations as simple as possible, the average fee per hour (based on 24 hours demurrage using a schedule from Tri-State Motor Transit Co., Docket No. MC-109397, Item No. 500) will be utilized. From this basis, the demurrage fee used in this study is $\$ 29.30$ per hour.

Charges for Shipments by Rail

Rail shipping charges are much more complicated than truck shipping charges. Rail charges are often not uniform with the distance traveled and can be affected by topography, state regulations, competition, and the route 
traveled. It is assumed in this study that Special $\operatorname{Trains}(a)$ will not be used, so the rail shipping charges that are developed are for general freight service.

Shipping charges assessed by rail carriers are specific for each origin-destination combination. Each origin and destination lies in a particular "rate-basing area" which is a major rail point where branch lines connect to local towns or communities. The shipping charges are assessed for transporting a commodity between specific rate-basing areas, regardless of the route or mileages traveled. Therefore, there is no such thing as a "generic" rail shipping charge. Specific origin-destination combinations must be defined. To obtain meaningful cost numbers for this study, charges were obtained for transporting radioactive materials between the locations shown in Table B.32. Shipping charges are the same regardless of the direction the materials were being transported; i.e., east to west or west to east. Also shown on this table are the approximate mileages between each location and the approximate transit times. Note that in some cases, especially in long hauls, the mileages and charges quoted may be the same for two different shipment origins. This is because shipping charges are established between rate-basing areas regardless of the route or distance traveled. The rail transit times are the hardest to define with any certainty. Too many variables are involved between any origin/destination combination to obtain a precise value. The times reported in Table B.32 are based on past experience and judgment for the areas and/or routes involved.

The charges for general freight service for spent fuel and $H L$ and TRU wastes are somewhat uniform when based on the mileages shown in Table B.32. Curves showing the shipping charges (per 100 lb) as a function of one-way miles are shown in Figure B.11 for loaded and empty containers. Minor variations are evident between shipments entirely within the East and entirely within the West. It appears that western shipments have higher charges, but there are too few data points to establish a conclusive pattern.

(a) Special Trains are defined as trains made up solely for the shipment of one commodity or for one shipper. 
TABLE B.32. Rail Shipping Charges, Distances, and Transit Times for Several Origin/Destination Combinations

\begin{tabular}{|c|c|c|c|c|c|}
\hline $\begin{array}{c}\text { From } \\
\text { (Origin) }\end{array}$ & $\begin{array}{c}\text { To } \\
\text { (Destination) } \\
\end{array}$ & $\begin{array}{c}\text { Dol1al } \\
100 \\
\text { Loaded } \\
\end{array}$ & $\begin{array}{l}\text { per } \\
\text { unds } \\
\text { Empty }\end{array}$ & $\begin{array}{c}\text { Approximate } \\
\text { One-way } \\
\text { Mileages } \\
\end{array}$ & $\begin{array}{c}\text { Approximate } \\
\text { One-way } \\
\text { Transit Time } \\
\text { (Days) } \\
\end{array}$ \\
\hline Hanford, WA & Barnwel1, SC & 16.89 & 15.83 & 2700 & $12-15$ \\
\hline Mercury, NV & Barnwe11, SC & 16.89 & 15.83 & 2200 & $10-13$ \\
\hline Berwick, PA & Barnwel1, SC & 7.13 & 6.69 & 750 & $5-7$ \\
\hline Palo, IA & Barnwe11, SC & 8.82 & 8.27 & 1050 & $9-12$ \\
\hline Port Gibson, MS & Barnwe11, SC & 6.79 & 6.37 & 700 & $6-8$ \\
\hline Waterford, CT & Barnwe11, SC & 7.88 & 7.39 & 900 & $8-11$ \\
\hline Eureka, CA & Barnwel1, SC & 19.15 & 17.95 & 2950 & $12-15$ \\
\hline Hanford, WA & Mercury, NV & 11.09 & 10.40 & 1000 & $9-12$ \\
\hline Berwick, PA & Mercury, NV & 16.89 & 15.83 & 2400 & $12-15$ \\
\hline Palo, IA & Mercury, NV & 13.39 & 12.55 & 1500 & $10-13$ \\
\hline Port Gibson, MS & Mercury, NV & 14.78 & 13.86 & 1600 & $10-13$ \\
\hline Waterford, CT & Mercury, NV & 16.89 & 15.83 & 2650 & $12-15$ \\
\hline Eureka, CA & Mercury, NV & 9.25 & 8.67 & 800 & $7-9$ \\
\hline Rainier, OR & Hanford, WA & 5.22 & 4.90 & 300 & $3-5$ \\
\hline Satsop, WA & Hanford, WA & 5.03 & 4.72 & 350 & $4-7$ \\
\hline Eureka, CA & Hanf ord, WA & 10.86 & 10.18 & 1200 & $7-9$ \\
\hline
\end{tabular}

Source: Personal communication with Mr. Frank Votaw, Rockwe11, Hanford Operations, Traffic Division, Motor Rates and Routes. 


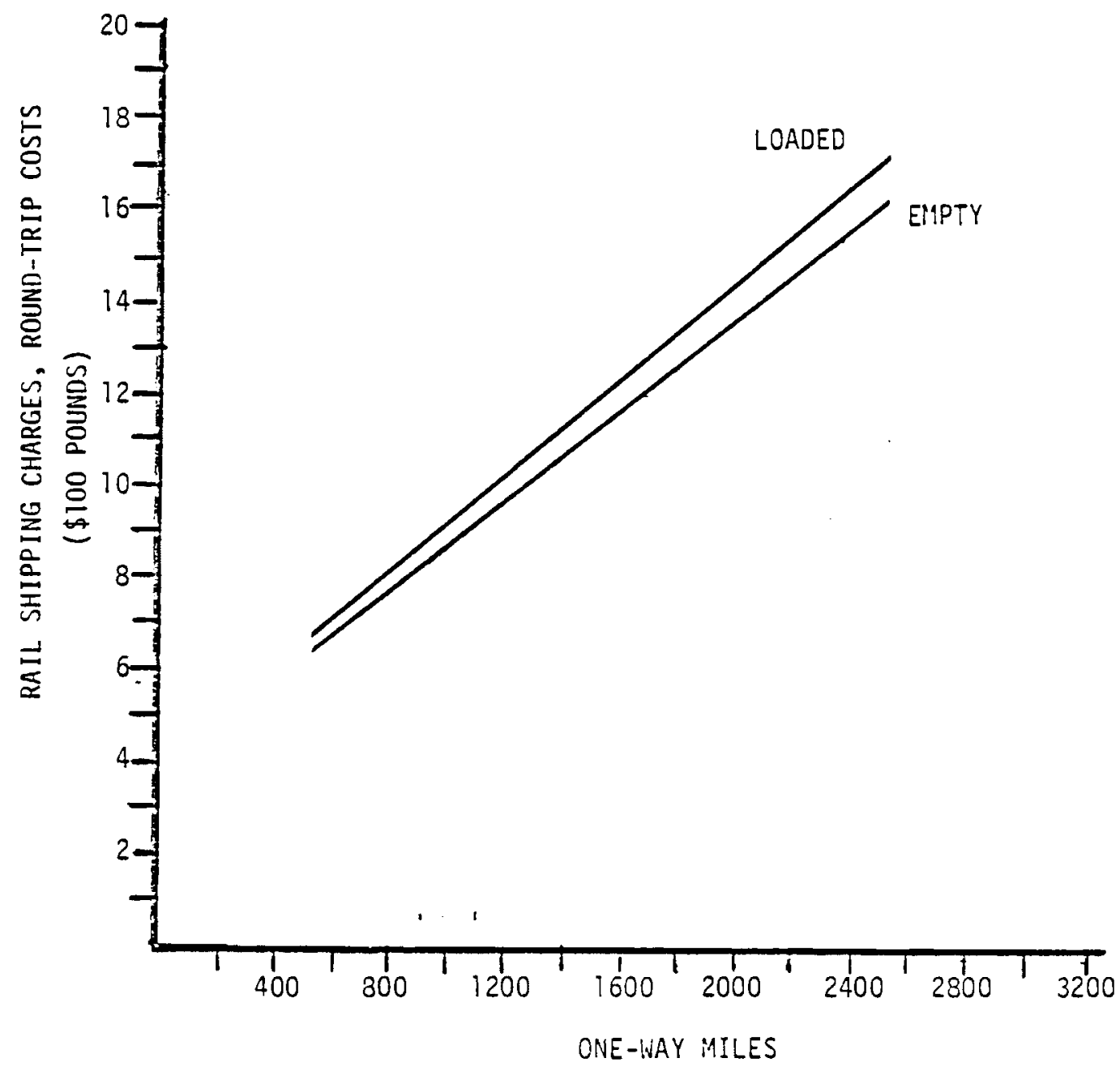

FIGURE B.11. Rail Shipping Charges for Loaded and Empty Shipments

Rail shipments of spent fuel require security provisions as do truck shipments. Rail shipments within heavily populated areas must be accompanied by two armed escorts that may or may not be members of a local $1 \mathrm{aw}$ enforcement agency. A shipment not within a heavily populated area must be accompanied by at least one escort (10 CFR 73).

Rail carriers have no provisions to supply an armed escort service, and it is expected that this service will be provided by the shipper. Rail carriers have indicated they will supply a car or caboose for the escorts to ride in. The charge for this service would be the price of a coach-class passenger ticket, or approximately 9 cents per mile per escort (Cole 1981). 
The total security costs must also include the wages and living expenses of the escorts. The charge for rail escorts can be estimated by using the truck charge of 20 cents per mile as an index. A truck with two drivers can travel about 900 miles in one day (Cole 1981). The salary and expenses per escort is thus $\$ 180$ per day. At least two escorts per trip are required so that the shipment can be constantly under surveillance. Using the approximate mileages and transit times shown in Table B.32, the average distance travelled per day by rail is 119 miles, which works out to an average speed of 5 miles per hour. This average makes the charge for rail escort service about $\$ 1.50$ per escort per mile or $\$ 3.00$ per mile for continuous surveillance. Adding the cost of the coach-class passenger ticket for each escort brings the total for rail escort service to about $\$ 3.18$ per mile.

Demurrage charges for rail shipments are included in the shipping system rental fees. This is because there are no guards or drivers who must wait for the shipping system to be loaded or unloaded. Demurrage charges for the transport vehicle (rail car or flatbed trailer) are included in the rental fees.

\section{Shipping Container Rental Fees}

One basis for this study is that transportation services for spent fuel, HL and TRU wastes will be supplied by private industry as a commercial venture. Therefore, the total transportation costs must include a fee for rental or lease of the shipping containers from their suppliers. These additional costs include operating costs, amortization of transport hardware, and profits. These costs would be calculated differently if, in the future, the U.S. Government decides to procure and operate its own transportation hardware.

Rental fees charged by shipping container suppliers are a negotiable item that can vary in each contract. These cask use and service charges include some field services, training, and maintenance of equipment in addition to operating and amortization costs and profits. Typical rental fees for the shipping system used in this study were obtained from contacts with the supplier companies. The reference rental fees are shown in Table B.33. Use and service charges for conceptual transportation equipment (i.e., HLW-T, 
HLW-R, and TRUPACT) are assumed to be the same portion of the capital costs as those for the equipment currently in use. It should be noted that the use and service charges shown in Table B.33 are based on short-term leases and are not the charges that would be assessed if the shipping containers were leased for a year or longer. Long-term use of shipping containers would result in significantly lower use and service charges than those shown in Table B.33. One factor that may tend to balance this effect is that the rental fees reported do not include fabrication of new equipment (that is, these fees are based partially on recovering the capital costs of equipment fabricated several years ago). The costs of fabricating new equipment have increased significantly, and therefore the rental fees charged by suppliers will most likely increase.

\section{Calculation of Unit Transportation Costs}

The final information required for transportation costs is the average weights of shipments or the average commodity (i.e., waste plus canister) unit weights. For the materials in this study, the average commodity unit weights are expressed in kilograms. Transportation unit costs will be expressed primarily in dollars per shipment for each type of waste and shipping system.

The average commodity unit weights for the high-level waste, RH-TRU waste special canister, and RHTRU waste drum shipping containers are straightforward because they haul only a single type of waste container. Their average commodity unit weights are calculated by multiplying the capacity of the shipping containers (see Table B.29) by the average weights of the loaded waste canisters (see Tabie B.28). To develop the average commodity unit weight for spent fuel truck shipments, the information in Tables B.28 and B.29 is used. Also, since about two-thirds of the commercial reactors are PWRs, an estimated two-thirds of the shipments will be PWR fuel elements. This ratio provides an average commodity weight of $628 \mathrm{~kg}(1385 \mathrm{lb})$ for truck shipments and $4775 \mathrm{~kg}(10,500 \mathrm{lb})$ for rail shipments. Similar procedures were used to calculate the average commodity weights for the TRUPACT. The ratio of drum shipments to box shipments was calculated from data derived by Fletcher (1982) from estimates of waste quantities and characteristics from the Barnwell 
TABLE B.33. Shipping Container Rental and Service Charges (Mid-1982 Dollars)

Single Shipment Cost, 8

\begin{tabular}{|c|c|c|c|}
\hline Shipping Container & Charge, \$/Day & 500 One-Way Miles & 2500 One-Way Miles \\
\hline G.E. IF-300 & $5,750(a)$ & 57,500 & 184,000 \\
\hline$N A C-1$ & $2,000(b)$ & 6,000 & 16,000 \\
\hline HLW-T & $1,750(c)$ & 5,250 & 14,000 \\
\hline$H L W-R$ & $4,375(d)$ & 43,750 & 140,000 \\
\hline CNS-7-100 & $175 /$ container & $\begin{array}{l}525(T)(f) \text { and } \\
5250(R)\end{array}$ & $\begin{array}{l}1,400(T) \text { and } \\
16,800(R)\end{array}$ \\
\hline CNS-14-170 & $75 /$ container & $\begin{array}{l}525(T) \text { and } \\
5,250(R)\end{array}$ & $1400(T)$ and \\
\hline TRUPACT & $700 /$ container $(e)$ & $\begin{array}{l}2,100(T) \text { and } \\
14,000(R)\end{array}$ & $\begin{array}{l}5,600(T) \\
44,800(R)\end{array}$ \\
\hline
\end{tabular}

(a) Based on truck and round-trip transit times of 3 and 8 days and rail transit times of 10 and 32 days for 500 and 2500 one-way mile trips, respectively.

(b) Calculate from first 30 days of use in schedule below:

No. Days of Use

$1-10$

$11-30$

$31-90$

$91-180$

over 180
Charge

30,000

ADD $1500 /$ day

ADD $1100 /$ day

ADD $900 /$ day

ADD $800 /$ day

(c) Fabrication costs for HLW-T cask are estimated at about $\$ 1 \mathrm{M}$. This is a conceptual cask system, and rental fees have not been calculated. The value in this table was calculated as follows. The estimated fabrication costs of the CNS-14170 is $\$ 100,000$. Assume the same ratio of fabrication costs to rental fee for HLW-T cask.

(d) Fabrication costs for HLW-R cask are estimated at about $\$ 2.5 \mathrm{M}$. See footnote (c) for rental fee calculation.

(e) Fabrication costs for TRUPACT are estimated at about $\$ 400,000$. See footnote (C) for rental fee calculation.

(f) $(T)=$ Truck, (R) = Rail. 
Nuclear Fuel Plant (Carr 1982). The average commodity weights and empty and loaded shipping container weights used to calculate transportation unit costs are shown in Table B.34.

Figures B.12 and B.13 show the transportation costs for each type of shipment under consideration in this study for truck and rail shipments, respectively. Each curve represents a different type of shipment. All curves represent the sum of the truck or rail shipping charges, cask use and service

TABLE B.34. Average Commodity Weights and Empty and Loaded Shipping Container Weights Used In Transportation Unit Cost Calculations

\begin{tabular}{|c|c|c|c|}
\hline $\begin{array}{c}\text { Materiall } \\
\text { Shipping Container }\end{array}$ & $\begin{array}{l}\text { Average } \\
\text { Commodity } \\
\text { Weight, } \\
\text { kg/Shipment }\end{array}$ & \multicolumn{2}{|c|}{$\begin{array}{c}\text { Shipping Container } \\
\text { Weight, } \mathrm{kg}\end{array}$} \\
\hline $\begin{array}{l}\text { Spent fuel } \\
\text { IF }-300 \\
\text { NAC-1 }\end{array}$ & $\begin{array}{r}4,775 \\
628\end{array}$ & $\begin{array}{l}63,490 \\
22,660\end{array}$ & $\begin{array}{l}68,265 \\
23,288\end{array}$ \\
\hline $\begin{array}{l}\text { High-level wastes } \\
\text { IF-300 } \\
\text { NAC-1 }\end{array}$ & $\begin{array}{l}5,250 \\
1,050\end{array}$ & $\begin{array}{l}63,490 \\
22,660\end{array}$ & $\begin{array}{l}68,740 \\
23,710\end{array}$ \\
\hline $\begin{array}{l}\text { RHTRU canisters } \\
\text { HLW-R } \\
\text { HLW-T }\end{array}$ & $\begin{array}{r}17,500 \\
3,500\end{array}$ & $\begin{array}{l}52,150 \\
11,700\end{array}$ & $\begin{array}{l}69,650 \\
15,200\end{array}$ \\
\hline $\begin{aligned} \text { RHTRU drums }(<5 \quad R / h r) \\
\text { CNS } 14-170 \text { (R) }(\mathrm{a}) \\
\text { CNS } 14-170(\mathrm{~T})\end{aligned}$ & $\begin{array}{r}12,600 \\
4,200\end{array}$ & $\begin{array}{l}46,200 \\
15,400\end{array}$ & $\begin{array}{l}58,800 \\
19,600\end{array}$ \\
\hline $\begin{array}{l}\text { RHTRU drums }(>5 R / h r) \\
\text { CNS 7-100 (R) } \\
\text { CNS 7-100 (T) }\end{array}$ & $\begin{array}{l}6,300 \\
2,100\end{array}$ & $\begin{array}{l}48,300 \\
26,100\end{array}$ & $\begin{array}{l}54,600 \\
18,200\end{array}$ \\
\hline $\begin{array}{l}\text { CHTRU wastes } \\
\text { TRUPACT (R) (b) } \\
\text { TRUPACT (T) }\end{array}$ & $\begin{array}{r}21,950 \\
9,610\end{array}$ & $\begin{array}{l}20,000 \\
10,000\end{array}$ & $\begin{array}{r}41,950 \\
19,610\end{array}$ \\
\hline
\end{tabular}

(a) Rail version consists of three shipping containers, transported on a railcar. Reported weights include this factor.

(b) Two TRUPACTs shipped per railcar. Reported weights include this factor. 
charges, and security costs (if applicable). These curves were drawn by plotting two points, one at $800 \mathrm{~km}$ (500 miles) and one at $4000 \mathrm{~km}$ (2500 miles). Therefore the uncertainty of these curves increases with the distance along the curve from these points. Care must be taken when using these data due to the many assumptions and uncertainties outlined throughout the text. Note that the unit transportation costs in these figures are the costs per shipment. To convert these costs to dollars per kilogram (waste plus canister), the appropriate factors can be found in Table B.30. Demurrage charges for truck shipments must be added to the total shipments costs by applying the charge rate previously reported to the facility turnaround times (to be determined by the individual contractors).

Special equipment charges and security costs are included in the curves for spent fuel and high-level waste shipping costs. If these additional charges are later determined to be not required for high-level waste shipments, the transportation costs for truck shipments would be reduced by 14 percent and 19 percent for $500 \mathrm{mile}$ and $2500 \mathrm{mile}$ one-way trips, respectively. The corresponding reductions in rail costs for 500 and 2500 one-way mile trips are 5 percent and 7 percent, respectively. 


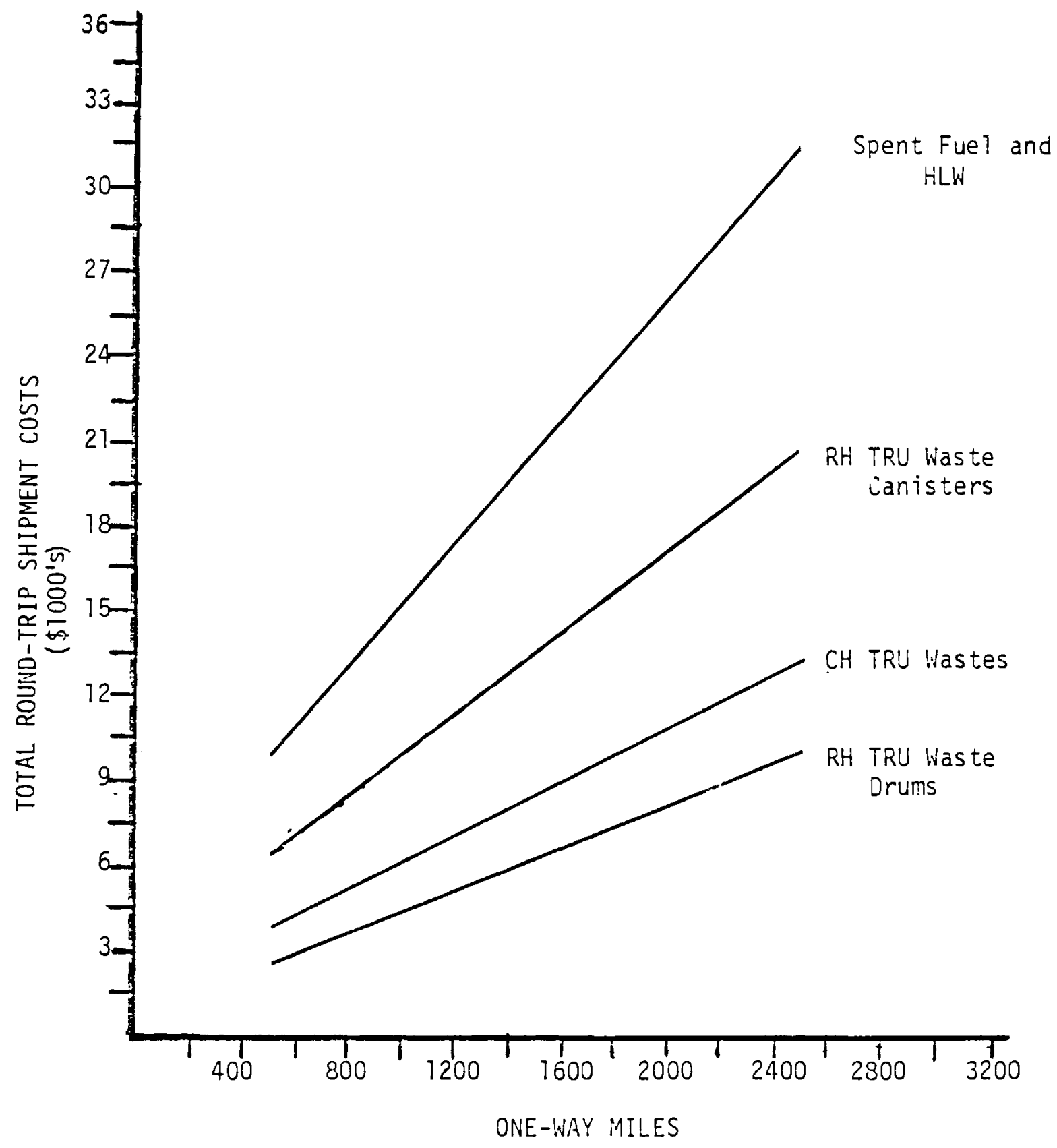

FIGURE B.12. Transportation Costs for Shipping Spent Fuel, High-Level and Transuranic Wastes by Truck 


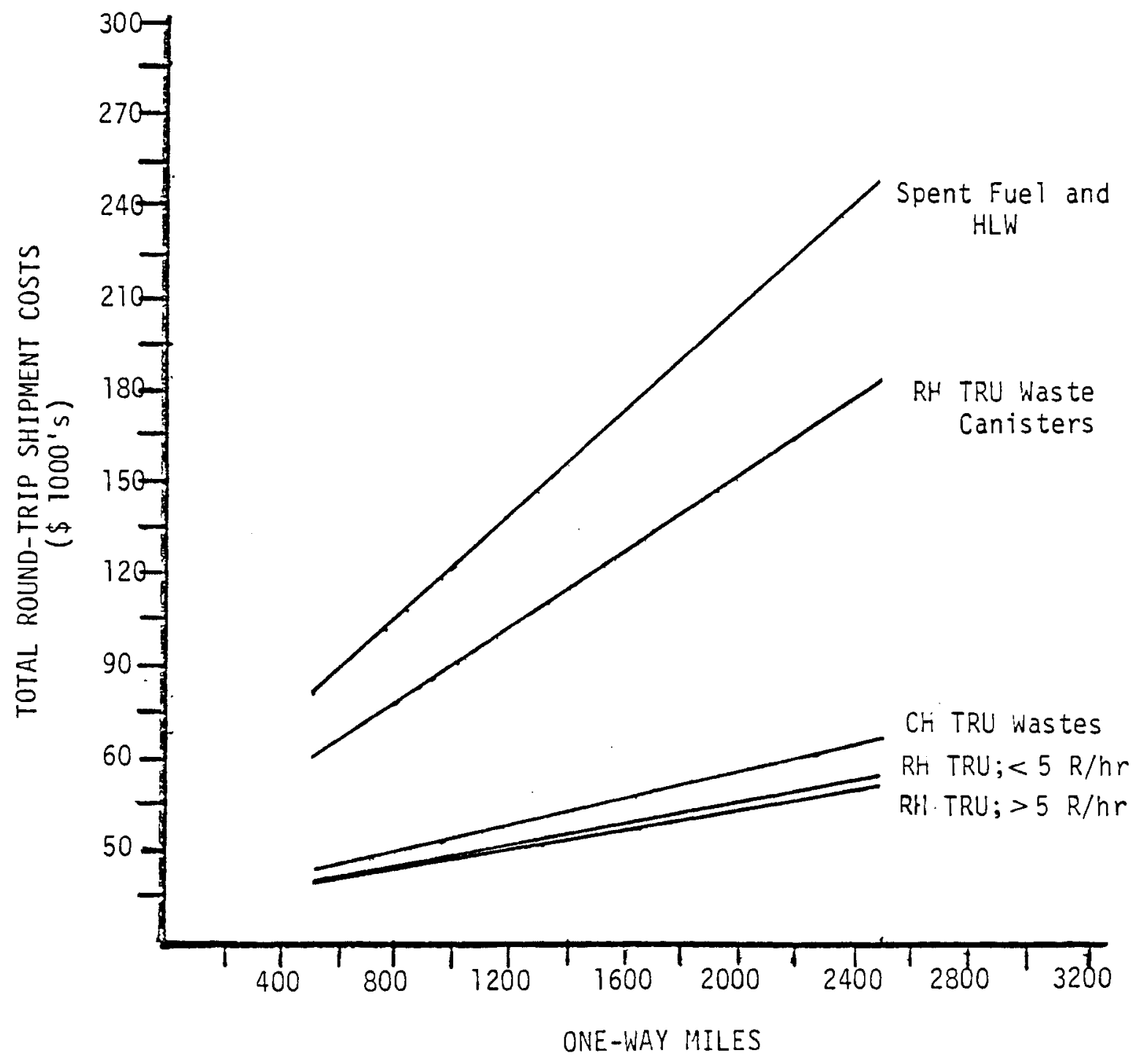

FIGURE B.13. Transportation Costs for Shipping Spent Fue1, High-Level and Transuranic Wastes by Rail 


\section{References}

1. Carr, W. H. 1982 (DRAFT). Estimation of Waste Types, Characteristics, and Quantities from the Barnwel1 Nuclear Fuel Plant. 0NWI/3092/TOP-01. Allied-General Nuclear Serices, Barnwell, South Carolina.

2. Cole, B. M. 1981. Shipping Charges for LWR Spent Fuel (letter report to John Cashwell, Sandia National Laboratories). Pacif ic Northwest

Laboratory, Richland, Washington.

3. Fletcher, J. F. 1982 (DRAFT MEMO). Draft Reference MRS Scenario.

Pacific Northwest Laboratory, Richland, Washington.

4. U.S. Code of Federal Regulations, Title 10, Part 71.

5. U.S. Code of Federal Regulations, Title 10, Part 73.

6. Tri-State Motor Transit Co. 1981. Docket No. MC-109397. Joplin, Missouri.

Information Sources not Cited in Text

Schneider, K. J., et al. 1981. Transportation Considerations Related to Waste Forms and Canisters for Defense TRU Wastes. PNL-3841. Pacific Northwest Laboratory, Richland, Washington.

Shipping Container Rental Fees: Verbal Communications with Mr. Chuck Johnson, Nuclear Assurance Corp., Atlanta, Georgia; Mr. Dick Miles, General Electric Co., San Jose, California; and Mr. Fred Gardner, Chem-Nuclear Systems Inc., Bellevue, Washington.

U.S. Nuclear Regulatory Commission. 1981. Directory of Certificates of Compliance for Radioactive Materials Packages. NUREG-0383. Office of Nuclear Material Safety and Safeguards, Washington, D.C.

Vigil, M. G. and G. C. Allen. 1982. Spent Fuel and High-Level Waste Transportation Systems for DOE Test ProgramS, SAND-82-0329. Sandia National Laboratories, Albuquerque, New Mexico. 


\section{ACKNOWLEDGMENTS}

The author of Appendix B.3 would like to express appreciation to Mr. Frank Votaw at Rockwell Hanford Operations and Mr. Billy Cole at Pacific Northwest Laboratory for their invaluable contributions to this study. Mr. Votaw provided assistance and research in the development of shipping charges for truck and rail shipments. Mr. Cole provided assistance and guidance regarding the collection of data and the calculation of transportation costs. 


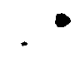




\section{DISTRIBUTION}

No. of

Copies

OFFSITE

K. 0. Laughon, Jr. Di rector

Office of Spent Fuel Management and Reprocessing Systems

U.S. Department of Energy

NE -40

Washington, DC 20545

K. A, Klein, Di rector

Division of LWR Fuel Cycle Projects

U.S. Department of Energy

NE -43

Washington, DC 20545

J. H. Carlson

Division of LWR Fuel Cycle Projects

U.S. Department of Energy

NE-43

Washington, DC 20545

S. P. Schneider

Division of LWR Fuel Cycle Projects

U.S. Department of Energy

NE-43

Washington, DC 20545

27 DOE Technical Information

Center

2 W. L. Godfrey

Allied-General Nuclear Services

P.0. Box 847

Barnwe11, SC 29812-0847

2 D. W. Ketchen

General Atomic Technologies, Inc.

P.0. Box 81608

San Diego, CA 92138
No. of

Copies

R. B. Pope

Sandia National Laboratories

Transportation Technology

Center

P.0. Box 5800

Albuquerque, NM 87185

J. M. Diggs

Sandia National Laboratories

Transportation Technology, Center

P.0. Box 5800

Albuquerque, NM 87185

ONSITE

6 DOE Richland Operations Office

P. A. Craig

H. E. Ransom

J. J. Schreiber

Human Affairs Research Center

B. Berk

30 Pacific Northwest Laboratory

K. R. Ames

N. M. Burleigh

T. D. Chikalla

J. F. Fletcher

D. L. Gale

C. A. Geffen

J. K. Gower

R. J. Hall

G. M. Holter

W. S. Kelly

R. C. Liikala

H. D. Massey

J. L. McEl roy

D. F. Newman

D. E. Rasmussen (5)

K. J. Schneider 
No. of

Copies

R. L. Shaub

M. J. Sherbin

R. I. Smith

Publishing Coordination (2)

Technical Information (5) 